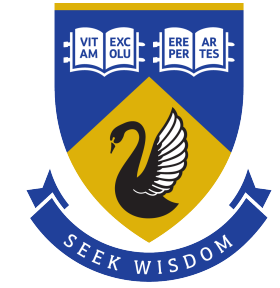

THE UNIVERSITY OF

WESTERN

AUSTRALIA

\title{
From 'opportunity' to 'insecurity': \\ the psychological contract of highly skilled immigrants \\ in Western Australia
}

\section{Renata Utchitel Casado, MSc MBA BComm}

This thesis is presented for the degree of

Doctor of Philosophy of

The University of Western Australia

UWA Business School

Management \& Organisations 


\begin{abstract}
The contribution by highly skilled immigrants (HSIs) to the Australian, and in particular the Western Australian (WA), economy has become crucial over the last decade. In that time, WA's economy has experienced a period of growth unlike any other in the state's history, doubling in size and witnessing records in immigration intakes (CCIWA 2010). However, despite their socio-economic relevance to the state, HSIs' labour market experience is still an under-explored area in academic research. Little is known about the perceptions of HSIs with regard to how their employment relationships influence their willingness to engage and remain in the WA labour force, or how they cope during times of economic downturn.
\end{abstract}

The psychological contract (PC) is a framework that has been largely used over the past three decades to explain how perceived workplace promises and expectations impact employees' behaviour and attitudes within the employment relationship (Guest 2004a). In contemporary research about the PC - that is, since Rousseau (1989) - the focus has been on understanding individual employees' perceptions as the most important influence on feelings, attitudes, and behaviour (Conway \& Briner 2005). In this study, however, the PC is informed by a critical approach, which argues that PC research must consider contextual eventualities that may impact the employment relationship, the individuals' perceptions, and the organisations' ability to fulfil the 'deal' (Cullinane \& Dundon 2006; Guest 2004a).

This thesis builds an original conceptualisation about the PC that blends ideas (Fauconnier 2001) from the field of economic sociology (Polanyi 1957 [1944]) with a critical management interpretation of the PC (Cullinane \& Dundon 2006; Guest 2004a, $2004 b$ ). It argues that the wider socio-political-economic context in which employment is embedded (Polanyi 1957 [1944]) influences the process, the state, and the outcomes of the PC. Thus, the research questions guiding this thesis are as follows: 1. How do wider contextual factors (WCFs) influence highly skilled immigrants' (HSIs) psychological contracts (PCs)? 2. How do highly skilled immigrants' (HSIs) psychological contracts (PCs) impact their intentions to stay in WA?

This is a qualitative longitudinal research (Holland et al. 2006) that draws on the extended case study method (Burawoy 1998, 2009). Sampling in this research was purposive (Miles \& Huberman 1994; Patton 2005), and included a selection of 26 
information-rich cases (Patton 2005). These individuals were first interviewed between 2010 and 2012. Repeated interviews were conducted in $2013(n=12)$ and $2014(n=14)$. Therefore, in total, the researcher conducted 52 interviews with HSIs. The participants represent 15 different countries and a range of occupational categories; however, all migrated to Australia with the key skilled-immigration qualifications listed in the Australia's Consolidated Skilled Occupations List (CSOL). Content and thematic analyses (Sparker 2005) were conducted with the support of both the NVivo10 and Leximancer software programs.

The findings suggest that context is highly influential in securing a 'deal' in HSIs' PCs. During Phase 1, the individuals' perceptions were very much marked by the mining boom, the abundance of construction and resources projects in the state, and by professional opportunities within the WA labour market. During Phase 2 and Phase 3, however, individuals reported experiencing insecurity and reassessment of both their PCs and their intentions to stay in WA, as a response to the slowdown in the state's economy. Therefore, the findings indicate that the context influenced HSIs' choice of destination, their normative expectations in the workplace, their employers' ability to fulfil their PCs, participants' outcomes from the employment relationship, and their intentions to stay (both with their employers, and in the WA labour market). 


\section{Preface}

About eight years ago, we decided to leave Brazil and come to Australia as skilled immigrants. Back in Brazil, I was a part-time academic teaching undergraduate students, as well as a full-time marketing manager. My husband was an engineer who had decided to quit his job as a manager in a large mining organisation, and our beautiful little boy was only three years old.

As we arrived in Perth and started our lives from scratch - choosing where to live, getting new jobs, and making new friends - we came across a large number of immigrant families, people who came from different parts of the world. They would speak different languages at home and serve different meals at their dining tables. Even so, despite some superficial differences, we had so much in common! Brazilian or German, North American or Chinese, we all had invested time and money in our professional development. We all have always pursued the best for our loved ones and ourselves, we embraced the world as a one of opportunities, and we have chosen Western Australia as the place to be.

As an aspiring academic passionate about research, I found myself trying to understand the similarities and differences amongst different groups, trying to figure out what pushed people away from their 'home', what drove people here, and what would make them stay. This research emerged as a result of my own personal experience and my thirst for enquiry.

The journey was not easy - nor short - though. When I started this journey, I had a toddler who was not even in kindergarten yet - and now he is a handsome and bright eleven-year-old boy. While I was doing my first wave of data collection, God gave me my second treasure, a loving and mature little boy who is now finishing pre-primary. Time does fly. Juggling the emotional pressure of a $\mathrm{PhD}$ with my own pursuit of being the best mother and wife I could be was a challenge in and of itself. It made me stronger, more faithful, and more mindful though. It made me more passionate about delivering meaningful work. It made me even more certain of the decision we made eight years ago.

I am grateful for having been received by this country as a skilled immigrant, and I am proud to call Australia home. 


\section{Table of Content}

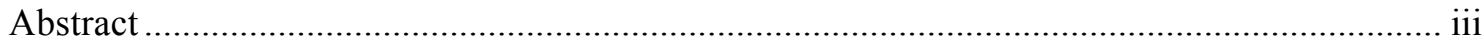

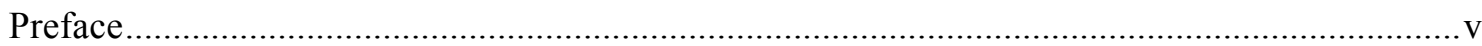

Table of Content

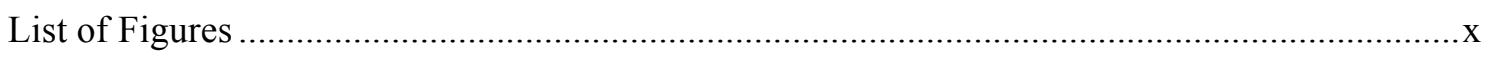

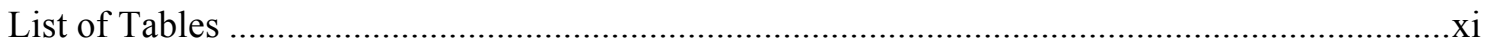

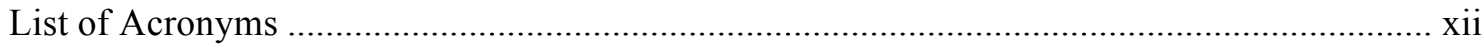

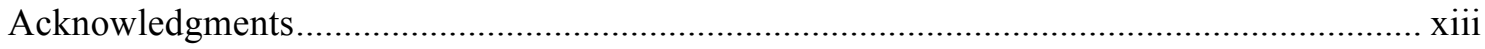

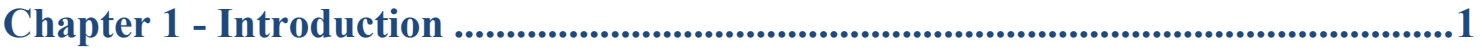

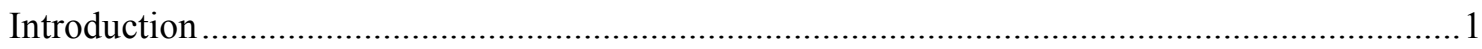

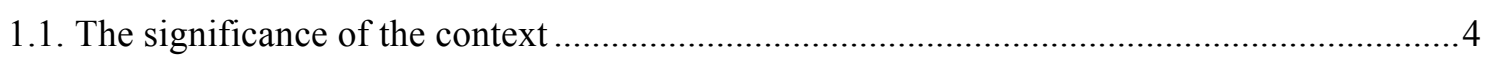

1.2. Aim of this thesis and research questions ….........................................................

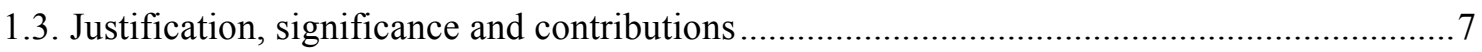

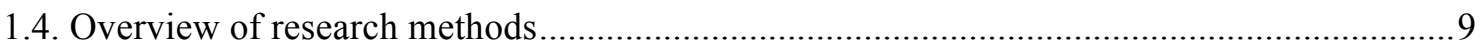

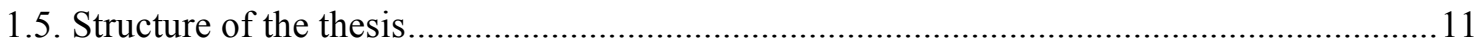

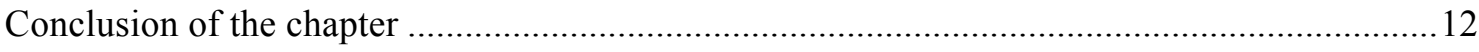

Chapter 2 - The Context of Skilled Migration ................................................................13

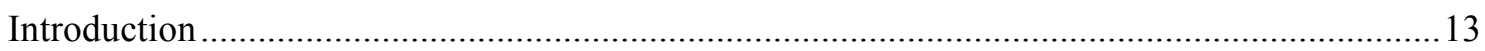

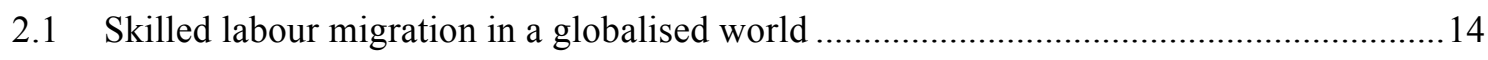

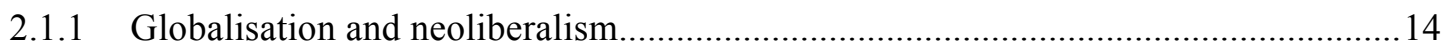

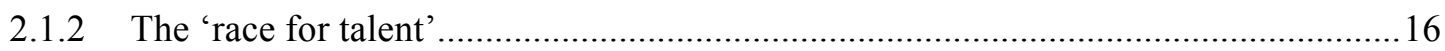

2.1.3 A definition for highly skilled immigrant (HSI) ................................................... 19

2.1.4 Labour market flexibility, the insecurity of the HSI, and issues of belonging ...........23

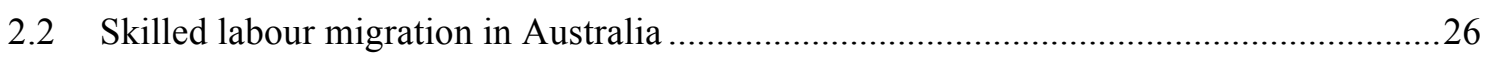

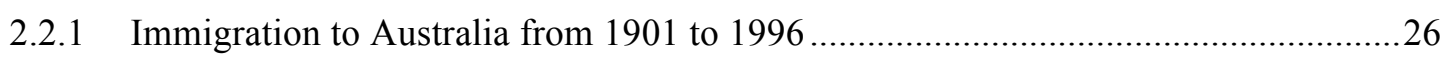

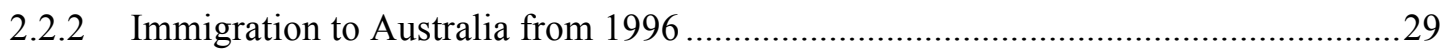

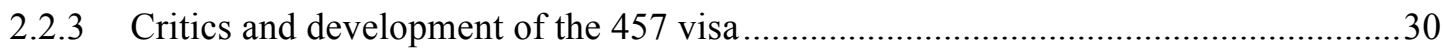

2.2.4 The intake of skilled individuals in the past 20 years ...............................................32

2.2.5 The transition from temporary to permanent ……......................................................33

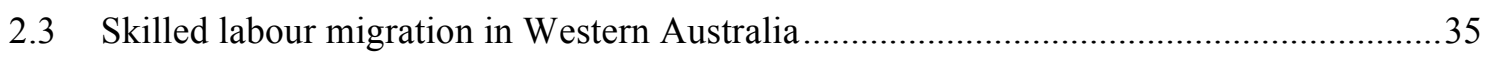

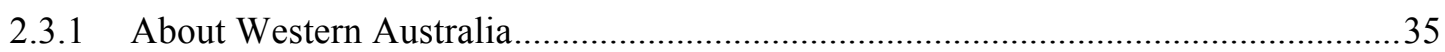

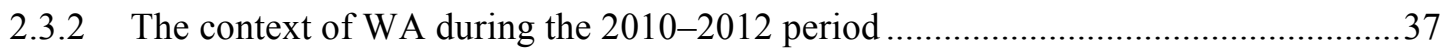

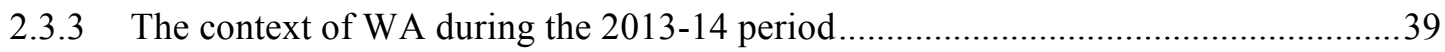

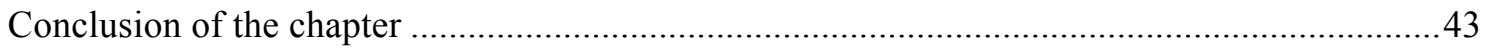

Chapter 3 - The Psychological Contract .....................................................................45

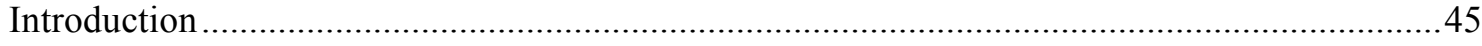

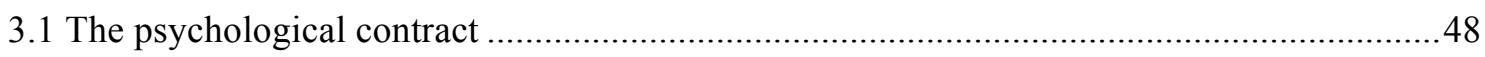

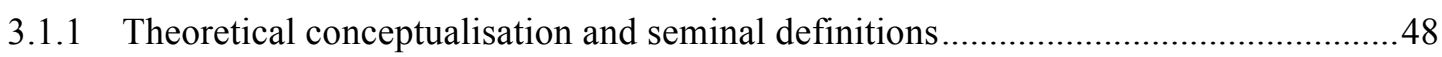


3.1.2 A contract between two parties: Issues of level and agency .....................................50

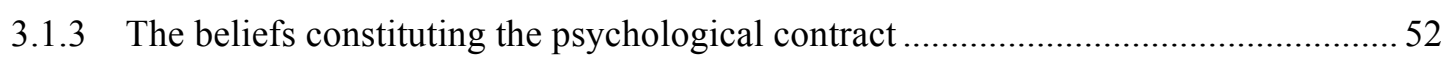

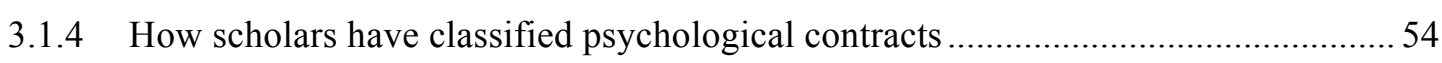

3.1.5 Breach and violation of the psychological contract....................................................56

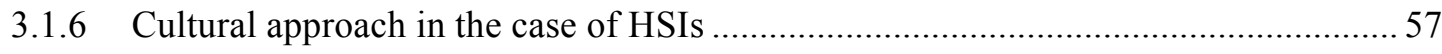

3.2 Conceptual framework: The psychological contract of an embedded lived experience ....... 59

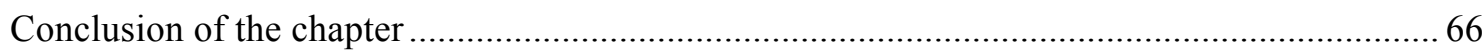

Chapter 4 - Research Design ..............................................................................................68

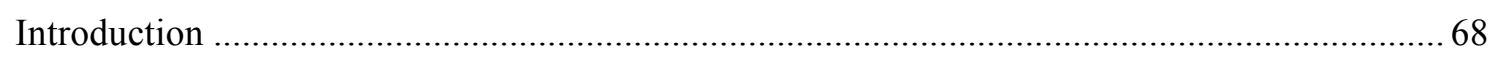

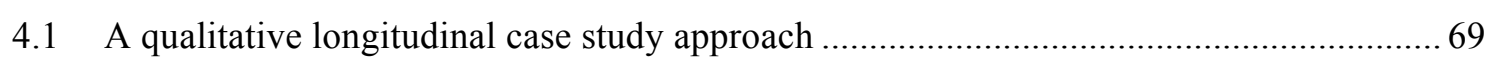

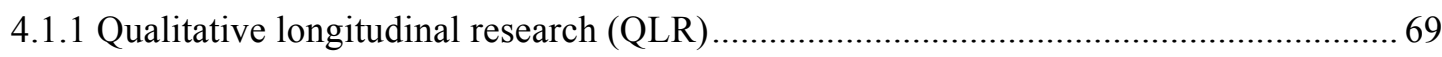

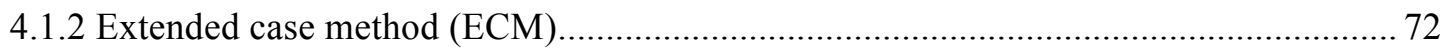

4.2 Methods used for data collection and analysis ................................................................. 74

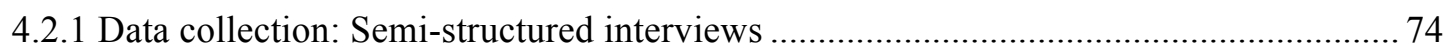

4.2.2 Data collection: Documentary analysis (secondary data analysis) ................................76

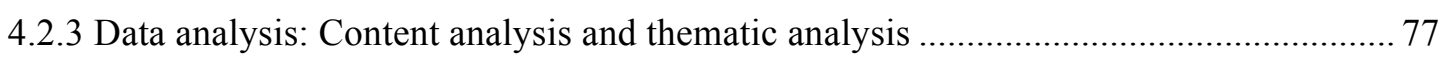

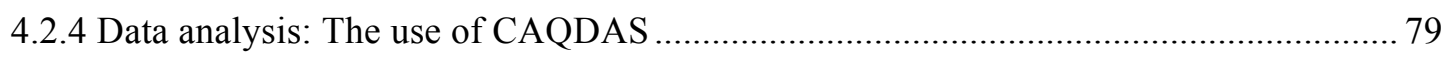

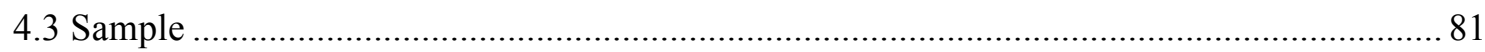

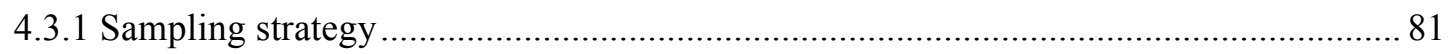

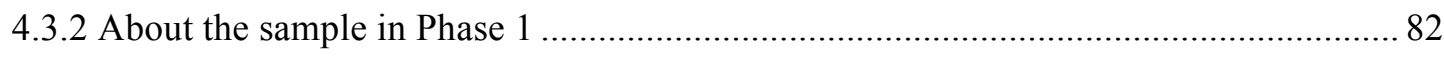

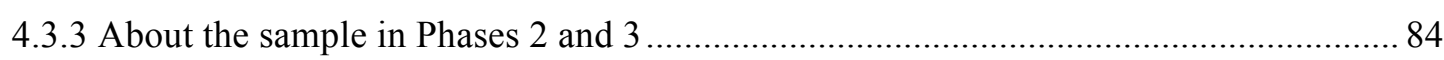

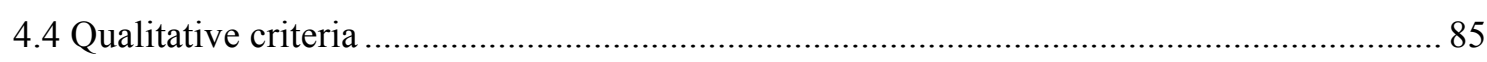

4.4.1 Limitations and trustworthiness in this study's methodology ...................................... 85

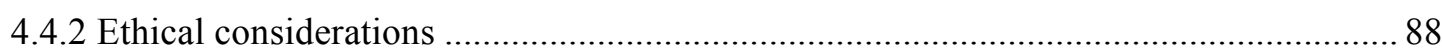

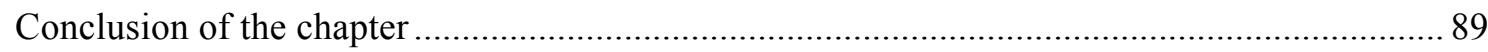

Chapter 5 - Findings Report (Phase 1): The PCs of HSIs in 2012 ...........................91

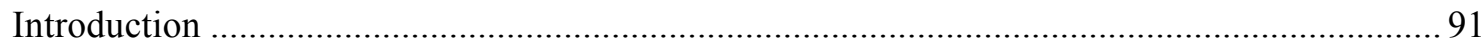

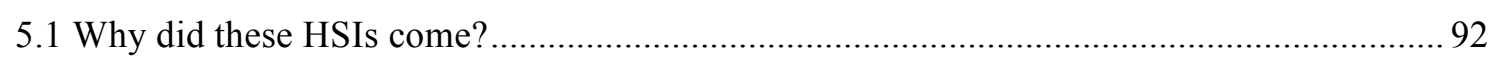

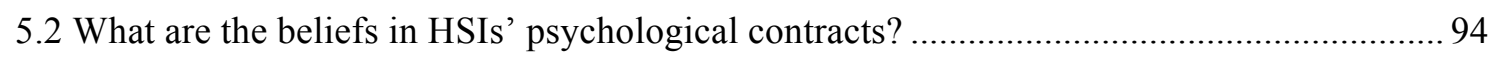

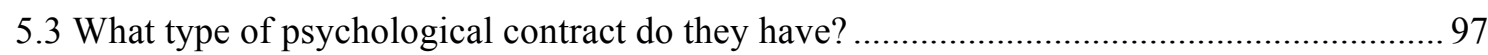

5.4 What do HSIs perceive to be breaches in their psychological contracts? ............................ 100

5.4.1 When the employer breaches the contract................................................................. 100

5.4.2 When expectations about the labour market are not fulfilled ...................................... 101

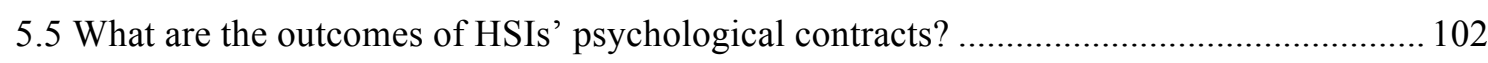

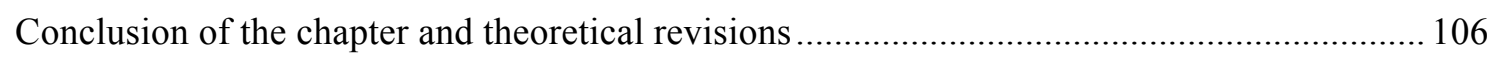

Chapter 6 - Findings (Phases 2 and 3): The PCs of HSIs in 2013-2014................. 112

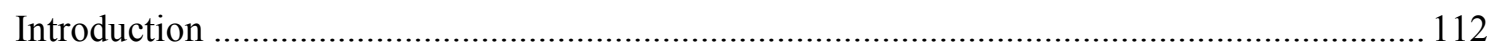

6.1 Institutional and economic factors impacting HSIs' new perceptions ................................ 113

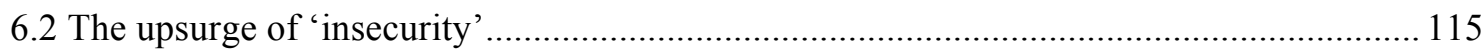


6.2.1 When expectations about the labour market are not fulfilled. 116

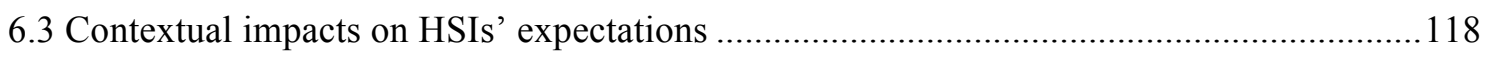

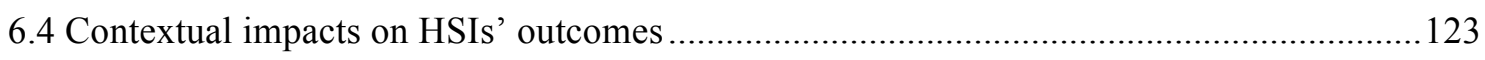

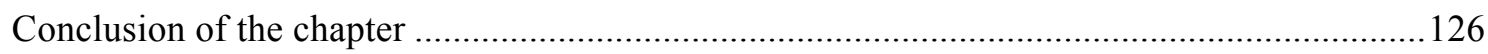

Chapter 7 - Findings: Are they staying in WA? .......................................................127

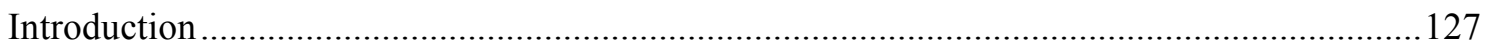

7.1 Following career opportunities elsewhere: The case of oil and gas global citizens ............128

7.2 Designing a Plan B to ensure permanency in Australia: The settled ones........................... 132

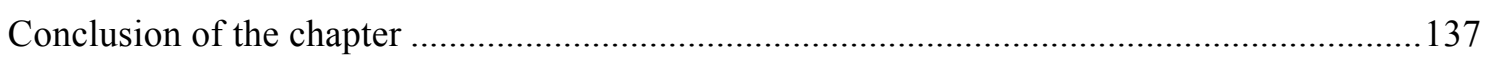

Chapter 8 - Discussion and Conclusion ..................................................................139

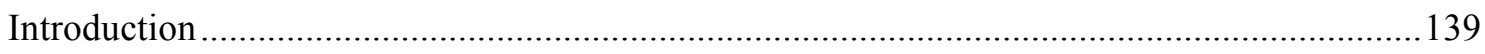

8.1 Contextual aspects and the role of embeddedness in the psychological contract................. 140

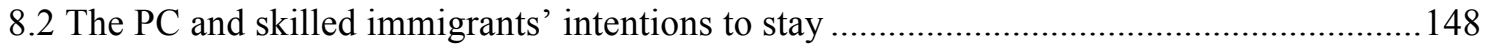

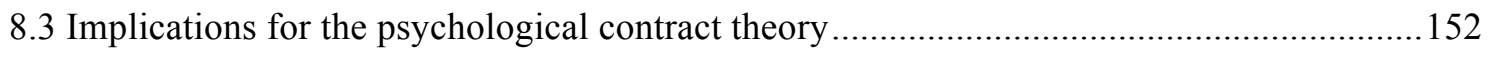

8.4 New outcomes to the PC: Issues of insecurity, membership and belonging ........................156

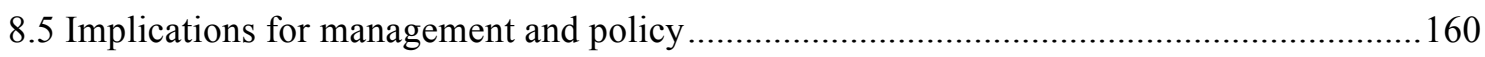

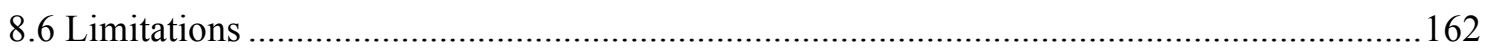

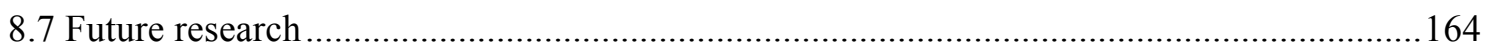

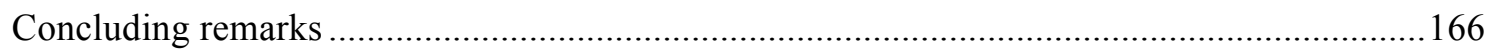

Reference List ................................................................................................... 171

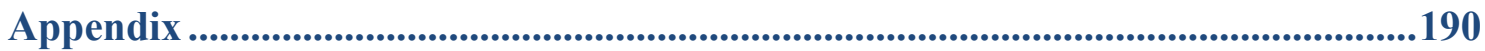

A1. Appendix 1 - The Australian Migration Framework ....................................................... 190

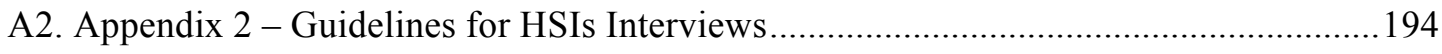

A3. Appendix 3 - Guidelines for Interviews with Intermediaries.......................................... 197

A4. Appendix 4 - Sample Characteristics in Phase 1 (Graphics) ........................................... 199

A5. Appendix 5 - Example of Data Analysis Process ..........................................................220

A6. Appendix 6 - Word-tree for 'Opportunities' (NVivo output, Phase 1)...........................201

A7. Appendix 7 - Table - Longitudinal Comparison of Changes According to participants'

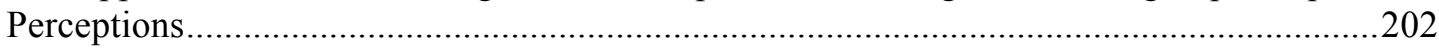

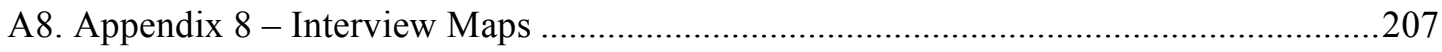




\section{List of Figures}

Figure 3.1. Rousseau's types of psychological contracts (Rousseau 1995, p. 98). 55

Figure 3.2. Employment contracts, the state of the psychological contract, and employee outcomes (Guest 2004a, p. 6). 62

Figure 3.3. The influence of wider conceptual factors. 63

Figure 4.1. Overview of research design. 69

Figure 4.2. Sample in Phases 1, 2 and 3. 85

Figure 5.1. HSIs' psychological contracts in Phase 1. 94

Figure 5.2. Leximancer output - Phase 1 - loyalty and gratitude in visa sponsorship (457 visa holders).

Figure 5.3. Leximancer output - Phase 1 - outcomes from PC (457 visa holders $x$ participants with PR).

Figure 5.4. Conceptual framework guiding this research. 109

Figure 6.1. Main institutional and economic factors impacting perceptions in Phase 2. 113

Figure 6.2. Concept maps: 457 visa holders $x$ PR, in Phase 1 x Phase 2 . 116

Figure 6.3. Highly skilled immigrants' expectations during the three phases of research. 119

Figure 6.4. Longitudinal investigation of expectations, P17 (male engineer with PR from Canada).__ 121

Figure 6.5. Longitudinal investigation of expectations for P22 (female IT Manager with a 457 visa from South Africa).

Figure 6.6. Longitudinal investigation of outcomes for P03 (male architect with PR from Brazil). 124

Figure 6.7. Longitudinal investigation of outcomes for P09 (female engineer with PR from Colombia).

Figure 7.1. Longitudinal observation: Job opportunities and the samples' movements. 125

Figure 7.2. Longitudinal investigation of intention to stay for P06 (female IT Manager with a New Zealand passport).

Figure 7.3. Longitudinal investigation of intention to stay for P24 (male engineer with 457 from Senegal) 130

Figure 7.5. Longitudinal investigation of psychological contracts and intentions to stay for P01 (male accountant with a 457 visa from Brazil). 135

Figure 7.4. Longitudinal investigation of psychological contracts and intentions to stay for P11 (female accountant with PR from South Africa). 136

Figure 8.1. Influence of context over individuals' perceptions. 141

Figure 8.2. The $\mathrm{PC}$ as a result of an employment experience embedded in context. 148

Figure 8.3. HSIs' intentions to stay or leave WA. 151

Figure A.1. Sample characteristics in Phase 1: gender, place of origin, visa on arrival, length of time in Australia, industry of employment and position in organisation 199

Figure A.2. Illustration of data analysis process for 'psychological contract'/ 'normative expectation' 200 Figure A.3. Word-tree for "opportunities" (NVivo 10, in Phase 1) 201 


\section{List of Tables}

Table 2.1. Contrasting qualities of expatriate assignment (Inkson et al. 1997, p. 352).

Table 2.2. Skilled migrant intake in Australia (permanent and temporary streams) from 1996 to 2014 (Sources: Phillips \& Spinks 2012; DIAC 2011, 2012, 2013; DIBP 2014c). 33

Table 2.3. Top countries providing permanent immigrants to Australia's states (adapted from DIAC 2012a, p. 106, refers to the last Census 2011). 36

Table 3.1. Summary of propositions. 67

Table 4.1. Sampling frame and sample characteristics in Phase 1. 83

Table 6.1. How economic and institutional factors affected industries in Phase 2. 114

Table A.1. Longitudinal comparison of Changes According to participants' perceptions 206 


\section{List of Acronyms}

AE

ASEAN

CAQDAS

CSOL

DIAC

DIBP

DTWD

ECM

ER

EU

GATT

GDP

GFC

GSP

IESCED

IR

ISCO

HRM

HSI

LNG

MESC

MNC

MODL

MSL

NAFTA

NESC

NIM

OECD

PC

PR

QLR

SE

SOL

TNC

UK

USA

WA

WCF
Expatriated Assignment

Association of Southeast Asian Nations

Computer-Assisted Qualitative Data Analysis Software

Consolidated Skilled Occupation List

Department of Immigration and Citizenship

Department of Immigration and Border Protection

Department of Training and Workforce Development

Extended Case Method

Employment Relations

European Union

General Agreement on Tariffs and Trade

Gross Domestic Product

Global Financial Crisis

Gross State Product

International Standard Classification of Education

Industrial Relations

International Standard Classification of Occupations

Human Resources Management

Highly Skilled Immigrant

Liquefied Natural Gas

Main English-Speaking Countries

Multinational Corporation

Migration Occupations in Demand List

Minimum Salary Level

North America Free Trade Agreement

Non-English-Speaking Countries

Net Interstate Migration

The Organisation for Economic Co-operation and Development

Psychological Contract

Permanent Resident

Qualitative Longitudinal Research

Self-Initiated Expatriate Assignment

Skilled Occupation List

Transnational Corporation

United Kingdom

United States of America

Western Australia

Wider Contextual Factors 


\section{Acknowledgments}

I would like to start my acknowledgments by expressing my gratitude to both my supervisors, Dr Donella Caspersz and Prof Rob Lambert. Donella, thanks for your guidance, your support, and your encouragement throughout this journey. More importantly, thank you for believing in me from day one. Rob, I received from you the hardest questions, but also some of the most inspiring ones. Thank you for sharing with me your knowledge, and for bringing me closer to sociology.

I am very grateful to the University of Western Australia for the infrastructure provided, my scholarships, and all the support I received over the past few years. Thanks to the staff at the Business School and Reid Library, who have assisted me in various ways. A special thanks to the team at the Research Office, for their continuous support, fantastic workshops, and - more importantly - for their understanding and capacity to accommodate my personal issues. I would also like to thank my colleagues from UWA Business School, particularly those who at some point participated in our ER writing groups, for always helping me with their constructive feedback.

Thanks to the 26 individuals who participated in my study. These people were kind enough to have a cuppa with a stranger, share their stories, and open their hearts. I wish you all the best in your journey! Thanks also to the executives at the Department of Training and Workforce Development, Downing Teal and Global Enterprise, for taking the time for an interview with me, helping me to understand the context of skilled migration in WA.

I must also express my gratitude to my relatives in Brazil. My mum and dad, who taught me the value of formal education and invested in it for as long as they could. My mother-in-law, who came to Australia many times in the past years to help me out with my crazy routine, allowing me a few more hours in front of my computer.

Thanks to some special people who I am lucky to have in my life. Thanks to my lifelong friend Tati Dale, who has the sharpest eyes for mistakes and kindly reviewed bits and pieces of my figures. Thanks to my always-supportive friend Flavia Kiperman, with whom I have had hundreds of cathartic coffee sessions and inspiring conversations. Thanks to a number of friends that I met because of my children and their school some super-mums that would stay with my kids every now and then so I could have 
(some more) hours in front of my computer, that would give me special good-luck gifts before important conferences, that would just be there for me.

Finally, I could not be more grateful for my dear family. Wil, thanks for your unconditional support - emotional, financial, logistical, you name it. Thanks for your love, patience, and encouragement during this period that - I know - was longer than we expected. Daniel and Nathan, thanks for your love, your patience, and your understanding. More importantly, thank you for motivating me every day to pursue the best me, and the best in this world. 


\section{Chapter 1 - Introduction}

\section{Introduction}

The focus of this thesis is to develop a conceptual framework and provide empirical support to better understand the lived employment experience of highly skilled immigrants (HSIs) in Western Australia (WA), and how this experience influences their decision to engage and remain in the WA labour market. To provide this analysis, the study investigated how the wider social, political and economic context has affected HSIs' psychological contract (PC) between 2010 and 2014, drawing on three phases of semi-structured, in-depth interviews with the same group of 26 participants.

Economic globalisation - as the intensification of economic interrelations across the globe (Steger 2010) - has created an increasing demand for highly skilled human capital within developed countries, prompting increased competition for highly trained workers in the world labour pool (Hugo 2006). Shortages in skilled labour have pressured governments and organisations worldwide to compete to attract the "best and the brightest" migrants (Shachar 2006, p. 151) and engage in a 'global quest' (OECD 2001) or a 'race for talent' (Shachar 2006). In this context, talent-recruiting countries have created selective immigration streams for the highly skilled (Castles et al. 2012; Hawthorne 2005), targeting their contributions for innovation, trade and investment, and the transfer of technology, skills and knowledge (Papademetriou et al. 2008; Shachar 2006; UN 2013).

Australia is a case in point. The foundations of the country's labour force lie in the extensive immigration program that has characterised the development of Australia as a nation (O’Donnell \& Mitchell 2000a). In the last 60 years, 6.8 million people from over 200 different nations have arrived in the country as new labour migrants (DIAC 2008). Currently, over a quarter of Australia's population were born overseas, and a further 20 per cent have at least one overseas-born parent (ABS 2012; DIBP 2014).

From the earliest days of European settlement, a close link between immigration and labour market policy has existed in Australia (O'Donnell \& Mitchell 2000b). Immigration was initially used to populate the country and then to facilitate and 
promote the development of a labour force to respond to Australia's economic needs. Nevertheless, in the past three decades, the Australian Government has developed policies designed to target HSIs for areas and industries experiencing particular skill shortfalls (Hawthorne 2005; Teicher et al. 2000).

Since the Keating ALP Government of the 1990s, the emphasis of Australia's migration program has changed from a 'supply-driven' approach towards one that is 'demanddriven' (Hawthorne 2005; Phillips \& Spinks 2012; Castles et al. 2012). The focus of Australia's Migration Program (see Appendix 1) has evolved from attracting migrants to increase Australia's population to attracting skilled migrants to meet Australia's temporary labour needs. As a result, temporary migration has become an important component of Australia's migration programme (Oke 2012b), and skilled-stream migrants entering Australia have consistently outnumbered the family stream since 1997 (DIBP 2015).

Today, migrants in the skilled-independent scheme are automatically entitled to permanent residency, while temporary, long-term business visa (457 subclass) migrants can also apply for permanent residency and, after four years, can become Australian citizens (DIAC 2012). Thus, like the 'competitor governments' of Canada and New Zealand (Hawthorne 2014), the Australian government has re-designed the policy regime, framing skilled migration to first and foremost promote and safeguard economic growth (Iredale 2001).

The WA case study particularly reflects these trends. Since the beginning of this century, WA's economy has doubled in size, experiencing a period of growth unlike any other in the State's history (ABS 2012a; CCIWA 2010). To manage increasing labour market needs and recurrent skill shortages, the WA government and employers have actively recruited skilled immigrants (DTWD 2011). In 2010, when this study started, WA had more immigrants per head of population than any other Australian jurisdiction, both from overseas and other parts of Australia (DIAC 2012). Currently, 33.4 per cent of the State's population is overseas-born, a percentage notably higher than the national average of 26.9 per cent (ABS 2015). WA's geographical position and the strong impact of the resources industry on the State's economy have shaped labour market characteristics (DIAC 2012a; DTWA 2014) and the subsequent features of a skilled labour movement into the State. 
However, despite their socioeconomic relevance, the labour market experience of skilled immigrants in Australia is still an under-explored area in academic research. Studies have been undertaken to understand aspects of temporary visa sponsorship (Khoo et al. 2007) in order to compare labour market outcomes for those migrating from the main English-speaking countries (MESC) with those arriving from nonEnglish-speaking countries (NESC) (Birrell \& Healey 2008; Hawthorne 2005), as well as to investigate precariousness among temporary migrants (Boese et al. 2013). Research has also focused on the factors associated with temporary migrants' decision regarding whether to become permanent residents in Australia (Khoo et al. 2008).

Still, little is known about the perceptions of skilled immigrants in terms of their employment experiences, and how such perceptions and experiences influence their willingness to productively engage and remain in the Australian labour force over time (Boese \& Campbell 2013; Hawthorne 2005; Kosny et al. 2016). A better understanding of the lived experience of HSIs in WA's labour market is expected to inform not only employment relations and the migration literature, but also policies and strategies to better attract and retain these workers. The concept of the 'lived experience' is one that has underscored much of critical theory. It refers to individuals' immediate consciousness of their everyday lives (Dilthey 1987; Van Manen 1990).

To develop this study, a framework was designed by blending (Fauconnier 2001) Polanyi's (1957 [1944]) concept of 'embeddedness' with a critical management interpretation of the psychological contract construct (Guest 2004a; Conway \& Briner 2005; Cullinane \& Dundon 2006). Polanyi's conception of embeddedness was used as a methodological principle to inform the research approach. Adopting an embeddedness perspective has helped to describe the linkages and interdependencies between economic phenomena and the social, institutional and cognitive environment (Schmidt 2016) surrounding HSIs' employment relationships. This will be discussed next in this chapter.

Nonetheless, lived experience is a 'personal' construct; that is, while influenced by the context, it is experienced at the level of the person or individual. The psychological contract, which is the focus of Chapter 3, was used as the lens for observing and exploring HSIs' perceptions and experiences with their employment relationship while in WA. The PC is commonly defined as the "individual's beliefs regarding the exchange relationship between themselves and the organisation" (Rousseau 2001, p. 261). It 
refers to employees' perceptions of promises and obligations in their exchange agreements with their employers, as well as the expectations that arise from them (Levinson et al. 1962).

Therefore, while this thesis draws on Polanyi (1957 [1944]) to engage with the concept of embeddedness of the lived experience of HSIs, it uses a critical management interpretation of the psychological contract (Cullinane \& Dundon 2006; Guest 2004) to develop the analysis of individuals' expectations and perceptions of their employment relationships while in WA. This involved conceptualising how the context influences the HSIs' PCs and the outcomes of their decision to either remain in or leave WA after their initial professional assignments in the labour market.

This chapter begins with a discussion of the significance of the context. Then, it presents an overview of the research questions, justifications, and methods adopted to achieve the study's objectives.

\subsection{The significance of the context}

This study blends (Fauconnier 2001) a critical management approach to the PC (Cullinane \& Dundon 2006; Guest 2004a, 2004b) with concepts from economic sociology to argue that any attempt to understand the contemporary employment relationships of skilled immigrants must take into account the fact that their lives are embedded in a wider context. As this section will discuss, a comprehensive understanding of the context is considered a requisite in this research because none of the actors in the employment relationship - neither the migrant employees nor the employers - are expected to form their opinions or create expectations in isolation from broader sociopolitical or economic influences (Guest \& Clinton 2010; Herriot 1992).

This approach is grounded in Polanyi's concept of embeddedness, which has become central to economic sociology literature. Polanyi (2002 [1934], p. 239, cited in Dale 2011, p. 320-321) argued that "no system of labor (Arbeitsverfassung) can be understood without first making sense of the social system in which is embedded". Throughout his work, Polanyi (1968, p. 117) emphasised the importance of grasping "the reality of society".

It was after Granovetter (1985) adapted the concept of embeddedness from Polanyi's (1957 [1944]) The Great Transformation that the term gained widespread acceptance 
and use (Beckert 2007). However, Granovetter's concept of embeddedness differs fundamentally from the meanings found throughout Polanyi's work, and these different uses of the concept have created vast inconsistencies in the literature (Beckert 2007; Krippner \& Alvarez 2007). Thus, over the past few years, academics have explored different interpretations (Dale 2011) and types (Zukin \& DiMaggio 1990) of embeddedness while comparing Polanyi's and Granovetter's approaches (Beckert 2007; Krippner 2001; Krippner \& Alvarez 2007).

Granovetter (1985) focused on the relationships among actors - networks of ongoing social relations - as the core variable for the explanation of economic outcomes (Beckert 2007; Dale 2011). Economic action, Granovetter (1985, p. 487) argued, is "embedded in concrete, ongoing systems of social relations". Granovetter's 'network approach' has been criticised for isolating one aspect of markets - networks of ongoing social relations - as "constituting the proper domain of economic sociology" (Krippner 2001, p. 799). If Granovetter's concept of embeddedness refers to identifying the relational basis of social action in economic contexts, Polanyi's work concerns the integration of economy into broader social systems (Krippner \& Alvarez 2007). These different approaches invite different foci of analysis and comprise different assumptions regarding the nature of the reality that they mean to describe:

We argue that Granovetter's conception of embeddedness puts forward what we call an exterior relationship between the economical and the social, whereas Polanyi's elaboration of the concept posits an interior view of this relationship. (Krippner \& Alvarez 2007, p. 222)

In this thesis, Polanyi's approach to embeddedness, which reinforces the "interconnectedness and wholeness" of different spheres, including the social, economic and political (Castles et al. 2011, p. 7), is adopted. Although Polanyi used the idea of embeddedness in his early writings and manuscripts (Gemici 2008), most discussions about embeddedness refer to The Great Transformation (Block 2003; Webster et al. 2008).

The Great Transformation presents the nineteenth century sociopolitical transformation that took place in Europe following the Industrial Revolution of 1789 and the consequent rise of economic liberalism. Economic liberalism rested on the idea of selfregulating markets and the assumption that economies would automatically adjust supply and demand through price mechanisms (Webster et al. 2008, p. 3). Laissez-faire values - which promoted a competitive labour market, an automatic gold standard and 
free trade - quickly became the organising principles in England by the 1830s, and as a result of English rule during this period, these creeds became the pillars of the world's market economy during that time (Castles et al. 2011).

The Great Transformation discusses the commodification of the human being, nature and money, as well as the measures adopted by society to protect itself against the damaging impact of this commodification (Castles et al. 2011; Harvey 2005; Munck 2002; Webster et al. 2008). Polanyi's ideas are shaped by a moral concern over the psychological, social and environmental destructiveness of these unregulated markets, an assessment that resonates today because such a persistent drive towards a market orientation lies at the very heart of globalisation and the contemporary ideals of individualism, competitiveness, flexibility, downsizing, outsourcing and casualisation (Webster et al. 2008, p. 4).

The market-oriented period described by Polanyi (1957 [1944], p. 33) as a "miraculous improvement of the tools of production" was accompanied by "a catastrophic dislocation of the lives of common people" - an idea that is believed to have many similarities with today's intensification of globalisation, as discussed in Chapter 2 of this thesis. A number of scholars thus argue that the world is now in the grip of a Second Great Transformation (Munck 2002; Webster et al. 2008), likewise characterised by "a seemingly miraculous development of capitalism", but also by "an equally profound dislocation of the lives of ordinary people across the globe" (Munck 2002, p. 2).

The neoliberalisation in the Second Great Transformation has emerged under different geopolitical and geoeconomic conditions and in response to historically specific political struggles and regulatory failures (Brenner et al. 2010). What is believed to be similar is that both the first and second Great Transformations are characterised by the emergence of new technologies and growing industrialisation, the development of market liberalism as a dominant ideology, and the rise of feelings of insecurity resulting from social changes and unregulated economic transformations (Brenner et al. 2010; Munck 2002; Webster et al. 2008).

Polanyi's concept of embeddedness guides this research as a methodological principle (Gemici 2008; Krippner et al. 2004), which posits that economy and society can only be analysed through a holistic approach: Economic life can only be understood though the 
examination of how it forms a part of social relations and institutions (Block 2003; Gemici 2008). As a methodological principle, the concept of embeddedness does not specify the relationship of the parts to the whole, nor does it create a scheme of how social relations and institutions structure economic life; rather, it points to units and objects of analysis that must be considered when studying economic life (Gemici 2008). Embeddedness, then, is used in this thesis as a "conceptual umbrella" that envelops the connections between economic activity and its social, political, institutional, historical and cultural elements (Krippner et al. 2004). As Beckert (2007, p. 796) summarised, "[embeddedness] points to the indissoluble connection of the actor with his or her social surrounding".

\subsection{Aim of this thesis and research questions}

This thesis thus argues that wider contextual factors, such as political and socioeconomic events, play a significant role in influencing HSIs' perceptions of promises and obligations in their workplaces and shaping the outcomes of their psychological contracts. As such, this longitudinal case study aims to examine HSIs' perceptions towards their employment experiences in WA's labour market, providing a greater understanding of how the context impacts their experiences and perceptions and how contextual factors influence HSIs' intentions to stay - an important outcome that should result from skilled immigrants' PCs.

The research questions posed to guide this investigation are the following:

1. How do wider contextual factors (WCFs) influence highly skilled immigrants' (HSIs) psychological contracts (PCs)?

2. How do highly skilled immigrants' (HSIs) psychological contracts (PCs) impact their intentions to stay in WA?

\subsection{Justification, significance and contributions}

The justification and significance of this thesis is twofold. From a methodological perspective, this thesis is justified by its uniqueness. Firstly, because qualitative longitudinal approaches are rare, given their operational difficulties (Freese et al. 2011). Secondly, because this is one of the initial attempts to empirically support a critical 
management approach to contemporary PC research (Cullinane \& Dundon 2006; Guest 2004a) and blend it with Polanyi's (1957 [1944]) concept of embeddedness.

As Chapter 3 will discuss, a focus on the significance of contextual factors in shaping PCs has already been canvassed by key scholars (Guest 2004a; Cullinane \& Dundon 2006; Guest \& Clinton 2010). The thesis builds on these studies by using Polanyi to broaden the conceptualisation of contextual factors, described herein as wider contextual factors (WCFs), and by specifying the outcomes of PCs to reflect the employment relations dynamics of HSIs. In addition, the thesis makes a unique empirical contribution that illustrates the efficacy of WCFs on the PC outcomes of HSIs. The qualitative longitudinal design adopted in this study, as described in Chapter 4, allows for the capturing of changes in employees' PCs over time and in light of the significance that contextual factors have for each particular individual. This study, therefore, contributes towards the development of the $\mathrm{PC}$ as a more appropriate construct to understand the employment relationships embedded in the context of globalising forces and neoliberal philosophies (Cullinane \& Dundon 2006).

From a practice and policy perspective, a unique contribution of this thesis is to use the PC to understand the perceptions of HSIs about their employment experiences, which allows for a better understanding of the outcomes that can be expected from them in the context of their importance in maintaining and enhancing Australia's competitiveness in the global economy (Hugo 2004). The focus on HSIs is justified by the prognosis that their contributions to the economic prosperity of the Australian economy and society will continue, even in the face of economic downturns (DIBP 2014; DTWD 2011). This is because of demographic changes facing Australian society (Caspersz 2012), combined with insufficient levels of investment in training (Caspersz 2007; Coelli \& Wilkins 2008) and the significance of labour migration to ensure flexibility in Australia's economy (Collins 2013; Shah et al. 2005; Wright 2014).

Little research is available about the experiences and perceptions of HSIs in terms of their employment relationships in the Australian labour market, and research is even scarcer when considering the particularities of WA. Many relevant outcomes from a volatile scenario must still be explored. The retention of HSIs, their adjustment to labour market flexibility, and their inclusionary status in society are just some key factors that must be thoroughly understood, presuming the following statements are true: 
- On a national level, "migrants are a key contributor to Australia's current labour force" (DIBP 2014, p. 15);

- On the Western Australian State level, "skilled migration will be an essential strategy in continuing trends of strong economic and job growth, low unemployment and high workforce participation" (DTWD 2011, p. 2);

- On an organisational level, expatriating employees put extra pressure on management, particularly in terms of costs (Guzzo 1996). The direct cost of an expatriate employee includes salary, training and travel and relocation expenses; while the indirect cost of losing one involves loss of knowledge and market share (Chew 2004).

In sum, this thesis is expected to make a number of contributions. The first is by describing a conceptual framework that extends the PC by incorporating the concept of the context, while the second is to provide empirical support for this framework. However, the discussion about the implications of the research for policy in this area is a further contribution to considerations about how to retain these workers within WA's labour market.

\subsection{Overview of research methods}

This study involved qualitative longitudinal research (QLR) that drew on an extended case method (ECM) approach (Burawoy 1998, 2009). QLR is a design focused on the investigation and interpretation of change over time and processes in a social context (Holland et al. 2006, p. 1). It entails repeated observations of the same research object over a period of time and considers the individual dynamics of transformation (Smith 2003). QLR provided an opportunity to understand and explore changes in respondents' PCs and their employment experience in light of contextual factors over a period of approximately four years. The use of ECM facilitated the reconstruction of wellgrounded and rich descriptions of participants' realities in their contexts (Burawoy 2009) - thus complementing the QLR - as well as the examination and improvement of the existing theory on the PC, as discussed in Chapter 4.

Sampling in this research was purposive (Miles \& Huberman 1994; Patton 2005), and the same group of individuals was invited to participate in three phases of data collection. In Phase 1, between 2010 and 2012, semi-structured, in-depth interviews were conducted with 26 HSIs whose cases exemplified some issues of great 
significance to the purpose of the investigation (Patton 2005). During Phase 2, in 2013, 12 repeated interviews were conducted; and in Phase 3, during 2014, another 14 repeated interviews were conducted. Thus, in total, the researcher completed 52 interviews with HSIs. All interviews were recorded and transcribed.

HSIs in the sample migrated to Australia with either a temporary or permanent skilled visa. They had diverse cultural backgrounds, coming from 16 different countries on six continents. Although they represented different industries and had qualifications in different areas, all of them had at least a bachelor's degree and had their occupations listed in Australia's Consolidated Skilled Occupations List (CSOL). Nine of these 26 professionals worked for mining companies during Phase 1 of the research, and 19 individuals received a weekly income of AUD\$1500 or more.

Interviews were also conducted with three 'intermediaries' in the migration process: representatives from the WA Department of Training and Workforce Development, an international recruiter, and a migration agent. Intermediaries are groups or organisations at the intersection between skilled migrants and the host country (Groutsis et al. 2015, p. 5). These may include a number of players in the migration industry, such as labour recruiters, brokers, travel and housing agents, as well as human smugglers and traffickers, each of whom have interests in the continuation of migration (Castles 2004; De Haas 2010). They serve at the middle and high end of the international labour market and have been increasingly involved in the process of migration for work purposes (Groutsis et al. 2015). Interviews with intermediaries offered significant background insights about the wider context in which these individuals and their migration experiences were embedded and were thus valuable as a triangulation strategy (Eisenhardt \& Graebner 2007).

Content and thematic analyses (Sparker 2005) were conducted in all three phases of data examination, with the support of computer-assisted qualitative data analysis software (CAQDAS). NVivo software was used in the first stage of analysis, with the aim of identifying main themes and assessing the frequency of some ideas. An independent rater was used to meet tests of robustness in using NVivo. Findings from NVivo informed a secondary analysis in which Leximancer was used to identify relationships among the concepts. The research design and methods are further discussed in Chapter 4. 


\subsection{Structure of the thesis}

The thesis is divided into eight chapters organised in the following manner:

Chapter 1, the current chapter, presents the research background and discusses the significance of the context for this particular study. It also identifies the aim of this thesis, research questions, justifications, significance and contributions. It also presents an overview of research methods, followed by the outline of the thesis.

Chapter 2 describes the context in which the lived experience of skilled labour migrants is embedded. This chapter starts with an overview of globalisation and neoliberalism as significant forces shaping both employment and labour movements in the last decades of the twentieth century (Castles 2013; Castles \& Miller 1998; Li 2008). It also discusses skilled labour migration in the context of the contemporary 'race for talent' (Shachar 2006), which has been embraced by many industrialised nations, including Australia. In addition, this chapter discusses the issue of skill shortages and its impact on the country's economic development (DIAC 2012c; Wright 2014), before describing WA and its particularities in terms of economic activity, labour markets and, consequently, migration intakes (ABS 2015; DIAC 2012a). The moments in which data were collected are portrayed as two distinct phases: the period between 2010 and 2012 , when WA was experiencing the resources boom; and the period between 2013 and 2014 (which encompassed both Phase 2 and Phase 3 of data collection), when the economic crisis hit WA's economy (Corben 2012; Tillet 2012).

Chapter 3 conceptualises the psychological contract as the framework guiding this research. This chapter defines the beliefs in PCs - individuals' perceptions of promises, obligations and their expectations regarding their employment arrangements (Lester \& Kickul 2001; Roehling 2008); what types of PCs are identified in the literature (Rousseau 1989); how breach and fulfilment of the PC are conceptualised (Morrison \& Robinson 1997); and the most common outcomes investigated in PC research. This chapter also describes how traditional PC research has been conducted thus far and discusses the critical-management approach that has emerged in the past decade (Cullinane \& Dundon 2006; Guest 2004a, 2004b). Lastly, propositions and a conceptual framework are presented.

Chapter 4 presents the research design and chosen methodology. It discusses the 
rationale behind the use of a qualitative longitudinal method (Flick 2006; Holland et al. 2006) and the use of the ECM (Burawoy 1998, 2009). The chapter presents the methods used for data collection and analysis and describes sampling strategies and sample characteristics. Finally, it considers limitations of this research, as well as reliability, validity and ethical issues.

Chapters 5, 6 and 7 describe the findings from the data collection at three different points in time. Chapter 5 presents the PCs of HSIs in the first phase of this research (between 2010 and 2012), when WA was experiencing a flourishing economy and skills shortages as an outcome of the resources boom (CEDA 2011; DTWD 2011). From the second half of 2012, however, this scenario started to change as economic constraints strongly impacted the State's labour market (Johnson 2013; Ker 2013; Uren 2013). Chapter 6 describes HSIs' PCs in this new context, with a particular focus on what has changed over time. This chapter examines the changes in perceptions during both Phase 2 and Phase 3, because such changes impacted the organisations - and therefore the individuals - at different times during the 2013 to 2014 period. Finally, Chapter 7 presents the findings regarding these individuals' intentions to stay in WA, as well as the reasons why some of them chose to leave Australia.

Chapter 8 further discusses findings from Chapters 5, 6 and 7 and answers the research questions previously stated in this chapter. Implications for PC theory, migration policies and management practice are also discussed. The limitations of this study are indicated, and matters for future research are suggested.

\section{Conclusion of the chapter}

This chapter identified and discussed the focus of this study, the research questions and justifications, and the significance of the research. Building on the concept of embeddedness (Polanyi 1957 [1944]), the chapter argued that importance must be given to the context of this particular study. The chapter also presented an overview of the research methods used in this investigation, followed by the structure of the thesis. Chapter 2 will describe the context in which the employment experience of HSIs are embedded. It will discuss the globalising forces and neoliberal ideas that emerged in the second half of the last century, reshaping employment relationships and migration flows all around the globe, before describing the settings for skilled migration in Australia and WA. 


\section{Chapter 2 - The Context of Skilled Migration}

\section{Introduction}

Drawing upon Polanyi's (1957 [1944]) principle of embeddedness, the aim of this chapter is to describe the connections between economic activity and social, political, institutional, historical and cultural elements (Krippner et al. 2004) that have influenced how the 'actors' in the thesis sample perceive their psychological contracts (PC).

This chapter thus begins by contextualising the significance of labour migration within the emergence of globalisation and the influence of neoliberalism (Li 2008). It discusses the intensification of the scope, pace and volume of labour migration in the global era, focusing particularly on the contemporary 'race for talent' (Shachar 2006), which has been embraced by many industrialised nations determined to manage labour shortages, ensure economic growth (Iredale 2001) and safeguard labour market flexibility (Hugo 2004; Wright 2012). A definition for highly skilled immigrants is also presented.

The second part of this chapter applies this discussion to the Australian context before focusing on the particularities of WA as the setting for this case study. An overview of migration flows to the country since the beginning of last century is presented, and main developments of Australia's migration strategies and programs over time are outlined, with particular focus on describing the shift in Australia's policies from migration for settlement towards migration on demand. The Australian Migration Framework that informs this chapter can be found in Appendix 1.

The third and final part of Chapter 2 presents the main characteristics of WA as the location for this case study. First, it discusses how WA's geographical position and the dominance of the resources industry in the State's economy affect both the entrance of skilled immigrants into this particular area of Australia and its labour market conditions. The chapter subsequently describes two very distinct phases of migration in WA, contrasting the characteristics of the first phase of data collection, when the State was still "in the grip of a boom mentality" (Birrell \& Healy 2012, p. 7), with economic conditions during the second and third phases of data collection, when WA had turned "from boom to bust" (Uren 2013 p. 19). 


\subsection{Skilled labour migration in a globalised world}

\subsubsection{Globalisation and neoliberalism}

Globalisation has been defined as the intensification of worldwide social relations, a 'stretching process' as the modes of connections among different regions and social contexts become networked across the globe (Giddens 1991, p. 64). Globalisation is a social transformation (Castles et al. 2011) manifest in the compression of the world and the unification of the global consciousness (Robertson 1992):

Globalization [is] a process (that) generates flows and connections, not simply across nation-states and national territorial boundaries, but between global regions, continents and civilizations. This invites a definition of globalization as an historical process (that) engenders a significant shift in the spatial reach of networks and systems of social relations to transcontinental or interregional patterns of human organization, activity and the exercise of power. (McGrew 1998, p. 98)

'When globalisation began' is a contested issue, with some scholars relating it to the rise of world religions about two thousand years ago (Robertson 1992) and others to the first circumnavigation of the Earth in the sixteenth century (Guillén 2001); other scholars have dated it to political-economic transformations that began from the late 1970s in parallel with the end of the Cold War and the collapse of communism (Hoodashtian 2001). The rise of globalisation is also associated with the opening up of the frontiers among nation states and the tendency towards deregulation and a free market economy (Castles 2013).

Since the late 1970s, neoliberalism has quickly developed as the dominant tendency of regulatory restructuring across the global capitalist system (Brenner et al. 2010; Castles 2003; Harvey 2007), becoming "hegemonic as a mode of discourse" (Harvey 2007, p. 23). Prioritising market-based, market-oriented, and market-disciplinary responses to regulatory problems, the focus of neoliberalism is to strengthen commodification in all realms of social life and to mobilise speculative financial instruments in order to open up new possibilities for capitalist profitmaking (Brenner et al. 2010, pp. 329-330).

Neoliberalism is believed to have developed from political strategies of the Thatcher and Reagan governments in Britain and the United States during the 1980s, which deliberately sought to roll back the welfare state and the high wage levels prevalent during the post-war boom period (Castles 2010). These governments actively promoted 
global capital mobility and economic deregulation in order to expose their economies as much as possible to global market forces and attract investment (Leys 2001, p. 3). The Thatcher and Reagan governments are considered to have "helped to write the book on neoliberalism as a modern political phenomenon" (Peck 2010, p. 2), kicking off the neoliberal revolution and sprouting the most recent 'Great Transformation' of our society (Harvey 2005; Leys 2001).

This movement has been uneven across places, territories and scales (Brenner et al. 2010), mostly because firms gravitate towards different modes of coordination in different economies (Hall \& Soskice 2001). Indeed, in liberal market economies organisational endeavours are coordinated primarily by markets. However, in coordinated market economies, the coordination is more strategic and social democratic, and firms and national governments respond not only to globalisation, but also to the dilemmas they have regarding economic and social policy making (Hall \& Soskice 2001). Nevertheless, most nation states have rapidly embraced neoliberal ideas, implementing deregulation, privatisation and the reduction of social provisions (Harvey 2005 , 2007). The neoliberal paradigm made global change look like an "inevitable and desirable form of modernisation" that could only be defied by "backward peoples or fundamentalist leaders" (Castles 2010 p. 1577).

The emergence of microelectronic technologies and widespread automation during this period undeniably supported the escalation of globalisation and the dissemination of neoliberal ideas (WTO 2001). Technological advances exponentially expanded communication, connected the world through information technology, eliminated geographical barriers for most kinds of commercial and financial activities (Leys 2001), and established new borders for knowledge flows around the globe (Castells 2010). Technological improvements also reduced the importance of distance and geographical location for production, allowing manufacturing to be broken into many basic steps and enabling access to the cheap labour available in developing countries (Hutchinson 2004). The advance of digitalised technology and communication has transformed the nature, efficiency and organisation of every aspect of production and distribution (Li 2008).

While dramatic technological advances enabled a growing number of companies to approach the world as a single production site (Castells 2010; Leys 2001), globalisation and free trade also gave countries and corporate firms access to new markets (Li 2008). 
The movement towards a global economy led many nations to dismantle barriers to trade and integrate trading zones. The world witnessed the development of the European Union (EU), the North America Free Trade Agreement (NAFTA) and the Association of Southeast Asian Nations (ASEAN). Australia, for instance, became one of the 128 signatories of the General Agreement on Tariffs and Trade (GATT), a pact committed to the principle of free commerce among its members through the development of a universal framework of trade (WTO 2001).

The emergence of global markets for standardised consumer products on a global scale allowed corporations to benefit from gigantic economies of scale in production, distribution, marketing and management (Levitt 1993). As a result, multinational and transnational corporations ${ }^{1}$ ascended in the global economy (Giddens 1990; Hutchinson 2004; Leys 2001; Munck 2002). Many economic sectors, such as oil, mining and agriculture (Munck 2002), quickly became dominated by no more than 10 to 12 large institutions worldwide (Webster et al. 2008). Global corporations increased in number from 7000 in 1970 to 60,000 by the 1990 s (Webster et al. 2008); by 2009, this number had risen to 82,000 enterprises managing production or delivering services, with 810,000 foreign affiliates (UN 2009).

Global corporations became important conveyors of capitalist relations worldwide and paved the way for globalisation and neoliberalism in the 1980s: "they have risen to a position where they dominate the global production and distribution of many goods and services, and are at the cutting edge of technological development" (Munck 2002, p. 28). The proliferation of transnational companies, commodities and capital also stimulated the freedom of the movement of people across national boundaries (Castles \& Miller 1998; Li 2008), giving the competition for human capital - skills, education, experience, and even personal characteristics - a place at the heart of global competitiveness (Papademetriou et al. 2008). This will be discussed next.

\subsubsection{The 'race for talent'}

Migration has been part of human history from the earliest times (Castles \& Miler 1998). The past six centuries have been marked by continuous waves of migration

\footnotetext{
${ }^{1}$ Although multinational corporations (MNCs) and transnational corporations (TNCs) have different definitions, commonly related to the presence or absence of a relationship to a home country, they are used interchangeably in this literature review because they are also used as synonyms in the globalisation literature. In this literature review, the use of multinational corporation or transnational corporation refers to any enterprise that is registered and operating in more than one country at the same time.
} 
intricately connected to colonialism, imperialism, and the development of capitalism (Lewis et al. 2015). Some of these movements include the European colonisation of the planet, the enslavement and trafficking of African tribes, the movement of indentured labour from Asia to Europe, Latin-American flows to the US, and post-Second World War migration towards the Global North (Lewis et al. 2015, p. 581).

However, the pace, scope, complexity and volume of world migration in the global era has been unprecedented (Li 2008, p. 1). Neoliberal market transnationalisation has been associated with a significant increase in international migration since the late 1970s (Castles 2013; Lewis et al. 2015). Economic globalisation has stretched the geographic boundaries of labour markets and altered the relationship between "territoriality and the acquisition of workers" (Walsh 2014, p. 587). It has also changed the main features of migration flows around the globe (Castles 2013; Hutchinson 2004; Tilly 2011) and prompted a level of competition for highly trained human capital among advanced, developed countries that has never been seen before ( $\mathrm{Li} 2008$ ).

The proliferation of transnational organisations, together with the development of international trade agreements, has led to a reduction of barriers to migration, particularly from South to North (Hugo 2006; Lewis et al. 2015). Technological innovation has also created a growing demand for highly trained human capital in many developed countries, boosting competition among nations for the best-qualified labour force (Li 2008). More importantly, a number of social and demographic aspects, such as skills shortages and an ageing labour forces in some developed countries, have forced nations to regulate migration according to their needs, facilitating the admission of a labour force with specific characteristics when required (Castles 2002; Rosewarne 2001).

Skilled migration has become driven towards managing shortages and safeguarding economic growth in the short term (Iredale 2001). The literature refers to a 'race for talent' (Shachar 2006) and to a 'global quest for talent' (OECD 2001) to describe the growing competition among industrialised nations to attract the 'best and the brightest' workforce (Shachar 2006, p. 151). In this competition, talent-recruiting countries try to outdo one another in order to attract those who can give them a relative advantage over competitors via their skills and capabilities (Hawthorne 2014; Papademetriou et al. 2008; Shachar 2006). This includes individuals who can support innovation (Abella 
2006), increase competitiveness (Abella 2006; Papademetrious et al. 2008; Shachar 2006), and allow greater labour market flexibility (Castles 2010; Hugo 2004).

Skilled migrants are able to choose among competing destination countries, and the offer of citizenship has become a competitive tool used by governments to attract and retain this world-class talent (Castles et al. 2012; Shachar 2006). Citizenship, concerning social closure and political participation, has become a fundamental process of inclusionary and exclusionary 'boundary-drawing' in the case of migrants (Faist 2010). National governments have proactively used their exclusive power over the property of citizenship to 'match' the offers of admission and settlement extended to the 'best and the brightest' by other nations (Shachar 2006, p. 159). Receiving countries that offer clear paths for permanent residency and citizenship usually hold superior value to foreign workers (Papademetriou et al. 2008):

Immigration and settlement agencies in OECD countries have come to recognize that highly skilled migrants from the rest of the world view the acquisition of political membership in a stable and affluent country as a valued good in itself. In exchange for their specialised knowledge and labour-market contributions, a select echelon of professionals gain not only access to cutting edge research and development work (and other professional advantages) but also the invaluable prize of establishing citizenship for themselves and their families in a stable, democratic, and affluent polity. (Shachar 2006, pp. 158-159)

Australia has not only created selective immigration streams for the highly skilled, but has also established naturalisation procedures to guarantee a subsequent transition to full membership in a short period of time (Castles et al. 2012; Shachar 2006). Those entering Australia in the skilled-independent scheme are automatically entitled to permanent residency. Those who come to Australia with a temporary, long-term business visa (457 subclass) can also apply for permanent residency and, after four years in the country, can become Australian citizens (DIAC 2012). With its skilled migration program, Australia attracts highly skilled workers by offering them a 'talentfor-citizenship exchange' (Shachar 2006, p. 178).

Together with Canada and some other 'competitor governments' such as the US and New Zealand (Hawthorne 2014), Australia is a country with selective admission procedures to attract HSIs able to contribute to its knowledge-based economy (Castles 2002; Schachar 2006; Hawthorne 2014). Australia is recognised as the most aggressive and successful player in this quest to attract talented immigrants (Cameron \& Harrison 2010; Papademetriou et al. 2008) because of its history of migration expertise, along 
with its appealing geographical location and characteristics (Cameron \& Harrison 2010; Shah \& Burke 2005). These aspects will be further discussed later in this chapter.

\subsubsection{A definition for highly skilled immigrant (HSI)}

Highly skilled migrants do not fall into a clearly outlined description in the literature nor are they part of a homogeneous group (Blitz 2010); however, they do share some particular features. They have been described as a 'transnational elite': A highlyeducated, highly paid, highly mobile workforce that maintains multicultural networks and reproduces cosmopolitan interests and practices (Beaverstock 2002). HSIs take economic and educational resources with them to host countries (Castles 2013), have greater flexibility, and a superior capacity to adapt to the receiving culture (Portes 2010).

Highly skilled immigrants are migrant workers who are usually granted preferential treatment regarding admission to a host country because of their skills or acquired professional experience (IOM 2011). They take up positions at a range of levels in organisations - although generally at a higher level, such as executives and senior managers, highly skilled specialists, specialised technicians and tradespersons, investors and businesspersons in general (Iredale 2001). HSIs possess a tertiary degree or have extensive specialised work experience as architects, accountants and financial experts, engineers, technicians, researchers, scientists, teachers, health professionals or IT specialists (Blitz 2010).

Definitions for highly skilled migrants vary notably from one country to another, in large part because national governments are frequently changing the criteria for eligibility for entry and rarely hold similar principles (Groutsis et al. 2015; Iredale 2000). Researchers (Caspersz 2012; Chaloff \& Lemaitre 2009; Chiswick \& Taengnoi 2007; Iredale 2000) have detailed the different approaches used by traditional receiving countries, such as Australia, Canada, New Zealand and the US, to acquire skilled immigrants, as part of their migration policies. The Organisation for Economic CoOperation and Development (OECD) also has a number of publications (see OECD 2001, 2008) aimed at defining and describing the international flows and economic impacts of highly skilled migration among OECD member and non-member countries.

In one of these publications, Chaloff and Lemaitre (2009) compared skilled migration policies among 27 OECD countries, describing how they differ in relation to demand- 
versus supply-driven systems, temporary versus permanent migration focuses, and the subjective criteria for selection of skilled labour migrants. Discrepancies emerging from these governments' policies partially arise from wide-ranging political and economic debates at the macro level regarding the needed skills, and partially from the lack of available data on this relatively disparate group (Freeman 2005).

In previous studies, however, researchers have established arbitrary specifications to their skilled samples. Chaloff and Lemaitre (2009), for example, adopted tertiary education, as defined in the International Standard Classification of Education (IESCED), as a cut-off for an educational threshold. In terms of occupations, their sample of highly skilled migrants followed the International Standard Classification of Occupations (ISCO), and included managers, professionals and associate professionals. In regards to wages, Chaloff and Lemaitre (2009) recognised considerable flexibility in remuneration threshold levels, but they reinforced the fact that these individuals' qualifications and work experiences must be valued in the receiving labour market.

Hawthorne's (1997) definition of the 'elite' sample of Australia's skilled migration program included recruitment under Australia's key skilled immigration categories, full and immediate recognition of overseas qualifications, at least five years of premigration professional experience, prime workforce age at time of arrival, and possession of intermediate-to-native speaker level in English. Hawthorne (1997) focused her work on engineers because of their position as the prime occupational group in Australia's skilled migration framework at the time her research was conducted.

In this research, the definition of highly skilled immigrant (HSI) closely follows Challoff and Lemaitre's (2009) approach, as well as Hawthorne's (1997) portrayal of an elite sample. It can be summarised as follows:

- Recruitment under Australia's key skilled immigration categories - either with a 457 Temporary Business Visa (with a sponsor, in an expatriate position or not) or Permanent Residency (as a result of a self-initiated migration to Australia);

- Full and immediate recognition of overseas qualifications:

- Tertiary education at the bachelor's level (minimum)

- With an occupation listed in Australia's Consolidated Sponsored Occupational List (CSOL) 
- Holding either a professional or a managerial position (in an employment relationship at the time of the interview);

- Substantial pre-migration professional experience (at least five years);

- Prime workforce age at time of arrival;

- Possession of intermediate-to-native speaker level in English.

\section{Modes of engagement: Differences among HSIs}

In the last two decades, the skilled migration literature has focused particularly on distinguishing skilled migrants who follow an international assignment as 'expatriates' - professionals sent abroad by their companies (Castree et al. 2013) - from those who pursue self-initiated ventures in other countries. For the purpose of clarity in terminology, this sub-section will compare the common definitions of these two terms: assigned expatriates (AE) and self-initiated expatriates (SE).

Assigned expatriates (AEs) are skilled individuals pursuing international jobs (or projects) within a foreign subsidiary of their employers on a temporary basis (Inkson \& Khapova 2008). Employees on expatriated assignments have a job arranged for them by their company, they frequently receive training prior to leaving for the assignment, and they often receive a compensation package that includes educational benefits for children, rental supplements and other benefits (Howe-Walsh \& Schyns 2010). International assignments are usually limited in terms of time, lasting anywhere from three months to five years. Among the AEs, the opportunity to work internationally arises from the employer, and many times they remain as employees of their homecountry organisation during their international transfer (Biemann \& Andresen 2010).

Self-initiated expatriates (SE), on the other hand, have made their own way to the destination country and job (Jokinen et al. 2008, p. 979). A number of terms are used to refer to the experience of these individuals. They include 'overseas experience' (Inkson et al. 1997), and 'self-initiated foreign work experience' (Suutari \& Brewster 2000), among others. SEs are described as individuals who relocate voluntarily to a foreign country independent of any employer or organisational assistance, to be hired under a local-country contract (Biemann \& Andresen 2010; Inkson et al. 1997). For selfinitiated expatriates, the overseas assignment is a feature of the boundaryless career (Inkson et al. 1997); a career that unfolds in multiple employment settings (Arthur \& Rousseau 1996), including those located in other countries. 
Although both AEs and SEs are highly qualified individuals who work away from their country of birth, scholars maintain that they hold significant differences emerging mostly from two sources: holding (or not holding) control over their careers, and initiating (or not initiating) the decision to work abroad (Andresen et al. 2012; Biemann \& Andresen 2010; Inkson et al. 1997; Jokinen et al. 2008; Suutari \& Brewster 2000). Inkson and colleagues (1997, p. 352) illustrated the contrasts between AEs and SEs in the following table:

\begin{tabular}{|l|ll|}
\hline \multicolumn{2}{|c|}{ Expatriate Assignment (AE) } & Self-Initiated Assignments (SE) \\
\hline Initiation & Company & Individual \\
Goals & Company projects (specific) & Individual development (diffuse) \\
Funding & Company salary and expenses & Personal savings and casual earnings \\
Career type & Organisational career & Boundaryless career \\
\hline
\end{tabular}

Table 2.1. Contrasting qualities of expatriate assignment (Inkson et al. 1997, p. 352).

Researchers have found that as a result of having different career types, goals and migration experiences, these two groups represent different interests, expectations and work outcomes (Biemann \& Andresen 2010; Doherty et al. 2011; Inkson et al. 1997; Suutari \& Brewster 2000). Comparing AEs and SEs, Biemann and Andresen (2010) suggested that SEs demonstrate higher organisational mobility with greater intentions of changing jobs, because pursuing several employment settings is characteristic of this new, boundaryless career paradigm (Biemann \& Andresen 2010, p. 441). Suutari and Brewster (2000) found that, in Finland, these groups differ regarding their perceptions of job security. The vast majority of expatriates in their sample declared that they relied on a future job opportunity because they had been given some kind of promise about a job upon repatriation. SEs, for their part, felt 'on their own' in restabilising their careers after an eventual repatriation (Suutari \& Brewster 2000).

Both groups, AEs and SEs, have been included in this study's sample. HSIs enter Australia with expatriate assignments or as a result of a self-initiated endeavours; but as statistics in Australia show (DIBP 2014b), temporary business immigrants have been increasingly using their assignments in the country as a pathway to permanent settlement. HSIs' transition from temporary to permanent engagement to Australia is further discussed later in this chapter. 
2.1.4 Labour market flexibility, the insecurity of the highly skilled, and issues of belonging

Systemic insecurity and precarity among the workforce have emerged as a result of neoliberal globalisation and global transformation previously discussed in this chapter (Lewis et al. 2015; Standing 1997, 2008, 2012). The rise of an economic ideology built on competitiveness, commodification and capitalist profitmaking promoted the idea of labour market flexibility (Lewis et al. 2015) as a means of ensuring the full and efficient use of human resources in organisations (Cappelli 1999).

Labour market flexibility can take different forms. Numerical flexibility refers to an adjustment of the number of employees to meet demand fluctuations (Atkinson 1984), which is achieved by legislation, regulatory reform and contracting (Standing 2012). With functional flexibility, organisations arrange employees for the best effect between activities and tasks (Atkinson 1984), which involves task redesign and unpredictable job movements (Standing 2012). Wage (or financial) flexibility means shifting the remuneration systems to facilitate numerical or functional flexibility (Atkinson 1984). Once this logic of labour market flexibility was accepted as a structural requirement for organisations worldwide, the growth of insecurity and the widespread of a global 'precariat' were inevitable (Standing 2012, p. 592).

Precariousness has long been related to uncertainty over the stability of employment, lack of control over wages and conditions, a low level of social protection against unemployment and discrimination, and insufficient income or economic vulnerability (Rodgers \& Rodgers 1989). Standing (2014, pp. 10-11) identifies the growth of a 'precariat' class in the context of these precarious employment conditions and economic insecurity that upholds an increasing lack of occupational identity and civil rights:

Those in the precariat have no secure occupational identity; no occupational narrative they can give to their lives (...) They are exploited outside the workplace as well as in it, and outside paid hours as well as in them. (...) Few in the precariat use their full educational qualifications in the jobs they have (...) They must rely largely on money wages, without non-wage benefits, such as pensions, paid holidays, retrenchment benefits and medical coverage (...) The precariat also lacks rights-based state benefits, such as unemployment benefits, as well as private benefits gained from investments and contributory insurance plans (...) The precariat is additionally defined by distinctive relations to the state: they are losing rights taken for granted by full citizens. Instead, they are denizens who inhabit a locale without civil, cultural, political, social and economic rights, de facto and de jure. 
Workers with 'non-standard' or 'atypical' employment contracts (Lewis et al. 2015, p. 585) are usually those who live in precarity (Standing 2012). These include individuals in casual, flexible, contingent, part-time work, multiple job holdings, and agency employment (Guest et al. 2006; McDowell et al. 2009). Standing (2012), however, argued that the greatest inflow into the 'precariat' group consists of migrants - a group he described as the "light infantry of global capitalism" (2012, p. 597).

The tendency towards using migration to meet labour market demands in Australia has indeed been compared to a tap that can be turned on and off in response to politicaleconomic interests (Castles 2000). When the economy grows, more labour migrants are absorbed; when the economy declines, fewer migrants are welcome to labour markets (Cerna 2010). Labour migration, particularly temporary labour migration, has been safeguarding Australia's numerical flexibility (Atkinson 1984), while offering a flexible and 'just-in-time' workforce with foreign workers who are employed and dismissed as the "market's pendulum swings" (Walsh 2014, p. 596).

Although Australia's temporary skilled migration program offers some protection for labour migrants (to be further discussed in section 2.2.3) and provides opportunities for economic gain and skill enhancement (Walsh 2014), temporary work visas create vulnerabilities for individuals, and "decouple work" from the political and social rights of citizens (Oke 2012b, p. 89). Scholars (Kosny et al. 2016; Reid 2012) have also argued that immigrants arriving in Australia face a number of assimilation and employment barriers. Reid (2012) found a large underutilisation of employment skills in the migrant population in Australia up to three years after immigration to the country. More recently, Kosny and colleagues (2016) reported that immigrants in Australia faced racism and had difficulty finding work that was commensurate with their education and training, eventually using strategies to disguise their culture and race in order to gain entry into Australian workplaces.

It is important to recognise, though, that migrant workers are a very heterogeneous group given their diverse backgrounds (Ong \& Shah 2012; Roberts 2011). Their perceptions are dependent on their degree of assimilation, their ethnicity, whether they have an English-speaking background (Ong \& Shah 2012), and their visa arrangements (Oke 2012b). In Reid's (2012) research, more than 40 per cent of the interviews were conducted in a language other than English, using interpreters or bilingual interviewers. Kosny and colleagues (2016), on the other hand, recruited participants for their research 
in migration settlement agencies, help centres and employment agencies. Therefore, the samples in both of these studies were focused on groups who were already struggling, not on 'highly skilled immigrants' as described in section 2.1.3 of this thesis.

Highly skilled migrants, as per this research definition, better fit the group of 'free workers' (Knell 2000; Pink 2001), who are actually believed to benefit from mobility and temporal flexibility. They have been called the 'newly empowered workers', who take control of their 'portfolio careers' in the fast-moving global economy, selling their high skills and acquiring new skills in a "controlled sweep among high-quality jobs" (Green 2008 p. 148). These individuals hold professional or technical skills that are in high demand, and have both the resources and knowledge to sustain their employability and their employment-related networks (Guest et al. 2006). They believe temporary jobs must be embraced, not feared, because they are in the position to take advantage of a 'new freedom' (Knell 2000). They view mobility as an opportunity, and commonly they have no interest in gaining residency in the country where they are working (Oke 2012a).

Therefore, in the 'global tertiary class structure' described by Standing (2012, 2014), HSIs should not be classified as the 'precariat' but rather as the 'proficians': a small group who earns satisfactory money even though they lack security. The 'proficians' have a sense of control over their occupational identity, holding skills and competencies, which earn them high incomes, and economic opportunity as they travel from project to project and employer to employer (Standing 2012, p. 589).

Nevertheless, the growing international mobility of skilled migrants also raises issues of 'belonging' - both political and cultural belonging - as these individuals hold multiple citizenships and commonly do not live in their countries of citizenship (Castles \& Davidson 2000). The literature includes skilled migrant stories characterised by their experiences of adjustment, settlement, nostalgia, isolation, renewal, loss, discrimination and a volatile sense of belonging (Beaverstock 2002; Roberts 2011; Skrbis 2008), despite benefiting from their mobility in a professional-economic perspective.

A sense of belonging is "an embodied, relational, and affective experience", based in the lived experience of inclusion and affinity and undermined by experiences of exclusion, marginalization and rejection (Taylor 2009, p. 299). Migrants' identities and perceptions of belonging thus concern matters of membership, cultural, moral and 
political values, territoriality, admission, legal status, social and political rights, and access to public resources (Vertovec 2004). Citizenship, although an important prerequisite, is not enough to ensure a sense of belonging to a nation, because belonging is a sensory and emotional assessment, based on connection and relationships (Taylor 2009).

The literature has claimed that only a minority of migrants can actually express a feeling of 'global belonging' - as seeing oneself as an integral part of the world and sharing concerns that transcend their own locality (Dye 1963). These are the individuals with continuous access to global information and communication technologies, who are well networked within transnational flows of information and capital exchange, and who productively exercise a high level of international mobility (Taylor 2009, p. 298).

\subsection{Skilled labour migration in Australia}

\subsubsection{Immigration to Australia from 1901 to 1996}

A number of authors have documented the historical context of immigration to Australia (Castles 2000; Castles \& Miller 1998; Collins 2008, 2013; Hugo 2006; O’Donnell \& Mitchell 2000a; Shah \& Burke 2005). Immigration has been a major source of the country's population growth (Collins 2013; Collins 1991), and most scholars recognise that the foundations of Australia's labour force can be found in the extensive immigration program that characterised Australia's development as a nation (O’Donnell \& Mitchell 2000a).

During the first decades of the twentieth century, however, Australia was still emerging from its colonial beginnings, promoting policies that encouraged the immigration of white British permanent workers only (Crock et al. 2012). The 'White Australia' policy and the 1901 Immigration Restriction Act restricted immigration in the country, particularly Chinese immigration, making official hostility grounded in racial characteristics (Collins 1991). The Australian system of workplace regulation stressed the security of permanent full-time work with standardised terms and conditions and was linked to a general consensus that labour - and Australian society - needed to be white and free (Crock et al. 2012, pp. 8-9). Asian migrants, called 'migrants of colour' (Crock et al. 2012, p. 9), were expected to undermine standards of work, as they would settle for lower wages and conditions. 
In the post-World War II period, labour migration played a central part in Australia's development and restructuring (Castles \& Miler 1998; Collins 2008). A target of 7.5 million was set for the Australian population, and the migration program was deliberately focused on attracting British immigrants. These immigrants were critical to Australia's economic growth, as their labour was much needed for manufacturing and infrastructure projects (Castles 2000).

Additionally, expanding the population base was seen as a necessary move to guarantee Australian sovereignty. The Japanese attacks on Darwin and Broome in 1942 had highlighted Australia's vulnerability and created concern about future invasions in remote areas (Collins 1991). 'Populate or perish' was a prevalent conviction, meaning that a policy of massive immigration was needed to build a population with the economic structure and workforce to defend itself (Stone 1995, p. 5). Borrie (1975, p. 197) quoted Calwell, Australian Minister for Immigration, in 1948:

Additional population is Australia's greatest need, for security in wartime, for full development and prosperity in peacetime, our vital need is more Australians. The Pacific War taught Australians a lesson we must never forget - that in any future war we can never hope to hold our country unaided against a powerful invader.

A policy of population growth was actually a policy of growth by immigration, because birth rates had fallen during the war and the baby boom was still a "gleam in the collective eye" (Stone 1995, p. 5). However, as history has shown, it was impossible to attract enough workers from only the United Kingdom. Thus, formal and informal agreements were reached with other European countries, such as Malta, The Netherlands, Italy, West Germany, Turkey, Austria, Greece, Spain and Belgium. An agreement with the International Refugee Organisation was also made to import additional labour migrants to populate Australia (Castles 2000; DIAC 2008; Khoo et al. 2008; O'Donnell \& Mitchell 2000a). In 1972, the 'White Australia' policy was abolished, and a policy of non-discrimination in relation to race, colour or nationality was introduced (DIAC 2007).

In 1977, the Fraser government asked Frank Galbally, a prominent Melbourne barrister, to be the chairperson in a review of post-arrival programs and services for migrants. This review was aimed at analysing and reporting on the effectiveness of these programs and services for migrants, identifying areas of need and concern (Koleth 2010). The resulting Galbally Report, presented to Parliament by Malcolm Fraser in April 1978, identified multiculturalism as a key concept for the future development of 
immigration policy in Australia, and reinforced the right of all Australians to preserve their culture without fear of prejudice (Koleth 2010). In 1978, following the Galbally Report, there was a shift in the government policy framework towards multiculturalism (DIAC 2007).

A more structured approach towards immigrant selection also emerged from the report's recommendations, including an emphasis on those who would represent a positive gain for Australia instead of on their ethnic characteristics (DIAC 2007). In 1979, the selection of permanent skilled immigrants became more sophisticated with the introduction of the Numerical Multifactor Assessment System, a method previously adopted by Canada (Crock et al. 2012; DIAC n.d.). This became the primary way in which immigration policy sought to value family ties as well as occupational and language skills as indicators of the probability of successful settlement in Australia.

During the early 1990s, a number of initiatives were also developed to convince Australian employers of the potential benefits of diversity, in line with tendencies previously noticed in the US, Canada and Scandinavia (Collins 2008; Hawthorne 2005). As noted by Hawthorne (2005, p. 670), in 1992, Prime Minister Keating highlighted the relationship between the employment of immigrants and Australia's economic potential:

\footnotetext{
Australia is a country of extraordinary achievements and equally extraordinary potential. In no small measure, this is because we are a country of immigrants... [F]or every country which constitutes a potential market for Australian companies, there are Australians who know their way around. The key to gaining better access to all markets is knowledge - knowledge of their cultures and languages, of their business practices and networks, and of their political and legal systems.
}

However, migrant labourers still faced market barriers due to limited English skills and the difficulty of having overseas credentials recognised, barriers that caused negative employment outcomes for the migrants and increasing community polarisation in Australia (Hawthorne 2005). Significant reforms in Australia's migration policies and frameworks have been gradually implemented, aiming to give equal treatment to noncitizens (DIAC n.d.), to simplify and facilitate business travel to Australia, and to increase flexibility in targeting occupations with a shortage of skilled workers (Crock et al. 2012, p. 14). One of these reforms was the introduction of the 457 (Business Long Stay) visa in 1996. 


\subsubsection{Immigration to Australia from 1996}

In 1996, Australia elected a coalition government formed by the Liberal and National Parties after 13 years of Labour government. At that time, the Australian Federal Government initiated a major review of its skilled immigration program (Hawthorne 2005 ) in response to the rising internationalisation of the Australian economy and concerns expressed by Australian businesses and trade agencies that existing migration procedures were too complex (Khoo et al. 2008, p. 28). The impact of market liberalism on Australian competitiveness in a number of sectors, such as the commodities industries, enhanced the political influence of business groups who actively promoted market-based mechanisms for meeting employers' skills needs, including liberal visa regulations (Wright 2015).

The new government put into effect a new policy framework, with a dramatic strategic shift "from altruism to pragmatism" (Hawthorne 2005, p. 681). Australia's migration program had always emphasised permanent settlement over temporary labour movements (Khoo et al. 2008; Robertson 2015a); individuals were granted permanent residence on the basis of their characteristics and were allowed to move to Australia even if they had no employment arrangements (Hawthorne 2005). The program, however, shifted to recruiting labour migrants on the basis of targeted skills needed in the economy, ensuring that labour immigrants in Australia were employed where demand was greatest (Phillips \& Spinks 2012). A 'demand-driven' approach to labour migration replaced the previous 'supply-driven' approach (Cully 2012; Phillips \& Spinks 2012), and applicants started to be sorted and selected primarily according to local labour market needs. The new framework was aimed at reducing the intake of independent skilled immigrants without prearranged employment in Australia, while increasing employer- and government-sponsored skilled migration (Phillips \& Spinks 2012). It improved the flow of skills to the country while allowing greater labour market flexibility (Khoo et al. 2008).

A number of reforms gave new shape to Australia's migration program in terms of targeting the desired human capital in the country and minimising the need for migrants' labour market adjustment (Hawthorne 2005). They also simplified business travel to Australia for entrepreneurs, investors and highly skilled employees (Crock et al. 2012). 
One of the most significant reforms was the introduction of the Temporary Work (Skilled) (subclass 457) visa into the Australian migration framework in 1996. The 457 was designed to allow eligible employers to address short-to-medium-term skill shortages in their businesses that could not be filled from the local labour market (DIAC 2012c). Employers were given, subject to eligibility conditions, the ability to select the migrants they would sponsor (Cully 2012). The subclass 457 became the most commonly used visa to bring overseas skilled workers to Australia on a temporary basis (DIAC 2012c).

The changes in the selection system also included a comprehensive review of the points test for independent and skilled visa applicants, which was now used to target those who could make a positive and immediate contribution to the Australian economy, budget and labour market (DIAC 1999). The changes included the adoption of minimum threshold standards for skill, age and English language ability as well as weighting for in-demand occupations (Hawthorne 2005). Through Australian professional bodies, pre-migration qualification screening was implemented that had the power to accept or block migrants from Australian registration (Hawthorne 2005). The government introduced the Migration Occupations in Demand List (MODL), assigning bonus points for applicants whose nominated occupations were featured on it (Cully 2012). The establishment of 'priority occupations' was based on governmental departments' specification regarding labour market needs and was a pro-active standpoint to encourage those qualified in the specific occupations to apply for migration (Abella 2006).

The many changes in the skilled migration process contributed to halving the unemployment rate among recently arrived immigrants - from 23.4 per cent in 1995 to 12.4 per cent in 1999 (Hawthorne 2005). The implemented measures also raised salary levels by around one-third for independent skilled visa holders and doubled the proportion of migrants earning 'high' salaries (Hawthorne 2005). The Australian Migration Framework is described in Appendix 1.

\subsubsection{Critics and development of the 457 visa}

The use of temporary labour migration and the 457 visa scheme is still very controversial. On the one hand, the labour of skilled immigrants is associated with economic and budgetary benefits for Australia (DIAC 2011a), as temporary skilled 
migration continues to be deployed for addressing key and emerging skill shortages and allowing for business establishment and investment (DIAC 2008, 2009). Temporary skilled migration is employed to achieve greater labour market efficiency and competitiveness in the international market (Wright 2012). In periods of rapid growth, when the gap between labour market demand and supply increases, Australian employers rely on immigration to meet their labour requirements (Wright 2012).

On the other hand, there are arguments that temporary labour migration places Australian jobs at risk (CFMEUWA 2012) and reduces domestic skills training (Toner \& Woolley 2008) because employers are able to decrease their training costs by importing 'ready-made' skilled workers instead of up-skilling domestic workers (AEGIS/AMWU 2006). Unions have also raised concerns regarding occupational health and safety requirements due to varying standards adopted among different countries (Caspersz 2012).

In the past, it was argued that the framework that fosters temporary labour migration increased the vulnerability of migrants to the risk of abuse, underpayment and unsafe working conditions (Caspersz 2007, 2012; Crock et al. 2012; Tham \& Campbell 2011). In response to this concern, progressive changes have been made to the subclass 457 visa since it was launched, aimed at providing overseas workers with the same workplace rights as Australian citizens.

A significant reform was the introduction of a Minimum Salary Level (MSL) for 457 visa holders in 2001 (Crock et al. 2012; Tham \& Campbell 2011) after a discrepancy between the MSL and domestic workers' wage levels raised concerns that temporary labour migrants were becoming a cheap source of labour (Caspersz 2012). The setting of a wage level was aimed at ensuring that 457 visa holders received a reasonable standard of living in the absence of social security support, encouraging employers to train and hire locals over foreigners whenever possible, and reducing the motivation of employers to inflate skill level descriptions (Crock et al. 2012).

Another significant reform was the inclusion of 457 visa holders under the Fair Work regime, the system of Australian employment relations in 2009. This reconfiguration sought to address the extreme exploitation of 457 visa holders (Berg 2016), tightening sponsors' obligations and giving migrants access to general protections provisions (Crock et al. 2012) - including protection from unfair dismissal by the sponsoring 
employer (Crock et al. 2012). These amending provisions also involved more substantial sanctions for employers who fail to comply with their obligations, which include securing appropriate accommodation for sponsored employees and refraining from attempts to recuperate costs from them (Crock et al. 2012). The amendments increased the required level of English language proficiency and reduced the number of occupations on the list that qualified for the 457 visa scheme (Crock et al. 2012; Tham \& Campbell 2011). Moreover, the regulations governing the 457 visa scheme were amended to prevent labour-hiring companies from using the visa for recruiting workers who would then be placed in other companies (Tham \& Campbell 2011).

Changes were also designed to facilitate 457 visa holders transition to permanent residency (Berg 2016), including, for instance, a greater priority to regional schemes. This led to the expansion of permanent visa categories that would encourage migrants to settle in regional areas with low population growth and density (Wright 2015). However, it also prioritized employer sponsorship, thus increasing employee's dependency on their employer-sponsor (Berg 2016).

A number of other amendments to the subclass 457 program were introduced in July 2013, following the debate about the scheme integrity (Berg 2016). The Department of Immigration identified that the use of this visa subclass was growing at a record rate in industries and geographical regions that did not appear to be experiencing skills shortages (DIAC 2013). Restrictions were then imposed in terms of the number of workers that could be sponsored by an organisation, together with an ongoing requirement for training, a strengthening in assessments of generalist occupations, and a change in market salary rates in relation to regional localities. Furthermore, on-hire employments that fell outside approved labour agreements were banned, preventing sponsors from engaging visa holders under independent contracting arrangements (DIAC 2013).

\subsubsection{The intake of skilled individuals in the past 20 years}

Table 2.2 in this section illustrates the skilled immigrant intake in Australia, in both permanent and temporary streams (temporary business long stay 457 visa), from 1996 to 2014 . The increase in the temporary immigration intake over the past 20 years was justified by a continued economic growth (Collins 2008). Major developments in Western Australia's and Queensland's mining industries, together with growth in the 
information technology, finance, hospitality, and health sectors across the country, accounted for much of the rise in labour immigration during this period (Wright 2012).

Although the intake of skilled individuals has risen steadily in the past 20 years, both in the permanent and temporary streams, there was a noteworthy fluctuation in the number of entrants through the temporary skilled scheme, particularly in the period between 2008-09 and 2010-11. This is because unlike permanent migration, temporary skilled immigration fluctuates according to levels of demand, from both those seeking to enter Australia and from employers seeking to sponsor temporary workers (Phillips \& Spinks 2012).

The fall registered in the 2008-2011 period was in large part attributed to the Global Financial Crisis (GFC), which led to a significant drop in demand for temporary workers in the Australian labour market (Phillips \& Spinks 2012). As Table 2.2 (below) shows, demand for the 457 visa decreased significantly again more recently, from 126,348 in $2012-13$ to 98,571 in 2013-14, after having experienced a substantial gain during the 2011-12 and 2012-13 periods (DIBP 2014a).

\begin{tabular}{ccc} 
Period & Permanent Skilled Immigrants & Temporary Business 457 visa \\
\hline $\mathbf{1 9 9 5 - 9 6}$ & 24,100 & - \\
$\mathbf{1 9 9 6 - 9 7}$ & 27,550 & 25,786 \\
$\mathbf{1 9 9 7 - 9 8}$ & 34,670 & 30,880 \\
$\mathbf{1 9 9 8 - 9 9}$ & 35,000 & 29,320 \\
$\mathbf{1 9 9 9 - 0 0}$ & 35,330 & 31,070 \\
\hline $\mathbf{2 0 0 0 - 0 1}$ & 44,730 & 36,900 \\
$\mathbf{2 0 0 1 - 0 2}$ & 53,520 & 38,592 \\
$\mathbf{2 0 0 2 - 0 3}$ & 66,050 & 41,936 \\
$\mathbf{2 0 0 3 - 0 4}$ & 71,240 & 42,437 \\
$\mathbf{2 0 0 4 - 0 5}$ & 77,880 & 49,137 \\
$\mathbf{2 0 0 5 - 0 6}$ & 97,340 & 71,737 \\
$\mathbf{2 0 0 6 - 0 7}$ & 97,920 & 87,937 \\
$\mathbf{2 0 0 7 - 0 8}$ & 108,540 & 111,019 \\
$\mathbf{2 0 0 8 - 0 9}$ & 114,777 & 101,432 \\
$\mathbf{2 0 0 9 - 1 0}$ & 107,868 & 67,980 \\
$\mathbf{2 0 1 0 - 1 1}$ & 113,725 & 90,120 \\
\hline $\mathbf{2 0 1 1 - 1 2}$ & 125,755 & 125,070 \\
$\mathbf{2 0 1 2 - 1 3}$ & 128,973 & 126,350 \\
$\mathbf{2 0 1 3 - 1 4}$ & 128,550 & 98,571 \\
\hline
\end{tabular}

Table 2.2. Skilled migrant intake in Australia (permanent and temporary streams) from 1996 to 2014 (Sources: Phillips \& Spinks 2012; DIAC 2011, 2012, 2013; DIBP 2014c).

\subsubsection{The transition from temporary to permanent}

There has been a tendency in the literature to dichotomise temporary migration from permanent settlement as if they were two separate and unrelated processes (Khoo et al. 
2008). However, migration policies in Australia have been enabling the 'fast-tracking' of skilled foreigners and providing them with 'stepping-stones' to labour market participation and permanent residency (Walsh 2014).

Immigration statistics in Australia reflect the fact that its temporary migration program is increasingly becoming a common pathway to permanent settlement. In the 2013-14 period, 44,990 individuals holding a subclass 457 visa applied for permanent residency in Australia, an increase of 11.7 per cent on the previous year (DIBP 2014b). Less than a decade before, in the 2004-05 period, just 14,604 individuals had applied for permanent residency when holding a temporary business entry visa to Australia (Khoo et al. 2008).

Khoo and colleagues (2008) found that for skilled temporary migrants entering Australia from other developed countries (i.e. from Europe, North America and Japan), temporary migration is commonly seen as an opportunity to gain international experience, and it only becomes permanent migration if individuals like the lifestyle or form local, personal relationships. According to their study, however, skilled temporary migrants from less developed regions are more determined to become permanent residents. Immigrants from Africa usually aim for settlement in Australia because they are unhappy with the social, economic or political conditions in their home countries. Better employment opportunities, higher salaries and better prospects for children have been implicated in attracting immigrants from Asia (Khoo et al. 2008).

In the literature, it has been argued that temporary migration is a learning experience for many individuals. It provides enhanced self-confidence and increased knowledge about the destination, so individuals sometimes change their original temporary intentions towards permanent migration (Balaz et al. 2004; Khoo et al. 2008). It has also been argued that some temporary immigrants may apply for permanent residence only because it could give them more residential and employment options, not necessarily because they intend to settle permanently in the destination country (Balaz et al. 2004; Khoo et al. 2008). From the employer side, those who have invested in the training of new workers are often reluctant to see them leave, as this has economic and operational implications; consequently, many firms push towards offering their employees visa sponsorship for permanent residency as a retention strategy (Abella 2006). 


\subsection{Skilled labour migration in Western Australia}

\subsubsection{About Western Australia}

The structure of the Western Australian economy is closely related to the abundance of natural resources and its proximity to Asia (DTWA 2014). The mining industry is the foundation of the State's economy, making up 29 per cent of its production (ABS 2012a; DSD 2014). Additionally, the growth of WA's resources sector in the past decade contributed to boosting the demand for social and economic infrastructure, as well as core services such as education and health (DTWA 2014). During the 2012-13 period, the services industry was the second largest sector of WA's economy (27 per cent), followed by construction (12 per cent) (DTWA 2014).

During the 2012-13 period, WA's Gross State Product (GSP) was worth \$242.7 billion, making it the fourth largest economy in Australia (DTWA 2014). WA recorded the higher per capita ratio amongst Australia's states and accounted for 16 per cent of national output, despite having only 10.8 per cent of the national population (DTWA 2014). WA has also outpaced the rest of the nation in real economic growth, and grew by an average of 4.9 per cent per annum in the past 10 years, compared to a national rate of 3 per cent (DTWA 2014).

The State's strong rate of growth is mostly attributable to oil and gas investments, such as the $\$ 50$ billion-dollar Gorgon liquefied gas $(\mathrm{LNG})^{2}$ project and the $\$ 28$ billion-dollar Wheatstone LNG project, as well as other significant ventures in the mining sector, especially in iron ore projects (DTF 2013). Given its quick development, WA's economy has doubled in size and witnessed not only the creation of almost 200,000 jobs but a record rate of immigration intakes as well (CCIWA 2010).

During the 2010-11 period, when the first phase of this research was conducted, WA attracted more immigrants per head of population than any other Australian jurisdiction, both from overseas and from other parts of Australia (DIAC 2012a). As a result, 33.4

\footnotetext{
${ }^{2}$ LNG is natural gas (methane) chilled to a liquid state. Once liquefied, LNG occupies about $1 / 600$ the space of methane in its gaseous form, and can be more easily exported. LNG projects in Western Australia, the Northern Territory and Queensland were alleged to have driven an unprecedented level of investment in Australia (more than $\$ 180$ billion), creating thousands of jobs and delivering export income and tax revenue (APPEA 2015).
} 
per cent of WA's population was born overseas, a percentage notably higher than the national average of 26.9 per cent (ABS 2015).

In addition, the composition of WA's immigrant profile differs from the east coast of the country. While China and India are the largest source countries to Australia as a whole - and specifically to most of its eastern states - permanent migration to WA includes mostly immigrants from the United Kingdom, New Zealand, the Philippines and South Africa (DIAC 2012a). In 2011, WA had the highest proportion of people born in the United Kingdom (10.9 per cent), more than double the Australian proportion of 5.4 per cent (ABS 2015). The State also recorded the highest proportion of people born in South Africa and Malaysia (ABS 2015).

It is believed that geographic factors play a role in this process, as well as individuals' social networks and occupational experiences. South Africa, for example, is not only closest to the west coast of Australia, but also has the world's fifth largest mining sector in terms of GDP value (Kearney 2012), which represents a crucial synergy with some of WA's most relevant labour market needs. The Philippines, on the other hand, is recognised as a global source of nurses (Lorenzo et al. 2007), one of the higher demand occupations in WA.

\begin{tabular}{|c|c|c|}
\hline \multirow{2}{*}{$\begin{array}{l}\text { State or } \\
\text { Territory }\end{array}$} & \multicolumn{2}{|c|}{ Source country } \\
\hline & 1st Largest Provider & 2nd Largest Provider \\
\hline NSW & People's Republic of China & India \\
\hline VIC & People's Republic of China & India \\
\hline QLD & New Zealand & United Kingdom \\
\hline WA & United Kingdom & New Zealand \\
\hline SA & People's Republic of China & India \\
\hline ACT & People's Republic of China & India \\
\hline NT & Philippines & India \\
\hline TAS & People's Republic of China & India \\
\hline
\end{tabular}

Table 2.3. Top countries providing permanent immigrants to Australia's states (adapted from DIAC 2012a, p. 106, refers to the last Census 2011).

Over the past decade, WA has also steadily recorded annual net interstate migration (NIM) gains from the rest of the country. NIM refers to the net gain or loss of population through the movement of people from one state or territory of usual residence to another. The gain in NIM in WA gradually increased from 2200 people in 2004-05 to a peak of 11,400 people in 2011-12, before decreasing to 1000 persons in 2013-14 (ABS 2015). 


\subsubsection{The context of WA during the 2010-2012 period}

In 2010, the Global Financial Crisis (GFC) triggered the "largest and sharpest drop in global economic activity of the modern era" (McKibbin \& Stoeckel 2009). The economic crisis, which began in the US with the housing market bubble in late 2007, was followed by a crash in financial markets and the collapse of financial services provider Lehman Brothers in 2008, resulting in a deep recession for most major developed economies around the world (McKibbin \& Stoeckel 2009).

A number of developed countries, such as Greece, Ireland, Italy, Portugal and Spain, faced a period of economic uncertainty, with sovereign debt issues (CEDA 2011), recurrent bailouts and record levels of unemployment (Kingsley 2012). In 2010, Australia's unemployment rate was 5.2 per cent, while Greece's was 12.5 per cent, France's was 9.8 per cent, and the US's was 9.6 per cent (ABS 2012c).

Despite the global downturn, during the 2010-11 period, Australia continued to perform well (ABS 2010; CEDA 2011; Healy et al. 2012). Australia avoided recession and was one of the most resilient OECD countries during the GFC (OECD 2010). The fast and positive response to the crisis was assigned to an appropriate macroeconomic policy, with structural flexibility of financial and labour markets (OECD 2010). It was also assigned to Australia's exports to fast-growing China and India, which stretched the country's industrial capacity (CEDA 2011; Collins 2008; Garnett 2012; OECD 2010):

The strong and rapid support of macroeconomic policies to activity convinced both consumers and businesses that the slowdown would be relatively mild. Moreover, the long-term outlook was positive with strong growth expected in key Chinese and Indian markets. In this context, business and consumer confidence rebounded in the early part of 2009. This limited the impact of the downturn on employment. (OECD 2010, p. 34)

Australia seemed to come out of the global turmoil "in the grip of a boom mentality" (Birrell \& Healy 2012, p. 7). In 2010, the country was not only experiencing a growing GDP and increased public investment (OECD 2010), but also a flood of investments throughout the resource industry (Healy et al. 2012). Between 2000 and 2010, the value of minerals and energy exports in the country rose by over 120 per cent, from AUD\$63.1 to \$139.1 billion (ABARES 2011). In October 2010, projects worth nearly $\$ 133$ billion were underway in different states across Australia, including specific energy and mineral ventures, resource-related infrastructure and processing projects (KPMG 2011). 
The economic impact of the resources industry certainly varied across the country, having much more significance and implications for WA and Queensland (Garnett 2012), where activity and demand for labour and capital were much stronger than in the rest of the country (OECD 2010, p. 42). WA's abundance of natural resources, along with its close proximity to Asia, has led to the increased dominance of the mining and petroleum industries in the State's economy since the beginning of this century (DTWA 2014). The contribution of minerals and energy to WA's GDP rose from 18 per cent in 2000 to over 30 per cent in 2010 (ABS 2012c; Garnett 2012), far exceeding the mining sector's contribution to GDP at the national level (this was at 9 per cent in 2010) (ABS 2011; OECD 2010).

In 2011, WA alone had a \$225 billion portfolio of resource and infrastructure projects under construction, committed to construction, or under consideration (DTWD 2011), and its mineral production was expected to continue to grow to meet the increasing demand of China and India (Burke 2011; CEDA 2011). A new port, rail and mining project at Geraldton was expected to cost over $\$ 4$ billion (CEDA 2011). A number of expansions in iron ore operations was also expected from BHP Billiton and Rio Tinto, among other mining companies (Burke 2011; Trenwith 2011).

This growth in the resources industry resulted in a flow-on effect to other industries across the State. It has, for example, put pressure on infrastructure (including electricity, water supply and roads), education and health services and facilities, and transport (Garnett 2012). This period of growth has therefore generated much wealth for WA, but has also put pressure on the extremely tight labour market and resulted in the emergence of severe and widespread labour shortages within the State (CCIWA 2010):

It's like putting a band-aid on a broken arm because our labour shortage is extreme (...) We are faced with the prospect of being short of hundreds of thousands of workers by 2015 - Peter Collier, West Australian Training and Workforce Development Minister. (Rout 2011)

Based on this scenario, the WA State government launched its own framework for addressing its future labour needs, which is focused on building, attracting and retaining a skilled workforce. The 'Western Australian Skilled Migration Strategy' was developed to supplement the local workforce with the skills and expertise demanded by the State's industries but unable to be met by local workers. As part of the attracting initiatives, WA's Training and Workforce Development Minister Peter Collier led delegations to Britain and Ireland in an effort to recruit workers. The visits were aimed 
at providing information to skilled workers about skilled visa options for Australia, and to address skill shortages in areas of occupational demand in the State, such as healthcare, engineering and select trade occupations (DIAC 2011b). WA's government also launched a website designed to help employers attract skilled migrants (Trenwith 2011).

\section{A note about WA's labour market in $\mathbf{2 0 1 0}$}

WA had a workforce of 1.28 million in November 2010, with almost one-third employed in construction, healthcare and retail (DTWD 2011). Demand for labour, however, was strongly associated with the resources industry (DTWD 2010, 2011). This was because employment in the mining sector jumped 150 per cent from 2000 to 2010 , when more than 200 thousand people were employed in the industry (ABS 2011a). Average employment growth for all other industries in the State was at about 26 per cent during that period (ABS 2011a). Additionally, the mining sector employed around 7 per cent of WA's workforce by 2011, a significant difference from the national proportion of around 1.8 per cent (Garnett 2012).

In 2010, WA's labour market was also undergoing relative wage differentials between those working in mining industries and those working in other sectors, which was contributing not only to upward pressure on housing and services' prices (Garnett 2012), but also to wage deterioration in other sectors (Yeates 2011). At that time, professionals in the mining industry were enjoying increases up to twice as large as the average worker in other activities, reflecting the impact of the resources boom in the job market and shortages in the industry (Yeates 2011). In May 2011, the mining industry recorded the highest average weekly ordinary time earnings (AWOTE) for full-time adults ( $\$ 2181$ for males and $\$ 1723$ for females) (ABS 2012c). Among all states and territories, WA recorded the highest average weekly earnings: $\$ 1632.60$ for males (ABS 2012c).

\subsubsection{The context of WA during the 2013-14 period}

The lesson learned since last September is that one of Australia's most important economic variables can turn from boom to bust and back to boom again on a sixpence. (Uren, 2013 p. 19)

Conditions for resources industries started to deteriorate by the end of 2012 as a result of high operations costs, lower commodities prices, and a general feeling of policy 
uncertainty in anticipation of federal elections (Hogan 2013). Total expenses in the mining and oil and gas industries increased by nearly 10 per cent during the 2012-13 period, which contributed to a sharp fall in profits (ABS 2014). Coal mining profits fell by over 88 per cent as a result of the value of sales dropping; metal ore mining profits also declined by 41.4 per cent (ABS 2014).

High wage costs and expenditures with environmental approvals on big projects which were up to 5 per cent of their total value - emerged as a threat to new projects in the State (Daley 2013). Australia was said to have the world's most expensive oil and gas workforce, one-third more expensive than US workers and almost double the global average (Daley 2013). Mining industries continued to pay the highest level of remuneration to Australian workers, with average weekly earnings sitting at $\$ 2388.20$ as of May 2012, while the average weekly pay for other workers in WA was $\$ 1328$ (ABS 2012b).

At the same time, the slowdown in China's economy as a result of the recession in Europe and weak economic growth in the US (Corben 2012) eventually hit the resources industry in Australia by the second half of 2012 (Uren 2013). The downturn in China was considered to be mostly related to China's slowing exports, due to a decline in demand, and to a tightening monetary policy that lead to decreasing investment in the Chinese economy (Corben 2012). China's recovery, more modest than expected in the first quarter of 2013, brought down the prices of key export mineral commodities in Australia (Fitzgerald 2013; Uren 2013).

While (China's GDP) is still impressive compared to anaemic growth elsewhere in the world, the growth rate was below most expectations, prompting fears of a slowdown and slackening in demand - at a time when the supply response by the global mining industry had finally caught up with the China-led and decade-long surge in minerals commodity demand. (Fitzgerald 2013, p. 3)

The mineral commodities' price decline caused by the slowdown in the Chinese economy had a significant effect on the Australian economy. In particular, there was a cut in export income of $\$ 2.6$ billion and a downgrade in investment intentions, especially for resources projects in WA (Uren 2013). Projects cancelled or delayed in the State were estimated to be worth about $\$ 149$ billion, and included liquefied natural gas (LNG) projects from Woodside Petroleum and Shell, BHP's Port Hedland outer harbour, and Aquila's West Pilbara Iron Ore Mine, all in WA (Daley 2013).

Unsurprisingly, WA experienced significant job losses. Fortescue Metals Group (FMG), 
one of the five largest iron ore producers in the world, announced cuts in costs and jobs by September 2012 (Evans et al. 2012). Mount Gibson, an independent Australian iron ore producer, reduced staff a month later (Tasker 2012). Rio Tinto, labelled the second best business in the world in 2012, announced a number of cuts in the first half of 2013, including about 50 senior management staff in its iron ore operations in WA (Ker 2013). Shell, one of the global energy giants, claimed that rising costs became a significant challenge in Australia, especially for gas producers who were operating in a highly competitive international market (Johnson 2013). In May 2013, WA's Premier Colin Barnett announced a cut of 1500 positions in the State's public sector, declaring that the "job for life era" was over:

There has been job security for life virtually, and I think those days have gone past us - WA's Premier Colin Barnett. (AAP, 30 May 2013).

In the education sector, the federal government created a new national funding system for schools based on recommendations from the Gonski Review, a comprehensive investigation of the way Australian schools have been funded since the 1970s, commissioned by the government in 2010 and chaired by businessman David Gonski (ABC News 2013). The reform agenda, however, was seen as "grossly inequitable" for WA as the State would receive only $\$ 300$ million of the $\$ 14.5$ billion in the budget for education (Murphy et al. 2013). In addition, the federal government announced a \$2.8 billion cut to the university sector to help pay for its school education reforms (Hawley 2013), putting extra financial pressure on Western Australian universities.

\section{Federal elections in Australia}

This economic scenario, when added to policy and government uncertainty in the lead up to the 2013 federal election, affected business confidence among Australian companies. Particularly in WA, political and business leaders demanded that the government deliver greater policy certainty for the resources sector in order to help businesses manage drops in commodity prices and rising cost pressures (Kitney \& Garvey 2013). In an analysis conducted by the Commonwealth Bank (2014), WA had gone from being the most confident to the least confident Australian state, falling from 17.3 to 5.8 points in their regular survey. Only 23 per cent of Western Australian organisations expected conditions to improve over the next six months. According to the bank, the slowing of the resources boom combined with government policy 
uncertainty, skills shortages and expectations of falling revenues all contributed to the decline of confidence in the State:

After a consistent rise in confidence over the past six months, the sudden drop we're seeing through the Index is a reflection of the uncertainty experienced by businesses. History tells us that an impending federal election generates conservative business conditions and the findings of the Index are consistent with that - Michael Cant, Executive General Manager, Corporate Financial Services, Commonwealth Bank. (Commonwealth Bank 2014, p. 3)

Meanwhile, both the Australian Labour Party and the Liberal/National Country Party Coalition focused their economic policy pre-elections debate on outlining competing visions for a period after the mining boom. As the resources boom lost its strength, both parties suggested that future growth would come from outside the resources sector, with Labour promising a "services export economy" and the Coalition promising to "lighten the load on business" (Crowe 2013, p. 2).

The Coalition, an alliance between the Liberal Party of Australia and the National Party of Australia, won the federal elections and Tony Abbott was elected Prime Minister in September 2013. The announcement of their first Federal Budget, in 2014, was acknowledged as the "toughest in a decade" (Craw \& Ma 2014). There were fears that the number of jobs to be slashed could be as high as 25,000 with budget cuts, asset sell offs and outsourcing; The Gonski School Funding Agreement was planned to slash $\$ 80$ billion from health and education over the next decade (Craw \& Ma 2014).

Despite a few claims that WA's economy was strong in the 2012-13 period, with investments worth $\$ 174$ billion planned or under construction and iron ore capacity projected to grow (DSD 2013), the State's unemployment rate was at its highest level in a decade (Janda 2013). Job opportunities had deteriorated not only in resources industries but also in other economic sectors, such as retail, construction and manufacturing (Hogan 2013).

The prognostic published by financial institutions for the State's economy was not positive either. The National Australia Bank (2015) forecasted an even greater decrease in employment, winding down of investments, and a slowdown in GSP growth. St. George Bank (2015) expected growth in WA to weaken in coming years, and a faster decline in mining investment to impact heavily on the general economy:

Dramatic declines in iron ore prices and a winding down of large mining investment projects is having (and will continue to have) a dramatic impact on the 
WA economy. The fall in iron ore prices from around USD 120 per tonne to around USD 50 per tonne (Chart 3) has wiped out more than $\$ 70$ billion dollars of potential annual revenue from Australian exports (the vast majority from WA). This also has flow-on effects to other industries as well as government revenues WA Budget sensitivity analysis suggests that iron ore royalties fall by $\$ 70$ million for every USD1 decline in the ore price. (NAB 2015, p. 3)

As a result of this scenario, both job advertising and skilled migration intakes declined sharply in this phase. During the 2013-14 period, Australia experienced a decrease of 4.2 per cent in the number of permanent migration visas granted, the first drop since the 2009-10 period (DIBP2014a). The demand for temporary skilled work also decreased, and the number of subclass 457 primary visas granted in this period was 24.2 per cent lower when compared to the previous program year (DIBP 2014e). In WA, the number of primary applications for 457 visas decreased 28 per cent for managers and 43 per cent for professional positions (DIBP 2014e).

\section{Conclusion of the chapter}

Chapter 2 aimed to contextualise the settings for this research. Firstly, contemporary competition for the 'best and brightest' skilled migrants was described in light of its importance in a globalised world with a neoliberal agenda. The discussion was then brought to Australia, one of the countries that has re-designed policies framing skilled migration to first and foremost promote and safeguard economic growth (Iredale 2001). This chapter illustrated how the Australian Migration Program has shifted from a supply-driven to a demand-driven approach focused on recruiting labour immigrants for areas and sectors where demand is greatest (Cully 2012; Phillips \& Spinks 2012).

A definition for highly skilled migrants was presented, grounded in empirical work previously conducted by Hawthorne (1997) and Challoff and Lemaitre (2009). In this research, a HSI is an individual recruited under Australia's key skilled immigration categories - either with a 457 Temporary Business Visa (with a sponsoring employer, in an expatriate assignment or not) or with Permanent Residency (as a result of selfinitiated migration to Australia); with full and immediate recognition of overseas qualifications and minimum tertiary education at a bachelor's level; with an occupation listed in Australia's Consolidated Sponsored Occupational List (CSOL); holding either a professional or a managerial position; with a minimum of five years of pre-migration professional experience; or with an intermediate-to-native level of English proficiency.

Finally, this chapter described the particularities of WA in terms of economic trends and 
migration patterns, justifying why this research needs to be framed as a case study about the State. As such, it described the different political-economic moments in which interviews for this research were conducted. Chapter 3 continues with the literature review, focusing on the psychological contract as the theoretical framework used in this study. 


\section{Chapter 3 - The Psychological Contract}

\section{Introduction}

We sought to understand the psychological contract as an attractive reading of contemporary socioeconomic dynamics. (Cullinane \& Dundon 2006, p. 125)

The changing context of neoliberal globalisation and the rise of a market-oriented philosophy impacted not only labour migration, as discussed in Chapter 2, but also employment relationships. As the barriers between countries have been redrawn with the formation of global trade and a new distribution of production and distribution across the world, firms have faced greater competition, market volatility and narrowing profit margins (Cappelli 1999; Harvey 1989).

The neoliberal revolution emphasised the centrality of markets and market-driven solutions, leading to increasing demand for organisational adjustment and fast adaptation (Berntson et al. 2006; Kalleberg 2009). International competitiveness pressured multinational corporations to invest and divest in their host countries (Dobbins et al. 2014). Large international organisations conducted 'efficiency reforms' to reduce costs, maximise production and consolidate their position in the global market; at the same time, economic and financial deregulation triggered waves of takeovers, mergers and closures among small firms, resulting in a more highly concentrated industry with stronger corporate power (Lambert et al. 2005).

Research has shown, for example, how quickly the appliances industry became concentrated and global in character (Lambert et al. 2005; Segal-Horn et al. 1998; Weiss \& Gross 1995). In 1982, there were 350 producers of major household appliances in Europe; by 1992, there were about 100 (Weiss \& Gross 1995). In North America, by the mid-1990s, only four companies accounted for 80 per cent of the white goods market (Weiss \& Gross 1995).

This market restructuring was supported by a number of changes in labour processes, including increased automation, just-in-time techniques, intensified labour, downsizing, flexibility and casualisation, which in turn led to rising levels of unemployment and precarity across the world (Kalleberg 2009; Lambert et al. 2005). The secure and long- 
lasting organisational career supported by a 'welfare state' (Standing 1997), which prevailed in the three decades following World War II (Kalleberg 2009), gave way to an employment relationship extremely sensitive to labour market conditions (Cappelli 1999).

The 'new deal' (Cappelli 1999) between employer and employee that took place in this phase was no longer characterised by job security and satisfying, life-long organisational careers (Kalleberg 2009). Rather, it was described by Cappelli (1999, p. 3) as "an uneasy dance between an open-ended relationship and the pull of the market, with the parties constantly negotiating their commitments". Employment relationships became characterised by more adaptable work regimes and contracts which pushed for entrepreneurial behaviour from employees (Harvey 1989), a rapid and deep deunionisation (Standing 1997), the dominance of short-term projects and temporary connections (Boltanski \& Chiapello 2005), boundaryless careers (Arthur \& Rousseau 1996), and uncertainty, insecurity and precarious work (Kalleberg 2009):

The old employment system of secure, lifetime jobs, with predictable advancement and stable pay is dead. What killed it were changes in the way firms operate that brought markets inside the organisation. In the process, labour markets were also brought inside the firm, and the pressures they create are systematically undermining the complex system of human resources practices that made longterm careers the staple of corporate life. (Cappelli 1999, p. 17)

In light of these organisational changes and their impact over employees' behavioural and attitudinal reactions in the workplace (Freese \& Schalk 2008; Rousseau 1995), the concept of the psychological contract (PC) gained popularity in the 1980s. Over the past three decades, the PC has become a popular construct regarded as a useful way of understanding and managing changes to employment relationships brought about by new economic and organisational circumstances (Conway \& Briner 2009). The PC has thus been the subject of a large volume of published journal articles and books in both employment relations and organisational behaviour areas. Human Resource Management (1994), Human Resource Management Journal (1994), European Journal of Work Psychology (1996) and Journal of Organizational Behavior $(1998,2003)$ are just a few of the journals that published special issues on the topic (Conway \& Briner 2009).

The PC framework has been used to explore how promises and expectations impact employees' attitudes and behaviours in the employment relationship (Guest 2004a; Rousseau 1989, 1995), as well as the outcomes when such promises are broken (Kickul 
2001; Robinson \& Morrison 2000). The theory has been applied to examining the impact of several changes in individuals' employment outcomes, such as the effects of downsizing (Beaumont \& Harris 2002), mergers and acquisitions (Bellou 2007), contingent work (Coyle-Shapiro \& Kessler 2002) and job insecurity (King 2000). Researchers have applied the PC in order to understand how different cultures engage in their employment relationships (Rigotti et al. 2007; Sparrow 1996, 1998; Thomas et al. 2010) and how expatriates adjust to new assignments in different countries (Haslberger \& Brewster 2009; Pate 2010). From a psychological perspective, studies have related the framework to a number of behavioural and attitudinal consequences, such as organisational citizenship behaviour (Hui et al. 2004; Kickul et al. 2004) and job satisfaction (Kickul et al. 2004; Nelson et al. 2006), amongst others.

However, empirical PC research has mostly been driven by the interest in more innovative people-management practices (Cullinane \& Dundon 2006). The interest in PC research developed as contextual transformations swept away previously agreed upon PCs, while employers still demanded a flexible, innovative and committed workforce (Anderson \& Schalk 1998). This chapter, thus, argues that a critical perspective of the PC's traditional framework needs to be adopted, one which goes beyond a 'managerialist interpretation' and takes into account the sociopolitical dynamics of the wider politico-economical context as an engaged frame of analysis (Cullinane \& Dundon 2006, p. 113).

More recent scrutiny of the construct (Guest 2004a, 2004b; Cullinane \& Dundon 2006; Guest \& Clinton 2010) has claimed that research on the PC needs to consider contextual eventualities that may impact the employment relationship and the parties' perceptions regarding the relationship beyond a surface level, because employment relations issues usually arise from a deeper explanation of political and economic power. That said, research should recognise that employment is a social exchange interaction, characterised by subordination under conditions of conflict of interest, with issues of trust, legitimacy and power being pertinent (Cullinane \& Dundon 2006).

This chapter begins with a theoretical conceptualisation and some seminal definitions of the PC construct, before presenting and discussing a critical approach in relation to its applicability to this research. Then, the conceptual framework guiding this research is presented in light of the discussion in Chapter 2 of the neoliberal and globalised context in which employment relationships are embedded. 


\subsection{The psychological contract}

\subsubsection{Theoretical conceptualisation and seminal definitions}

The term psychological work contract emerged in the literature during the 1960s, when Argyris (1960) first mentioned it in a footnote in his book Understanding Organisational Behaviour; in it, Argyris recognised that workers' perceptions about their exchange relations in the workplace affect their behaviours and interactions. He was referring to implicit agreements between foremen and employees in a US factory when he wrote:

Since the foremen realize the employees in this system will tend to produce optimally under passive leadership, and since the employees agree, a relationship may be hypothesized to evolve between the employees and the foremen, which might be called the 'psychological work contract'. The employee will maintain high production, low grievances, etc., if the foremen guarantee and respect the norms of the employee informal culture. (Argyris 1960, p. 97)

Two years after Argyris' (1960) first conceptualisation, Levinson, Price, Munden, Mandle and Solley (1962) used the PC to better understand worker well-being and published a book developing the concept. Drawing on interview data from employees at a US utility plant, Levinson and his colleagues (1962) found that individuals would deploy effort to contribute to the needs of a company if their own needs were fulfilled. They defined the PC as follows:

A series of mutual expectations of which the parties to the relationship may not themselves be even dimly aware but which nonetheless govern their relationship to each other (...) The psychological or unwritten contract is a product of mutual expectations. These have two characteristics: (a) they are largely implicit and unspoken, and (b) they frequently antedate the relationship of person and company. (Levinson et al. 1962, pp. 21-22)

In this early perspective, the PC's main features included three characteristics: (1) it was mostly unspoken, commonly referring to implicit promises in the workplace; (2) it could emerge before the employee and the employer actually engaged in an employment relationship; and (3) it was assumed to be dynamic, as it could be "affirmed, altered or denied in day-to-day work experience" (Levinson et al. 1962, p. 21). According to Conway and Briner's (2009) analysis of the work of Levinson and colleagues (1962), a key idea in their arguments was the role of largely unconscious psychological needs, driving reciprocation in PCs: "in exchange for the employer fulfilling these needs, the employee will deploy effort to contribute to the needs of the 
company" (Conway \& Briner 2009, p. 75). Levinson and colleagues (1962) identified a number of different types of conscious and unconscious needs comprising the employees' side of their PCs; these needs related to job security, economic rewards, performance, the use of specific skills and social relations in the workplace. The company's expectations, on the other hand, were portrayed as resulting from the company's historical and commercial environment.

However, the concept generated very little empirical interest in its early years (Conway \& Briner 2009; Tipples 2009). The PC construct and initiatives for assessing and measuring it only gained popularity in the 1980s "after a hiatus of more than two decades" (Rousseau \& Tijoriwala 1998, p. 679). This period was characterised by many changes at the organisational level (Cappelli 1999), and the PC became a tool to explain the consequences of these changes in the workplace, including behavioural and attitudinal reactions among employees (Freese \& Schalk 2008).

Nowadays, a number of scholars argue that the history of PC research can be structured in relation to its seminal reconceptualisation by Denise Rousseau (Conway \& Briner 2005, 2009; Cullinane \& Dundon 2006; Meckler et al. 2003; Roehling 1997, 2008; Schalk et al. 2010). Since its publication in 1989, Rousseau's influential article has been referenced repeatedly in writings about the PC, marking the transition from early developments to recent elaborations in the PC literature (Roehling 1997). Moreover, as Rousseau continued her studies and publications, she offered ways of measuring the PC, classifying it with different types of employment relationships while increasing understanding regarding the impacts of its fulfilment and breaches:

In her initial and later work with colleagues, she has redefined the psychological contract (Rousseau 1989), introduced and reconceptualised key psychological contract concepts, such as breach and violation (Rousseau 1989; Robinson \& Rousseau 1994), identified terms for organising the content of psychological contracts (i.e. transactional and relational psychological contracts) (Rousseau 1990), and developed and validated widely-used measures of psychological contracts (Rousseau 1990, 2000). (Conway \& Briner 2009, p. 77)

Rousseau (1989, p. 123) initially described the PC as the "individual's beliefs regarding the terms and conditions of a reciprocal exchange agreement between the focal person and another party". In her definition, Rousseau (1989, p. 123) also stated that "key issues here include the belief that a promise has been made and a consideration offered in exchange for it, binding the parties to some set of reciprocal obligations". 
These two parts of Rousseau's definition fuelled two of the most intense debates regarding the conceptualisation of the PC during the years that followed. The first debate involved the level at which the PC should be theorised - the individual level or the relational level - including the expectations of both parties in the employment relationship. The second debate involved the "psychological contract beliefs" (Conway \& Briner 2005, p. 24) and whether expectations, promises and/or obligations should be considered part of the contract. These two debates will be explained next.

\subsubsection{A contract between two parties: Issues of level and agency}

There exist two main conceptualisations of the PC with regard to the level of its theorisation. The first conceptualisation stresses the PC as formulated in the mind of the employee only. Rousseau's (1989) influential definition emphasises that the PC should be conceptualised at the level of the individual because it refers to the individual's subjective beliefs: "the term psychological contract refers to individual's beliefs regarding the terms and conditions of a reciprocal exchange agreement between the focal person and another party' (Rousseau 1989, p. 123). For Morrison and Robinson (1997, p. 229) the PC is about the "employee's beliefs about the reciprocal obligations between that employee and his or her organisation" (Morrison \& Robinson 1997, p. 229). In this approach, then, the PC emerges when one party believes that a promise of a return has been made, a contribution has been given, and consequently, a reciprocal obligation has been produced (Rousseau 1989).

The second conceptualisation is grounded in the notion that there are two parties involved in the employment relationship (Cullinane \& Dundon 2006; Guest \& Conway 2002; Herriot \& Pemberton 1997; Meckler et al. 2003). These two parties, the organisation and the employee, have mutual obligations and mutual perceptions to take into account (Guest \& Conway 2002; Herriot \& Pemberton 1997; Meckler et al. 2003). Building on a definition provided by Herriot and Pemberton (1997, p. 45), Guest and Conway (2002, p. 22) have described the PC as "the perceptions of both parties to the employment relationship, organisation and individual, of the reciprocal promises and obligations implied in that relationship". For Kotter (1973, p. 92), the PC regards "an implicit contract between an individual and his organisation which specifies what each expect to give and receive from each other".

Investigating the employer's perspective in the PC, however, can be problematic as the 
organisation is usually represented by a number of actors who speak and negotiate on behalf of the employer (Coyle-Shapiro \& Shore 2007; Freese \& Schalk 2008; Guest \& Conway 2002; Herriot \& Pemberton 1997; Rousseau \& Schalk 2000; Schalk \& Rousseau 2001). Some examples of these actors include recruiters, the HR team, managers, and supervisors. As Cullinane and Dundon (2006) have noted, employees are likely to come into contact with a wide range of organisational agents on a daily basis, particularly in large companies. As a collective, all these different agents representing the organisation do not necessarily have (and communicate) the same expectations to the employee or make the same promises in the name of the organisation. On the contrary, organisations' representatives may send different and even incompatible messages when communicating on their behalf (Herriot \& Pemberton 1997).

Also, some contract makers can play a dual role in an organisation (Rousseau 1995). Within the same company, they may simultaneously be employees and agents of the employer. Such is the case with managers, who have PCs themselves but play a central role in being agents for other employees. As Meckler and colleagues (2003, p. 217) pointed out, "the psychological contract is an agreement between management and employee". Every manager performs an employee role; yet as a manager, he or she is an agent for many other individuals.

Finally, the PC theory considers the power of the organisation's structural contract making. These structural signals are vehicles used by the organisation to promote the culture and convey commitment, thus motivating specific behaviours (Rousseau 1995). In recruitment and compensation, for example, organisational documents and practices can perform a structural signal role in the company (Rousseau 1995). Such materials become relevant when trying to understand the contract they support.

Therefore, few researchers to date have attempted to investigate the employer's perspective in the PC. Guided by an understanding of the PC as a perception of both parties, Coyle-Shapiro and Kessler (2000), along with Guest and Conway (2002), have used samples of managers to understand the PC from the eyes of the employer. For their part, Schalk and colleagues (2010) have used the PC as part of an international project involving a number of countries, exploring the perspectives of both employers and employees with regard to temporary versus permanent work. 
This research focuses on investigating HSIs' perceptions and expectations regarding their employment experiences in WA. Although it is recognised that because the employment contract involves two parties it is opportune to also canvass the view of employers in studying the PC of employees (Guest 2004a), this study relies on a unilateral perspective of HSIs' PCs (Morrison \& Robinson 1997; Rousseau 1989). This is because the focus is on understanding how WCFs influence individuals' perceptions, rather than on how employment relations between the parties in the employment relationship influence the PC of employees. Chapters 1 and 2 describe these WCFs.

\subsubsection{The beliefs constituting the psychological contract}

Early publications about the PC stressed beliefs about expectations, as can be seen in the definition by Levinson and colleagues (1962, p. 21) and later in Schein's (1965, p. 11) conceptualisation:

A series of mutual expectations of which the parties to the relationship may not themselves be even dimly aware but which nonetheless govern their relationship (...) The psychological or unwritten contract is a product of mutual expectations. (Levinson et al. 1962, p. 21)

The notion of a psychological contract implies that the individual has a variety of expectations of the organization and that the organization has a variety of expectations of him. These expectations not only cover how much work is to be performed for how much pay, but also involve the whole pattern of rights, privileges, and obligations between workers and organizations. (Schein 1965, p. 11)

In a more recent study, Meckler, Drake and Levinson (2003) re-emphasised that the original conceptualisation of the PC focused on understanding individuals' unconscious needs for affection and recognition, dependency or ego ideals - needs that drive motivation and behaviour in the workplace (Levinson et al. 1962). Meckler and colleagues (2003, p. 218) also argued that much of the current work on the construct "ignores the core psychological needs relevant to the psychological contract", which is ultimately about the fulfilment of these "powerful, largely unconscious needs... [resulting from] idiosyncrasies on the individual level” (Meckler et al. 2003, p. 219).

Indeed, since the publication of Rousseau's aforementioned paper (1989), the focus of the construct has shifted away from a psychological approach to one grounded in social exchange (Blau 1964). According to Blau (1964, p. 91), social exchange refers to voluntary actions of individuals that are motivated by the returns they are expected to (and typically do) bring from others. 
Thus, most contemporary studies of the PC have tended to follow this emphasis and adopted the promissory focus of Rousseau's (1989) conceptualisation and its assumption of reciprocity, or "the belief that a promise has been made and a consideration offered in exchange for it, binding the parties to some set of reciprocal obligations" (Rousseau 1989, p. 123). This contemporary theorisation asserts that the PC should arise not from individual, generic expectations but from promises made by one of the parties (Herriot \& Pemberton 1997; Morrison \& Robson 1997; Rousseau 1989).

Robinson and Rousseau (1994, p. 246) explained that the PC, unlike expectations, requires a belief in what the employer is obliged to provide, based on perceived promises of reciprocal exchange. This assumption of reciprocity forms the heart of the PC; that is, that there is a 'deal' (even if it is an implied deal) that something will be exchanged for something else (Conway \& Briner 2005). Anything offered by the organisation (as professional development) or by the individual (as working extra hours) remains contingent on a reciprocal offering.

However, the content of an employee's PC can emerge from either verbal or inferred messages, indirectly or directly communicated by the organisation (Lester \& Kickul 2001; Rousseau \& Schalk 2000). It may include written terms, such as a job offer letter; verbally communicated terms, such as a promise of training; and other expressions of future intention, such as references to past company practices (Rousseau 1995). A perception of a promise also emerges through interpretations of patterns of past exchanges in a given organisation (Conway \& Briner 2005). Thus, it can be said that a very subtle line separates implicit promises from normative expectations, which are beliefs regarding what ought to occur, based upon a prevailing normative standard (Roehling 2008).

Often, these different beliefs - expectations, promises and obligations - extend past each other's boundaries, making their conceptualisation inaccurate. Recent overviews and analyses of PC theory (Bankins 2014; Conway \& Briner 2005; Roehling 2008) have claimed that the differences among expectations, promises and obligations are not clearly elaborated on or examined in the literature, "reflecting the field's apparently limited concern for definitional or conceptual clarity and precision" (Conway \& Briner 2005, p. 25). 
This is because both promises and normative expectations can create the perception that there is an obligation between two parties that can lead to understandings about fairness and trust. As Roehling (2008) has noted, obligations in a relationship arise from a number of sources, including promises that have been made, contractual commitments, and requirements imposed by law, but they also arise from social norms and perceived moral responsibilities:

In social relations (Blau 1964), and in law-including modern contract lawobligations are created and exist without promises (Macneil 1980). An employee may not perceive that a promise has been made, yet still believe a party is obligated to act in a certain way because the employee believes that there is either a social, moral, or legal requirement that compels the party to act in a certain way (Roehling 2008, p. 264)

This research follows Roehling's (2008) assumption that different beliefs are connected and have a role to play in individuals' PCs, but cannot be used interchangeably as if they have the same meaning. Therefore, in the conceptual framework guiding this study, PCs are shaped by normative expectations, promises and obligations in the employment relationship (Roehling 2008).

\subsubsection{How scholars have classified psychological contracts}

Despite the fact that a number of typologies of PCs have been suggested to classify and describe the differences individuals and organisations face in their exchange relationship, the distinction between relational and transactional types of contracts have received more attention in the literature (Conway \& Briner 2005). The transactional-relational theory is grounded in the work of the legal scholar MacNeil (1974) and has been adjusted for management research, especially by Rousseau (Conway \& Briner 2005). According to this concept, transactional and relational types of PCs should be considered extremes occupying the ends of the same continuum (MacNeil 1974; Rousseau 1989).

Transactional contracts are centred on short-term and monetary exchanges, exemplified by Rousseau (1995, p. 91) as “a fair day's work for a fair day's pay”. They involve specific exchanges with narrow scopes, taking place over a well-specified period of time. Individuals in transactional PCs use existing skills and usually experience economic conditions as their primary incentive, have limited personal involvement in their jobs, a close-ended time frame (like temporary employment), easy exit and high turnover, little flexibility and little learning (Rousseau 1995). 
Relational contracts, at the other end of the continuum, are open-ended relationships involving considerable investment by both the employee and employer (Rousseau 1995, p. 91). They are characterised by trust and a belief in fairness (Rousseau 1990); they are broader and subjectively understood by the parties involved (Conway \& Briner 2005). Individuals in relational PCs usually experience emotional involvement as part of the economic exchange, open-ended time frames, pervasive conditions affecting personal and family life, and high membership and affective commitment (Rousseau 1995). These individuals frequently contribute through commitment and involvement with their organisation, often in the form of organisational citizenship behaviour (Robinson \& Morrison 1995), believing that the organisation will deliver loyalty, a sense of community and opportunities for professional growth as its part in the bargain (Thompson \& Bunderson 2003).

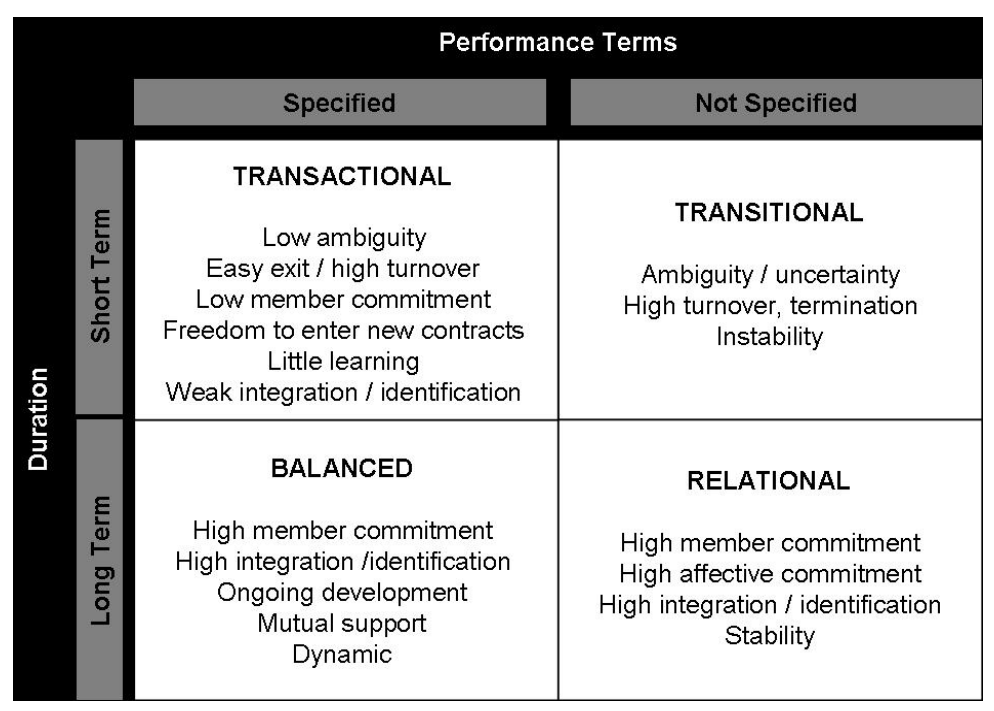

Figure 3.1. Rousseau's types of psychological contracts (Rousseau 1995, p. 98).

In an attempt to adjust this continuum to modern employment contracts, Rousseau (1995) developed a 2 x 2 framework, including timeframe and performance requirements as contract features. In Rousseau's (1995) model (see Figure 3.1), timeframe refers specifically to the duration of the employment relationship (a limited/short-term or open-ended/long-term arrangement). Performance requirements refer to the specification of performance as a condition of employment and to the connection between possible rewards and performance requirements (Hui et al. 2004). When these two contract features are set in Rousseau's (1995) 2 × 2 framework, four types of contracts, with different behavioural characteristics, emerge. Together with the 
transactional and relational open-ended/long-term contracts previously described, transitional and balanced contracts also arise.

Transitional contracts are those with short-term duration and unspecified performance terms, more common in temporary situations of uncertainty and instability, and are usually experienced during an organisational merger or acquisition (Rousseau 1995). Balanced contracts, on the other hand, blend transactional and relational terms. They combine the need to attain specific goals (a transactional feature) with the presence of shared values and commitment (a relational feature). Additionally, they occur when long-term relationships are desired but the organisation requires performance as a condition of membership (Rousseau 1995, p. 99). Individuals in balanced PCs usually experience high membership commitment in a situation of mutual support, including ongoing development, integration and identification (Rousseau 1995).

\subsubsection{Breach and violation of the psychological contract}

Particularly during the 1990s, and in light of the organisational changes described in the introduction of this chapter, several researchers focused their studies on comprehending employees' reactions to unfulfilled PCs (Kickul 2001; Robinson 1996; Robinson \& Rousseau 1994; Rousseau 1995). It was noted that organisational restructuring, characterised by mergers, acquisitions, downsizings and casualisation, usually impacted employees' perceptions and expectations in the workplace (Inkson et al. 2001).

Employees faced difficulty in accepting and adjusting to the new terms of their PCs after organisational change, experiencing stress, uncertainty and insecurity in the workplace (Panchal \& Cartwright 2001). Unfulfilled PCs decreased employees' trust in their employers, satisfaction with their jobs, and perceived obligation to their organisations (Morrison \& Robinson 1997; Robinson \& Rousseau 1994; Robinson \& Morrison 1995; Robinson 1996). Ultimately, it was noticed that PC violation led to negative impacts on employee behaviour, including the intention to quit (Morrison \& Robinson 1997; Robinson \& Rousseau 1994).

In empirical research, individuals' perceptions and responses to PC renegotiation have been categorised at the levels of contract breach (Kickul 2001; Robinson 1996) and contract violation (Robinson \& Rousseau 1994; Rousseau 1995). The term perceived breach is used to refer to the perception that one party has failed to meet one or more obligations within the other's PC. As such, the perceived breach represents a cognitive 
assessment of contract fulfilment based on an employee's perception of what each party has promised and provided to the other (Morrison \& Robinson 1997).

The term violation, on the other hand, is reserved for the emotional and affective state that may follow the belief that one party has failed to satisfactorily maintain the PC (Morrison \& Robinson 1997, p. 230). The literature reinforces that, in the case of a violation, a strong emotional experience is usually expressed, involving "feelings of betrayal and deeper psychological distress [whereby]... the victim experiences anger, resentment, a sense of injustice and wrongful harm" (Rousseau 1989, p. 129). The strength of the emotional and behavioural reactions that follow a contract breach, turning it into a violation, seem to be moderated by how an individual interprets fairness judgements, outcomes of the breach (magnitude and implications), and the type of exchange one has with the organisation (Kickul 2001; Morrison \& Robinson 1997).

Organisations frequently need to manage and renegotiate the PC they have established with their employees (Kickul 2001; Rousseau 1995). Breaches and violations of the PC might result from organisational inability to meet obligations regarding distributive, procedural or interactional aspects of justice (Andersson 1996; Pate et al. 2003), which happens as a result of managerial failure, market pressure (Guest \& Conway 2002), or the subordination conflict that is inherent to employment relationships (Cullinane \& Dundon 2006).

Distributive violation happens when policy decisions are perceived to be unfair - for example, financial rewards (Pate et al. 2003). Procedural violation occurs when there is a perception of inequitable use of organisational processes, such as in the case of an individual's promotion or dismissal. Interaction violation refers to employees' perception of trust in the relationship, usually occurring when individuals feel they have been treated badly (Pate et al. 2003, p. 560).

\subsubsection{Cultural approach in the case of HSIs}

Scholars have argued that cultural norms and values affect PC perceptions and outcomes (Kickul et al. 2004; Rigotti et al. 2007; Sparrow 1998; Thomas et al. 2010). Most of these studies, however, have used a value-based approach (Hofstede 1980) to compare groups of employees from different countries, such as between workers in the US and Hong Kong (Kickul et al. 2004), and to assess the impact of their cultural backgrounds on their responses to PC fulfilment or breach. In these studies (Kickul et 
al. 2004; Rigotti et al. 2007; Sparrow 1998; Thomas et al. 2010), individuals were surveyed or interviewed while living and working for firms in their country of birth; thus, participants were embedded in their own national cultures.

Whilst focused on the lived experience of HSIs in the context of globalisation and market-driven employment relationships, this research draws on a constructivist view of culture (Hong 2009; Hong \& Mallorie 2004; Swidler 1986) to argue that the specific impacts of HSIs' national cultures over their PCs while working in WA can be overlooked. According to the constructivist approach, culture should not be conceptualized as a "monolithic entity" (Hong \& Mallorie 2004, p. 63); rather, it must be perceived as a loose network of cognitive structures for which an individual can hold more than one cultural meaning system.

Individuals may have more than one set of cognitive components that can be combined and recombined and, in a given situation, they may use the sets of ideas, values, and schemas that are most accessible to them (Zellmer-Bruhn \& Gibson 2014). This is particularly relevant in the case of highly skilled immigrants. Skilled migrants are often bilingual, moving effortlessly among different cultures to pursue cultural, political or economic interests (Portes 1997, 2010). Skilled migrants adapt themselves easily to a receiving country even while maintaining strong emotional and financial ties with their places of origin (Portes 1997, 2010; Vertovec 2004).

Given their intercultural experience, skilled migrants develop a configuration of value orientations, which they are able to access and contemplate whilst selecting suitable cultural responses in different situations (Chao \& Moon 2005). These individuals do not hold one predisposed cultural content based on their national origin, but rather hold multiple contents that are stimulated and applied differentially (Zellmer-Bruhn \& Gibson 2014). Therefore, HSIs become multicultural within themselves, holding multiple cultural values concurrently (Brannen \& Thomas 2010; Vertovec 2004).

For instance, while studying the case of Ukrainian Jews who have developed 'transnational orientations' towards the Ukraine, Israel and other Jewish communities in the US and Germany, Golbert (2001, p. 725) noted that their daily reality seemed to be embedded in a transnational frontier of intersecting ideas, relationships, histories and identities. Golbert (2001) described how they used a 'double consciousness' to assess 
their interactions and everyday experiences, acquired from their transnational connections and concept of self.

It has also been argued in the literature that professional development programs, which HSIs usually undertake, are leading to a 'massification' of higher management education, allowing institutions across the globe to conform to international practices and offering students worldwide a common framework for cultural sensitivity, adaptability and interaction (Goh 2009; Yang 2003). With the increasing number of Master of Business Administration (MBA) degrees and other, similar programs, it has been argued that individuals are increasingly exposed to more uniform organisational techniques and values, grounded on a Western-based managerial philosophy (Armstrong \& Krasnostein 1995; Goh 2009; Holton 2000; Weber 1969):

\footnotetext{
The experience of a Western education, whether at Harvard, Oxford, the Sorbonne, or the University of Sydney, not only diffuses Western forms of knowledge but also helps to create interpersonal networks of value in the functioning of international organizations like the United Nations, the World Bank, and the United Nations Educational, Scientific, and Cultural Organization (UNESCO), as well as global corporations. In this sense, the development of a global culture is driven not only by mass-marketing strategies but also through the emergence and interests of a cross-national global elite. (Holton 2000, p. 143)
}

Therefore, given the characteristics of the sample in this research - a very skilled and mobile group of people, highly qualified and largely employed in MNCs, as described in Chapter 4 - it is argued that, once in WA's workplace, HSIs do not refer to one set of cultural practices and values received in home countries; rather, they refer to a framework learned through transnational professional experiences and qualifications in order to conform to international management practices (Goh 2009; Yang 2003). Thus, their cultures are a result of their values, cognitive frameworks and accumulated knowledge (Portes 2010).

\subsection{Conceptual framework: The PC of an embedded lived experience}

The context helps not only to shape the content of the exchange that forms the psychological contract, but also the responses to it. (Guest 2004b, p. 549)

As previously discussed in this chapter, differences of opinion still exist at the most fundamental levels of conceptualisation of the PC. Scholars continue to debate whether PCs encompass only individuals' subjective beliefs about their employment relationship, or whether they instead result from a mutually agreed upon and shared understanding of the exchange relationship between two parties (Roehling 2008, p. 
261). Furthermore, there are still multiple definitions for the PC construct; some assert that it involves only perceptions of promises, while others contend that it refers to expectations in the employment relationship (Conway \& Briner 2005).

Criticism about the PC theory goes even further, though. In their review of the PC, Cullinane and Dundon (2006) critiqued many of the construct's theoretical assumptions. They questioned the continued use of the notion of a 'contract' in the PC, as the idea of a contract implies an agreement between the involved parties. Cullinane and Dundon (2006) also argued that the PC may develop from mixed messages and divergent expectations, and thus the construct may be attempting to "measure the unattainable" (2006, p. 119). They also dealt with the structural, sociopolitical and cultural interpretations surrounding the $\mathrm{PC}$, arguing that the construct must be considered in light of the "wider political economy of capitalism" (2006, p. 117).

The conceptual framework guiding this thesis draws on Cullinane and Dundon's (2006) argument that several contextual forces exist which challenge employers to meet employee expectations in the workplace; factors that must be considered in the context of neoliberal globalisation, as discussed in Chapter 2. Guest (2004a, 2004b) also contended that significant contextual factors have thus far been ignored by psychological contract research, despite their relevance for exploring exchange agreements between employees and employers. The propositions and framework presented in this chapter are thus informed by this more critical management understanding of the PC (Cullinane \& Dundon 2006; Guest 2004a, 2004b; Thompson 2011).

It has been argued that the PC construct neglects the design of the employment relationship under capitalism (Cullinane \& Dundon 2006), as an economic system symbolised by capital accumulation, wage labour and a competitive market (Hyman \& Baptist 2014). Therefore, current PC research neglects the fact that employment is actually a relationship of subordination under conditions of interest conflict, in which the employee is a resource to be used for profitable ends, in the context of competitive pressures and the pursuit of lower costs (Cullinane \& Dundon 2006).

Employers' and employees' objectives, thus, co-exist in 'growing divergence and dysfunctionality" (Thompson 2003, p. 473). While employers retreat from investing in human capital, and press their workers for discretionary effort, labour is asked to invest 
more of themselves at work (Thompson 2003, 2011). Individuals in managerial positions are tasked with the responsibility for pursuing high performance from labour and are tied to a number of financialised practices through corporate measures - while they lack the capacity to sustain the enabling conditions and struggle in the position of employees themselves (Thompson 2011).

Within an "increasingly financialised capitalism", driven by the pursuit of shareholder value (Thompson 2003, p.473), the contingent nature of employees' experiences are contextually moulded over time by the interplay of external structural forces and the internal social relation that they hold with their employers (Dundon \& Dobbins 2015, p. 918). Violation or breach in PCs, therefore, may result not only from institutional inertia or managerial failure, as is commonly claimed, but also from the impact of external contextual factors on the social exchanges underpinning the employment relationship (Cullinane \& Dundon 2006):

A great deal of the literature finds that, more often than not, management fail to live up to their side of the bargain. Conventional psychological contract literature explains this as a result of managerial failure and, to some extent, market pressures (Guest \& Conway 2002). Such explanations are limited insofar as they fail to comprehend that these are merely surface level issues that arise from a deeper explanation of political and economic power. (Cullinane \& Dundon 2006, p. 121)

Guest (2004a, 2004b) and Cullinane and Dundon (2006) thus suggest that the PC framework needs to take into account contextual eventualities that influence the employment relationship and the parties' perceptions regarding their deal. These scholars advocate that PC research should be built "around a model that links the employment contract to the psychological contract, while taking into account the employment context" (Guest 2004a, p. 16). The psychological contract should therefore be recognised as a social exchange interaction in which the imbalance of power is inherent (Cullinane \& Dundon 2006; Guest 2004b) and responsive to the compulsory and coercive relationship between its social actors (Weber [1922] 1947).

When considered from this perspective, the PC extends beyond merely being considered in terms of a social exchange (Blau 1964) and the promissory focus of Rousseau's (1989) conceptualisation, to considering how the broader dynamics of society and economy affect individuals' beliefs in their employment relationships. In identifying these aspects from a PC perspective, Guest (2004a, p. 6) proposed and applied a PC framework that takes into consideration factors which lie outside 
organisational boundaries and the individual-organisational sphere to develop what are described as 'wider contextual factors' (WCF).

While investigating the impacts of flexible employment arrangements on individuals' outcomes, Guest (2004a) expected that national legislative, economic and employment factors would impact employees' perceptions regarding the delivery of the deal in terms of fairness and trust. Figure 3.2 illustrates Guest's (2004a) proposed framework, which is a starting point for the conceptual model guiding this research.

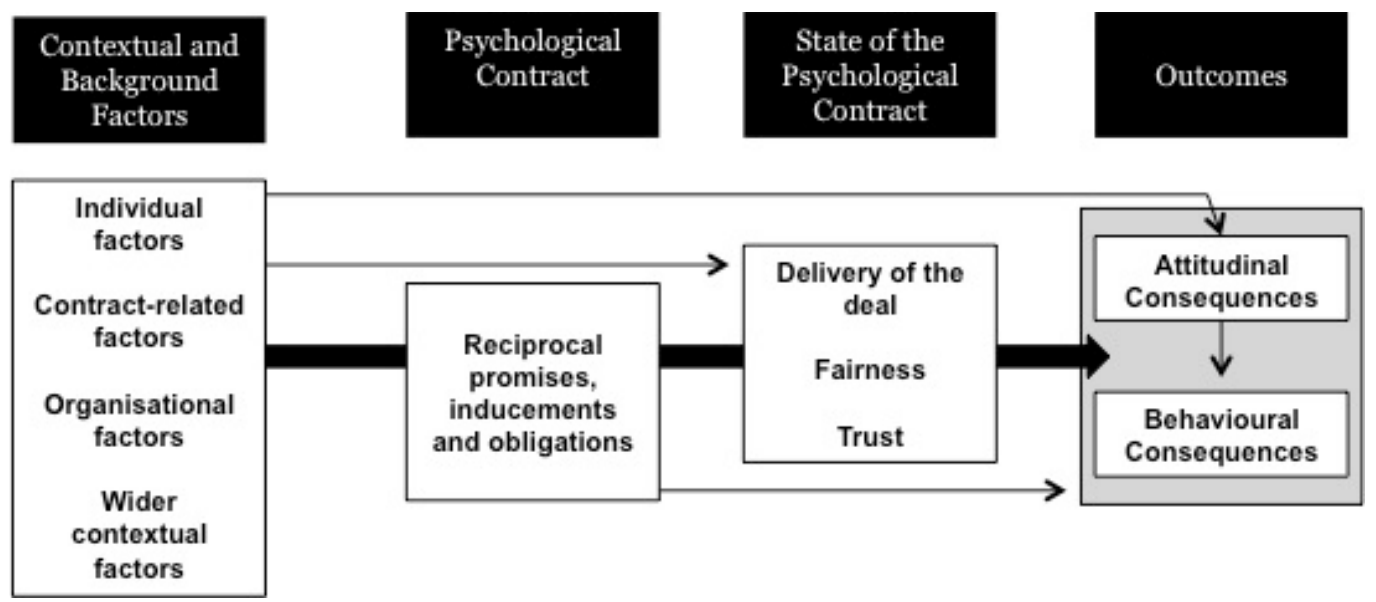

Figure 3.2. Employment contracts, the state of the psychological contract, and employee outcomes (Guest 2004a, p. 6).

However, the discussion of WCFs (in Chapters 1 and 2) that influence the employment experience of HSIs both globally and in Australia suggests that WCFs are more than just "contextual and background factors" as per Guest (2004a). Instead, it is argued that WCFs independently influence the individual, contract-related and organisational factors that comprise Guest's (2004a) conceptualisation of the contextual and background factors that influence the PC. That is, it is argued that WCFs in fact influence individual, contract-related and organisational factors that constitute the contextual and background factors that influence the PC, the state of the PC, and subsequent outcomes. Figure 3.3 below illustrates the iterative formulation of this conceptualisation in relation to Guest's (2004a) model. 


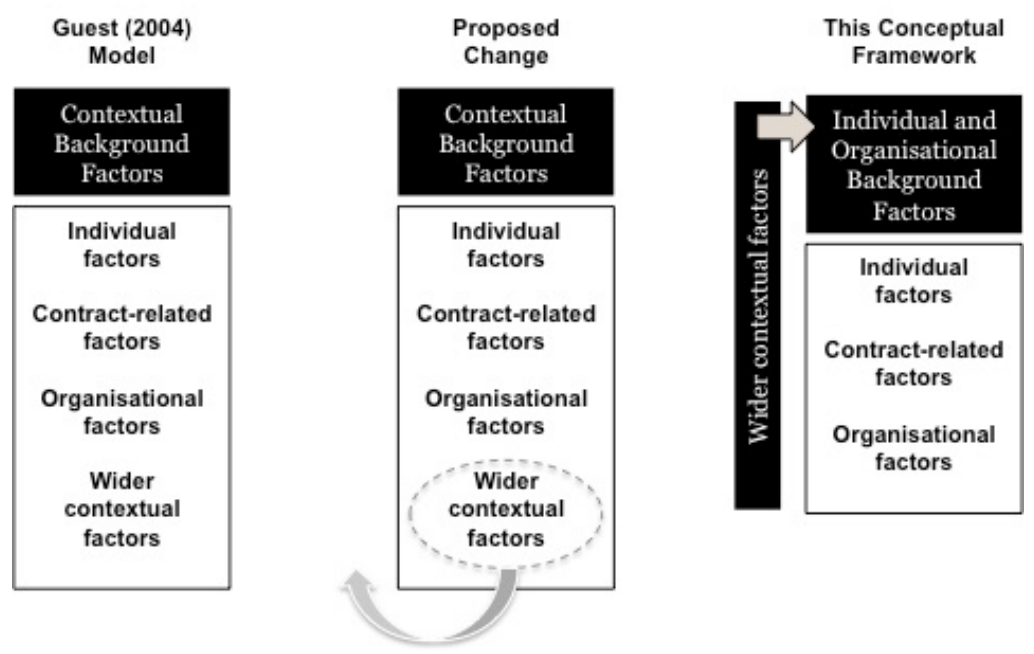

Figure 3.3. The influence of wider conceptual factors.

Positioning WCFs in this way thus extends Guest's (2004a, 2004b) model and aligns with the discussion by Cullinane and Dundon (2006), who argue that PC research must take into consideration the broader socioeconomic context in which employment relations occur. However, the conceptualisation of WCFs as a separate influence is also informed by the migration literature, which suggests that human mobility must be considered in light of the socio- and political-economic environment that connects areas of outward and inward migration (Bakewell 2010; Castles 2010; De Haas 2010; Van Hear 2010).

Therefore, like employment relations, migration processes must be observed in relation to their interconnectedness and placed in the context of global change (Castles 2010). Migration flows should be considered in light of the WCFs that stimulate emigration in areas of origin and destination, as well as migrants' motivations, goals and aspirations (Bakewell 2010). As Chapter 2 describes, these WCFs refer not only to how globalisation and the ideology of neoliberalism have changed patterns of production and hence labour market dynamics in sending countries, but also to how activities by receiving countries have sought to pull HSIs into their localities.

Thus, Polanyi's (1957 [1944]) notion of embeddedness fruitfully conceptualises the significance of WCFs as described in the study. Polanyi's interpretation of embeddedness refers to the idea that just as the economy is not autonomous but is in fact influenced by politics and social relations (Block 2003; Webster et al. 2008), so too are political and social relations influenced by the economy. Accordingly, because Polanyi's analysis reinforced the "interconnectedness and wholeness" of social, 
economic and political spheres (Castles et al. 2011, p. 7), individual agency is highly responsive to WCFs. Therefore, while WCFs include the national legislative, economic and employment factors, as suggested by Guest (2004a), when considered from a Polanyian perspective, they also encompass the globalising forces and neoliberal philosophies discussed in Chapter 1 and they also include the "swings and shifts" (Caspersz 2012) in the economy and society that triggered changes in the regulation of labour migration in Australia and WA as described in Chapter 2.

Hence, when conceptualised in this way, WCFs are likely to influence individual factors such as, for example, local livelihood opportunities, which in turn can affect individuals' aspirations (De Haas 2010) and decisions to migrate (Khoo et al. 2007). As a result, in the context of a policy framework, WCFs such as multiculturalism policies and employment legislation in the receiving country (Castles 2004; Caspersz 2012), will impact on 'contract-related' and 'organisational factors' (Healey et al. 2012) that Guest (2004a) identified as shaping the PC. Given this discussion, it is proposed that

\section{Proposition 1a: WCFs affect HSIs' individual background factors, which are some of the factors shaping their PCs.}

\section{Proposition 1b: WCFs affect contract-related factors at the organisational level, which will also influence HSIs' PCs.}

Moreover, given that WCFs are conceptualised as external to other factors (see Figure 3.4), they are also expected to influence the beliefs comprising HSIs' PCs, including their expectations, perceptions of promises and obligations in their workplaces. As discussed in Chapter 2, shortages in skilled labour have impacted a number of countries. Labour migration is perceived as a 'quick fix' response to this dilemma, enabling receiving countries to maximise labour market flexibility (Hugo 2004) and gain a competitive advantage by deploying labour migrants on an on-demand basis (Papademetriou et al. 2008; Shachar 2006). In exchange for these HSI contributions, employers and governments offer a range of incentives, from attractive professional trajectories (Papademetriou et al. 2008) to guaranteed membership in more stable and developed societies (Shachar 2006). Thus, WCFs influence the ideas (that is, the 'promises, inducements and obligations'; see Figure 3.4) that are held by HSIs regarding what they may expect to obtain in the receiving labour market and their employment arrangements. Therefore: 
Proposition 2: WCFs shape the content of HSIs' PCs, including expectations, perceptions of promises, inducements and obligations in the workplace.

However, given the dynamism inherent in WCFs, it is likely that they will also impact the 'state of the psychological contract', by influencing the organisation's ability or capacity to deliver the 'deal' to HSIs and individuals' assessment of their deals. As Chapters 1 and 2 describe, there have been many shifts in WCFs both globally and specifically in Australia and WA that have both 'pulled' HSIs to Australia and WA and 'pushed' (Castles 2000) them away. The promises and deals made by organisations in good faith may break down due to contextual shifts. WCFs thus (directly and indirectly) may lead to breaches, violations, or at least a renegotiation of contract-related matters (Kickul 2001; Rousseau 1995).

Still, whether an individual perceives that an organisation has been able to 'deliver the deal' or not depends on a belief in what the organisation is obliged to provide, based on perceived promises of reciprocal exchange (Robinson \& Rousseau 1994). These normative expectations, or beliefs regarding what ought to occur, are based upon a prevailing normative standard in the organisation (Roehling 2008). Thus, fairness and trust that the employer/organisation will 'deliver the deal' in accordance with these normative standards in the employment relationship (Fox 1974; Guest 2004a) lie at the heart of employees' assessments about whether the 'delivery of the deal' by employers meets these normative expectations (Fox 1974; Guest 2004a).

Perceptions of fairness in the employment relationship may emerge from a number of sources, including individuals' judgements concerning the outcomes of their deals, the procedures implemented by the firm, and the quality of the interpersonal treatment received from those representing the organisation (Morrison \& Robinson 1997; Kickul 2001). Trust, on the other hand, will develop from the expectation that one party in the relationship will perform a particular action and foster a willingness to be vulnerable to the actions of the other party (Mayer et al. 1995).

In summary, WCFs affect the ability of an organisation to meet what HSIs expect from their PC. HSIs' perceptions of fairness and trust influence whether they perceive an organisation's inability to meet their expectations as a breach or violation of the outcomes expected from their PCs. Thus, the following is proposed: 
Proposition 3: Because WCFs impact an organisation's capacity to deliver what HSIs expect, WCFs will affect these individuals' outcomes in their employment relationships.

In PC research, a number of outcomes, such as organisational citizenship behaviour (Hui et al. 2004; Guest 2004a), commitment (Coyle-Shapiro \& Kessler 2000; Kickul et al. 2004) and job satisfaction (Nelson et al. 2006), have been assessed at both attitudinal and behavioural levels. These outcomes emerge from individuals' assessments of the 'state of the psychological contract', including perceptions regarding fulfilment or breach of their deal with their organisations. However, absence of prior research about the PCs of HSIs, particularly in the context of understanding RQ 2 (How do HSIs' PCs impact their intentions to stay in WA?) has made it challenging to conceptualise what outcomes would result from HSIs' PCs in this study. By using the ECM (Burawoy 1998; see Chapter 4), this thesis will be able to make a unique empirical contribution by developing a more in-depth understanding of the outcomes relevant to the PCs of HSIs, by exploring what emerges within the sample.

Figure 3.4 below depicts the conceptual framework guiding this research and the significance attributed to WCFs in the PC process.

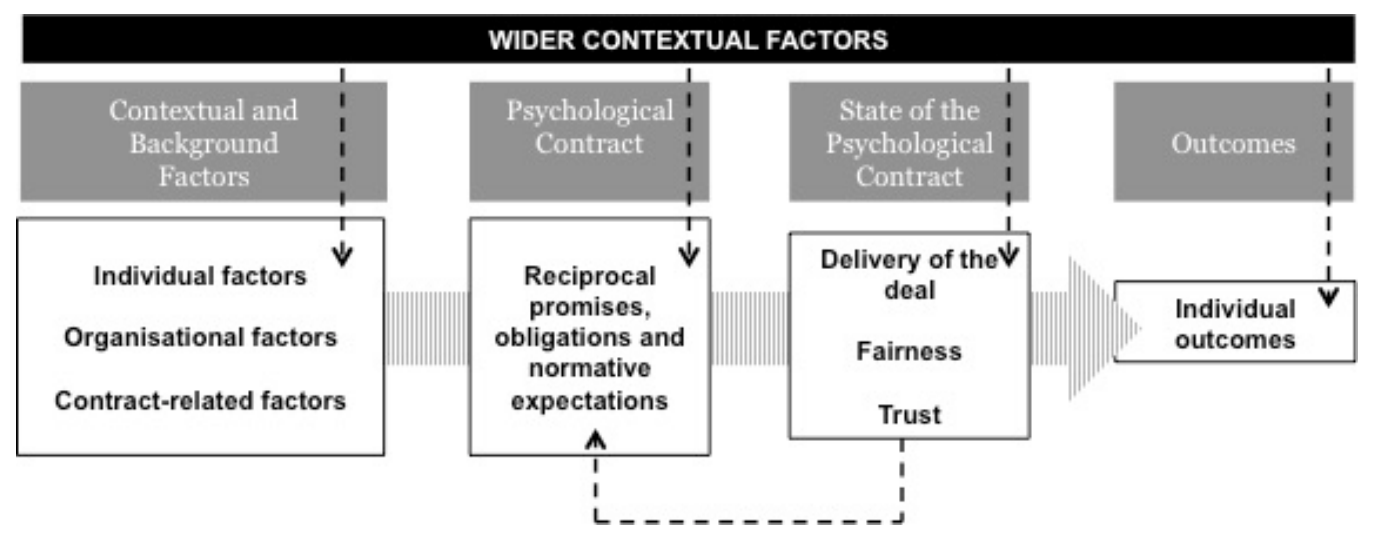

Figure 3.4. Conceptual framework: Wider contextual factors and the psychological contract.

\section{Conclusion of the chapter}

Chapter 3 has presented a conceptualisation of how the PC is used to explore the employment experience of HSIs and their willingness to stay in WA. The chapter began with an overview of the PC's conceptualisation and definitions. It presented 
justifications for an idiosyncratic approach (Rousseau 1989) as well as the reasoning behind considering promises, obligations and normative expectations as valid PC beliefs for investigation (Roehling 2008).

The second part of this chapter described the conceptual framework that has been developed to explore the PCs of HSIs in WA and how their perceptions and experiences influence their decision to engage and remain in WA's labour market over time. This conceptual framework was developed by drawing upon a critical management approach (Cullinane \& Dundon 2006; Guest 2004a, 2004b) that claims that PC research must take into account the WCFs that influence the employment relationship. The following propositions emerged from this discussion:

\section{Propositions}

\section{Proposition 1a \\ WCFs affect HSIs' individual background factors, which are some of the factors shaping their PCS.}

\section{Proposition 1b}

WCFs affect contract-related factors at the organisational level, which will also influence HSIs' PCS.

\section{Proposition 2}

WCFs shape the content of HSIs' PCs, including expectations, perceptions of promises, inducements and obligations in the workplace.

\section{Proposition 3}

Because WCFs impact an organisation's capacity to deliver what HSIs expect, WCFs will affect these individuals' outcomes in their employment relationships.

Table 3.1. Summary of propositions.

To allow a broader understanding of the contextual factors that surround the employment experience of HSIs during the timeframe of this research, Polanyi's (1957 [1944]) concept of embeddedness, which reinforces the "interconnectedness and wholeness" of social, economic and political spheres (Castles et al. 2011, p. 7), was used as a methodological principle. Burawoy's (1998) extended case method (ECM) was also used as a methodology to support this undertaking, as presented in Chapter 4. 


\section{Chapter 4 - Research Design}

\section{Introduction}

Research design refers to the logic that links the data to be collected - and the conclusions to be drawn - to the initial questions of study (Yin 2014, p. 26). This chapter thus aims to present a detailed overview of the research methodology employed to explore highly skilled immigrants' (HSIs) expectations and their perceptions of promises and obligations in their Western Australian workplaces - that is, to investigate these individuals' psychological contracts (PCs) in light of the contextual factors in which their employment relationships are embedded.

As presented in Chapter 1, there are two questions guiding this study:

1. How do wider contextual factors (WCFs) influence highly skilled immigrants' (HSIs) psychological contracts (PCs)?

\section{How do highly skilled immigrants' (HSIs) psychological contracts (PCs)} impact their intentions to stay in WA?

A comprehensive understanding of the individuals' PCs lies at the heart of these two questions, but as previously described in Chapter 3, the $\mathrm{PC}$ is a highly subjective perception that differs among individuals (Guest et al. 2006; Rousseau 1995). The PC is dynamic (Rousseau 1995), idiosyncratic (Rousseau 1989), and dependent on context (Conway \& Briner 2002; Cullinane \& Dundon 2006). Ultimately, it can be said that the $\mathrm{PC}$ refers to a very subjective personal construction of one's employment reality.

The methodological approach guiding this thesis must thus allow for a proper grasp of participants' unique perspectives in different circumstances and provide well-grounded and rich descriptions of these individuals' realities in their particular contexts. At the same time, because this thesis aims to empirically illustrate a critical management perspective towards the significance of the context for PC research, its methodology must also allow for the examination and improvement of the existing theory. Burawoy's (1998, 2009) approach towards the extended case method (ECM) as a reflexive scientific model properly addresses these two undertakings and therefore informs the 
qualitative longitudinal research (QLR) approach adopted in this thesis.

This chapter begins with an overview of the contributions that a QLR approach bring to this investigation, before describing and justifying the use of Burawoy's extended case method. Procedures used for data collection and analysis are then described. In-depth interviews and a range of secondary data were used in three phases of data collection and examination, which included content and thematic analyses (Joffe \& Yardley 2004; Vasmoradi et al. 2013). In the third part of this chapter, before methodological limitations of the study are discussed, the sample is presented, together with the qualitative criteria implemented by the researcher. The figure below illustrates the research design for this thesis.

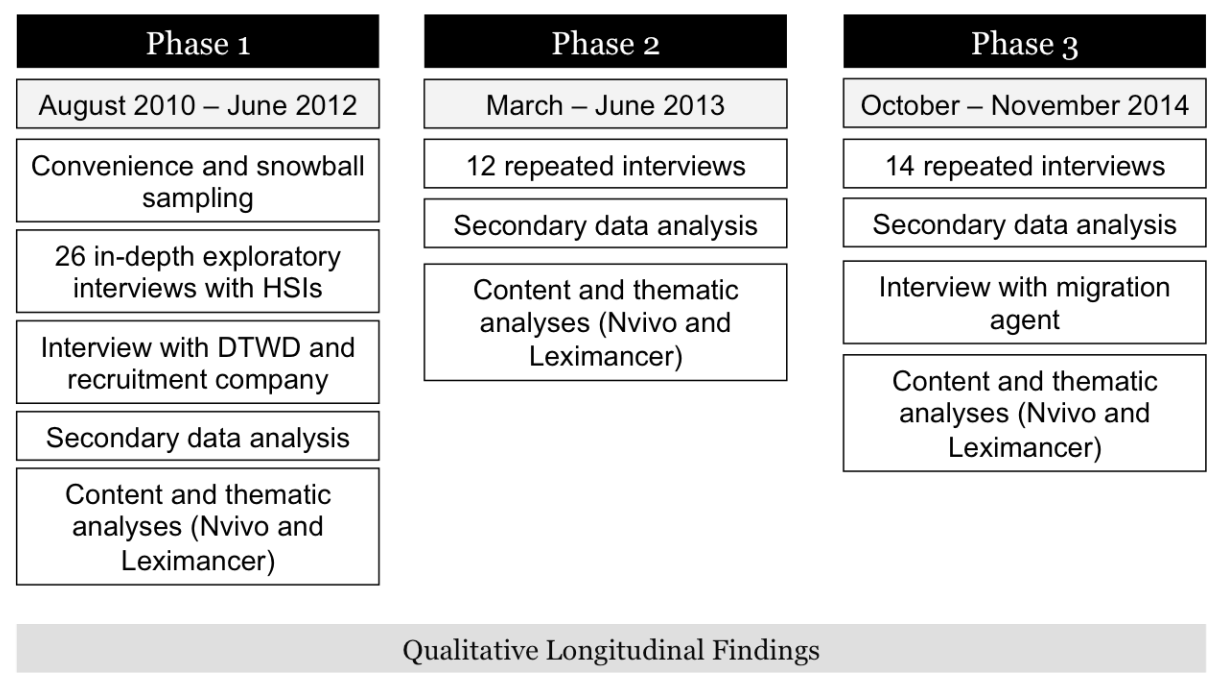

Figure 4.1. Overview of research design.

\subsection{A qualitative longitudinal case study approach}

\subsubsection{Qualitative longitudinal research (QLR)}

Qualitative research has a specific relevance for the study of social relations because the "pluralisation of life worlds" requires a method that allows some sensitivity (Flick 2006, p. 12). As an emergent, interpretive and interactive research method (Creswell 2007), qualitative research allows for systematic, in-depth, holistic examinations of individuals' experiences in their natural settings, with participants' voices at the forefront of the study (Creswell 2007; Denzin \& Lincoln 2005; Miles \& Huberman 1994). 
A qualitative research approach can be expected to give appropriate significance to aspects that are subjective in essence but need to be investigated and comprehended in order to answer the research questions (Flick 2006). In this study, these aspects refer to the implicit and explicit messages received by the HSIs in the sample, their perceptions of fairness and trust in their workplaces, their individual histories and backgrounds, and a number of broader contextual factors that are relevant when investigating their experiences.

In this research, a qualitative longitudinal approach was adopted because it was necessary to examine the process of change across and between different moments of enquiry (Smith 2003). Qualitative longitudinal research (QLR) is a design in which the investigator performs repeated interviews with participants to assess and explore changes that occur over time and the processes associated with these changes (Flick 2006; Farrall 2006; Holland et al. 2006). What distinguishes qualitative longitudinal research from other methodological approaches is the deliberate way in which temporality is included in the research process, making change itself a central focus of analytical attention (Thomson et al. 2003; Vallance 2005).

A number of advantages has been highlighted in the literature in reference to QLR. Data collection over a sustained period allows for increased comprehension of the phenomenon under study (Maykut \& Morehouse 1994; Miles \& Huberman 1994). The repeated assessment of data also enables a richer description of the phenomenon, representing it more adequately from the participant's viewpoint (Stark \& Torrance 2004). In a more epistemic approach, Carter (2006) claimed that the significance of the relationship developed between the investigator and the participant is another important contribution of a qualitative longitudinal design, because during repeated interactions, participants are able to process previously discussed topics and build a memory of the experience.

Particularly with reference to the subject of this research, it has been argued in the literature that the study of skilled migration demands a longitudinal approach because the continuum of migrant experiences over time and space needs to be more fully understood (Ho 2011; Roberts 2011; Robertson 2015a). Methodologically, migration should not be understood as a single act of mobility in time, but as a complex and possibly fragmented process - of decisions, actions and occurrences - across time (Robertson 2015a). 
Likewise, a longitudinal approach towards psychological contract studies can facilitate a better understanding of the messages employees receive over time from the wider political economy in which their employment is embedded (Cullinane \& Dundon 2006) and in light of organisational changes that trigger PC adjustment and breach (Conway et al. 2014). However, despite its great strength, the longitudinal strategy has rarely been used, at least explicitly, in qualitative research (Carter 2006; Flick 2006; Pettigrew 1990). The scarcity of published research is because, in practice, longitudinal research faces two critical obstacles: continued access to participants and lack of control over the events that occur in the intervening period (Pettigrew 1990).

This research had three phases of data collection:

- Phase 1 (September 2010 - June 2012) occurred in a period still marked by skills shortages in Australia (Bowen 2012; McLeod 2012), as described in Chapter 2. During this time, there was a campaign to attract immigrants from European countries that were facing an economic downturn, such as Britain, Ireland and Greece (Spooner 2012). Twenty-six exploratory and semi-structured in-depth interviews were conducted.

- Phase 2 (February - June 2013) was conducted when market constraints began to impact WA's economy (Tasker 2012; Tillett 2012); in addition, anxiety regarding the federal elections began to emerge as businesses were concerned about policy stability (Kitney \& Garvey 2013). In this phase, three participants had already left WA, others were unreachable, and only 12 of the previous respondents accepted the invitation to participate again.

- Phase 3 (October - November 2014) followed the confirmation of the federal budget and new government policies. Fourteen repeated interviews were conducted. Two participants who were unavailable during Phase 2 were interviewed again in this phase.

The QLR literature suggests that judgements regarding the number of data collections and their points in time depend on the phenomenon under observation. Young and colleagues (1991) argued that a span of at least one year should be adopted, while Kelly and McGrath (1988) claimed that a longitudinal design should involve multiple waves of observation over a lengthy timeline, including months or years. 
In this research, these decisions were made in light of the research questions being pursued (Pettigrew 1990; Saldaña 2003). A changing context was mandatory for a proper investigation of the change in individuals' PCs and their intentions towards WA's labour market, and the change in scenario was perceptible by the second half of 2012, when it could be traced and scrutinised with the support of secondary data. Decisions made regarding the number of data collections also took into consideration resource constraints (Pettigrew 1990; Saldaña 2003); and this research, as a doctoral study, had a noteworthy time limitation, as discussed in Chapter 8 . Therefore, this fouryear interval, with three waves of data collection, allowed for proper observation of contextual change, while also ensuring that the timeframe was not detrimental to the study.

\subsubsection{Extended case method (ECM)}

A case study approach is considered to be particularly useful when observable facts cannot be extracted from their real-world context, or when the boundaries between phenomena and context are not clearly evident (Yin 2014). Stake (2005) defined case studies as multifaceted objects embedded in a number of historical, cultural, social, legal, economic, and ethical contexts and backgrounds, thus arguing that qualitative case studies call for the examination of the complexities related to the contexts, their meanings, and their relationships.

Burawoy's (1998) extended case method (ECM) was chosen to inform this case study for two reasons. Firstly, Burawoy's methodological approach allows for a comprehensive understanding of HSIs' distinctive perspectives in different circumstances, supporting rich descriptions of these individuals' realities in their particular contexts. This is because, through its principles of process and structuration, the ECM acknowledges the significance of both the micro-level world and the external influences that shape and constrain daily life.

Secondly, the ECM approach supports this study's aim to contribute towards the psychological contract literature by empirically illustrating the importance of context in the PC framework. This is because, in essence, the goal of research in the ECM is not the generalisation of findings, but the continued reconstruction and improvement of existing theory and concepts (Burawoy 1998; Samuels 2009). The ECM builds from 
existing theory, identifies weaknesses that cannot be explained, and then, through the exploration of such weaknesses, seeks to add value to the initial theory (Sappey 2006).

The four principles (or dimensions) of the ECM - intervention, process, structuration and reconstruction - as well as how they are applied to this study, are described next.

\section{The four practical principles of ECM}

Intervention refers to the researcher's involvement in data collection and interpretation, which is regarded not only as an inevitable feature of qualitative social research, but also as an advantage that can be used to develop a better understanding of "the hidden secrets of participants' worlds" (Burawoy 1998, p. 14). It is this 'perspectival view' (Maykut \& Morehouse 1994) that gives the researcher the possibility of perceiving nuances of meaning and gaining an in-depth understanding throughout individuals' discourses. The researcher simultaneously adopts the role of 'question-asker' and 'answer-interpreter', assessing the incoming data while guiding the conversation. The outcomes of different conversations are never the same (Burawoy 1998), opening up a range of constructs that guide and sensitise the researcher to possible lines of inquiry while giving meaning to what is being explored within a holistic setting (Rossiter 2009).

Process refers to the method of collecting multiple readings of a single case participants' situational experiences - and aggregating them into social processes, just as survey research combines data into statistical distributions to make causal inferences (Burawoy 1998). This principle is generally achieved in the ECM when the researcher, as an observer, moves with the participants through their own space and time. Knowledge is then acquired through individuals' narratives, but also through participation, as research does things with and to those who are being studied (Garfinkel 1967, cited in Burawoy 1998).

Given the infeasibility of establishing long-term relationships with the participants' organisations (Langley \& Stensaker 2012), ethnography was not used in this study. Instead, individuals' social processes were reconstructed from repeated interviews (Burawoy 1998), data triangulation (Denzin 1978), and discussions of findings with the participants during their exit interviews (Saldaña 2003). Research methods for data collection and analysis will be further described later in this chapter. 
Structuration refers to the investigation of the everyday world from the standpoint of the external field within which the interviews occur. According to Burawoy (1998, p. 15), an interview cannot be contemplated outside the 'field of forces' that shape it instead, the 'external field' must be understood as the conditions of existence of the locale in which the research occurs. Structuration is particularly relevant because of this study's approach towards embeddedness (Polanyi’s (1957 [1944]), and allows for a better understanding of significant external factors impacting the phenomenon under investigation - in this study, HSIs' PCs.

Finally, reconstruction refers to the significance of deepening a given understanding in order to properly elaborate on existing theory, rather than on generalising findings and discovering new theory (Burawoy 1998). In this study, a collection of individual cases was used in order to investigate HSIs as a population and their experience in WA as a general condition (Stake 2005). Selecting different cases from different organisations, cultural backgrounds and professional fields helped the researcher to explore differences regarding how each group experiences certain issues (Simons 2009). This approach did not aim to ensure representativeness, but rather to explain relevant differences (Simons 2009), thus contributing to challenging and reconstructing the existing theory.

\subsection{Methods used for data collection and analysis}

\subsubsection{Data collection: Semi-structured interviews}

An interview, as Dexter (1970) has described, is a conversation with a purpose. Interviews offer insights into respondents' memories and explanations (Maykut \& Morehouse 1994) as well as descriptions of current issues and aspirations (Stark \& Torrance 2004). Interviews produce direct quotations from people about their feelings, opinions, experiences and knowledge (Patton 2005, p. 1634). Perakyla (2005, p. 869) claimed that the interview is also a "very convenient way of overcoming distances both in space and in time", as past events and experiences can be recounted when interviewing people who took part in them.

According to Brinkmann (2013), interviews range from being 'relatively' structured to 'relatively' unstructured. Brinkmann (2013) argued that, in qualitative research, there is no such thing as a completely structured interview, as people say things that defy the 
prefabricated structure. Similarly, there cannot be a completely unstructured interview because the researcher always has an idea about what should take place in the conversation. This research, as previously mentioned, used a semi-structured approach. In a semi-structured interview, a guide leads the conversation but allows flexibility in terms of following up on whatever angles the interviewee feels are important or for further focusing the conversation on issues that the interviewer deems important in relation to the research project (Brinkmann 2013).

An interview guide or 'schedule' is a list of questions or general topics that the interviewer wants to explore during each conversation (Lofland \& Lofland 1984). Although the guide is prepared to ensure that essentially the same data are obtained from each participant, there are no predetermined answers, and the researcher is free to explore responses in greater depth if necessary. Interview guides ensure good use of limited time, allow more systematic and comprehensive data collection, and help to keep interactions focused (Lofland \& Lofland 1984). The guides for this study's semistructured interviews are presented in Appendix 2.

Phase 1 was an exploratory phase in which participants were asked not only about their employment relationships but also about their backgrounds, migration experiences and cultural perspectives. Questions for Phases 2 and 3 were aimed at re-assessing individuals' perceptions regarding their employment relations and their PCs, as well as exploring the importance of different contextual factors over participants' perceptions. Phase 3 was also established as a stage for final exit interviews, with questions designed to assess individuals' own perceptions of differences and changes through time, along with their own predictions about the future (Saldaña 2003). These final exit interviews also allowed opportunities to "fill in the holes" (Saldaña 2003, p. 37) with additional data. The literature that guided these interviews is discussed in Chapters 2 and 3 of this thesis.

The semi-structured questionnaires used to guide the conversations with some intermediaries in the HSIs' migration process are presented in Appendix 3. Intermediaries are groups or organisations who work at the intersection between skilled migrants and their host countries (Groutsis et al. 2015); and in this research, they helped to build an understanding of WA's labour market and the messages received by HSIs before, during and after their arrival in WA. Intermediaries' responses also supported triangulation (Denzin 1978), as will be discussed later in this chapter. A representative 
from the Western Australia Department of Training and Workforce Development, a leading recruitment consultant for resources and engineering industries, and a migration agent were interviewed in this research. They represent intermediaries with an increasing role in the recruitment and placement of individuals in the high end of the labour market (Groutsis et al. 2015).

All of the interviews, with both HSIs and intermediaries, were held face to face and ranged from 30 minutes (when a repeated interview) to 60 minutes (initial conversations). Because interviews were dependent on the participants' availability, some were conducted in the interviewees' offices and others during lunch or over coffee. All interviews were recorded and transcribed for later analysis.

\subsubsection{Data collection: Documentary analysis (secondary data analysis)}

Aside from using secondary data for the purpose of triangulation (Denzin 1978), this study used in-depth analysis of secondary data to understand the contextual aspects surrounding the lived experience of HSIs in WA. Secondary data analysis refers to the use of data and archival information collected by others (Stewart \& Kamins 1993, p. 1). It involves the summarisation, collation and/or synthesis of existing data, rather than primary research (Crouch \& Housden 2003).

An assortment of material was used to inform this thesis: books and journals available at the university library, articles published in newspapers and business magazines, and reports published by the Department of Immigration and Border Security (DIBP), the Western Australia Department of Training and Workforce Development (DTWD) and the Australian Bureau of Statistics (ABS). Government reports and newspaper/magazine articles were organised in electronic files by their date of publication, and their thematic analysis allowed the researcher to build a context to frame the experiences of HSIs in each phase of the research (Krippendorff 2004).

Secondary data may not precisely meet the researcher's needs or be sufficiently recent, but scholars agree that these materials are usually the starting point for any study (Corbetta 2003; Crouch \& Housden 2003; Stewart \& Kamins 1993). Secondary sources are generally quick and cheap to acquire (Stewart \& Kamins 1993; Crouch \& Housden 2003) and are extremely useful in the familiarisation process and for generating ideas (Crouch \& Housden 2003). Secondary sources provide a convenient starting point for 
additional research by suggesting problem formulations, research hypotheses and research methods (Stewart \& Kamins 1993).

However, secondary data is by definition 'old data' and care should be taken with respect to when the material was published (Stewart \& Kamins 1993, p. 6). Scholars also recommend paying attention to bias in secondary sources, as data are often collected with a specific objective in mind (Corbeta 2003; Stewart \& Kamins 1993). To control bias, especially with regard to newspapers and magazines, the researcher attempted to cross-examine and compare information from different sources as much as possible. To control the freshness of the information published by governmental departments, their databases were visited frequently, at least twice a year, in an effort to update numbers and other relevant information.

\subsubsection{Data analysis: Content analysis and thematic analysis}

Different epistemological perspectives have created an assortment of approaches for qualitative data analysis methodologies; content analysis and thematic analysis are just two of them. The literature recognises that there are substantial similarities and even an overlap between these qualitative approaches in terms of their methods, procedures and techniques. Content and thematic analyses have been used interchangeably in the literature, as misunderstandings still exist in terms of their similarities and differences and due to the absence of specification regarding the boundaries between them (Joffe \& Yardley 2004; Vasmoradi et al. 2013).

Both content and thematic analyses allow for a qualitative analysis of data. Summarily, these two approaches share the same purpose of systematically examining narrative materials from life stories by breaking the text into smaller units of content and subjecting them to descriptive treatment (Sparker 2005). Most content analysis, however, results in a numerical description of features of a given material, while thematic analysis pays greater attention to their context and other qualitative aspects (Joffe \& Yardley 2004).

Content analysis is a method that outlines the presence of words or concepts in textual documents (Weber 1990) and breaks down qualitative material into manageable categories and relationships, helping the researcher to highlight what is more frequent and most relevant. When doing content analysis, the researcher can analyse data qualitatively and, at the same time, quantify the data (Gbrich 2007). For this reason, 
Joffe and Yardley (2004, p. 56) described content analysis as a "partially quantitative method".

Because content analysis places significance on the frequency of codes, scholars have argued that it poses an imminent risk of missing significant information throughout the analysis (Joffe \& Yardley 2004). This is because the frequent occurrence of words in content analysis might simply reflect the willingness or ability of one participant to talk at length about a given topic, rather than the importance of a specific concept. The scarcity of some words, on the other hand, might result from the interchangeable use of different names or concepts when referring to the same object.

In contrast, Joffe and Yardley (2004) argued that thematic analysis allows the researcher to combine an analysis of the frequency of the codes with an analysis of their meaning in context. This is an approach more suitable to qualitative analysis because it offers a context within which the available texts can be examined (Krippendorff 2004; Vaismoradi et al. 2013). Thematic analysis thus allows researchers to create a world in which the texts 'make sense' in order to answer their research questions (Krippendorff 2004).

The analytical strategy adopted in this thesis incorporated both content and thematic analysis in order to properly address the two research questions. Content analysis was used to map the most significant expectations, perceptions of promises and obligations among the individuals in the sample, thus supporting the examination of the content of individuals' PCs. Thematic analysis allowed for a comprehensive examination of the influence of contextual factors over HSIs' PCs during the three phases of this study.

The process of content and thematic analysis followed a combination of steps as suggested in the literature (Braun \& Clarke 2006; Schmidt 2004). First, categories of analysis were created after repeated reading of the interview transcripts. This step was informed by theory (Burawoy 1998) and grounded in the literature review presented in the first chapters of this thesis. Second, a guide for analysis and coding was created, containing detailed descriptions of each of the categories used. Third, each interview was assessed and classified, and portions of transcripts were coded. In the fourth step, which involved content analysis, results from coding were compiled, yielding frequencies in each of the analytical categories. In the fifth and final analytical stage, extracts were selected and organised in terms of their relationship to the research 
questions and to the literature. An example of this process is illustrated in Appendix 5. A combination of NVivo 10 and Leximancer software was used to support content and thematic analyses and to expand analytical possibilities, as discussed below.

\subsubsection{Data analysis: The use of CAQDAS}

A common characteristic of qualitative longitudinal research is the massive volume of data produced (Smith 2003). This thesis generated more than 40 hours of interviews in 55 files, which were recorded, transcribed, analysed and coded. Every view expressed by each participant about each issue needed to be analysed not only in relation to the other responses in that phase of data collection, but also to findings of the previous phases of fieldwork and the broader context in a given time period.

Two computer-assisted qualitative data analysis software (CAQDAS) programs were used in this process to improve data management and analysis (Bazeley \& Jackson 2007; Tesch 1990) and better aid conceptual and theoretical thinking (Barry 1998). CAQDAS refers to any software program that is specifically designed to analyse qualitative text, be they statistical content analysis tools or more interpretive instruments (Sinkovics \& Alfoldi 2012).

In the first step of data analysis, NVivo 10 was used to aid in the process of coding the transcriptions. NVivo is a code-based theory-building program that supports the codeand-retrieve process and also allows representation among codes and categories (Weitzman 2000). NVivo's capacity for sorting, matching and linking enabled a proper exploration of data without losing the context in which the data were embedded (Bazeley \& Jackson 2007). NVivo therefore particularly supported classification across the data set and the comparison of extracts relevant to each code (Braun \& Clarke 2006).

In NVivo, coding is the action by which references to all text relating to a particular category or code are stored in a container called a 'node'. NVivo creates a number of nodes and then allows organisation into sub-categories if necessary (Vallance 2005). NVivo coding tools supported the identification of important themes within individuals' responses (such as their 'feeling of belonging' or 'normative expectations'). Coding and the definition of 'themes' were informed by the literature review (see Chapters 2 and 3 for the literature, and Appendix 5 for an example of this process). 
NVivo also allowed the researcher to map participants' psychological contracts (Rousseau 1989) by coding and quantifying their references to perceptions of promises, obligations and expectations in their employment relationships. Therefore, the software also assisted the process of content analysis by allowing a more effective, efficient and trustworthy work process (Sinkovics \& Alfoldi 2012).

Following this analysis, Leximancer was used to support both the conceptual and relational analyses of the material, assessing the presence of defined concepts in the respondents' interviews and the interrelations among them. Leximancer is a conceptual network builder, a program that allows graphic representations of the relationships among concepts (Weitzman 2000). Leximancer was mostly used to compare data among the different groups of participants (such as those who were sponsored and those with self-initiated migration experiences) and to compare the data from different phases of the research, therefore supporting the longitudinal analysis. Leximancer also allowed a verification of the relevance of themes previously identified with NVivo (Weitzman 2000), as the categories of analysis formerly acknowledged as significant with NVivo were expected to have relevancy in Leximancer maps as well.

The outputs from the NVivo and Leximancer software were concept maps, reports, graphs and tag clouds - thematic plots that supported thematic analysis (Leximancer 2011; Vallance 2005). They allowed for a visual presentation of themes, codes and their relationships, thus helping the researcher when reviewing ideas and supporting the identification of coherent themes (Braun \& Clarke 2006). Part of these outputs is available in Chapters 5 through 8, in which the findings are presented and discussed.

Scholars have acknowledged the benefits of using CAQDAS in qualitative research (Sinkovics \& Alfoldi 2012; St. John \& Johnson 2000; Vallance 2005). Validity and credibility are enhanced by the provision of an audit trail, greater rigour and transparency in the analysis process (St. John \& Johnson 2000). CAQDAS is also believed to enhance systematisation, trustworthiness, reflexivity and operational effectiveness in qualitative research without jeopardising the analytical and interpretive process carried out by the researcher (Sinkovics \& Alfoldi 2012).

However, some concerns about the use of qualitative data analysis software have also been previously highlighted in the literature. Scholars have mentioned that CAQDAS may focus on quantity instead of meaning and depth of analysis (St. John \& Johnson 
2000). They have also claimed that the use of software could encourage the imposition of rigid structures on the type of analysis techniques used (Tesch 1990). Finally, as Barry (1998) has argued, non-users of CAQDAS frequently fear that technology might distance people from their data and take control of their analysis.

This research design took these criticisms into account, together with some other recommendations found in the literature. Special care was taken with the wholeness of the information during the coding process in order to avoid decontextualising pieces of data and consequently losing their meaning (Miles \& Huberman 1984). St. John and Johnson (2000) recommended caution with respect to the amount of data and possible codes, raising the possibility of researchers 'drowning' in the amount of material. In the current study, the researcher strived to have a maximum of seven major themes, with no more than three sub-levels each, during the coding process. This was a strategy suggested by qualified NVivo instructors during software training and capacitation to avoid losing meaning in the analysis process.

Finally, the literature has stressed that CAQDAS may support data analysis but cannot conduct it alone, thus reinforcing the role of the researcher during the research process (Barry 1998; Joffe \& Yardley 2004; Vallance 2005; Weitzman 2000). This role is particularly important in the ECM, a form of knowledge production in which the researcher carries out all the tasks of the research activity, making evaluations as the 'product' develops from the process (Burawoy 1998). Qualitative analysis, then, requires an intimate knowledge of the data, which can be only attained by a repeated and close reading of the transcripts (Barry 1998; Vallance 2005).

\subsection{Sample}

\subsubsection{Sampling strategy}

Scholars have argued that the logic and power of sampling in qualitative research must lie in picking information-rich cases: those that can truly exemplify a circumstance or hold a characteristic of significance to the subject matter under investigation (Miles \& Huberman 1994; Patton 1990; Ritchie et al. 2014). A small sample of great diversity can generate high quality and detail-rich descriptions of different cases, but also reveal important shared patterns across contextual circumstances (Patton 1990). 
Sampling in this research was purposive (Miles \& Huberman 1994; Patton 2005) and evolved as Phase 1 of fieldwork was conducted (Miles \& Huberman 1994).

As described and justified in Chapter 2, the sampling frame (Miles \& Huberman 1994) used in this inquiry was informed by the research questions and conceptual framework and built upon work by Hawthorne (1997) and Challoff and Lemaitre (2009). Participants thus had to (1) hold either a 457 Temporary Business Visa or have Permanent Residency as a result of a self-initiated skilled migration to Australia; (2) have full and immediate recognition of overseas qualifications; (3) hold a tertiary education at a bachelors level; (d) work in their area, with an occupation listed in Australia's Consolidated Sponsored Occupational List (CSOL); (4) hold either a professional or a managerial position; (5) have at least five years of pre-migration professional experience; and (6) have fluency in English. Participants' experiences in WA's labour market were the main object of the sampling strategy used in this study (Sandelowski 1995), and because of that the sampling frame also aimed to reflect WA's labour market in terms of its main industries and most common sources for a skilled labour force.

The sequence of the sampling process was thus theoretically driven - observing one individual invited comparison with another, and understanding one key experience in the setting of this research revealed aspects to be studied in others (Burawoy 2009; Miles \& Huberman 1994). Phase 1 ended with a collection of 26 cases that clarified whether a finding was peculiar to a single case or common among a number of cases (Eisenhardt \& Graebner 2007; Patton 2005; Yin 2014), and which also allowed for a broader exploration of the research questions (Eisenhardt \& Graebner 2007).

Repeated interviews with 26 individuals in subsequent phases of data collection $(n=12$ in 2013; $n=14$ in 2014) allowed for a collection of 52 representations of HSIs' experiences. These 52 'pictures' allowed for a deep analysis of the experiences of these individuals, which helped the researcher to 'sharpen' the existing theory by illustrating and illuminating the gaps in the PC literature (Siggelkow 2007, p. 21), as discussed in Chapter 8 . The sample characteristics are presented below.

\subsubsection{About the sample in Phase 1}

The 26 individuals in the sample came from 15 different countries: Brazil, Canada, Colombia, China, Croatia, Germany, Italy, Malaysia, Mauritius, the Netherlands, New 
Zealand, Senegal, South Africa, the UK and the US. About 58 per cent of them were males and 42 per cent females. About half of these individuals (52 per cent) had arrived in Australia less than three years before their first interview.

\begin{tabular}{|c|c|}
\hline $\begin{array}{l}\text { HSI DEFINITION } \\
\text { (see section 2.1.4) }\end{array}$ & SAMPLE IN THE STUDY \\
\hline $\begin{array}{l}\text { Recruitment under Australia's key skilled } \\
\text { immigration categories - either in a } 457 \\
\text { Temporary Business Visa (expatriate } \\
\text { assignment) or holding Permanent } \\
\text { Residency (PR); }\end{array}$ & $\begin{array}{ll}\checkmark & 42 \% \text { arrived with a } 457 \text { visa; } \\
\checkmark & 30 \% \text { arrived with PR; } \\
\checkmark & 15 \% \text { (4 participants) arrived with a New Zealand } \\
& \text { passport, although only one was born there; } \\
\checkmark & 8 \% \text { (2 participants) came to study (post-grad); } \\
\checkmark & 4 \% \text { (1 participant) had a spouse visa; }\end{array}$ \\
\hline $\begin{array}{l}\text { Occupation listed in Australia's } \\
\text { Consolidated Sponsored Occupational List } \\
(\mathrm{CSOL}) ;\end{array}$ & 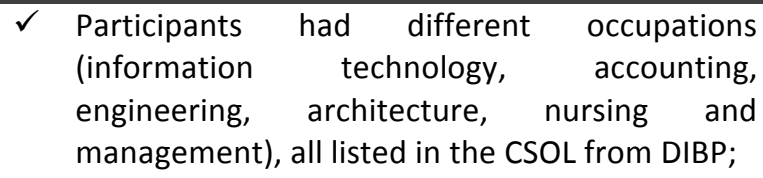 \\
\hline $\begin{array}{l}\text { Full and immediate recognition of } \\
\text { overseas qualifications; }\end{array}$ & $\begin{array}{l}\checkmark \text { All individuals received immediate recognition } \\
\text { of overseas qualifications and worked in their } \\
\text { area of qualification; }\end{array}$ \\
\hline $\begin{array}{l}\text { Tertiary education at a bachelor's level } \\
\text { (minimum); }\end{array}$ & $\begin{array}{ll}\checkmark & \text { All individuals had at least a bachelor's degree; } \\
\checkmark & 50 \% \text { completed post-graduate studies; }\end{array}$ \\
\hline $\begin{array}{l}\text { In an employment relationship, holding } \\
\text { either a professional or a managerial } \\
\text { position; }\end{array}$ & $\begin{array}{ll}\checkmark & 38 \% \text { were managers in Phase } 1 ; \\
\checkmark & 62 \% \text { were professionals in Phase } 1 ;\end{array}$ \\
\hline $\begin{array}{l}\text { Substantial pre-migration professional } \\
\text { experience (at least } 5 \text { years); }\end{array}$ & $\begin{array}{ll}\checkmark & \text { Average professional experience: } 14.1 \% ; \\
\checkmark & 62 \% \text { had previous international experience; }\end{array}$ \\
\hline Prime workforce age at time of arrival; & $\checkmark \quad$ Participants' mean age was 38.2 years old; \\
\hline Intermediate-to-native English fluency. & $\checkmark \quad$ All interviews were conducted in English. \\
\hline
\end{tabular}

Table 4.1. Sampling frame and sample characteristics in Phase 1.

Individuals worked for different industries; however, most of them worked for resources (mining and oil and gas), construction and engineering, or management/IT consulting serving these industries. About 73 per cent of the participants were working for a MNC during Phase 1, and 15 per cent of them were employed in WA's high education sector. Individuals worked and lived in WA, and 19 of them declared a weekly income of $\$ 1500$ or more. The table below presents some other characteristics of the sample, reflecting the inclusion criteria as per the definition provided in Chapter 2. Graphics illustrating the sample's characteristics are presented in Appendix 4. 
It must be reinforced that participants were diverse in a number of ways, but they do not necessarily represent the experience of skilled migrants in general. Their characteristics as 'highly skilled migrant', as described above, reflect the fact that these individuals were highly educated and experienced, highly paid and highly mobile (Beaverstock 2002), characteristics that put them in a privileged position when compared to other migrant groups.

\subsubsection{About the sample in Phases 2 and 3}

The same group of 26 individuals who took part in Phase 1 were invited to participate in Phases 2 and 3. They were mostly invited by email; in some cases - particularly when individuals changed employment (and therefore their email details) - social media (Facebook or LinkedIn) was used to contact them.

Contact was lost with eight of the participants from Phase 1. Three left Perth, and two other individuals became contractors. Their second interviews were excluded because they opened their own businesses and thus were no longer holding an employment relationship (as per the definition in Chapter 2). Four individuals who were not available in Phase 2 accepted being interviewed in Phase 3, as the table below shows. Three individuals who participated in Phase 2 left Australia before Phase 3, but accepted the invitation to participate in a follow-up exit interview, which was conducted using Skype and Facetime.

In sum, 12 repeated interviews were conducted in Phase 2, and 14 repeated interviews were conducted in Phase 3. This process allowed a minimum of two interactions with 16 individuals. During the duration of the research, most HSIs in the sample became Australian citizens or at least permanent residents. The only exception was one IT manager who was transferred to Australia by her employer, but stayed no longer than two years. Only about one-third of participants changed jobs during this four-year period (2012-2014). 


\begin{tabular}{|c|c|c|c|c|c|c|c|c|c|c|c|c|c|}
\hline Index & From & $M / F$ & $\begin{array}{l}\text { Year of } \\
\text { arrival }\end{array}$ & $\begin{array}{c}\text { Previous } \\
\text { international } \\
\text { experiences }\end{array}$ & $\begin{array}{l}\text { Visa status } \\
\text { when arrived }\end{array}$ & $\begin{array}{c}\text { Professional } \\
\text { experience } \\
\text { (years) } \\
\text { (Phase 1) }\end{array}$ & $\begin{array}{l}\text { Length of } \\
\text { time in this } \\
\text { ER (years) } \\
\text { (Phase 1) }\end{array}$ & Industry (Phase 1) & $\begin{array}{c}\text { Visa status } \\
\text { (Phase } 2 \text { or } \\
\text { 3) }\end{array}$ & $\begin{array}{l}\text { Changed jobs } \\
(\mathrm{Y} / \mathrm{N})\end{array}$ & $\begin{array}{c}\text { Career } \\
\text { Level }\end{array}$ & Phase 1 & Phase 2 \\
\hline P01 & Brazil & M & 2009 & USA & 457 & 6 & 1 & Small Bs - Wholesales & citizen & No (soon) & M & & \\
\hline $\mathrm{PO2}$ & Brazil & M & 2008 & USA & $P R$ & 15 & 2 & Mining & Citizen & Yes & MLM & & ntractor \\
\hline P03 & Brazil & M & 2008 & Israel, USA & PR & 16 & 2 & Engineering/Construction & Citizen & No & MLM & & \\
\hline P04 & Brazil & M & 2004 & China, Italy & Student (PG) & 22 & (3 months) & Mining & Citizen & (Not known) & PM & & Moved to \\
\hline P05 & New Zealand & F & 2008 & UK & $\mathrm{NZ}$ & 8 & 2 & Engineering/Construction & (Not known) & (Not known) & p & & Back to NZ \\
\hline P06 & UK & F & 1986 & China, USA, UAE & NZ & 27 & 3 & Mining & citizen & Yes & MLM & & USA \\
\hline p07 & Malawi/UK & M & 2008 & UK & 457 & 9 & 8 & oil \& Gas & PR & Yes & $\mathrm{p}$ & & \\
\hline P08 & Netherlands & F & 2008 & UK, Sweden & 457 & 5 & 2 & Health & $P R$ & No & p & & \\
\hline P09 & Colombia & $\mathrm{F}$ & 2005 & & Student $(P G)$ & 5 & 5 & Engineering/Construction & Citizen & No & p & & \\
\hline P10 & South Africa & F & 2005 & UK & PR & 12 & 2 & Education & Citizen & No & p & & \\
\hline P11 & South Africa & F & 2009 & Germany & $P R$ & 12 & (6 months) & Education & citizen & No & $p$ & & \\
\hline P12 & Canada & M & 2007 & & 457 & 16 & 5 & Mining & citizen & No & MLM & & \\
\hline P13 & Malaysia & M & 2010 & & $P R$ & 20 & (6 months) & Mining & (Not known) & (Not known) & $p$ & & \\
\hline P14 & Germany & M & 2007 & & 457 & 15 & 4 & Consulting & citizen & Yes & OM & & \\
\hline P15 & Colombia & F & 2000 & & 457 & 24 & 19 & Mining & citizen & No & MLM & & East Coast \\
\hline P16 & USA & M & 2002 & & Spouse & 22 & 1 & Consulting & Citizen & No & OM & & \\
\hline P17 & Brazil/Canada & M & 2011 & Canada & PR & 12 & 1 & Engineering/Construction & PR & Yes & $\mathrm{p}$ & & \\
\hline P18 & South Africa & F & 2008 & & $P R$ & 20 & 1 & Small Bs - Construction & (Not known) & Yes & M & & Became contractor \\
\hline p19 & Brazil/taly & M & 2011 & Italy, Portugal & 457 & 9 & 1 & Consulting & $P R$ & No & $p$ & & \\
\hline 120 & South Africa & M & 2011 & & 457 & 21 & 5 & Engineering/Construction & (Not known) & (Not known) & p & & \\
\hline P21 & Mauritius & M & 2005 & & $\mathrm{NZ}$ & 7 & (6 months) & Engineering/Construction & Citizen & (Not known) & $p$ & & \\
\hline P22 & South Africa & $\mathrm{F}$ & 2010 & uK & 457 & 17 & 7 & Engineering/Construction & 457 & Yes & MLM & & Canada \\
\hline P23 & China & F & 2011 & UK & 457 & 5 & 1 & Education & $P R$ & No & oM & & \\
\hline P24 & Senegal & M & 2011 & Nigeria, Brazil & 457 & 8 & 5 & oil \& Gas & $P R$ & No & PM & & Indonesia \\
\hline P25 & South Africa & M & 2010 & & PR & 15 & 2 & Education & Citizen & No & MLM & & \\
\hline$P 26$ & Croatia & F & 2000 & Germany, NZ & $\mathrm{NZ}$ & 20 & 1 & oil \& Gas & Citizen & Yes & PM & & \\
\hline
\end{tabular}

$\mathrm{M}=$ Manager; $\mathrm{MLM}=$ Middle Level Manager; $\mathrm{OM}=$ Office Manager (in small boutique consulting firms); P = Professional; PM = Project Manager; Green box = participated; Red box = did not participate.

Figure 4.2. Sample in Phases 1, 2 and 3.

\subsection{Qualitative criteria}

\subsubsection{Limitations and trustworthiness in this study's methodology}

Godard (2014) has argued that although Human Resources Management (HRM) has traditionally been closely associated with the field of industrial relations (IR), it has increasingly been taken over by industrial and organisational psychology, posing a significant underlying problem for research. This ‘psychologisation' of HRM (Godard 2014, p.1) leads to an emulation of the research paradigm of the physical sciences into the field, allowing for a 'hyper-positivist' approach (Godard 2014, p. 10) and, as such, particularly directed at prediction and control, rather than real understanding (Harney 2009).

I-O (industrial and organisational) psychologists seem to view human beings almost as if they are billiard balls, subjected to rather simple laws of behavior and with no capacity for independent thought or action (or at least. There is no interest in this capacity). Under this view, it is possible to develop elaborate models, with numerous arrows and boxes (...), and then to 'test' these models with carefully developed research 'instruments' consisting of endlessness questions asking about multiple individual-level attitudes and characteristics and with highly sophisticated measurements and data analysis (Godard 2014, p.10)

In this positivistic approach, research often abstracts the subject from the human society, its context and the realities of employment relations (Godard 2014; Thompson 
2011), even when the wider context plays a central role in setting the framework for contemporary employment relations (Guest 2004a). No quantitative model can compensate for the absence of serious account of the structural constraints that capitalism enforces over HR practices in the workplace (Thompson 2011).

However, although the use of a qualitative methodology is justified and supported by the exploratory objectives of this research, qualitative methods are commonly doubted, especially in terms of their trustworthiness. Two main limitations are often expressed with regard to qualitative research. First, it usually does not allow for generalisation, as it is not possible to replicate findings from one group (or even a small number of qualitative cases) to a larger population (Stark \& Torrance 2004). Second, there is the issue of selective plausibility (Flick 2006), which refers to the researcher's credibility when handling cases and passages, which are analysed and selected in light of what the researcher believes are either illustrative or deviant.

Burawoy's (1998, p. 10) four principles of the ECM respond to these critiques, as the ECM challenges the "four prescriptive beliefs of positive science" - also known as the '4Rs' (Katz 1983). The 4Rs refer to 'reactivity' (the isolation of findings from a researcher's influence), 'reliability' (the capability of findings to accurately represent the phenomenon under investigation), 'replicability' (the possibility of repeating the study with similar results), and 'representativeness' (which refers to the possibility of generalising the findings).

Burawoy (1998) argued that social science cannot live up to the 4Rs, because in qualitative research the respondent does not react to the question alone, stripped of the context in which it is posed; because the interview is a social context embedded in other social contexts, all of which lend meaning to the questions and answers; and because situation effects threaten the principle of representativeness - meanings, attitudes and even knowledge are only constituted in social situations, which change constantly.

Hence, Burawoy $(1994,1998)$ offered an alternative conceptualisation for qualitative criteria in which the principle of reactivity is replaced by inter-subjectivity. This intersubjectivity is achieved through the immersion of the observer into the participant's world; as such, intervention is recognised as an inherent feature of all social sciences. Validity is achieved through the extension of observations in time and place, because the researcher acknowledges that even when the question is standardised, the 
respondents' interpretations cannot be. To achieve reliability, the researcher collects and analyses data in a systematic fashion, in which coding and recoding data into emergent categories offers the lens for further observation.

Replicability in Burawoy's conceptualisation $(1994,1998)$ is less concerned with the replication of data collection. If in positivist science the question must be "a stimulus isolated" and the external conditions "must be controlled" (Burawoy 1998, p. 8), in reflexive science contextual conditions are taken as a "point of departure" (Burawoy 1998, p. 4). Contextualisation, then, as the extension from the situation to the wider field of social relations, plays a significant role in the ECM; yet, the context cannot be replicated because the context is always changing.

Finally, if the representativeness achieved by statistical sampling procedures in quantitative studies allows the researcher to make broader inferences about the whole population, in qualitative inquiries the data are often derived from a few cases unlikely selected on a random basis (Silverman 2010). However, the use of multiple, carefully selected case studies may allow the researcher to predict either similar or contrasting results among them (for reasons grounded in theory), thereby allowing 'theoretical replication' (Yin 2014, p. 57). In ECM conceptualisation (Burawoy 1994, 1998), the selected case materials are used to challenge and then reconstruct pre-existing theory.

Thus, in this thesis, by using the ECM, the opportunity emerged to develop a new theoretical understanding of the outcomes of the HSIs' PCs. As suggested in Chapter 3, the absence of relevant prior research posed a difficulty in conceptualising such PCs. However, by drawing on the ECM to guide the process of data collection, the opportunity was also presented to engage in an iterative process of theory construction. In this thesis, this discussion is presented at the end of Chapter 5 (Phase 1) and 6 (Phases 2 and 3) when discussing the outcomes of the HSIs' PCs.

Nevertheless, credibility in qualitative inquiry depends on rigorous techniques and methods for gathering high quality data, which should be carefully analysed (Patton 1990, p. 461). To increase the rigor and trustworthiness of this thesis, a set of practical criteria as suggested in the literature was adopted.

First, 'multiple sources of evidence' were sought when gathering data (Yin 1989, p. 42). These included repeated interviews with skilled immigrants at three different points in time, a range of secondary data, such as government reports and newspaper articles, and 
interviews with intermediaries who confirmed the researcher's perceptions regarding contextual aspects. The researcher used these intermediaries to understand the phenomenon - skilled labour migration - from diverse perspectives (Eisenhardt \& Graebner 2007), as previously described in this chapter. This data triangulation (Denzin 1978) was important for clarifying meanings and verifying the repeatability of the researcher's interpretation (Stake 2005). It was also imperative for reconstructing the scenario in which participants' lived experiences were embedded (Burawoy 1998).

To minimise problems with reliability in the coding process, particularly during content analysis, measures were taken to ensure that classification was accurate and grounded in theory (Burawoy 1998; Krippendorff 2004). First, all of the transcriptions were thoroughly reviewed prior to analysis. A number of adjustments were made, for example, in terms of consistency in the use of the words 'employer' when replacing the organisation's name. Codes were named after constructs previously found in the pertinent literature, such as 'relational psychological contract' (Rousseau 1989).

To maximise the strength of the analysis process (Patton 1990) and reduce the risk of selective plausibility (Flick 2006), an investigator triangulation (Denzin 1978) was conducted during Phase 1. For this, a research assistant was hired to review and analyse the quality of the coding adopted. The research assistant (also a $\mathrm{PhD}$ student in the management area) reviewed booklets extracted with NVivo 10 that contained reports of every coding (in light of its theoretical definition) for each piece of interview transcript.

Finally, 'member checking' (Lincoln \& Guba 1985; Yin 1989) was used as a strategy of validation for the interpretations and perceptions of participants' experiences by the researcher. During a process of member checking, the researcher submits preliminary drafts of findings for review by data sources (Lincoln \& Guba 1985; Yin 1989). In this research, participants in Phase 3 (during their exit interviews) were invited to review their own maps, with their own storylines, and to comment on the researcher's interpretations and preliminary findings. These maps can be found in Appendix 8.

\subsubsection{Ethical considerations}

Miles and Huberman (1994) identified a number of possible ethical issues regarding qualitative research: the possibility of harm and risk, the need for honesty and trust, privacy, confidentiality and anonymity. Carter (2006), on the other hand, highlighted that the most important threat in longitudinal design is the amplified need for ethical 
clarity, particularly when interviews revisit past ordeals. In this case, the researcher needs to ensure that the long engagement is not damaging and that an extended relationship with the interviewer does not create a sense of obligation to participate (Carter 2006).

Following the university's Human Research Ethics Office guidelines, a document of informed consent was particularly important in this research. Informed consent means that individuals interviewed or observed during the research had to give their permission, expressing full knowledge of the purpose of the research and the consequences of taking part in it (Piper \& Simons 2004, p. 56). A written informed consent form had to be signed by each of the participants. They were informed that they were free at any time to withdraw consent to further participate without any negative repercussions. Participation, therefore, was freely given, voluntary and uncoerced (Miles \& Huberman 1994).

Confidentiality and anonymity were a matter of special attention during both data analysis and report writing. Confidentiality is a principle that allows people to talk in confidence, while anonymisation is a procedure that protects participants' privacy and confidentiality (Piper \& Simons 2004, p. 57). No information or material that could be used to identify participants or organisations, nor harm them in any way, was released or used in this report.

\section{Conclusion of the chapter}

This chapter presented the research design and methodology. Burawoy's (1998, 2009) approach towards the ECM as a reflexive scientific model informed the qualitative longitudinal design (Holland et al. 2006) adopted in this thesis. The ECM allowed for a proper grasp of HSIs' subjective perceptions at different moments of their experiences in WA's labour market, and supported the reconstruction of their stories.

The original primary data in this study was collected in three phases of semi-structured, qualitative interviews. A group of 26 individuals participated in Phase 1 (2010-2012), and repeated interviews were conducted in $2013(n=12)$ and $2014(n=14)$, providing a collection of 52 representations of HSIs' experiences. Semi-structured interviews were also conducted with intermediaries (Groutsis et al. 2015): The Western Australian Department of Training and Workforce Development, an international recruiter, and a 
migration agent. The researcher largely used secondary data (Stewart \& Kamins 1993), such as government reports and articles published by newspapers, to inform the reconstruction of the context of this study (Burawoy 2009). Findings of this research emerged from a combination of content analysis and thematic analysis (Sparker 2005), conducted with the support of NVivo 10 and Leximancer software. 


\section{Chapter 5 - Findings Report (Phase 1): The PCs of HSIs in 2012}

\section{Introduction}

From an economic point of view, WA is the best place in the world to be right now (P16).

The next three chapters report the findings from this longitudinal research. Chapter 5 presents highly skilled immigrants' (HSIs) perceptions and experiences of Western Australia's (WA) labour market during Phase 1 of the research, conducted between September 2010 and June 2012.

As previously described in Chapter 2, at that time a number of developed countries particularly in Europe - were facing severe economic uncertainty, with sovereign debt issues (CEDA 2011), recurrent bailouts and record levels of unemployment (Kingsley 2012). Australia, on the other hand, continued to avoid the Global Financial Crisis (GFC) and sustain economic growth (ABS 2010; CEDA 2011). Australia's performance was attributed to its macroeconomic policy (OECD 2010) and its exports of natural resources to fast-growing China and India (CEDA 2011; DTWA 2014; Garnett 2012; OECD 2010). In 2011, WA alone had a \$225 billion portfolio of resource and infrastructure projects under construction, committed to construction, or under consideration (DTWD 2011).

The first part of this chapter presents a picture of the psychological contract (PC) for a group of 26 HSIs within this particular political-economic context. These findings are discussed in five sub-sections, each with a different focus: the HSIs' reasons for coming to WA, the content of their PCs, the types of their PCs, the situations in which they perceived breaches in their PCs, and their commitment, loyalty and gratitude as the outcomes of their employment relationships.

The data for these chapters predominantly came from interviews, government documents and newspaper articles. When referring to interview data in the text, reference is made to the code number given to the respondents' interview transcripts in order to protect confidentiality and anonymity. The lived experience of each of the participants - as their own retelling of their everyday lives (Dilthey 1987; Van Manen 1990) - is presented in 'interview maps' that can be found in Appendix 8. Appendix 8, 
therefore, presents a summary of the perceptions and experiences reported by these 26 participants.

\subsection{Why did these HSIs come?}

Before assessing HSIs' expectations in their Western Australian workplaces, this research explored the contextual factors that pushed these individuals away from other countries and towards WA in an effort to better understand their background factors. As discussed in Chapter 2, the migration literature has previously explored push (demographic pressures, shortage of economic opportunities, political oppression) and pull (economic opportunities, demand for labour, political-religious freedom) factors behind labour movements (Castles \& Miller 2003).

Findings from Phase 1 reflected these previous investigations regarding the reasons behind individuals' decisions to leave their countries of origin (Castles \& Miller 2003; Khoo et al. 2007). However, findings also showed that, for most individuals in the sample, the perception of professional opportunities in Australia, and particularly the skills shortages in WA, was the main driver for their decisions regarding migration. A general perception of 'opportunity' attracted these HSIs from all over the world to Perth:

I came to Perth because on the East Coast, which is my favourite place to live, I couldn't find a job paying 50\% of my current income (P04).

I came here following work because I used to work in the oil and gas arena; now I work in mining, but oil and gas is predominant in WA (P06).

I am a geologist, so the payment and the benefits are so much better, maybe twice as good here (P07).

A word tree extracted from NVivo 10 (Appendix 6) illustrates this general perception of 'opportunities' during Phase 1. This perception is related to what these individuals could observe in Australia, in WA, and in their organisations. A word tree displays the results of a query conducted in the data uploaded to NVivo as a tree with branches representing the various contexts in which a selected word occurs. The word 'opportunity' and its stemmed words was the 24th most frequent word throughout the interviews with HSIs during the first wave of data collection. It was mentioned 163 times, an average of more than six times per participant. 
Even those individuals who did not have a sponsor or a job arrangement in Australia when migrating - thus not following a specific professional opportunity - considered Australia "a country in which (their) profession was recognised" in a labour market that was "very good back then" (P03). The prospect of career opportunities thus played a central role in these HSIs' decisions to come to WA; it created a general expectation of easily obtaining a job and quickly progressing along an attractive career path:

Back in the UK, I couldn't get a permanent position; I was just working several shifts. I thought here would be quite easy to get something and it was. It was very easy (P08).

So there are a lot of opportunities in Australia, but I think it is driven by the mining boom, so there is a huge demand for human resources; a lot of projects are currently underway, so it is easy to find managerial type roles. So your progression is on a fast track (P12).

Seven individuals, from either South Africa or Brazil, also reported socioeconomic push forces in their country of birth (such as economic constraints and violence) as significant reasons for their migration. Brazil has witnessed a process of 'brain drain' for more than three decades. High inflation and low economic growth in the 1980s, followed by the government's unsuccessful liberal economic policies in the 1990s, motivated millions of Brazilians from various socioeconomic levels to emigrate to other countries in search of economic opportunities (Amaral \& Fusco 2005). South Africa, on the other hand, had in 2010 one of the world's highest crime rates, with an average of 50 murders per day (Smith 2010). As one South African described:

We just thought that we were living in a prison; we had bars, and an alarm system. We had a dog, and we lived in a complex so it was gates within gates. We just didn't want to live that way anymore (P11).

Those emigrating from developed areas, such as European countries or Canada, frequently associated career opportunities in Australia with the country's lifestyle as determinant pull factors driving migration. Some of them recounted tight labour market conditions in the United Kingdom as a push factor:

In the UK now... there are a lot of people there trying to find a job. I know people in the same position as me, and they haven't actually seen any sort of pay rise in three years or something like this in the UK (P07).

Nonetheless, the Australian lifestyle - characterised by cultural diversity, an egalitarian society, a sporty and outdoorsy culture, and good climatic conditions (DFAT 2012) represented the strongest pull force amongst this group of HSIs: 
I think what persuaded me really was just being outside all the time; the lifestyle is so good with kids, compared to what we had. Here we are, glorious sunshine in the middle of the winter (P08).

\subsection{What are the beliefs in HSIs' psychological contracts?}

As discussed in Chapter 3, this thesis was guided by an understanding that PCs are constituted by a combination of perceptions regarding promises and obligations in the employment relationship (Rousseau 1989) and normative expectations (Levinson et al. 1962; Roehling 2008; Schein 1965). Thus, during Phase 1, participants were asked to describe: (1) their perceptions of obligations in their workplaces - both their obligations as employees and their employers' obligations; (2) expectations that they had of their jobs; and (3) eventual promises made by their employers. Figure 5.1, built upon content analysis, summarises and illustrates participants' answers.

\begin{tabular}{|c|c|c|c|}
\hline \multicolumn{4}{|c|}{ HSIs' PSYCHOLOGICAL CONTRACTS IN PHASE 1} \\
\hline Employer Obligations & Employee Obligations & Promises & Normative Expectations \\
\hline $\begin{array}{c}\text { Provide resources and } \\
\text { safety }(7)\end{array}$ & $\begin{array}{c}\text { A valuable contribution to } \\
\text { the company (14) }\end{array}$ & $\begin{array}{c}\text { Good financial package } \\
\text { (3) }\end{array}$ & $\begin{array}{l}\text { Career growth and } \\
\text { opportunities (16) }\end{array}$ \\
\hline Respect the contract (6) & Obligation to stay (6) & $\begin{array}{l}\text { Flexibility \& WLB (4) - } \\
\text { working hours and shifts. }\end{array}$ & $\begin{array}{l}\text { Learning and } \\
\text { develonment (14) }\end{array}$ \\
\hline Fair treatment (6) & \multirow{2}{*}{$\begin{array}{c}\text { Contractual obligations } \\
(3)\end{array}$} & & \multirow{2}{*}{$\begin{array}{c}\text { Challenge and excitement } \\
(11)\end{array}$} \\
\hline Offer ongoing & & PR sponsorship (4) & \\
\hline development (4) & & & \multirow{2}{*}{$\begin{array}{c}\text { Job security and stability } \\
\text { (8) }\end{array}$} \\
\hline $\begin{array}{l}\text { Offer professional } \\
\text { opportunities (3) }\end{array}$ & & & \\
\hline
\end{tabular}

Figure 5.1. HSIs' psychological contracts in Phase 1.

As can be noticed in the first column of this figure, participants had mixed perceptions regarding what they considered to be the employer's obligation. Providing adequate resources and a safe work environment was the most popular perception of employer obligation $(n=7)$, followed by respecting the contract $(n=6)$ and treating employees fairly $(n=6)$. Few participants $(n=3)$ felt that their employers were obliged to provide them with ongoing development and professional opportunities:

Every obligation is in the contract, so (employers obligations are) just respecting the contract and sticking to it (P26).

Individuals' perceptions regarding their own obligations as employees could be classified under three categories. First, the majority of individuals $(n=14)$ believed they had to provide a meaningful contribution to the firm, performing according to the 
employer's expectations, 'adding value' to their organisations, and sometimes going beyond their roles:

My main obligation to (this employer) is to add value to the company. That is what I think. So, I want to do a good job, I want to improve the company's performance, if this is possible with my skills (P01).

I just feel that we've been engaged to do a role, to perform something in a particular role, so we have to do our best. Sometimes things are not straightforward because it is not in your scope, but you need to go out and make sure it is done (P13).

Second, individuals who had their visa sponsored $(n=6)$ also mentioned that they felt an 'obligation to stay' with their employers, a feeling of obligation which emerged from both a contractual source and an emotional one. A minimum commitment of two years is usually explicit in skilled immigrants' employment contract with their 457 sponsors; nonetheless, this feeling of obligation towards employers also seemed to result from individual feelings of gratitude towards a visa sponsorship. This will be discussed later in the chapter:

I have a kind of a moral obligation (P01).

I feel in a sense that, yes, I do owe them for that. (...) I think there is a two-year period in which I have to work for them. There is a contract (P20).

Third, women with part-time assignments $(n=3)$ described their obligations to their employers as merely 'contractual'. Although they were highly skilled and sometimes even the primary holders of their PR visas, they had part-time job arrangements in order to cope with family needs and their children's school hours:

My obligations with (this employer) are... I think to do what they employed me for (P11).

Only three types of expectations emerged from individuals' perceptions of promises (or offers) clearly made by their employers. Two of them were grounded in contractual aspects of the employment relationship: wage and working hours. These expectations included financial packages $(n=3)$ and flexibility (or work-life balance), the latter of which was a significant expectation mostly for women with children $(n=4)$. The third expectation grounded in perceptions of promise referred to sponsorship for permanent residency, which was mentioned by the 457 visa holders $(n=4)$ :

(The employer) should be obligated to me, so they should be trying to get me permanent residence. (The employer) will help me (P07). 
The majority of individuals $(n=16)$ in the sample described workplace expectations regarding career growth and professional opportunities from their employment relationships. These expectations were justified by WA's resources boom and the State's skilled shortages, but also by the opportunities for career progression that participants noted within their organisations:

(This company) has different business units; I have had the opportunity to work for more than one business unit, and in one of them, you could see the advertising opportunities for internal movements, and you know, a good marketing of that, like "this opportunity can be yours" (P02).

What I want is to become a partner in the organisation in the next two to three years. I am very much relying on WA's economy as well, especially in consulting (P16).

This is a very big company; there are a lot of opportunities within the company. There are opportunities even if I want to go overseas, because they have many offices (P26).

According to participants, working for an organisation in WA during the resources boom was also an opportunity for potentially exciting challenges $(n=11)$ and for learning and professional development $(n=14)$ :

(This company) is very dynamic; it is very fast. They had plans, and they succeeded in implementing things that they were told they couldn't do in 10 years. They did them in 18 months (...) (this employer) went full steam ahead fast track, and I wanted to get in on the ground and make my mark, and set things up the way I knew it should be set up. So I applied to work here. I chose them. I wanted to work for this employer (P06).

It was a global kind of outlook for me so this was what really interested me. You know, we are the kind of people that wanted the option to travel and this kind of stuff. So that was what I was looking for. And I had worked for government agencies in the UK, and it was the most boring time of my life! So I wanted something a little bit more, you know, exciting, challenging (P07).

Therefore, as can be noticed in the fourth column of Figure 5.1, HSIs' PCs seem to be mostly grounded in normative expectations. Employers have not made explicit promises or any suggestion that could be perceived as a promise, but individuals created expectations from what they perceived to be normal practices around them. Their expectations emerged mostly from the context in which their employment relations were embedded. 


\subsection{What type of psychological contract do they have?}

As discussed in Chapter 2, the literature on skilled migration has previously revealed that assigned expatriates (AE) and skilled professionals in self-initiated expatriate assignments (SE) hold significant differences regarding career goals, expectations and outcomes in their employment relationships (Andresen et al. 2012; Biemann \& Andresen 2010; Inkson et al. 1997; Jokinen et al. 2008; Suutari \& Brewster 2000). AEs are skilled individuals assigned to international jobs (or projects) by their employers on a temporary basis (Inkson \& Khapova 2008). SEs are those who migrated independently of any employer and without any organisational assistance, to be hired under a local contract (Biemann \& Andresen 2010; Inkson et al. 1997).

Following this body of work, the sample in this study was distributed into two different groups according to their visa arrangements. Individuals who migrated to Australia with a subclass 457 visa, a business long-stay visa category designed to assist Australian employers in filling skilled vacancies that they had been unable to fill through local employment, were considered to be in an expatriate assignment $(\mathrm{AE})^{3}$. This was because of the nature of their contract, the temporality of their assignments, and the support received by their employers.

Those who migrated to Australia through the skilled independent category in the skill stream of Australia's migration program (that is, individuals who migrated independent of any employer) were considered to be in a self-initiated venture (SE). For the purposes of analysis, the following individuals were also considered under the SE group: those who applied for PR after completing postgraduate studies in Australia; those who arrived with a New Zealand passport; and those skilled individuals who held a spouse visa.

Findings from Phase 1 suggest that features of individuals' PCs are commonly related to the presence (or absence) of visa sponsorship. The discourse from the SE group was very much marked by long-term commitment to their employers and specified performance terms. Although these HSIs displayed high levels of commitment to project success and to their teams and were very conscious about the key performance indicators (KPIs) they had to achieve, their testimonials did not reflect emotional

\footnotetext{
${ }^{3}$ Only one of the 457 visa holders in the sampe was sponsored by his employer onshore, and was likewise included in this group for analysis purposes.
} 
attachment to their employers, following Rousseau's (1995) classification of balanced contracts. SEs shared organisational values and goals; however, they were more concerned about the effects of their current projects and roles on their careers, reputations and professional objectives:

Definitely I feel committed to stay for a while, because to be really honest, I don't know how long it will take till I can find a similar job, this size of investment, this size of project! (I'd like) To probably perform a job in the best possible way, complying with the company's procedures, to be part of the team, somehow - the organisational team - and to do my best to ensure the project is successful (P04).

On the other hand, feelings of loyalty and gratitude were common among those who came to Australia with a sponsored visa. AEs acknowledged the role their employers had in their migration process, expressing appreciation and reporting a positive emotional connection to them (Adler \& Fagley 2005). Participants also clearly expressed loyalty to their employers as a practical disposition to continue in a valued associational attachment to their organisations (Kleinig 2007). AEs' loyalty to their employers was justified by a perception of employer 'generosity' in providing support during their migration process to Australia. The discourse of the AE group, therefore, more closely resembled relational contracts (Rousseau 1995), involving ideas of socioemotional exchanges, implicit promises, loyalty and appreciation:

As I said, my relationship with them exceeds the professional, you know. I now have them as my friends, you know. They are investing in me as well (P01).

This relationship is very special; it is very trustful, and my obligation is loyalty I think. I wouldn't just hand in my resignation and leave (P14).

I have a great deal of gratitude for the people bringing me over here (...) It is still the place where I want my children to be able to play in the park, and I think the gratitude comes from there $(\mathrm{P} 20)$.

Figure 5.2 below shows a pathway extracted with Leximancer software. In Leximancer, pathways are intended to describe the most likely relationship chain between two concepts and to display stories that emerge from the text (Leximancer 2011). In practical terms, when selecting two concepts with this tool, Leximancer indicates the stronger trail between them. This output reflects the loyalty and gratitude commonly expressed by the 457 visa holders, and this pathway suggests that in Phase 1, there was a feeling of loyalty and gratitude among sponsored immigrants stemming from their psychological contracts and their perception that their employers helped them to come to Australia. 


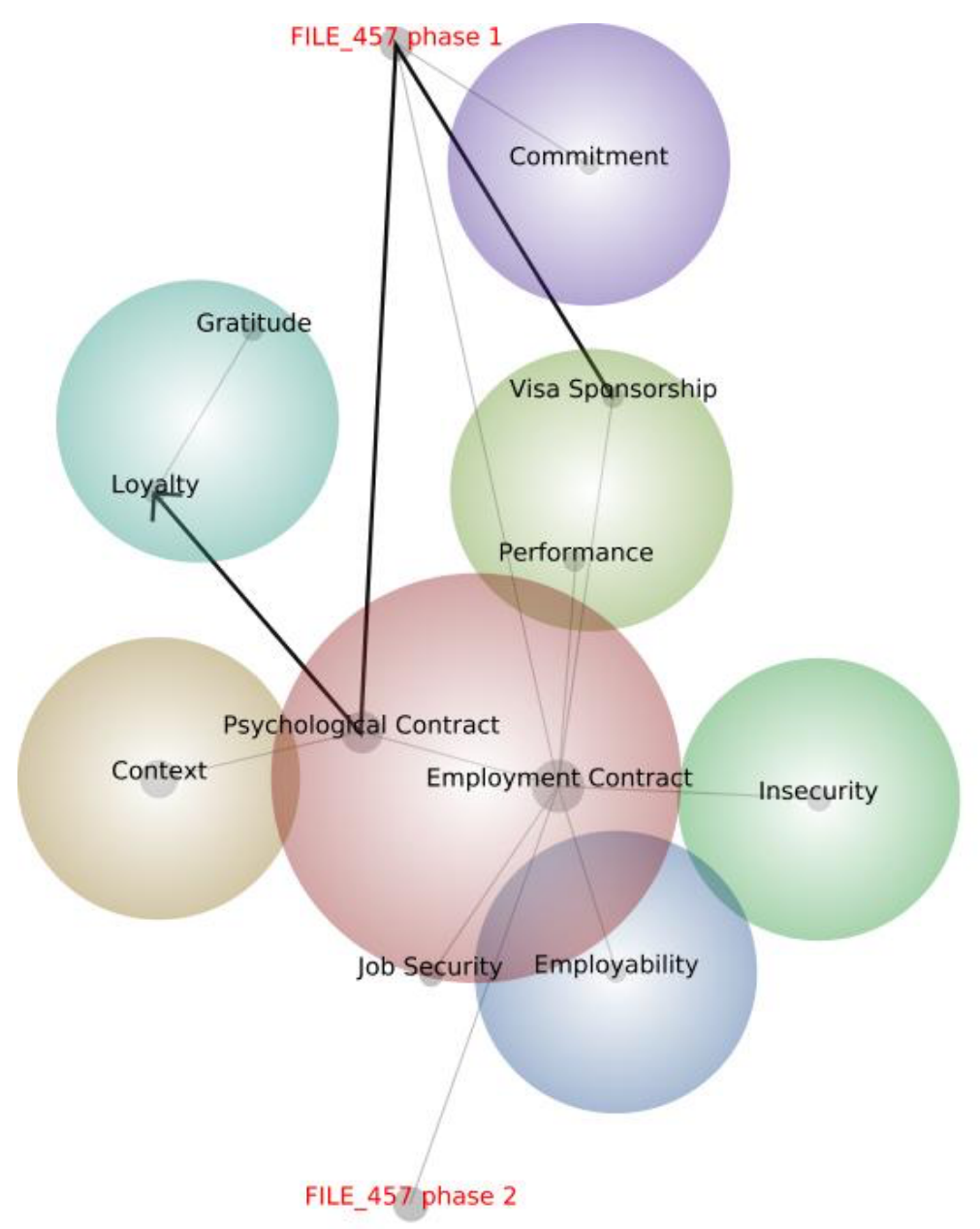

Figure 5.2. Leximancer output - Phase 1 - loyalty and gratitude in visa sponsorship (457 visa holders).

Finally, there was little $(n=3)$ evidence of transactional contracts among this group of HSIs. According to Rousseau (1995), transactional contracts are those of limited duration with very specific performance terms. They are short term, and the exchange is monetarily-based with explicit negotiation terms (Conway \& Briner 2005). In this sample, the examples of transactional contracts were only found among part-time employed women who were juggling professional activities with their family roles:

I don't have loyalty to the university because I don't have a contract with them past these six months. So at the end of the six months, I can turn around and say, "Thank you for the opportunity but goodbye". So doing what they are paying me to do and doing that well, providing a quality service, I don't think there is any other obligation (P11). 


\subsection{What do HSIs perceive to be breaches in their psychological contracts?}

\subsubsection{When the employer breaches the contract}

In Phase 1, there were only two circumstances in which participants reported a breach of what they expected from their employers. First, an individual in a mid-level position working for a large Engineering, Procurement, Construction Management (EPCM) company acknowledged that she expected mentoring, leadership and training from her employer, but had to be 'hands on' sooner than anticipated:

I've ended up kind of, I guess, holding a lot of knowledge in the name of the team, when actually I came not knowing anything and expecting to learn. So the role is all reversed (...) The whole 'psychological contract', when I signed up to the job, was that I was going to learn and grow from others. And now others are learning and growing from me and I don't feel ready for that (P05).

In the second case, a senior professional working for one of the largest shipyards in Australia reported that she expected her employer's support for a $\mathrm{PhD}$, which would involve hours of studying a topic relevant for the business, but this support was not offered. As she described:

\footnotetext{
I enrolled for a PhD with a topic that should be very interesting for the company I was working for, and I was hoping I would have (my employer's) support, but it didn't happen. Regardless of that, I was expecting to have at least some time, which they would give me; that also didn't happen. The workload was bigger than ever, and I ended up working on my PhD during the weekends. After a year like that, I just figured that was impossible. So in a way, I was disappointed with them, and because they are the biggest company in the industry in Western Australia, the only option was actually to look for other alternatives, and the closest alternative was actually moving to the offshore industry (P26).
}

While these are different situations, both P5 and P26 reported a procedural violation of their PCs, as they perceived unfair organisational processes (Pate et al. 2003). They contended that their employers were not able to fulfil their expectations because they were 'stretching' the use of their human resources. P5 particularly acknowledged managerial failure in her situation of breach; P26, on the other hand, recognised the influence of the skills shortages in her industry and the resulting lack of qualified professionals to support or substitute her while in professional development activities:

The person who employed me, he left, and there were a couple of other people that left and the team dynamics changed (P05).

(This employer was) very busy in interior design, and they didn't have resources (P26). 


\subsubsection{When expectations about the labour market are not fulfilled}

Most perceptions of breach reported during Phase 1 seemed to result from a clash between individuals' experiences in WA's labour market and their pre-migration expectations. Their pre-migration expectations were not formally promised by anyone, but were normative expectations built on the assumption that Australia would present them with opportunities.

These expectations resulted from the message that participants received from the WCFs - not only from WA's government, but also from industry organisations, employers, newspaper articles, migration agents and their own personal and professional networks. These expectations were grounded in an image of Australia as a land of opportunities with a severe deficiency of skilled professionals and an open door for those who checked all the boxes. In WA, immigration policy settings had been adjusted to accommodate a boom culture. The government, industry representatives and organisations had made major efforts in order to attract temporary and permanent skilled migrants to address current and future labour market constraints (CCIWA 210; DTWD 2010, 2011):

Our labour shortage is extreme (...) We are faced with the prospect of being short hundreds of thousands of workers by 2015 - Peter Collier, West Australian Training and Workforce Development Minister, in 2011. (Rout 2011)

In 2010, the State government launched its own framework for addressing future labour needs - 'The Western Australian Skilled Migration Strategy' - supplementing a number of other efforts that were in place at the federal level. As described by a representative of the Department of Training and Workforce Development (DTWD) during an interview conducted for this research in May 2012, the government was using a message substantiated by professional opportunities and lifestyles in WA to attract individuals who could supplement the local workforce with the skills and expertise demanded by the State's industries:

So the message is that the whole economy is growing; that we need skilled labour, which I guess is the primary message, and the secondary message and the attractive message is that it is a great place to live. And you can look through the portal and it talks about all the different lifestyle factors I guess we are promoting (DTWD representative).

Some HSIs in the sample who came to Australia with no job, in a self-initiated venture, found that obtaining a good job in Perth was not as easy as initially expected $(n=4)$. 
Only one of the participants recounted taking longer than six months to get his first job in Perth. However, some participants $(n=9)$ reported taking a step back in their careers in order to jump-start their trajectories in WA's labour market:

(Talking about her husband, an accountant) I think it has been quite demoralising for him. In South Africa, he was headhunted; here, he has not even been shortlisted for a position. I think we were not expecting this, because when you come in with a skills visa, I mean, your accounting skills, your teaching skills, are some of their requirements skills. It is where we get points, so this only creates the expectation that your skills are required, so you'll be sorted out after that. That is why you've been led into the country, and it doesn't quite happen like that (P11).

We hoped it would be the same, but it wasn't. They knew we had the experience, that we could do the job; but (the employer) put you back 10 years, because you don't have any experience here, because they value an Australian experience (P18).

Participants' disappointment with the labour market reality in WA is in accordance with research previously conducted in Canada, where "overly optimistic employment expectations" created by the Canadian point system and not adequately mediated by migrants' networks have been creating a general feeling of frustration and unmet anticipations (Somerville \& Walshworth 2009, p. 155).

\subsection{What are the outcomes of HSIs' psychological contracts?}

Phase 1 of this study sought to explore the outcomes of HSIs' PCs on their willingness to engage productively and stay in WA. As stated in Chapter 3, there were no outcomes proposed apart from the broad attitudinal and behavioural outcomes identified in previous research on PCs (Coyle-Shapiro \& Kessler 2000; Guest 2004a; Kickul et al. 2004; Nelson et al. 2006). However, the findings from this phase of research suggest that there are three key outcomes that emerge from the HSIs' PCs: commitment, loyalty and gratitude.

Commitment is a psychological state that characterises an employee's connection with an organisation and has implications on their decision to continue or discontinue the employment relationship (Meyer \& Allen 1991, p. 67). The construct has been explored widely in PC research (Cassar \& Briner 2011; Schalk \& Roe 2007; Sturges et al. 2005), especially in relation to PC breach and violation (Lapointe et al. 2013). Regarded as a quasi-standard research approach, the Organisational Commitment Model by Meyer and Allen (1991) has dominated commitment research in past decades (Freese et al. 2011). It ties together three aspects of earlier commitment research, the work of Buchanan 
(1974), Wiener (1982) and Mowday and colleagues (1982), in conceptualising organisational commitment as a three-dimensional construct consisting of affective, continuance and normative commitment.

Affective commitment refers to an individual's emotional attachment to and identification and involvement with an organisation (Meyer \& Allen 1991). It also encompasses a component of desire, as individuals enjoy their membership (Freese et al. 2011) and 'want to' give continuity to it (Meyer \& Allen 1991, p. 67). Continuance commitment is based on a perceived cost-benefit assessment of maintaining or leaving organisational membership (Freese et al. 2011). Those whose primary link to an organisation is grounded on continuance commitment remain with the organisation because they 'need to do so' (Meyer \& Allen 1991, p. 67). Aspects considered in this cost-benefit assessment may involve social costs (such as status or network) and economic costs (such as pension accumulation). Normative commitment refers to a feeling of obligation to stay in the organisation (Freese et al. 2011). Those with a high level of normative commitment feel that they 'ought to' endure in their relationship with the organisation (Meyer \& Allen 1991, p. 67). A number of organisational investments - in one's training or even migration sponsorship, for example - may create a feeling of obligation in repaying a debt to the organisation (Wiener 1982), thus creating a normative commitment.

While the three different types of commitment - normative, affective and continuance commitment - could easily be identified throughout participants' narratives, continuance commitment was the most common outcome to emerge from the sample during Phase 1. In their cost-benefit assessment process, HSIs commonly took into consideration the professional opportunities the employer could offer, the potential networks, the organisation's reputation (as their first professional experience in Australia) and the significance of projects in which they were involved. Individuals felt like staying with their employers so long as doing so was beneficial to their careers:

Well, my current job gives me a lot of visibility in the workplace because it is a very large project with a lot of challenges. That's why it is a tough job; but at the same time, doing it well, I know that it will look very good on my resume. It is an open-ended relationship in my case (P17).

Participants with visa sponsorship more commonly expressed affective and normative commitments. Some HSIs with 457 visas expressed not only the desire to continue in the employment relationship, but also a strong emotional attachment to their employers. 
These expressions of affective commitment were commonly associated with the other two outcomes noted in the first phase, that of gratitude and loyalty.

Gratitude is described as consistently feeling and expressing the emotion of thankfulness across situations and over time (Emmons \& Crumpler 2000). Based on the work of Roberts (1991) and Berger (1975), Emmons and Crumpler (2000) asserted that the most essential feature of gratitude is its response to perceived benevolence; a behaviour arises from grateful feelings in response to the perception of others' generosity in providing help during a given situation. Emmons and Crumpler (2000, p. 58) portrayed gratitude as a relational virtue that involves strong feelings of appreciation and debt towards significant others. This perspective emerged from the ideas of moral philosophers, such as Adam Smith (1976 [1790]), who suggested that human emotions exist to provide individuals with direction for moral judgement and behaviour.

Adler and Fagley's (2005) approach to gratitude is most useful in exploring the thesis context; that is, the recognition of others in both the immigration process and the impact of migration on one's career. Gratitude, from Adler and Fagley's (2005) perspective, is a component of appreciation, defined as acknowledging the value and meaning of something and feeling a positive emotional connection to it. The gratitude aspect of appreciation, therefore, refers to noticing and acknowledging a benefit that has been received; it means feeling thankful for the efforts and actions of another (Adler \& Fagley 2005, p. 83).

Thus, the findings from Phase 1 suggest that participants' responses usually reflected an emotional attachment to their employers, along with thankfulness for different situations - visa sponsorship and professional development, for example:

This (employer) has given me so many good opportunities. Not only when I was transferred here, but before then. So I always had the feeling that I am committed to them, because I think what I am, who I am, and all of the benefits that I have, there were so many opportunities... I feel all the time that, you know, I am very lucky and this brings to me naturally some commitment, to be able to return what (my employer) has invested in me (P15).

On the other hand, organisational investments - in one's training or migration sponsorship, for example - sometimes created among the HSIs a feeling of obligation in 'repaying a debt' to the organisation. Individuals felt like they 'ought to' sustain their employment relationship because they needed to return what the employer had invested 
in bringing them to Australia:

When you have a sponsor, you have to be attached to that company for a certain period of time - in my case, four years. It doesn't stop me from taking an opportunity in another company because they can transfer my visa, but I have a kind of moral obligation (P01).

For me, saying that I am going to another company, I do have that feeling that after all the effort that they put in my development... I feel a bit like "No!" (P09).

This outcome thus more closely resembles that of loyalty. Loyal employees tend to continue in an intrinsically valued associational attachment with their employers, an attachment that involves a commitment to secure or at least not to threaten the interests of their organisations (Kleinig 2007). The associational obligation of loyalty is its most important aspect. According to Kleinig (2007), loyalty arises from the intrinsic value that the association has come to have for the loyal person, besides the sense of identification that it expresses.

Along with gratitude, loyalty is commonly described as a virtue in the philosophy literature. Josiah Royce was one of the first philosophers to write about the subject, and in his 1908 book, The Philosophy of Loyalty, he defined loyalty as the "willing and practical and thoroughgoing devotion of a person to a cause" (Royce 1908, p. 16). More recently, loyalty has been classified as an executive virtue, or a "virtue of the will"; one that assists a person in carrying out projects and duties, such as sincerity and courage (Kleinig 2007).

In the psychology and management literature, loyalty is frequently discussed as part of the theoretical framework of exit, voice, loyalty and neglect (EVLN), originally developed by Hirschman (1970) to classify individuals' reactions to dissatisfaction with their employment relations. Hirschman's (1970) EVLN suggests that employees have four ways of dealing with a company when their relationship is in decline: (1) they may leave the organisation altogether (exit); (2) they may stay and take the initiative to move the organisation in a desired direction (voice); (3) they may neglect the organisation with absenteeism, lateness and less attention to quality (neglect); or (4) they may stay loyal to the organisation, engaging in extra roles and organisational citizenship behaviour (loyalty) (Turnley \& Feldman 1999). Hirschman's framework has been applied in PC research to explain individuals' reactions to psychological contract violations (Turnley \& Feldman 1999; Freese et al. 2011). 


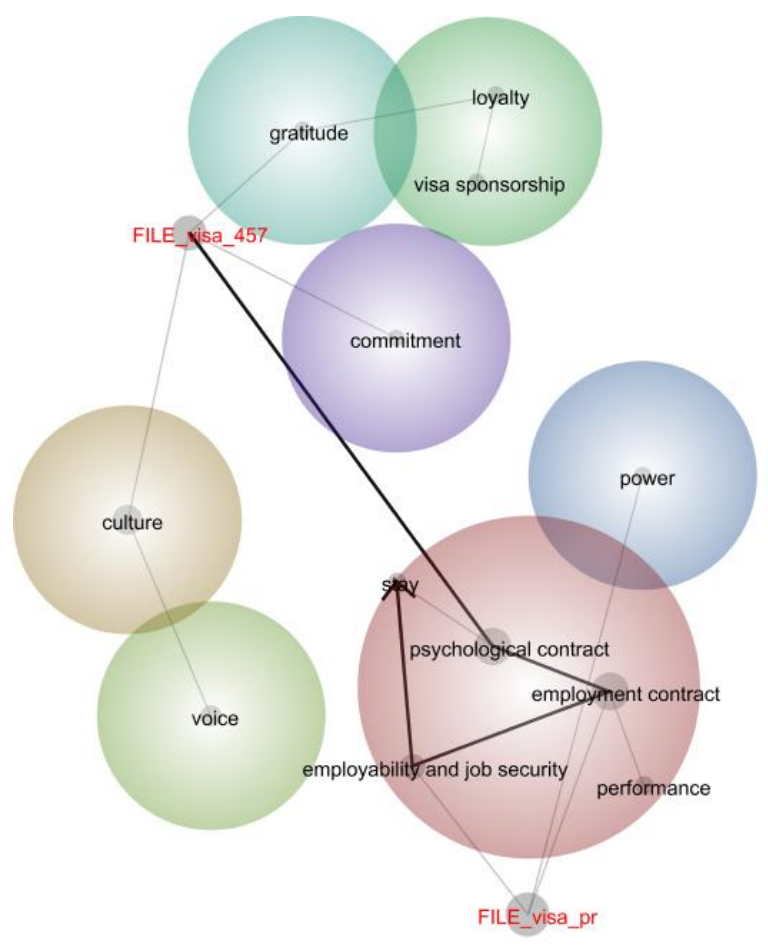

Figure 5.3. Leximancer output - Phase 1 - outcomes from PC (457 visa holders x participants with PR).

In terms of these outcomes, Figure 5.3 depicts Leximancer output in which main clusters of concepts from Phase 1 were plotted. As can be seen, this concept map reflects the proximity of gratitude and loyalty to visa sponsorship and, unsurprisingly, to the group of participants holding a temporary 457 visa. It is interesting to note that commitment, on the other hand, is clustered in a warmer colour, which denotes that this is a more relevant outcome, and is represented in a slightly more central position between the two groups of HSIs.

\section{Conclusion of the chapter and theoretical revisions}

This chapter presented research findings in light of the political-economic context in WA from 2010 to 2012, when the first phase of interviews occurred. Findings from Phase 1 focused particularly on HSIs' PCs: their expectations of employment relationships, their perceptions of promises and obligations, their emotional attachments to their employers, and their viewpoints of perceived breaches. This chapter also presented the group's reasons for choosing WA as a destination.

Findings from the first phase of this study suggest that, in the case of HSIs in this sample, their mobility was mostly work-motivated. Even when these individuals did not come to WA with a sponsor and a job, labour market characteristics and perceptions of 
opportunities in the State played an important role in their decision-making process. Their reasons for migrating and observations of WA's economy reflect their preliminary expectations of the labour movement, despite their employers or employment arrangements. These anticipations, in turn, seemed to affect their expectations with regard to their employment relationships.

Results also indicate that HSIs' PCs are mostly grounded in normative expectations (Roehling 2008). Participants' expectations are usually related to the professional opportunities - for career growth and professional development - that they perceive as normal practices around them, at an organisational level or even outside the company's borders. These expectations do not arise from corporate promises, and these perceptions go beyond the corporate border because of individuals' awareness of the context in which their organisations and the labour market are embedded.

The significance of contextual factors is reinforced many times throughout the participants' quotes in Phase 1. They influence not only what is expected from WA (i.e. their reasons for migrating, as discussed in Chapter 2), but also what is expected from employers and what is perceived as a PC breach. Ultimately, the existence of a sponsorship relationship between employer and employee seems to drive the type of attachment the employee will have with his or her employer-sponsor, and eventually any outcomes from there.

The findings suggest that the behavioural and attitudinal outcomes that these individuals express in their employment relationships, as well as their perceptions of their obligations to their employers, are related to the presence (or absence) of visa sponsorship. Individuals who came to Australia with 457 visas, and were therefore sponsored by their employers, tend to express commitment (Meyer \& Allen 1991), gratitude (Emmos \& Crumpler 2000) and loyalty (Keinig 2007), and also tend to hold a relational type of PC (Rousseau 1989). These will be explored further in Phases 2 and 3.

Chapter 6 presents the longitudinal findings, focusing on changes in HSIs' PCs over time. It illustrates these changes with data from both Phases 2 and 3. These two subsequent rounds of interviews were aimed at providing the researcher with an opportunity: (1) to develop a deeper understanding of HSIs' PCs by considering how shifts in WCFs influenced their PCs, the state of the PC, and outcomes; and (2) to negotiate meanings and validate the researcher's interpretations with participants. 
As Chapter 6 will reflect, Burawoy's (1998) approach towards the research process - as the method of collecting multiple readings of a participant's situational experiences and aggregating them into social processes - allowed for a dynamic rather than static approach to engaging with research findings. Polanyi's (1957 [1944]) interpretation of embeddedness has assisted in highlighting the aspects within WCFs that should be addressed - that is, globalisation, neoliberal philosophy and the swings and shifts in policy regimes and regulatory responses towards labour migration in Australia and WA.

From drawing on both Polanyi's (1957 [1944]) principle of embeddedness and the ECM (Burawoy 1998) to guide the qualitative longitudinal research design used in this study, a significant implication for methodology emerged. Rather than generalising findings and discovering new theory, as is the case with both positivistic research and interpretive genres such as action and grounded theory (Burawoy 1998), the use of the ECM principles of process, structuration and subsequently reconstruction required responding to new findings and conceptualising these during the research process (Burawoy 1998, 2009) to further explore with participants before concluding the research process (Saldaña 2003). Thus, the outcomes of commitment (Meyer \& Allen 1991), gratitude (Emmos \& Crumpler 2000) and loyalty (Keinig 2007) that emerged in Phase 1 have been conceptualised and included in the conceptual formulation used to guide Phases 2 and 3 in the process of data collection.

However, while the WCFs in Phase 1 promoted outcomes of commitment, gratitude and loyalty, which can be interpreted as reflecting a desire to continue to contribute to their organisations (Meyer \& Allen 1991) and a continued attachment to organisational interests (Kleinig 2007), as the researcher was preparing to conduct Phase 2 of data collection (2012), newspapers emphasised layoffs in many of the interviewees' organisations. The WCFs in WA had started to shift (see section 2.3.3), and the feeling of insecurity became prominent in interviews with HSIs recruited for the study.

To continue to explore the research questions and propositions - and in particular RQ2 - two further foci were added to the overall framework originally described in Chapter 3, which has since been amended as a result of the Phase 1 findings (see Figure 5.4 below). 


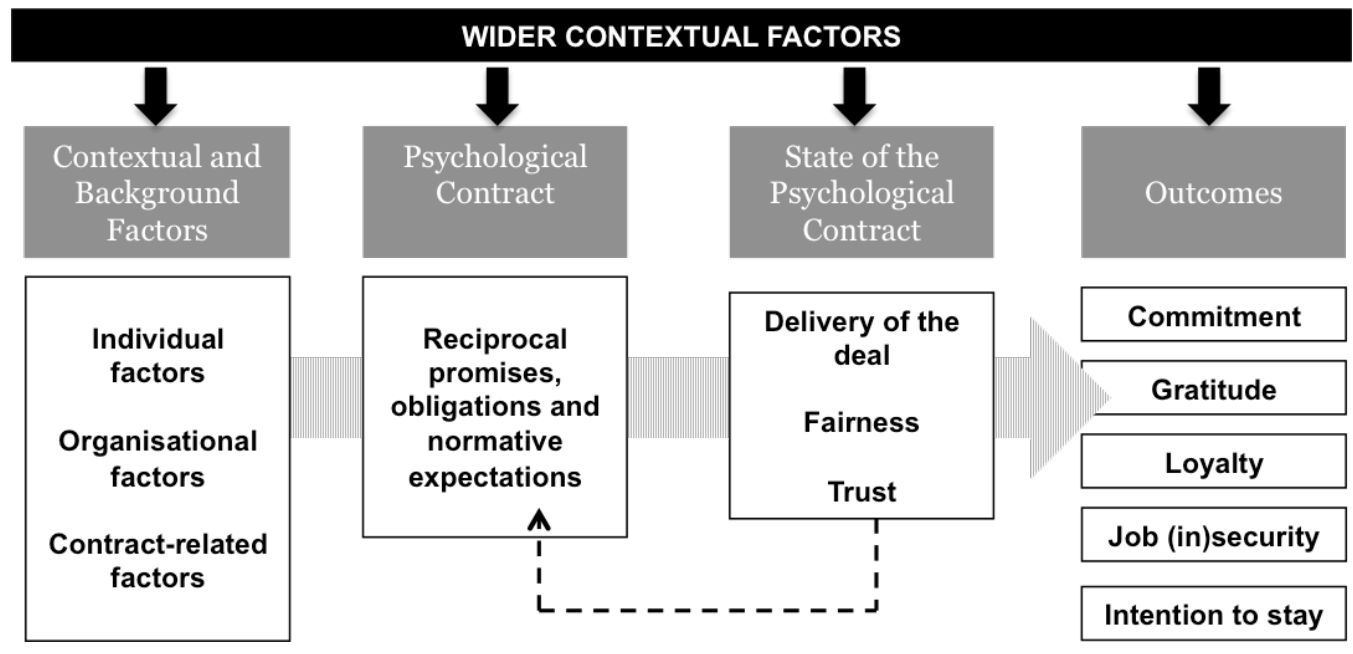

Figure 5.4. Conceptual framework guiding this research.

The first focus was to explore HSIs' intended relocation pathways (Roberts 2011) in order to assess RQ2 (How do highly skilled immigrants' (HSIs) psychological contracts (PCs) impact their intentions to stay in WA?). However, the concept of intended relocation pathways (Roberts 2011) in this research not only refers to intentions to physically relocate elsewhere, but also to the intentions of participants to 'relocate' their career by enhancing their human capital through training or even self-employment (Dickmann \& Harris 2005; Suutari et al. 2013).

The second focus was to explore job insecurity given the emergence of this trend in the WCFs (see Appendix 2). Perceived job insecurity is a contemporary work stressor that affects individuals' mental and physical health. As Strazdins and colleagues (2004, p. 297) have described:

Uncertainty about the future, the personal and financial ramifications of job loss, and the perceptions that one's job is on the line could erode employees' capacity to cope with job strain (high demands and low control) and constrain their ability to negotiate better conditions.

Studies have already used the PC to explore the feeling of job insecurity among employees. Beaumont and Harris (2002), for example, have used the PC to investigate white-collar downsizing and the violation of employment security in the UK. McDevitt and colleagues (2013) focused on understanding the perceptions of both 'survivors' and 'victims' in downsizing strategies in American organisations as a result of the recession that hit the country in 2007. Katou (2013) investigated the impacts of the most recent economic crisis in Greece on employees' feelings about their employment relationships.

This literature has claimed that during times of economic crisis, organisations typically 
dismiss their employees in order to be more cost-efficient (Campbell 1997; Katou 2013; McDevitt et al. 2013); this, in turn, creates a general feeling of job insecurity among their workforce (Berntson et al. 2010; Katou 2013; Sverke et al. 2006). Job insecurity refers to the perception of a threat of job loss and an individual's powerlessness to maintain desired continuity in a vulnerable job situation (Greenhalgh \& Rosenblatt 1984). The experience of job insecurity is individual and subjective, and is mostly based on an involuntary change from a secure to a non-secure situation (Sverke et al. 2006).

Research has also found that when skilled employees no longer experience the feeling of lifelong job security, they shift their focus away from the organisation and towards their own career development, assuming responsibility for maintaining their own security and for developing their own careers (Baruch 2001; King 2000). As a result of escalating insecurity in contemporary workplaces, employees have been increasingly focusing in developing new skills, so they can increase their employability in external labour markets in the event of dismissal (Katou 2013). Thus, being employable in an occupation of choice became dependent on an individual's own level of control over their accumulated human capital and learning and development trajectories (Kanter 1993).

This approach towards individuals' accountability for their own human capital development, however, is believed to neglect the social and economic structures that constrain the quantity of labour and the particular skills that are actually in demand (Dobbins et al. 2014; Keep and Mayhew 2010). It disregards the idea that the availability of skills in a given labour market does not automatically create its own demand for employers to use it (Dobbins et al. 2014). It also disregards the reality, that is, the labour market is not formed by mobile, high-powered knowledge workers (Thompson 2003).

To investigate individuals' perceptions of job security in this study, the guidelines for the second interviews were adjusted (see Appendix 2) to explore the severity of the threat (of losing a job in Australia) and the individuals' response as proposed by Greenhalgh and Rosenblatt (1984). These dimensions have been applied elsewhere (e.g. Ashford et al. 1989; Berntson et al. 2010), including in PC research (King 2000). The first dimension refers to the severity of the threat to stability in a work situation. This depends on the scope and significance of the potential loss, as well as the subjective probability of the loss occurring (Greenhalgh \& Rosenblatt 1984). The second 
dimension refers to the individual's response. Greenhalgh and Rosenblatt (1984) suggested that this is generally a sense of powerlessness. To explore this, it is suggested that research collects individuals' perceptions regarding forms of protection, organisational procedures for dismissal, organisational culture and the employees' own expectations (Greenhalgh \& Rosenblatt 1984).

Thus, while continuing to assess the outcomes of commitment (Meyer \& Allen 1991), gratitude (Emmos \& Crumpler 2000) and loyalty (Keinig 2007) that emerged in Phase 1, during Phases 2 and 3 the interview guidelines (see Appendix 2) were adjusted to explore the intended relocation pathways (Roberts 2011) and the perception of job insecurity (Greenhalgh \& Rosenblatt 1984) among participants (see Appendix 2). 


\section{Chapter 6 - Findings (Phases 2 and 3): The PCs of HSIs in 2013-2014}

\section{Introduction}

I see Houston booming where Australia is in a slump, which I don't see changing in the next couple of years (P06).

This chapter reports findings from the second and third phases of this study, with particular focus on changes that occurred in individuals' experiences and perceptions over time. In 2013, repeated interviews were conducted with 12 of the individuals who had previously participated in Phase 1. In 2013, another 14 repeated interviews were conducted. This allowed at least two interactions with a group of 16 highly skilled immigrants (HSIs).

As previously described in Chapter 2, WA's labour market faced significant changes from the second half of 2012. Australia's resources industry was hit by the slowdown in China's economy, which in turn resulted from the recession in Europe and weak economic growth in the US (Corben 2012). When Chinese demand declined, commodities prices dropped, putting pressure on WA's economy (Fitzgerald 2013; Uren 2013). The combination of low commodities prices and high operational costs in both the mining and oil and gas industries (ABS 2014), along with a general feeling of economic and political uncertainty (Hogan 2013), led to projects being shelved and dismissals in many economic sectors. It also led to a decrease in the intake of immigrants under the temporary work (skilled) (subclass 457) program (DIAC 2013a).

As expected, participants' general perceptions regarding WA's labour market differed greatly from their narratives in the initial phase of this research. Therefore, findings in this chapter are particularly focused on the rise of these different perceptions among HSIs - no longer a perception of opportunities, but a perception of insecurity. Findings also focus on the impacts of these changes on individuals' expectations and outcomes with their employers and WA's labour market. This chapter combines findings from Phase 2 and Phase 3 because the enquiry was focused on contextual changes, and these changes were noticed by the participants at different moments between 2013 and 2014, depending on their industries and organisations. 


\subsection{Institutional and economic factors impacting HSIs' new perceptions}

Phases 2 and 3 of this research were aimed at exploring the interplay between contextual changes and HSIs' expectations and perceptions in their workplaces. Phase 2 , conducted in 2013, was particularly relevant because at that moment, politicaleconomic circumstances had strongly changed in WA compared to those in 2012. The moment was defined by economic turmoil and massive dismissals in different sectors, as previously discussed in Chapter 2. The political-economic context was repeatedly described by each of the 12 individuals who participated in the second phase:

Companies that require million-dollar projects are striving to survive, and this is very WA-specific because of the way the economy is structured in WA. It is pretty narrow, cashing everything in resources, and the way prices are structured, and the outrageous salaries companies pay in WA (P03).

We can feel that the industry is changing a bit; the company has lost big, big projects very recently, so in terms of expectations... you know, this is not the only (employer) that is having this trouble in terms of work, in terms of projects and everything. Many companies are facing the same (situation) worldwide in this industry (P24).

Institutional and economic factors impacting participants' perceptions were mapped throughout their statements in Phase 2. These were significant issues impacting their observations at that particular time, in accordance with the context recounted by newspaper articles and in governmental and industry reports. The figure below summarises the most significant institutional and economic factors embedding individuals' perceptions during Phase 2:

\section{Institutional Factors}

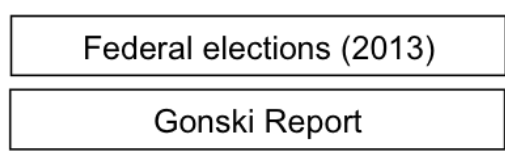

\section{Economic Factors}

\begin{tabular}{|c|}
\hline Funds for education \\
\hline WA's economic downturn \\
\hline WA's dependency on resources \\
\hline Downfall in mineral price \\
\hline Oil \& Gas projects worldwide \\
\hline
\end{tabular}

Figure 6.1. Main institutional and economic factors impacting perceptions in Phase 2.

In the institutional sphere, the 2013 federal elections were a significant factor mentioned by interviewees in the engineering and construction sector. Participants attributed to the elections a number of projects being cancelled or put on hold due to a general feeling of political uncertainty (see Table 6.1). The Gonski Report, a national funding system for 
schools and universities (see section 2.3.3), put extra pressure on the education sector, greatly impacting perceptions and expectations of those working for this industry.

In the economic sphere, WA's dependency on resources industries and the State's economic downturn as a result of the fall in mineral prices was mentioned by most participants, particularly when trying to understand and justify the significant job losses in a number of large firms. In addition to these factors, professionals employed in the oil and gas industry revealed an upsurge in interesting projects in countries other than Australia. Participants' quotes below exemplify ways in which these institutional and economic factors specifically impacted each one of these individuals' industries:

\section{How economic and institutional factors affected industries in Phase 2}

\section{Mining}

In the end, the general feeling is that it was a market change. The price of the mineral came down, the commodity went down, and things are no longer viable; they are too expensive (P17).

\section{Construction}

There are hopes that after the election we will gain some projects, and everything will be more stable (P09).

\section{Oil and Gas}

The things that are affecting it are the government that's in and the voting in September. So I believe it is more to do with that, and people not wanting to take on projects, and the monetary issues around that, and where the work needs to be done. I think the remainder of this year into early next year will be quite a slog in WA for oil and gas (P06).

\section{Consulting}

In terms of the Perth market and the situation here in WA, obviously there is a risk because we rely on (mining) at the moment to a certain extent. We are just getting the purchase orders and stuff sorted for the next financial year, which sees quite a big chunk of our business already secured, which is great news. It is not a guarantee; they (the client) can turn around any day and say, "I cancelled the contract; I don't need you here" (P14).

\section{Manufacturing / Wholesales}

Anything that happens in mining affects everybody in Australia, every single person, because how many people work for the mining and resources sectors? If this person is fired, he doesn't have money to buy small appliances, so everything is linked (P01).

\section{Education}

The funding gap is actually massive (...) So that's the one thing that leaves you with a gap in terms of your funding. The other thing is you just look at the budget deficit that they are having to try and close and there is only one way they are going to close that, and they are going to have to switch things off. Now if they want to put a lot of money into the schooling sector, which is what they are proposing with the Gonski Review, then they are going to have to take it from somewhere. I mean, some of the funding that they have taken out of the higher education sector comes directly off what we get given in terms of the Commonwealth contribution (P25).

Table 6.1. How economic and institutional factors affected industries in Phase 2.

Different institutional and economic factors, therefore, were acknowledged and described by each of these individuals; HSIs were very aware of the effects of these 
factors on their industries and organisations. The rest of this chapter will explore how these HSIs adjusted their normative expectations (Roehling 2008) in this new scenario, and how they perceived breaches in their PCs as an organisational response to these contextual factors, as Chapter 3 has proposed.

\subsection{The upsurge of 'insecurity'}

In 2013, WA's unstable political-economic scenario gave rise to a general feeling of uncertainty among the participants. HSIs' quotes during Phase 2 strongly contrasted with their statements described in the previous chapter, in which their perceptions of opportunities were manifest. In Phase 2, 11 of the 12 individuals reported some level of insecurity in the new context, while two of them had new employment arrangements:

What do I value more in my employment relationship? The fact that I have a job and an employment relationship! It is that bad these days. I don't know the guys you've been talking to and where they are, but it is that bad; it is awful. So the fact that I have a job, I am just happy with it (P03).

They are doing a global restructure so what they do during that process is if there is going to be no suitable role for you here, they may offer you work elsewhere. If you don't take that option, then obviously you would be the same as a contractor; you would need to be finished (...) I don't believe anything is really fully permanent ever (P06).

Two years ago, they were actually looking for anyone with any kind of engineering experience to make an easy transition. Today they have available all these skilled people, so why would they choose someone who has to learn and make a transition? (...) Our main competitor has just made redundant 90 people, just very recently. So things are getting tougher (P26).

Table A8, presented in Appendix 7, presents a longitudinal comparison of changes in participants' perceptions throughout the three phases of this research. The concept map extracted with Leximancer, displayed below, compares Phase 1 with Phase 2 for both groups of HSIs investigated in this study: those who came with sponsored temporary 457 business visas and those who self-initiated their migration experience (SE). 

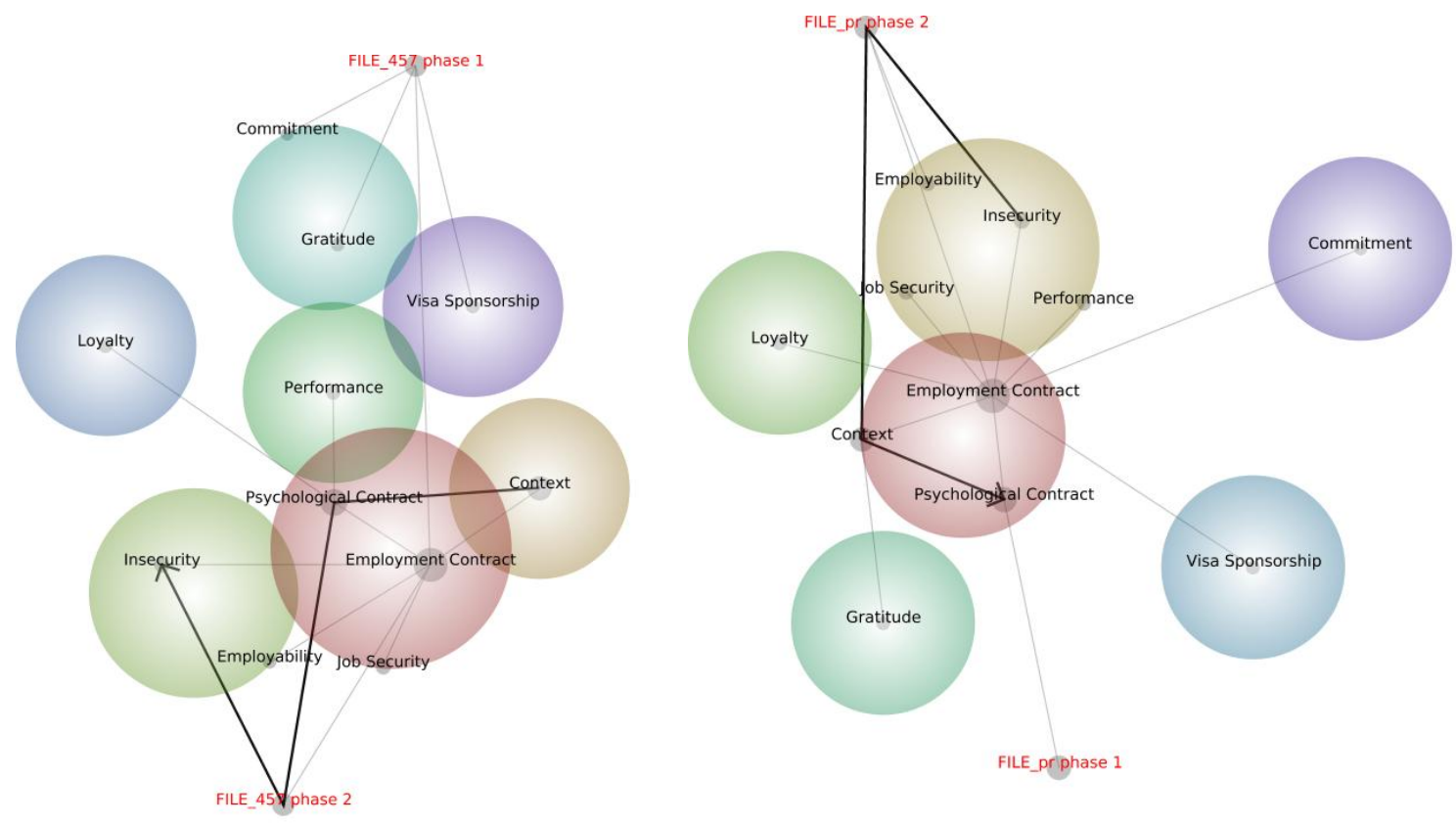

Figure 6.2. Concept maps: 457 visa holders x PR, in Phase 1 x Phase 2 .

In a concept map, clusters of concepts - or themes - are shown as coloured circles on the map. The themes are heat-mapped, meaning that hot colours (red, orange) denote the most important themes, and cool colours (blue, green) denote less important themes. The map above also shows the "categories" (such as the 457 group, in Phase 1) in proximity to their "discriminating discovered concepts" (in this case, some outcomes) (Leximancer 2011).

Naturally, concepts that were classified inside the themes psychological contract or employment contract were the most recurrent ones in both maps; after all, they were the central focus of this research. However, it can be noticed that 457 visa holders predominantly referred to visa sponsorship and emotional outcomes related to the experience of coming to Australia during Phase 1. In Phase 2, the concepts of employability (Kanter 1993) and job insecurity (Greenhalgh \& Rosenblatt 1984) emerged for both groups.

\subsubsection{When expectations about the labour market are not fulfilled}

The severity of the threat of losing a job while in WA and the feeling of powerlessness to counteract it (Greenhalgh \& Rosenblatt 1984) were explored in the second phase of this research. Findings suggest that because of the scope of the loss, the severity of the threat of losing a job was stronger for those with a 457 temporary skilled visa. 
This is because a 457 visa is granted to a skilled immigrant on the basis of employer sponsorship. If there is a dismissal, then the immigrant has 28 days to either find another employer willing to sponsor him or her, apply for another type of visa for which he or she may be eligible (a student visa, for example), or leave Australia altogether (DIAC 2012d). ${ }^{4}$

Therefore, in the case of 457 visa holders, the severity of the threat seemed to go beyond the loss of financial income and the job itself. It involved individuals' - and their families' - personal lives as well, as losing their jobs also meant leaving the country, leaving school and leaving relationships behind. For this reason, skilled individuals who came to Australia with a 457 temporary visa perceived acquiring permanent residence (PR) as an achievement that increased their security. Obtaining permanent residence would eliminate the pressure of having only a few weeks to find a new job and sponsor in case of dismissal:

I mean what concerned me was indeed if you lose your job, you have four weeks to leave the country unless you find a new job. And during that period, obviously, that didn't appear to be that easy (P14).

Obviously, my PR adds me a bit more security. Also, the way that the (employer) sees you, you are now being part of their business, makes them feel more secure as well with us, because they know that we won't be leaving for another job quickly (...) Because we accepted the PR, they know that they have us at least for the next two years, and they are happy with that (P24).

In terms of HSIs' powerlessness to counteract the threat of job loss, findings from Phase 2 suggest that although these HSIs perceived the insecurity in their environments, they did not feel defenceless. Rather, they felt quite in control once they had permanent residence, professional networks and working experience in Australia. These three 'assets' - residency, networks and experience - actually seemed to ensure some level of security for these individuals:

(I have) networks, so I know people; and especially in Perth, it is all about knowing people and having those networks. The second thing is I have been through many different situations during my employment here in terms of negotiating with customers, with employees. You know the working culture, everything around contractual issues; I am responsible for that as well. So while I had the German knowledge, I didn't have the Australia-specific knowledge, and I have gathered that over the last few years (P14).

\footnotetext{
${ }^{4}$ This period of 28 days was amended to a period of three months in an Integrity Review published in 2015. However, this was the 457 visa holders' reality when their interviews were conducted in 2013.
} 
Participants also expressed a strong perception of employability (Kanter 1993), which would complement their feeling of power to neutralise an eventual threat of job loss (Greenhalgh \& Rosenblatt 1984). These individuals repeatedly recounted their strategies to enhance their human capital and value to a potential new employer, such as making an effort to acquire new skills. Therefore, once they had a PR to live in Australia, they felt more in control, because most of the individuals in the sample said they believed in the possibility of finding new employment if necessary:

This is one of the reasons why I took this challenge to manage these three other groups that are not in my professional background: to raise employability. Because once you manage people, it doesn't matter. You have expertise in managing people and selling a product, you can work for a bank, for cars, cigarettes, anything (P03).

My experience enables me to get jobs in my industry because I've got two skills, in both IT and finance. So I've got one up on other people in the same industry as me (P18).

\subsection{Contextual impacts on HSIs' expectations}

As discussed in Chapter 5, HSIs' PCs with their employers were still mostly grounded in normative expectations (Roehling 2008). Even when participants' expectations were thoroughly discussed with their employers, individuals usually did not seem to recognise explicit promises in them:

Yes, I discussed (my expectations) with him (the employer) briefly. I told him my intentions in relation to this company; just like I said to you, the company will grow, and we will grow together, and maybe one day I may become a CFO or something like that. But no... there is no promise in there though ( $\mathrm{P} 01)$.

Figure 6.3 below accounts for the presence of normative expectations and expectations grounded in promises in each of the three phases of this study. 
HSIs' EXPECTATIONS

PHASE 1 (26 individuals)

Normative Expectations

Career Growth \&

Opportunities (16)

\section{Learning \& Development} (14)

Challenge \& Excitement

(11)

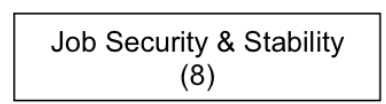

From Promises

\begin{tabular}{|c|}
\hline $\begin{array}{c}\text { Work-Life Balance \& } \\
\text { Flexibility (4) }\end{array}$ \\
\hline
\end{tabular}

PR - Visa Sponsorship

(4)

Financial Package / Bonus (3)
HSIs' EXPECTATIONS

PHASE 2 (12 individuals)

Normative Expectations

Career Growth \&

Opportunities (8)

Learning \& Development

(4)

Challenge \& Excitement
(3)

Job Security \& Stability

(2)

From Promises

\begin{tabular}{|c|}
\hline $\begin{array}{c}\text { Work-Life Balance \& } \\
\text { Flexibility (3) }\end{array}$ \\
\hline
\end{tabular}

PR - Visa Sponsorship

(0)

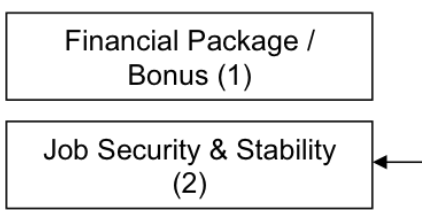

HSIs' EXPECTATIONS

PHASE 3 (14 individuals)

Normative Expectations

Career Growth \&

Opportunities (3)

Learning \& Development

(2)

Challenge \& Excitement (6)

Job Security \& Stability

(0)

From Promises

Work-Life Balance \&
Flexibility (5)

PR - Visa Sponsorship

(0)

Financial Package / Bonus (0)

Job Security \& Stability (1)

Figure 6.3. Highly skilled immigrants' expectations during the three phases of research.

Some participants were consistent in terms of their responses over time, repeating the same expectations at different moments. This was common among mothers with young children (P08, P10, P11), for example. Three of the female employees named 'flexibility' as their main expectation in each one of the three phases, because they needed to juggle professional commitments with school hours and their personal lives. Their expectations were not normative, however, but clearly discussed with their employers and grounded in what they perceived to be an organisational promise regarding a contractual aspect of their employment arrangements (working hours). Yet, for other individuals in the sample, the turbulent political and economic scenario faced by organisations in WA between 2013 and 2014 (Kitney \& Garvey 2013; Janda 2013) greatly impacted what they expected from their employers (P14, P17, P24) as well as their perceptions regarding what their organisations were able to deliver (P01, P09, P25).

Thus, Figure 6.3 reflects what has changed over time: individuals' approaches to job security and their beliefs towards career opportunities. Job security, which was a strong normative expectation during Phase 1 because of the opportunities perceived in the wider context of the WA labour market (Wilson-Chapman 2012), was significantly 
reduced in Phase 2. A normative expectation regarding job security was almost nonexistent from 2013; rather, job security was communicated, or even promised, in very few specific circumstances. This was, for example, the case of P19, who had formal meetings with his leadership about the layoffs happening in his organisation:

(I had) all these meetings with the CEO and the chairman and I was constantly receiving messages and clues and being communicated that "your position is secure", so I had this sense that okay, the company is going through this very difficult process, but I will survive. I felt pretty confident and nowadays I know that my position is secure because they came to everybody who stayed and said "now your position is secure" (P19).

Still, in other cases, individuals' PCs were negatively impacted by their perceptions that management was unable to handle the pressure of a changing environment. Participants reported that employers often used a position of power to reinforce the feeling of uncertainty in the market, thus strengthening their employees' feelings of dependence and subjugation, as well as the imbalance of power in the employment relationship (Cullinane \& Dundon 2006; Guest 2004a). Among the participants, as P09 for example, leadership behaviour reinforced a general feeling of insecurity, impacting individuals' PCs in terms of expectations, assessments and outcomes:

I think it was an intention from (the employer) or from my boss to create a bit of panic, a little bit of awareness about the possibility of losing your job, about you having to be utilised much more... It was really a straight message, that sometimes you can't control these variables, so it made people worried about losing their jobs. So there are all the situations of "whom are you measuring against?" "Can I take holidays?" And so on ... (P09).

Interview maps for all 26 participants can be found in Appendix 8, and these maps particularly reflect shifts in HSIs' expectations in light of their own perceptions about the context around them. Individual cases were chosen as examples of the complex intersection of HSIs' PCs with the contextual environment in which their migration experiences and employment relationships were embedded, and will be detailed in the continuation of this chapter and in Chapter 7. 


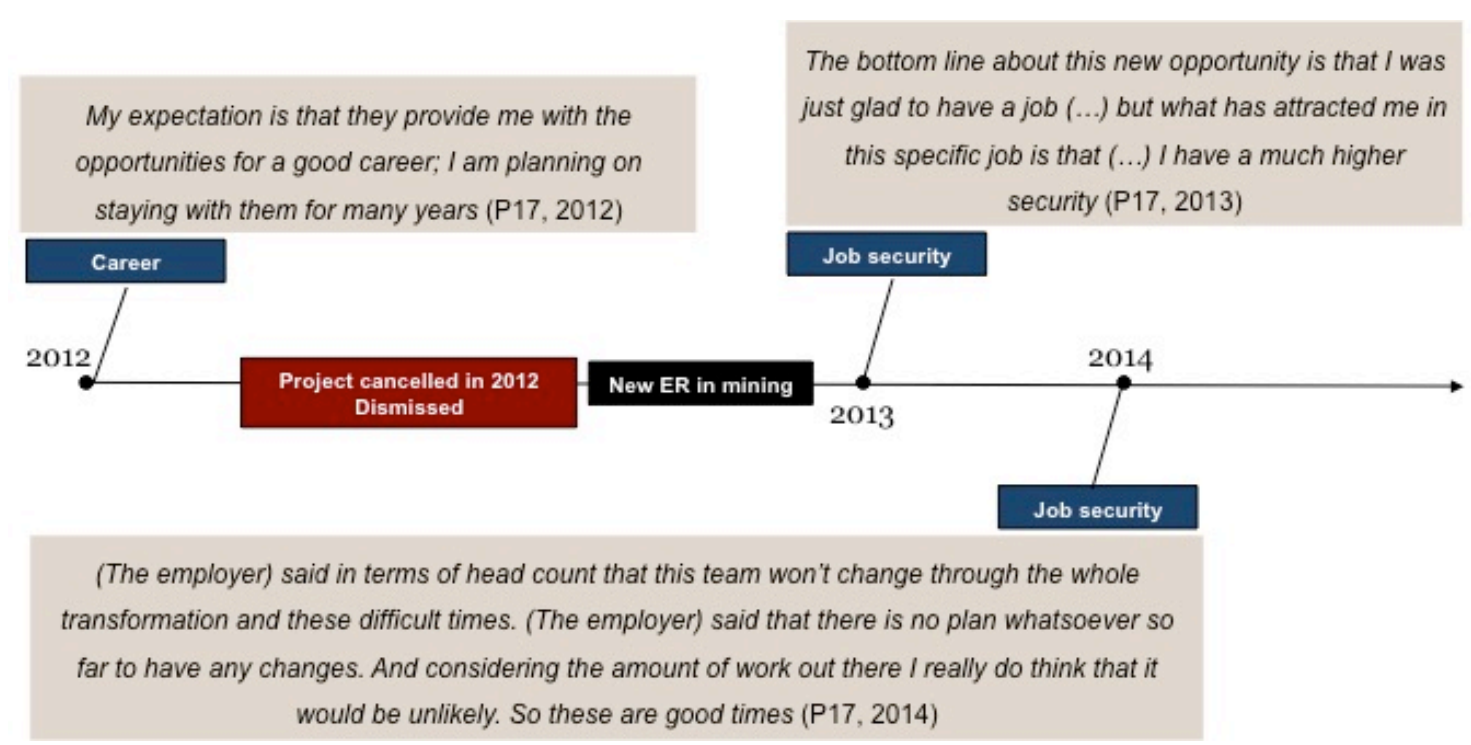

Figure 6.4. Longitudinal investigation of expectations, P17 (male engineer with PR from Canada).

P17 is an engineer who migrated from Calgary, Canada, expecting professional opportunities in a nicer climate and lifestyle. He obtained his Australian permanent residency himself and then contacted his employer asking for a transfer to Perth because the organisation had a number of interesting projects in WA. The project in which he was allocated in Perth, however, was shelved by the end of 2012, and he was dismissed:

I can quite say I am used to that, because this is the nature of engineering work that I do. It is always project driven, and projects are driven by market conditions. When market conditions change, things get shattered (P17).

P17 got another job with a large mining company in Perth. During his second interview, he mentioned that this new opportunity gave him a greater feeling of security because he was no longer allocated to "one big multi-billion-dollar project" but to "several smaller budget projects that need[ed] to happen". However, the downturn in commodities prices greatly affected his second employer between Phases 2 and 3, and this company also made hundreds of employees redundant. P17, however, perceived a clear promise regarding job security. He described how this organisation handled the contextual change and how this expectation emerged as a consequence:

(The employer) left the teams pretty much in the dark for a long time. I think the company itself was also trying to sort out what they needed to do or not, but the feeling that I have at least is that once they figured out the plan that they were going to go for, they came to us and communicated effectively with addressing the 'elephant in the room' and really saying black and white: "This is what's going to happen; these teams are not going to get impacted" (P17). 


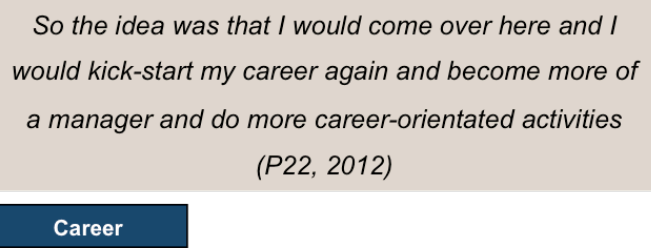

I want less of the stability and more of the challenge (...) Australia is contracting so the job has become a lot less than it was (P22, 2013) Challenge \& Excitement

Moved to Canada

Figure 6.5. Longitudinal investigation of expectations for P22 (female IT Manager with a 457 visa from South Africa).

P22 is a South African IT manager who had been transferred from the UK and sponsored by an $\mathrm{EPCM}^{5}$ group. She accepted the role in Australia primarily because she had a contractor position in the UK, and she was looking forward to having a bit more security and stability; she would have an expatriate assignment in a growing economy, leaving behind the volatile European economy. She had quite an emotional attachment to her employer as well, saying, "I love working for this employer, I really do, and I'll work for them as long as they will have me" (P22).

Her employer, however, had a number of projects cancelled in WA during 2013 in response to the downturn in construction, mining and the oil and gas industries (Hobbs 2012; Ker 2012; Coopers 2013; Urens 2013). Dismissals did not impact her role, but the overall organisational climate did. In her perceptions of breach, she pointed out poor management decisions, disappointment and PC adjustment. Just before Phase 3, she left her employer and moved with her partner to Canada:

We had a pretty badly managed performance review at the beginning of the year, where my expectations weren't met. For me, that was kind of final confirmation that it was time to go (P22).

\footnotetext{
${ }^{5}$ EPCM refers to engineering, procurement and construction management. It is a usual form of contracting arrangement for large projects within the energy, mining and infrastructure industries.
} 


\subsection{Contextual impacts on HSIs' outcomes}

Chapter 5 presented the primary outcomes that emerged from HSIs' PCs during Phase 1 , describing the occurrence of gratitude, loyalty and different types of commitment. In Phases 2 and 3, interviews were aimed at examining whether HSIs' outcomes had changed in response to shifts in their PCs in a different contextual environment. Through the interview maps, Appendix 8 demonstrates the shifts from phase to phase for each of the 26 individuals in the sample. This sub-section discusses the most significant aspects observed.

Participants' outcomes in the workplace indeed changed in the context of market constraints in WA, when their organisations had to reduce costs, decrease their work force and restructure operations, as detailed in Chapter 2. With their employment relationships embedded in a new volatile and unstable political-economic scenario, individuals adjusted their PCs. As previously discussed, they amended expectations and reassessed their organisations' ability to fulfil them. The feeling of insecurity (Greenhalgh \& Rosenblatt 1984) was a new outcome that emerged from these individuals' perceptions and PCs from Phase 2.

The rise of a feeling of insecurity, however, was not the only change in these individuals' outcomes. Although most HSIs showed some commitment in every interview - in some cases, commitment to their employers (P03, for example); in others, commitment to the scope of their projects or to their teammates (P17, for example) individuals' commitments changed over time, usually as a response to adjustments in PCs.

Normative commitment, which was very strong among sponsored individuals during Phase 1, was non-existent among the sample as soon as these individuals got their permanent residency status and finished their two-year obligation with their employers. Affective commitment also seemed to fade during Phases 2 and 3, as participants acknowledged insecurity or PC breaches over time. P14, for example, a sponsored HSI who initially presented strong emotional attachment to his employer and affective commitment towards his job, declared in his second interview (a few weeks before presenting his resignation letter): 
I am a very loyal person (...) and I am still grateful to them (but) if certain things that frustrate you are not overcome, then at some stage, you need to make the hard decision and say, "Okay, it was good, but I need to move on" (P14).

Continuance commitment, grounded in a cost-benefit assessment of the employment relationship, was still strong among part of the sample during Phase 2 and Phase 3. Aspects commonly considered in this cost-benefit appraisal involved trust and fairness, as well as the fulfilment of PCs. More importantly, three individuals in the sample who were promoted and held major management positions in Phase 3 reported that their feelings of obligation and commitment towards their organisations had actually increased with their new roles:

Obviously today, because I have a bigger responsibility, I need to really wear the shirt of the company (...) I have to take the company like on my shoulder and really believe in the company and really be proud of it because I have got to actually be selling their services to clients. Now I think it is even more important that I really believe in the company and I really have this relationship with the company. It is even more important than before (P24).

The cases described next offer a longitudinal perspective on these changes in individuals' outcomes over time.

\section{The case of Participant 03: "Security is a utopia"}

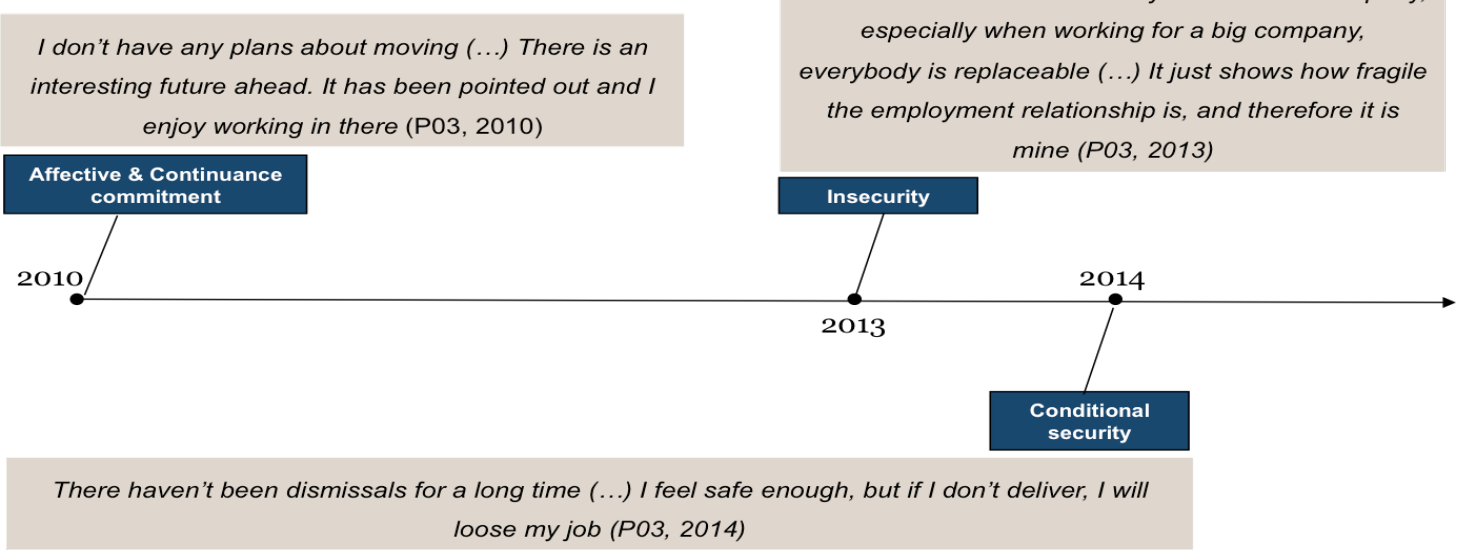

Figure 6.6. Longitudinal investigation of outcomes for P03 (male architect with PR from Brazil).

In the case of P03, a Brazilian architect who migrated to WA with a PR granted in the skilled stream of Australian migration program, insecurity emerged strongly in Phase 2 as a consequence of PC breach. Initially, this individual had clear expectations of career opportunities and stability with his employer. In his first interview (2010), he said, "I like it. There is an interesting future ahead. It has been pointed out and I enjoy working in there. It is stable" (P03). Indeed, he had been promoted a number of times, and he felt 
that the organisation had delivered sufficiently challenging and exciting opportunities. An important part of his expectations - with both migration and his employer - had been fulfilled.

However, in 2013, during Phase 2, P03 saw his expectations of stability threatened. As his organisation faced the economic downturn, he himself had to conduct layoffs. He vented, "I'd love to have security, but I think this is a utopia" (P03). His pleasure and commitment with his job faded with the pressure for performance and delivery: "If I don't deliver, I will lose my job too" (P03). His outcomes changed from affective and continuance commitment in Phase 1 to a strong feeling of insecurity during Phase 2, as well as the perception that his job security was conditional on delivering high KPIs during Phase 3

\section{The case of Participant 09: "This is an institution based on money"}

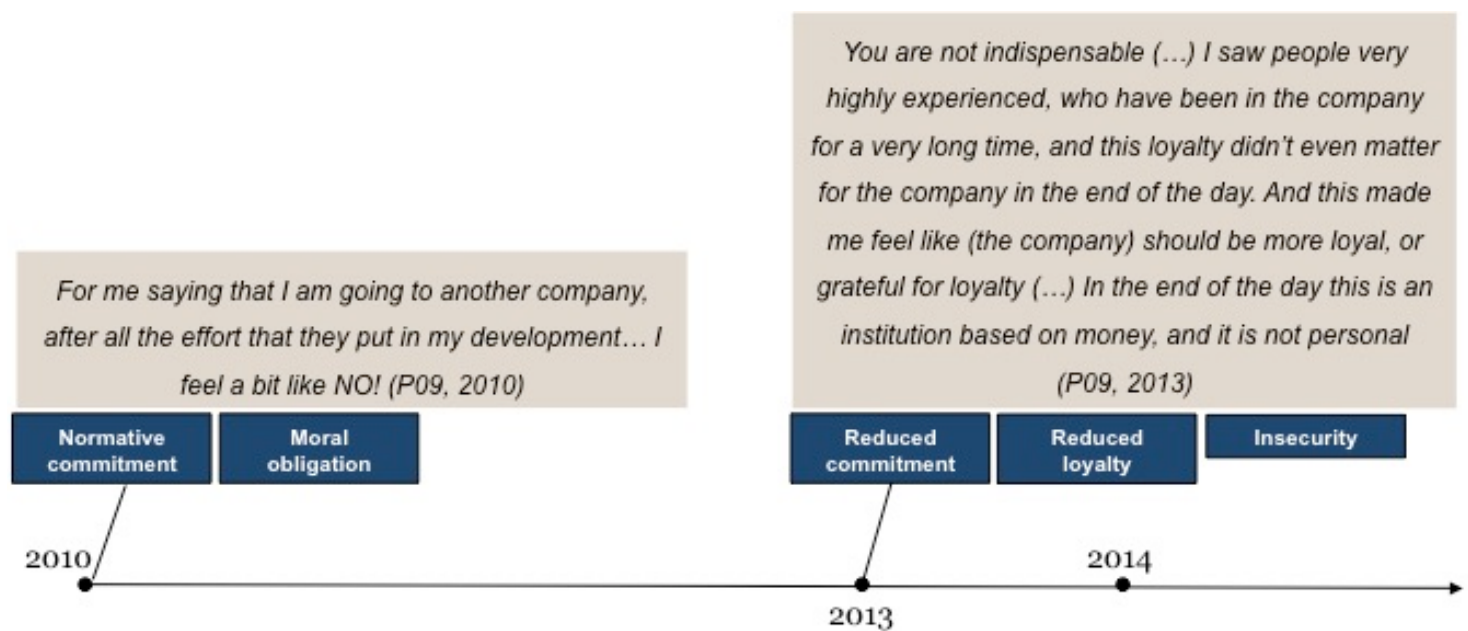

Figure 6.7. Longitudinal investigation of outcomes for P09 (female engineer with PR from Colombia).

Participant P09, a female engineer from Colombia, came to WA to pursue postgraduate studies and then applied for her permanent residency. Her expectations regarding career growth were fulfilled between Phases 1 and 2. However, in Phase 2, there was a significant perception of breach towards her work-life balance when she perceived her organisation to be putting forward strong measures to increase workers' productivity and create "awareness about the possibilities of losing your job" (P09):

It was all delivered very straightforward when we had these meetings in the end of the year, when all those people were made redundant. The attitude of many was "Wow, I should be worried, we all should be worried". I think it was to force people to work more efficiently, but it is not the way you should really engage people to work harder, because they are working out of a fear, more than out of 
motivation (P09).

In her second interview, P09 mentioned that people felt like they had to "be utilised much more" (P09), which worried many employees. More importantly, the feeling of unfairness emerged in a climate of insecurity, ignited by dismissals and enflamed by the way management handled the difficult moment in the organisation she had previously described as a "protective environment". P09 responded to the feeling of insecurity with reduced commitment and reduced loyalty towards her employer.

\section{Conclusion of the chapter}

This chapter presented findings from Phases 2 and 3, with a particular focus on what has changed for the HSIs over time. The changes in WA's political-economic scenario from the second half of 2012, as described in Chapter 2, framed the findings reported in this chapter, particularly the general perception of job insecurity that emerged among the sample. Findings from Phases 2 and 3 thus reflected individuals' awareness about the context in which their employment relationships were embedded (Polanyi 1957 [1944]).

Findings from Phases 2 and 3 also revealed the impact of HSIs' feelings of insecurity towards (1) their expectations in the workplace, (2) their perceptions regarding what their employers were actually able to provide/deliver, and (3) their outcomes in their employment relationships. The results show that both normative and affective commitment faded over time as people finished their two-year commitment with their employers and experienced PC breaches. Results also indicate that the severity of the threat of losing a job (Greenhalgh \& Rosenblatt 1984) was particularly strong for those with temporary business visas, given the fact that these individuals needed a sponsoring employer to stay in the country.

Chapter 7 will specifically discuss the findings with respect to RQ2; that is, HSIs' intentions on staying in WA and contributing to the State's economy and society. 


\section{Chapter 7 - Findings: Are they staying in WA?}

\section{Introduction}

Individuals' plans toward settling in WA were explored in different phases of this study. As described in the initial chapters of this thesis, the input of HSIs has become a critical aspect of WA's labour market. Their individual-level career decisions have significant societal-level effects related to the supply and utilisation of labour wherever they go (Carr et al. 2005). Therefore, investigating their intentions towards contributing to WA's economy in the long term is aimed to inform the broad discussion of skilled migration in Australia, including policies and practices regarding these individuals, as well as HR implications for organisations. Given the longitudinal approach adopted in this research, it was possible to explore the continuum of HSIs' experiences and decisions over time. The figure below summarises HSIs' flows - in response to contextual shifts - during the research period.

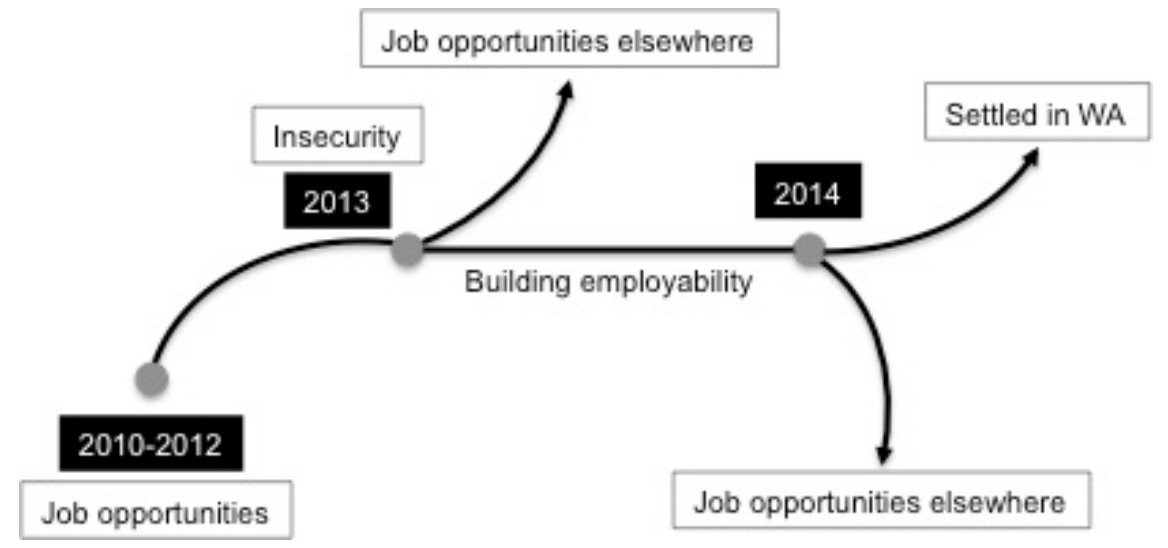

Figure 7.1. Longitudinal observation: Job opportunities and the samples' movements.

The HSIs in the sample arrived before 2010 pursuing job opportunities in WA, as Chapter 5 has reported. In a moment of labour market insecurity, between 2012-13, a group of individuals left WA in pursuit of opportunities in other countries or Australian cities. By the end of this research, in 2014, most individuals who were not intending to stay had already left, particularly seeking oil and gas projects in other countries. At the time of the exit interviews, however, most of the HSIs in the sample had settled in WA and were not planning to leave. In some cases, as a response to their own personal 
needs, individuals started to design alternative paths and even to change their careers in order to guarantee income and safeguard their permanency in Perth.

This chapter will describe these two contrasting collections of cases. First, it presents the cases of the HSIs who left WA in pursuit of global careers - as those individuals whose careers typically include various international positions and assignments in various countries (Suutari \& Taka 2004). Then, it presents the cases of those individuals who would do anything to stay with their families in WA.

\subsection{Following career opportunities: The case of oil and gas global citizens}

The oil and gas industry is truly global in nature and competes for a limited pool of international investment capital. Funding lost from the domestic oil and gas industry will not be spent in other parts of the Australian economy - it will be redirected overseas. (APPEA 2013, p. 1)

Before Phase 3, the decline of oil and gas projects in WA and the emergence of ventures in the industry worldwide (Blackmond 2013; Johnson 2013) pushed away three participants. Two left WA to pursue opportunities in oil and gas elsewhere; a third participant left because her partner was transferred, also to pursue opportunities in the oil and gas arena. It is important to mention that the other two individuals who used to work for the oil and gas industry back in 2012 stayed in Perth, but changed employers and economic sectors by the end of 2013 .

There were still existing and prospective oil and gas developments in several regions around Australia, prompting optimism that the sector would remain strong over the next few decades (ATC 2013). Nonetheless, the industry in Australia was struggling with an inefficient regulatory framework (APPEA 2013). Compliance costs created by a number of overlapping and duplicate laws (APPEA 2013), together with increasing operational costs and a very expensive workforce (Daley 2013; Johnson 2013), imposed significant economic impacts and project delays.

At the same time, the US emerged as an important player in this market and strongly impacted the global energy sector by introducing new sources into the global energy matrix (Deloitte 2014; KPMG 2013). Along with the US, the increasing importance of other producing countries like Canada, Mexico, Brazil and Kazakhstan started to push traditional suppliers, like Australia, to compete more aggressively in order to maintain market share and attract a skilled workforce (Deloitte 2014). As a participant who left 
WA for Texas in 2014 described:

The labour market in Houston is booming (...) I see Houston booming where Australia is in a slump, which I don't see changing in the next couple of years. I think the US will gain momentum, and this will be an oil and gas hub again for expats; this is the place to be for the next few years (P06).

For the HSIs in the sample who were 'global careerists' (Suutari \& Taka 2004; Suutari et al. 2013; Suutari et al. 2014), the emergence of projects in other countries, which gave momentum to the rise of new competing markets, was seen as an opportunity to benefit from their acquired skills, mobility and flexibility (Knell 2000; Pink 2001). Some HSIs thus did not miss the chance to 'sweep' to a new 'high quality' job elsewhere (Green 2008 p. 148). This was particularly the case for Participants 06 and 24, whose experiences are detailed next.

\section{The case of Participant 06: "Just a global person"}

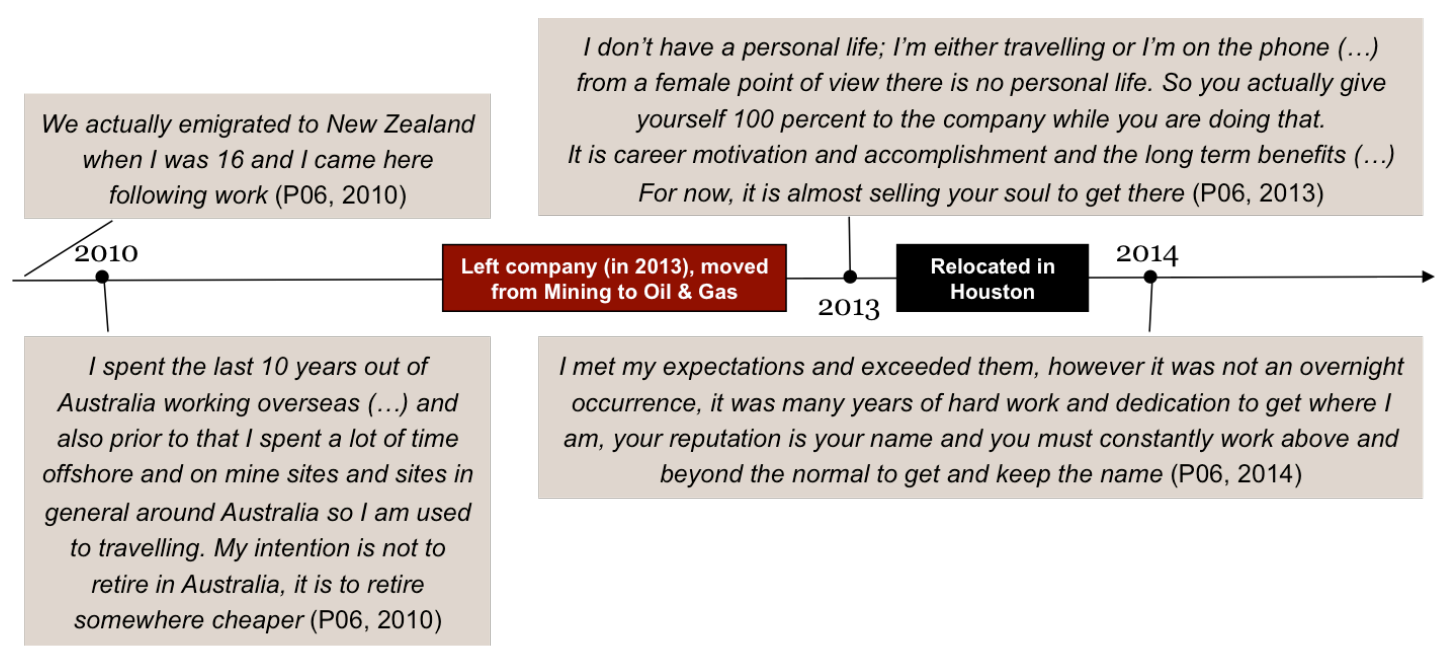

Figure 7.2. Longitudinal investigation of intention to stay for P06 (female IT Manager with a New Zealand passport).

P06 has always pursued a global career, having previously followed assignments in the Middle East, China and the US. She was born in the UK and migrated with her family to New Zealand when she was 16; in her 20s, she came to WA following work in the oil and gas industry. During her first interview in 2010, she revealed no feeling of belonging to Australia - or anywhere in the world:

I don't feel like I belong here even though I have an Australian passport, because I am not Australian. I think you are just a global person. I don't think you ever really fit anywhere; you don't have those connections and friendships that you have as a child from school. You never do that; you make friends and 
acquaintances, but it is not quite the same. So I don't feel that I fit anywhere really.

I am just living here because I like to live here (P06).

She has always been career driven: "Whether I like to admit that or not, it is pretty clear and apparent that that's the way I am: I am a workaholic" (P06). As a result, her PC has always been grounded in professional challenges and opportunities. She stepped aside every time something was not contributing fully to her professional goals. She left her employer in the mining sector in 2013 when she perceived a PC breach, as her role was no longer as exciting as she expected. In 2014, she left Australia in response to the perception that the industry there could no longer deliver her desired career growth: "If that opportunity was not there (in the US), I would probably move elsewhere; that is the point of where I need to be for what I am doing" (P06), she explained. Her new employer, a major player in the oil and gas sector, offered her a role in Houston, as her organisation was going through global restructuring and dismissing people at the Western Australian office. For her, this was a promotion "not to be missed" (P06) and a reinforcement of her expectations regarding career growth.

\section{The case of Participant 24: In a company ready to fulfil his 'demands'}

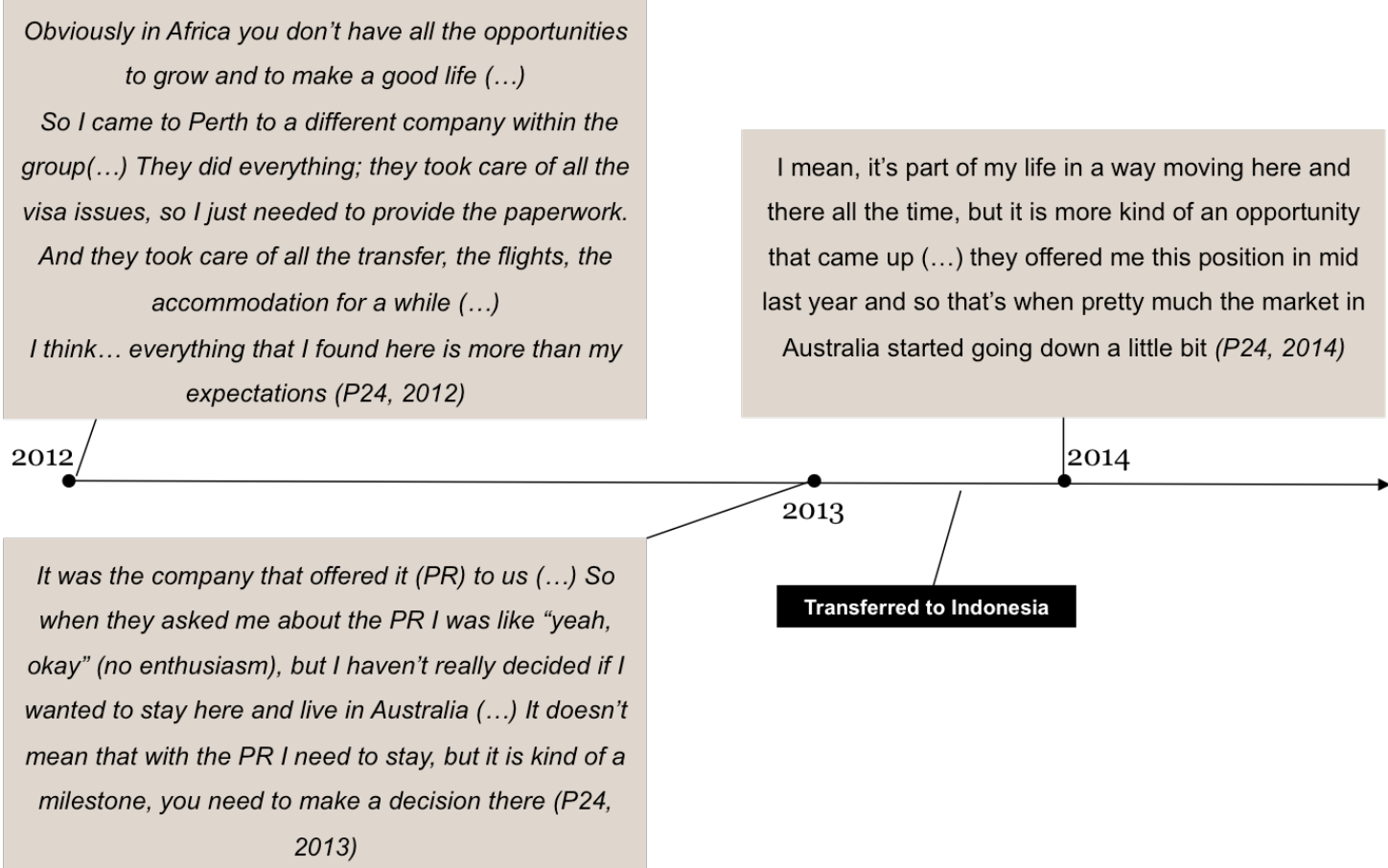

Figure 7.3. Longitudinal investigation of intention to stay for P24 (male engineer with 457 from Senegal).

P24, an engineer from Senegal, is the second case that exemplifies the group of individuals who consider themselves 'global citizens' and pursue professional 
opportunities wherever they happen to be. Working for an EPCM in the oil and gas industry, he described the industry in Australia:

In Australia, there are many projects; it is just that the investments for those projects are not approved, they are not out there (...) in my company, many of our engineers left either voluntarily or they were just laid off and I know of many companies that were the same as well. In the rest of the world, I think the industry is still going all good; it is really good in the US, and the head hunters are searching anywhere you can imagine, like the Emirates, and Singapore, but very few for Australia (P24).

P24 migrated to Australia in 2011, after being transferred by his employer. Although he is a young man in his mid-30s, Australia was already his third international assignment. He always had high expectations regarding his career, learning and professional development, which the employer fulfilled from the beginning: "As soon as I joined the company, my aim was to show them my capabilities straight away, and after a year I got a promotion, and the company was ready to fulfil many of my demands (...) like projects in other countries, training courses" (P24). This employer not only sponsored his 457 visa but also his permanent residency two years later, which he perceived as recognition of his hard work.

During the difficult time in the oil and gas industry, the organisation did not have a position for him in Perth, so his employer offered him a new challenge in Jakarta, Indonesia:

They offered me this position mid last year and so that's when pretty much the market in Australia started going down a little bit. I can't say that I didn't see any threats to my position in Australia, but it was kind of a little bit complicated because we had pretty much no job back in Australia and not much to do there and no good future coming up (P24).

With this new position, also a promotion, his employer reinforced his expectations towards career growth, professional challenge and excitement.

These two individuals, among a few others (see Table 7.1 below), have always endeavoured to be hypermobile, which involves prospects of remigration and return (Richmond 1991) rather than permanent migration and settlement in Australia. They did not express a feeling of belonging to any particular country, including Australia. They were motivated by exciting opportunities and career development, and they were willing to follow these opportunities wherever they led. Australia seems to have been just one more step in their trajectories, and if they were aware of this fact, their employers also seemed to be. In the context of the economic downturn and labour 
market constraint, in which their employers had to decide who would stay and who would be dismissed, these career-driven 'global citizens' (Suutari \& Taka 2004) were the employees chosen for promotion and/or relocation to more challenging and economically booming environments.

\begin{tabular}{ll}
\hline & \multicolumn{1}{c}{ International assignments of the 'global citizens' } \\
\hline Participant & Professional Trajectory and length of stay in each country \\
P04 & Brazil; China (1 year); Italy (2 years); Brazil (10 years); Australia (12 years), \\
(Australian citizen) & but moved from WA to the eastern coast of Australia. \\
P06 & UK; New Zealand; Australia with assignments in China (2 years), US (1 year) \\
(Australian citizen) & UAE (2 years); US \\
P22 & South Africa; UK (15 years); Australia (4 years); Canada \\
(457 visa holder) & \\
P24 & Senegal, Nigeria (1 year); Brazil (1 year); Australia (3 years); Indonesia \\
\hline
\end{tabular}

Table 7.1. Global citizens' spatial career paths.

\subsection{Designing a Plan B to ensure permanency in Australia: The settled ones}

Among the 11 participants who were still in WA during the third phase of this research, only a married couple expressed the desire to live in other places, as well as some uncertainty regarding their future in WA. Coming from the UK, P07 and P08 were transferred to Perth by their employers. During Phase 1, they were both excited about new professional challenges in Perth and relieved after leaving behind the European labour market. However, living in Australia was never a long-term plan for this couple, and moving elsewhere became more difficult after they had children:

I would like to (leave); it is that... it is a big decision isn't it, with the kids? It is almost easier to stay put. I know in my heart I would like to work in lots of different places; I'd like to work in the outback or go to Africa in the future (P08).

In 2014, these two HSIs, P07 and P08, were the only participants who were still living in Perth without Australian citizenship. All of the other HSIs in the sample had become citizens by Phase 3; they were settled and did not intend to leave. If HSIs' choice of destination was mostly grounded in Australia's skills shortages and labour market conditions, as discussed in Chapter 5, staying in WA was a decision justified by their families' lifestyle, safety and new personal ties. Settlement in this thesis is understood as the post-arrival process of adjustment undergone by migrants, typically characterised 
by a set of needs including income, accommodation, information about and access to services including schools, transport and health services, access to employment and education, the development or improvement of English-language skills, and the formation of individual and family social networks (Boese 2015, p. 402).

As these participants started families, had Australian-born children, and developed stronger participation in their communities - through school, sports or church involvement, for example - they felt settled (Boese 2015) and reported a stronger sense of belonging (Taylor 2009) to Australia. They achieved thorough political belonging with social and political rights (Castles \& Davidson 2000; Vertovec 2004) and felt like gradually increasing membership, admission and cultural proximity (Vertovec 2004) to Australian society:

I belong here more. This is what has changed in the past few years. Because my child starts school now, I don't want to move her around too much. I feel happy in my work; I feel I have a community support group, a church, and a good group of friends, so I think we are quite settled now (P10).

So I have this sense of belonging. When I go to Africa or Europe or Brazil, I always have this feeling I want to go back home, and home is Australia (P19).

The sense of belonging to Australia was not a general feeling, though. Some participants expressed contrasting emotions in their final interview. Some held a fear that they would always feel like an 'outsider' in Australia, despite feeling great satisfaction about being in WA (P01, P03, P10, P11, P25, P26). As Castles and Davidson (2000, p. viii) have previously argued, an increasing number of citizens feel they do not belong, many times because they hold multiple identities, such as HSIs who live at the intersection of two (or more) cultures. Nonetheless, although some things still felt 'foreign' to them, they were all counting on the fact that their children would not experience the same feeling:

We are settled in Australia, but there will always be something that's foreign. Do you know what I mean? Because we weren't born here (P25).

What does it take to become part of this country? I don't know. Maybe when my kids grow up and they establish more roots than us, especially with the culture (P04).

Despite the mixed feelings regarding 'belonging', at the end of Phase 3, all participants who were settled in WA noted that the expectations they had when migrating to Australia were absolutely fulfilled: 
I was very lucky to come during that time of really huge growth in Western Australia, especially Perth. So I cannot even describe this experience, how it was beneficial... it fulfilled all my expectations, I don't know whether anything describes the professional achievements that I had. I couldn't feel happier. I simply feel that it has been great (P26).

Findings also show that, by Phase 3, participants seemed to have reassessed the importance of work and career in their lives, mostly in response to their life cycle. During their exit interviews, it was not uncommon to hear how much participants' personal lives had changed, and that work had gained a secondary place in their priority list as they became involved with children and family commitments:

The importance of work in my life is what has changed, more than ever. It was priority number one when we made the move. So now my priority changed, and the job is just a job (P03).

Just for being older, and having kids, this is probably (what has changed) more than anything else. And maybe my expectations regarding what is important in life ... I came here and life is very different from what it would be back in the States, generally. Maybe what was more important there is not so important here, and that is not a bad thing. We have more lifestyle, kids focused, and that is what is really important (P16).

As a result of this shift in participants' personal circumstances, many of them started to aspire for a better work-life balance instead of promotions and professional challenges, as previously illustrated in Figure 6.3. P03, for example, expressed how his routine had changed so that work would have less impact on his personal life; similarly, P07 noticed that in the new labour market context, characterised by greater instability and flexibility, he would be able to easily renegotiate his working hours:

I will do my best to leave the office by 5pm every day (...) I will do my best to be home as soon as possible because that is what matters. Life is outside the office. I am not defined by my profession, by my job (P03).

Four days a week, it should be (fine). I know there are other people who do it, and you'd think at a time where the workforce is getting reduced, actually being on four days isn't a bad thing (P07).

It is important to note that as participants were going through a difficult phase of insecurity, watching their peers lose their jobs (as previously reported in Chapter 6), they started to make alternative plans to guarantee some income and their permanency in WA, even in the event of losing their jobs. They were no longer attracted by labour mobility, and following opportunities elsewhere was not an option. Rather, they were more interested in definitively settling in WA. During the final phase of interviews, a 
number of individuals mentioned that they had been considering a back-up plan in case of job loss:

I guess it is time for me and my wife to have a back-up plan (P04).

Because we are aware of it (the possibility of job loss), that there is a good possibility of it, you start looking around and you start making other plans (P11).

You want to give yourself that buffer so if the eventuality comes you can just say, "Well that's okay, I'll just go and do something else; I'll qualify in something else, and I'll go and find work". It may not necessarily match your current income, but you will be able to live (P25).

For many HSIs in the sample, thus, staying in WA was a case of pragmatic "make do and mend" (Dobbins et al. 2014). Given the labour market constraints in the State, HSIs reported that they would take less qualified jobs if necessary. This was, for example, the case of P01, an accountant that weeks after Phase 3 of this research accepted a job as a gym manager.

The case of Participant 01: The grateful employee who had to change careers

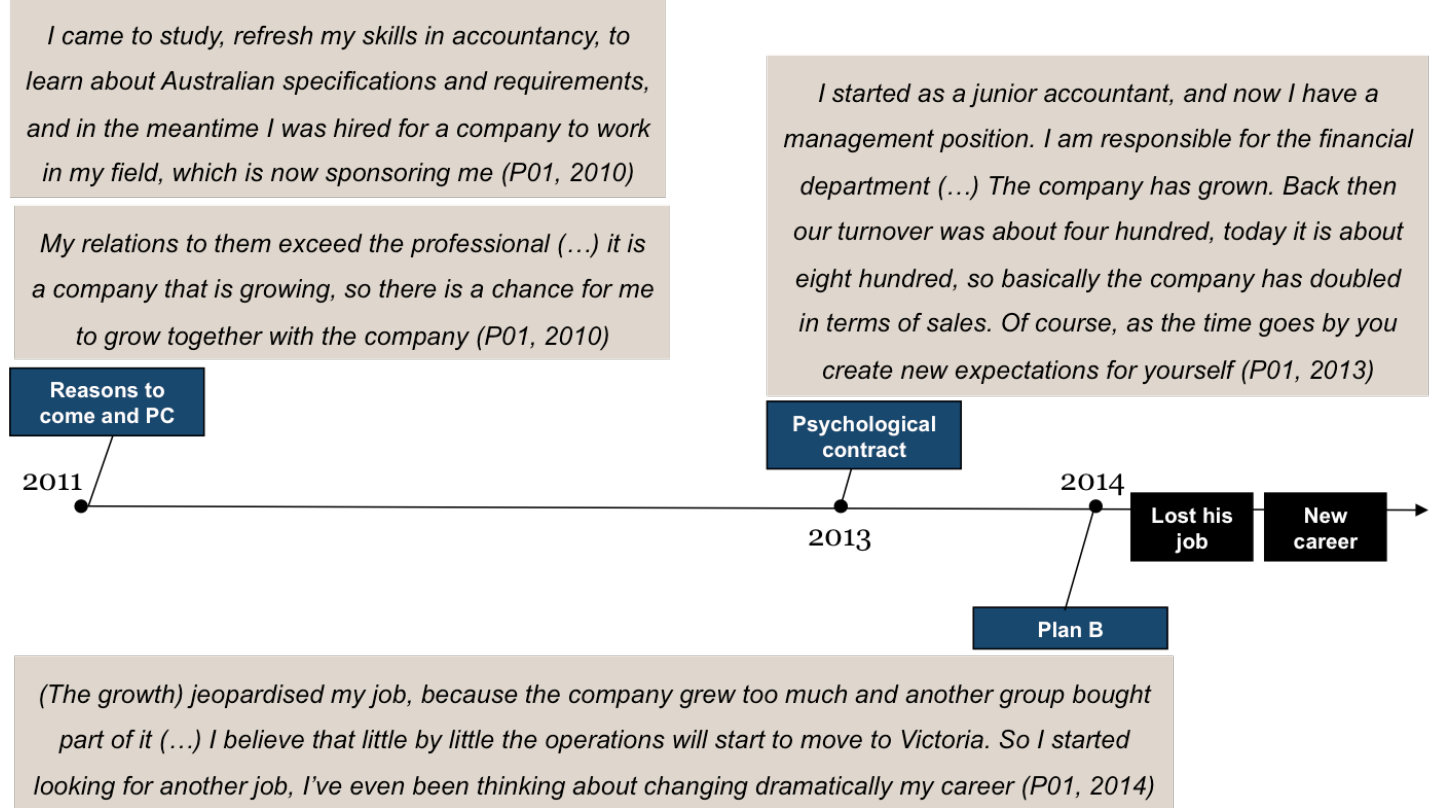

Figure 7.5. Longitudinal investigation of psychological contracts and intentions to stay for P01 (male accountant with a 457 visa from Brazil).

P01, an accountant from Brazil, had to find an opportunity in a different field of work in order to stay in Perth. He came to Australia in 2009 to pursue postgraduate studies and quickly got a position in a small wholesales firm. The firm's owner sponsored his 457 visa, and later, his family's PR. His involvement with this employer has always been 
marked by an emotional attachment, and his PC has been grounded in future opportunities as he watched this small organisation grow. In Phase 2, he declared:

I want the company to grow, because if the company grows, then consequently I will grow together. So that is what I hope will happen. My expectations are in terms of career. More people will probably come to this company; other positions may be available, and I may become a CFO (P01).

The company indeed did grow, but to a point where another group bought it. The entire financial department was transferred to Melbourne, but he decided not to go because he had a child living in Perth with his ex-partner. When the third interview was conducted, he stated that he knew he would not have a job for long, but he was still assessing the opportunities:

I don't think it is going to be easy (...), I just have this general feeling that time is passing and everything is becoming harder for everybody. You have to be more and more qualified; the job opportunities are getting smaller (P01).

\section{The case of Participant 11: Possibilities for a back-up plan}

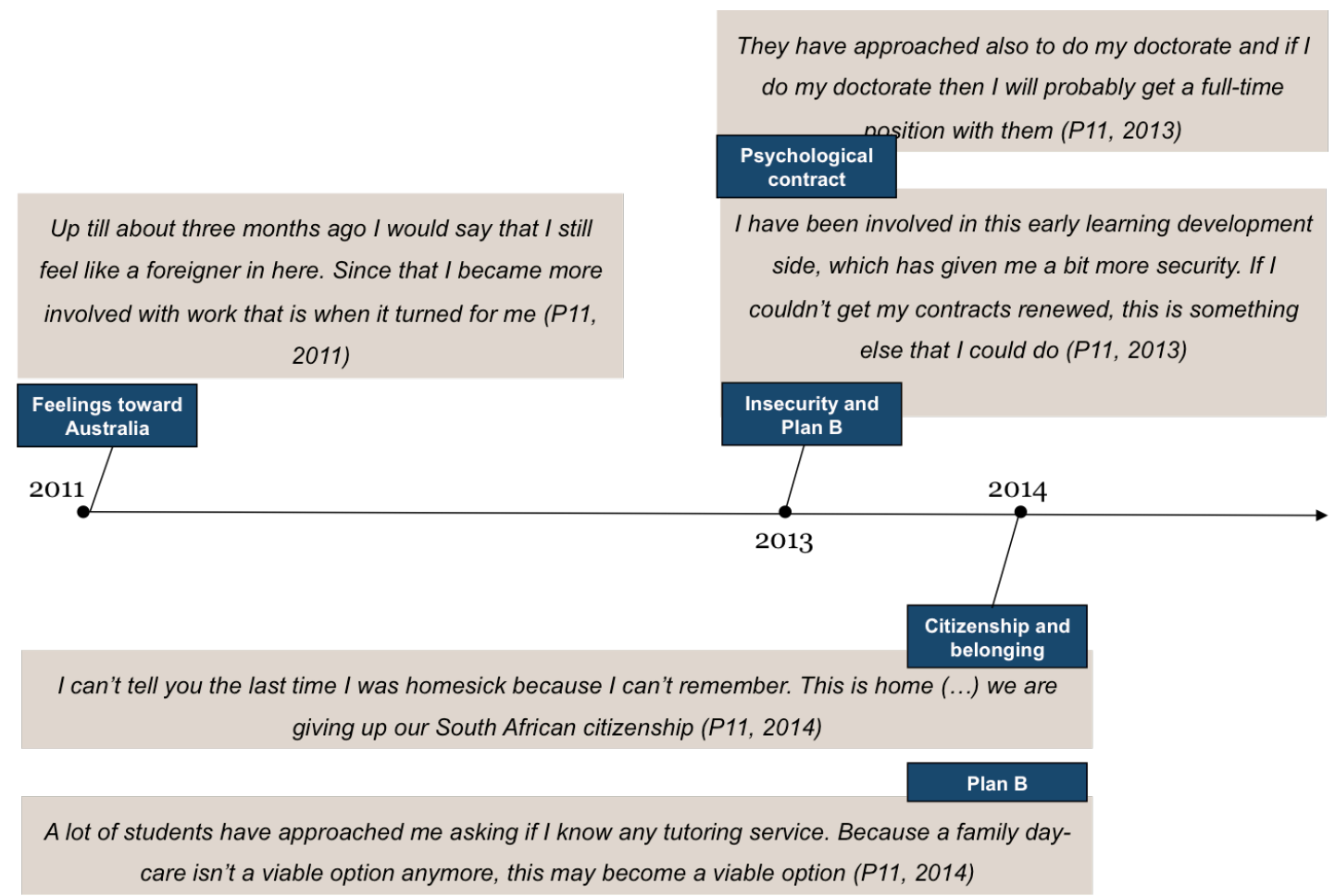

Figure 7.4. Longitudinal investigation of psychological contracts and intentions to stay for P11 (female accountant with PR from South Africa).

P11, an accountant from South Africa, was taught from her early years that she needed to compromise: "I hated accounting, but my mum convinced me that I would have job security" (P11). She worked as a sessional in higher education for five years in order to 
keep working in her field while caring for her two daughters' needs. During the economic turmoil, she noticed that her employer would not be able to keep offering her casual contract work indefinitely.

Her employer had promised a permanent position in the future, if she acquired a $\mathrm{PhD}$ degree. However, she concluded that this academic work would impose too much pressure on her family. She decided that she needed a Plan B, particularly because her husband was also in the education sector at a university that had been fairly impacted by economic pressures in the prior few years. Together, they assessed a number of possibilities for a back-up plan, including day-care, aged-care and children's education. Recently, she started to evaluate the possibility of starting a tutoring business, with a focus on university students. The picture above summarises her feelings towards Australia and her career prospects.

\section{Conclusion of the chapter}

As this chapter has discussed, some participants in the sample intended to settle in WA from the beginning. Arriving with either a temporary business visa or as a permanent resident, they left their personal belongings behind and came to Australia for good, pursuing a safer environment or a better lifestyle for their families. Others, on the other hand, did have temporary intentions, and left WA as soon as the labour market conditions changed in 2013. Finally, there were participants who did not intend to settle in WA, but ended up staying because of family circumstances. This chapter discussed the reasons behind individuals' decisions for staying or leaving WA.

Findings suggest that although affected by their life cycle and personal conditions, HSIs' decisions about staying or leaving was tempered by their lived employment experience and general perceptions about not just WA's labour market, but the global market as well. As these HSIs' personal lives evolved and their employment relations became embedded in a much more turbulent economic environment, some participants decided to leave WA and pursue opportunities in other labour markets. Findings show that holding a PR status or an Australian passport made no difference in their decisions. It was the pursuit of career opportunities - in order to fulfil psychological contracts that pushed participants towards assignments elsewhere. 
However, although most of the participants came to WA motivated by career opportunities and professional development, the findings also indicate that what made them stay was the decreasing role of 'career' in their lives, the reduced attractiveness of mobility, and the increasing feeling of membership in Australia. Those who did not intend to leave WA were those who settled with their families. In order to stay, they were willing to work for different industries and follow more flexible professional paths. These participants were also the HSIs who felt some feeling of belonging to Australia. By Phase 3 of this research, the 'settled ones' had chosen Australia and had become Australian citizens. 


\section{Chapter 8 - Discussion and Conclusion}

\section{Introduction}

Building on the critique of the PC developed by Guest (2004a; 2004b) and Cullinane and Dundon (2006), the focus of this study was to understand how the PCs of HSIs living and working in WA changed in response to WCFs. The increasing global significance of labour migration as a strategy for a country such as Australia to manage the demand for skilled labour needs unable to be met through the domestic supply of labour was the justification for focusing on HSIs. Within Australia, the unique influence of HSIs in enabling WA to realise production demand, especially in the mining and natural resources sectors, justified the selection of this location for an in-depth case study (see Chapters 1 and 2).

After reviewing the literature about the WCFs that influenced the migration, employment and lived experiences of HSIs in Australia and WA (see Chapters 1 and 2), a conceptual approach was developed to account for the influence of WCFs on the PCs of HSIs (see Chapter 3) in order to guide the empirical exploration of the following research questions:

1. How do wider contextual factors (WCF) influence highly skilled immigrants' (HSIs) psychological contracts (PCs)?

2. How do highly skilled immigrants' (HSIs) psychological contracts (PCs) impact their intentions to stay in WA?

The following research propositions subsequently emerged to guide the analysis:

Proposition 1a: WCFs affect HSIs' individual background factors, which are some of the factors shaping their PCs.

Proposition 1b: WCFs affect contract-related factors at the organisational level, which will also influence HSIs' PCs. 
Proposition 2: WCFs shape the content of HSIs' PCs, including expectations, perceptions of promises, inducements and obligations in the workplace.

Proposition 3: Because WCFs impact an organisation's capacity to deliver what HSIs expect, WCFs will affect these individuals' outcomes in their employment relationships.

In addition to the unique conceptual contribution that has been made about WCFs and the PC, the findings (see Chapter 5,6 and 7) present a further unique empirical contribution about the influence of WCFs on the PCs of HSIs, using a sample of those living in WA. As a result, and in keeping with the methodological approach adopted for this study (see Chapter 4 and the conclusion of Chapter 6), the original conceptualisation was revised to present a more fine-grained understanding of the outcomes that the HSI participants in this study expected from their PCs (see Figure 5.4). Drawing on this and the findings from Phases 1, 2 and 3, Chapter 7 discussed those factors that contribute to HSIs leaving or remaining in the labour market of WA.

The aim of this chapter is to discuss how the findings address the research questions and propositions posed for the study and to consider their implications for future conceptualisations of the PC and managerial practice. The chapter will conclude with a discussion of the limitations of this study, while highlighting future research directions in this area.

\subsection{Contextual aspects and the role of embeddedness in the psychological contract}

An interaction between WA's political-economic context and the PCs of HSIs in the sample was noticed across the three phases of this investigation. This section discusses how changes in the WCFs - mostly between Phase 1 and Phase 2 - affected individuals' perceptions, expectations and outcomes with respect to their employment relationships. It also discusses the propositions that guided this study. 


\begin{tabular}{|c|c|c|}
\hline $\begin{array}{l}\text { S225 billion portfolio of resource } \\
\text { and infrastructure projects in WA } \\
\text { (DTWD 2011); } \\
\text { Mineral production expected to } \\
\text { continue to grow to meet increasing } \\
\text { demand of China and India (CEDA } \\
\text { 2011). }\end{array}$ & $\begin{array}{l}\text { Downgrade in investment for } \\
\text { resources projects, cancellation and } \\
\text { postponement of a number of gas } \\
\text { and mining developments (Daley } \\
2013 \text {; Uren 2013); } \\
\text { - Organisations announced cuts in } \\
\text { costs and jobs from second half of } \\
2012 \text { (Johnson 2013; Ker 2013). }\end{array}$ & $\begin{array}{l}\text { - Unemployment rate in WA in } \\
\text { highest level in more than a decade } \\
\text { (Tillet 2014); } \\
\text { - More jobs eliminated, especially in } \\
\text { mining (Ingram 2014); } \\
\text { - Oil \& Gas industry boomed in other } \\
\text { places, such as Texas (Blackmon } \\
\text { 2013). }\end{array}$ \\
\hline$\dot{v}$ & ì & $\dot{v}$ \\
\hline Phase 1 & Phase 2 & Phase 3 \\
\hline August 2010 - June 2012 & March - June 2013 & October - November 2014 \\
\hline 26 exploratory interviews & 12 repeated interviews & 14 repeated interviews \\
\hline $\begin{array}{l}\text { KEYWORD } \\
\text { Oppotumiles }\end{array}$ & $\begin{array}{l}\text { KEXWORD. } \\
\text { IISEcuity }\end{array}$ & $\begin{array}{l}\text { KEYWORDISI: } \\
\text { Move or settle }\end{array}$ \\
\hline $\begin{array}{l}\text { General perception of } \\
\text { security, opportunities } \\
\text { reinforced by government } \\
\text { and recruitment, } \\
\text { confirmed by the } \\
\text { economical context. }\end{array}$ & $\begin{array}{l}\text { Perception of shift in } \\
\text { power, labour market } \\
\text { insecurity, and reduced } \\
\text { loyalty, in response to } \\
\text { changes in the economy } \\
\text { and wider context. }\end{array}$ & $\begin{array}{l}\text { Opportunities elsewhere } \\
\text { pushed people away. Those } \\
\text { who stayed are settled and } \\
\text { counting on increased } \\
\text { employability, with back-up } \\
\text { plans. }\end{array}$ \\
\hline
\end{tabular}

Figure 8.1. Influence of context over individuals' perceptions.

Figure 8.1 summarises how WCFs shifted the perceptions of HSIs about their employment experiences. The changes that took place in the WCFs from 2010 to 2014 are described in Chapters 1 and 2. In brief, while WCFs that led to the investment of billions of dollars in infrastructure and resource projects (DTWD 2011) created 'pull' conditions for HSIs (Rout 2011; Trenwith 2011) in Phase 1, by the latter end of that phase and in Phase 2 (2013) and Phase 3 (2014), WCFs triggered increasing unemployment and 'pushing-away' conditions for HSIs (Blackmon 2013; Janda 2012). The keywords 'opportunities', 'insecurity', and 'move or settle' in Figure 8.1 reflect the main themes in the discourse of HSI participants about the WCFs during each phase of the study. This chapter now turns to a discussion of how the findings inform the research propositions and, subsequently, the research questions.

As Chapter 5 suggests, at time T0, even before HSIs arrived in WA, WCFs - in both sending countries and in Australia as the receiving country - were the trigger for participants' decision to migrate to Australia. The findings in Chapter 5 highlight that the WCFs that HSIs faced in their sending countries, such as inflation, low economic growth and the high incidence of criminal activity, when compared to the Australian WCFs of positive economic indices, lifestyles, skills shortages and resulting professional opportunities for those with a matching skill set, clearly influenced their decision to migrate. Participants arrived in Australia with a 'pre-migration' expectation. 
The WCFs in Australia at T0 matched their own individual aspirations (De Haas 2010) and thus informed their motivation to migrate (Khoo et al. 2007).

However, as Chapter 5 shows, the unique WCFs in WA specifically attracted HSIs to this location. A general perception of 'opportunities' emerged not only from participants' corporate environment, but also from the wider context in which their organisations were operating. WA was "in the grip of a boom mentality" (Birrell \& Healy 2012, p. 7), with a flow-on effect in many industries (Garnett 2012).

As a result, most participants reported 'initial expectations' regarding career growth, in an environment in which they would be presented with learning opportunities, professional development and exciting experiences. The term initial expectations describes those expectations that happen in the early stages of a longitudinal analysis (Sutton \& Griffin 2004). In the case of the HSIs in this study, their initial expectations were sown in their pre-migration perception of the outcomes they could expect from their employers, but germinated in Phase 1 because of the influence of WCFs. That is, the initial expectations (Sutton \& Griffin 2004) of HSIs that WA offered opportunities for their own individual aspirations (De Haas 2010) of career growth were reinforced through their lived experiences and observations of opportunities in their own individual workplaces.

Following the resources boom, the WCFs in Phase 1 of WA's growing economy (CEDA 2011) enabled organisations to continually remind HSIs of the chances available inside and outside their organisations for career development. Respondents (P3, P20 and P23, for example) were promoted a number of times. Others (P22 and P24) reported that recruiters would make continuous and frequent attempts to relocate them to better-paid jobs or more noteworthy projects:

I used to receive job offers twice a week, at least once a week for Australia. It is quite challenging because you are in a company that you like but you are still receiving jobs (offers) and you know that you are gonna get more money (P24).

With regard to HSIs' outcomes for their PCs, most participants expected career growth from their employment relationships and responded with affective and continuance commitment (Meyer \& Allen 1991) during Phase 1 (see Appendix 7). Those with 457 visas frequently also demonstrated normative commitment, as they felt obliged to stay with their employers because of their visa sponsorship (Freese et al. 2011). 
Whereas the context promoted the idea that there were opportunities for respondents working in WA during Phase 1, the economic downturn (Daley 2013; Tillett 2012) in Phase 2 changed participants' perceptions towards one of insecurity and arguably a PC state that reflected loss of confidence. Respondents described the 'new' PC as one characterised by constraint and instability during the second phase (2013) of interviews. Participants' feelings of uncertainty clearly resulted from changes in WA's politicaleconomic context, particularly WA's economic downturn, after the drop in mineral prices and the slowdown of China's economy (Corben 2012; Uren 2013). The upcoming federal elections in Australia only boosted the feeling of political-economic insecurity (Kitney \& Garvey 2013).

The inability to handle the impact of these WCFs at both the organisational and immediate leadership level (Guest \& Conway 2002) compounded the feeling of insecurity for HSIs and the subsequent loss of confidence in the PCs they had formed with their organisations:

They are doing a global restructure so what they do during that process is if there is going to be no suitable role for you here, they may offer you work elsewhere. If you don't take that option, then obviously you would be the same as a contractor; you would need to be finished (...) I don't believe anything is really fully permanent ever (P06).

Participants' perception of insecurity thus emerged from the organisational responses to the new political-economic context. Situations of PC breach (Kickul 2001; Robinson 1996) resulting from limitations imposed by market conditions were reported by half of the sample during Phase 2. This was particularly the case for P03, P09, P14, P22 and P26: participants who described breach, insecurity and reduced commitment.

As individuals watched their peers lose their jobs, some reassessed their employment relationships. They re-examined their loyalty (Kleinig 2007) to their employers, as they considered that their leadership was not acting fairly or being trustworthy. Affective commitment (Meyer \& Allen 1991) faded as respondents noticed insecurity, unfair dismissals, or breaches in their PCs over time. Normative commitment (Freese et al. 2011), initially very strong among those with visa sponsorship, was non-existent in the sample as soon as they attained permanent residency status and completed the two-year requirement with their employers, thus experiencing relief that they no longer had to rely on their employers for continued employment in WA: 
(I have) networks, so I know people; and especially in Perth, it is all about knowing people and having those networks (...) while I had the German knowledge, I didn't have the Australia-specific knowledge, and I have gathered that over the last few years (P14).

While the findings (see Chapters 5 and 6) highlight that participants repeatedly assessed the costs and benefits of their current employment in comparison to other available alternatives, as the WCFs (that is, wider social, political and economic factors) shifted in WA from the latter part of Phase 1 and during Phase 2, a number of HSIs came to believe that their employers were not providing the rewards they associated with their PCs. As a result of these WCFs, some HSIs explored additional relocation pathways by changing their employment status (P06, P07, P17), becoming independent contractors (P02, P18), or leaving WA (P04, P05, P15).

With the deepening of the economic downturn (Ingram 2014; Tillet 2014) during Phase 3 , the response of some other participants was also to move away from WA or Australia in general (P06, P22, P24). HSIs' decision to stay and settle is discussed later in this chapter. Before that, the theoretical propositions that guided this study (see Chapter 3) should be revisited.

\section{Proposition 1a}

WCFs affect HSIs' individual background factors, which are some of the factors shaping their PCs.

In Chapter 3, it was argued that contextual factors would affect HSIs' individual background factors, including their aspirations (De Haas 2010) and motives for migrating (Khoo et al. 2007); this would in turn shape what HSIs expected and perceived from their employment relationships. As presented in Chapter 5 and further discussed in this chapter, the findings show that HSIs entered the Australian and Western Australian labour market with a pre-migration expectation associated with the possibility of career advancement, a better lifestyle, and economic prosperity. In particular, the pull (Khoo et al. 2007) of economic prosperity was a major attraction to WA for HSIs, as this WCF provided HSIs with the opportunity to meet their individual aspirations (De Haas 2010). Thus, there is support for Proposition 1a. 
WCFs affect contract-related factors at the organisational level, which will also influence HSIs' PCs.

The findings also show how participants acknowledged the organisational inability to handle the impact of WCFs (Guest \& Conway 2002), which fostered insecurity and loss of confidence among employees - particularly 457 visa holders. For this group, a breach of their employment contract, imposed by contextual conditions, also implied the cancellation of their working visa. Shifts in WCFs affected HSIs' perceptions and employment experiences and shaped their PCs towards outcomes that illustrated the uncertainty and insecurity. Thus, it can be said that shifts in WCFs changed the contract-related factors at the organisational level as well as participants' PCs, providing support for Proposition $1 b$.

\section{Proposition 2}

WCFs shape the content of HSIs' PCs, including expectations, perceptions of promises, inducements and obligations in the workplace.

Building on Guest's (2004a) work, Proposition 2 argues that contextual factors will influence the beliefs comprising an HSI's PC, including his or her expectations, perceptions of promises, inducements and obligations in the workplace. Findings presented in Chapters 5 and 6 explored the impact of contextual factors on the beliefs that comprise HSIs' PCs. Although participants' perceptions regarding obligations both their obligations as employees and their employer's obligations - could not be directly related to contextual factors, findings from the three phases of this research suggest that HSIs' PCs are mostly grounded in normative expectations, which are beliefs regarding what ought to occur based on a dominant standard (Roehling 2008). Therefore, participants in this study did create expectations from what they perceived to be normal practices around them.

During Phase 1, 16 participants described workplace expectations regarding career growth and professional opportunities grounded in both pre-migration expectations and the skills shortages they observed in WA (Burke 2011; DIAC 2010). Participants recounted that skills shortages motivated recurrent contacts from head hunters who were recruiting for other projects and companies, and created opportunities for quick career 
progression within their organisations. However, the changes in the WCFs during Phases 2 and 3 triggered further shifts in the content that HSIs expected of their PCs. Thus, there is support for Proposition 2.

\section{Proposition 3}

Because WCFs impact an organisation's capacity to deliver what HSIs expect, WCFs will affect these individuals' outcomes in their employment relationships.

During Phase 2, HSIs' expectations changed in response to the constrained economic scenario (AAP 2013; Daley 2013; Janda 2013) in which their employment relationships became embedded. As organisations reduced costs and dismissed employees (Bridges \& Evans 2012; Ker 2013; Tasker 2012), HSIs reported a perception of insecurity. However, they also recognised an organisational inability to deliver career growth and learning and development opportunities as initially expected because of politicaleconomic conditions (Uren 2013). As one of the participants described in 2013: "What I want I can't get (...) I believe that the 2008 GFC didn't exist, and the GFC is right now" (P03). Proposition 3 is therefore supported by the findings in this study.

Proposition 3 argues that because WCFs impact organisational power to deliver what HSIs expect, they will also affect these individuals' outcomes in their employment relationships. Feelings of gratitude, loyalty and commitment were explored, together with individuals' intentions to stay in WA.

Feelings of gratitude and loyalty were described in situations of visa sponsorship (P1, P14, P15, P20, P23, P25), as discussed in Chapter 5. Participants' normative and affective commitment shifted in response to PC breach and fulfilment, as did their perceptions of fairness and trust. However, continuance commitment, which is based on a perceived cost-benefit assessment of maintaining or leaving organisational membership (Freese et al. 2011), was impacted by WCFs throughout the different phases of this study. In Phase 1, continuance commitment was strong among those in the sample because participants considered the employment experience to be valuable for their careers:

They are the biggest company in the country and for me it is actually very good for my career since I don't have any history in Australia, and building my initial history here with a name like theirs is actually a good thing, it is a differential (P02). 
However, as the scenario changed from the second half of 2012 and opportunities became scarcer, staying with an employer in some cases became necessary:

I think the power lies in the economy. In bad times, the employer will have the power; in good times, your skills have the power, your experiences have the power. Right now, I think it would be a bit difficult to get another job because of the current conditions. If the economy was more normal, it would be easy for me to find a job (...) A year ago or two years ago I was thinking it would be a good time for a change (P09).

Finally, as the findings discussed in this chapter indicate, HSIs' decision to leave WA was very much grounded in professional opportunities in other countries as pull factors, particularly for those career-driven individuals working in oil and gas projects. Participants' decision to stay was justified by their life cycle and by a lived experience of inclusion and affinity with Australia's culture and values, as previously argued in the literature (Taylor 2009; Vertovec 2004). Belonging, membership and intentions to stay will be discussed later in this chapter, but it can be said here that findings from this research provide some support for Proposition 3.

Therefore, findings from this case study confirm that participants' PCs did change in response to market constraints in WA, when their organisations had to cut costs, reduce the workforce and restructure operations. With their employment relationships embedded in a new volatile and unstable political-economic scenario, HSIs amended their expectations and perceptions towards their organisations' ability to fulfil them. Furthermore, HSIs' orientations towards their outcomes in their employment relationships responded t the "real-life contexts" they found themselves in (Dundon \& Dobbins 2015).

Thus, in answering Research Question 1 (How do wider contextual factors influence highly skilled immigrants' (HSI) psychological contracts (PC)?), findings show that wider contextual factors are internalised by HSIs and thus impact PCs by shaping HSIs' motivations to migrate (and choice of destination) and their normative expectations, as reported in Chapter 5. WCFs also seem to impact the organisational ability to fulfil HSIs' expectations, as this chapter has discussed.

Figure 8.2, presented below, is an adjustment of the conceptual framework presented in Chapter 5 in light of this discussion: 


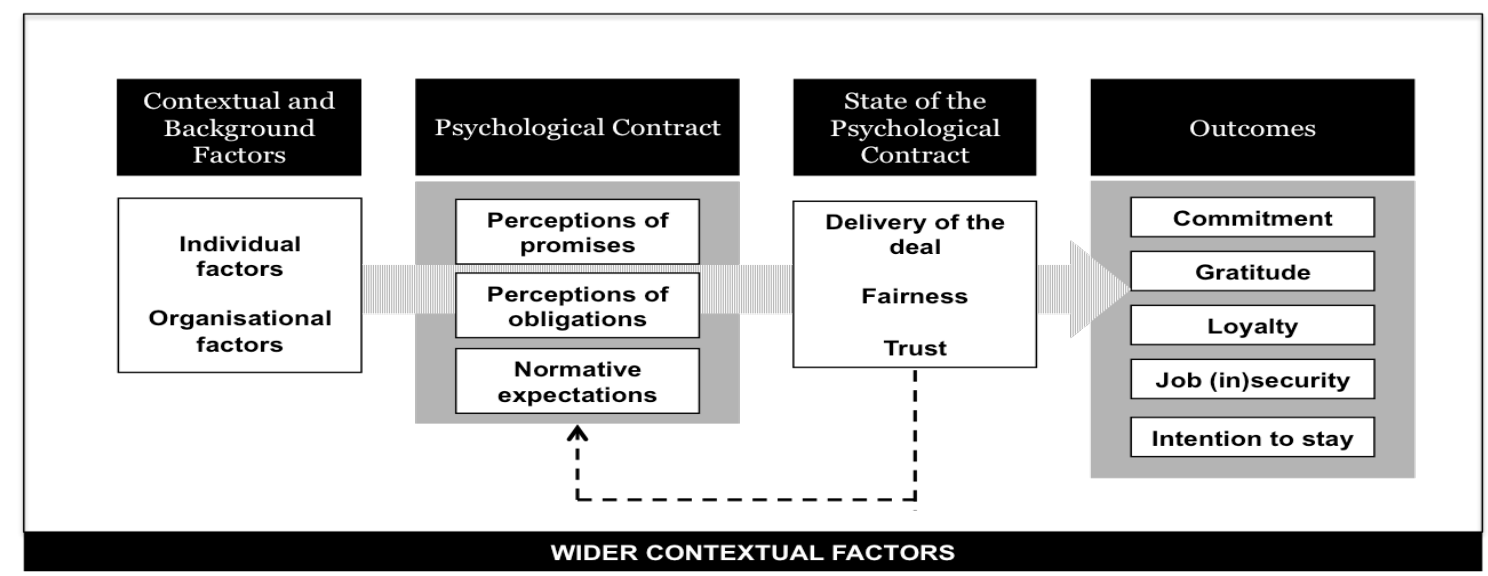

Figure 8.2. The PC as a result of an employment experience embedded in context.

Figure 8.2 illustrates the idea that contemporary PCs must be observed in light of their embeddedness in a web of social, political and economic scenarios that are constantly changing. Outcomes from this research, therefore, support the argument that greater consideration must be given to the neoliberal environment in which employment relationships are constrained and shaped (Cullinane \& Dundon 2006). This is particularly important when considering highly skilled and mobile groups whose aspirations and motivations are shaped by the neoliberal agenda of individual entrepreneurial freedom and skills (De Haas 2010).

\subsection{The PC and skilled immigrants' intentions to stay}

It has been argued in the literature that people's mobility - in terms of whether they feel like belonging or not, or whether they stay temporarily or settle in their chosen destination - is affected by a number of factors that encompass their experiences and local constraints (Roberts 2011; Skrbis 2008). Previous studies conducted elsewhere have suggested that some of these factors include experiences with racism and xenophobia, economic developments, and familial pull factors (Banerjee \& Ridzi 2008; Sadowski-Smith \& Li 2014; Wadhwa et al. 2009). Research has also concluded that skilled migrants sometimes leave after accumulating satisfactory human and financial resources, or as a result of unsuccessful or failed integration in the receiving society (Borjas \& Bratsberg 1996; Gundel \& Peters 2008).

This sub-section aims to discuss the aspects that impacted HSIs' decision to stay or leave WA and thus answer one of the research questions guiding this study. Findings from this study suggest that perceptions regarding the global labour market - or economic developments in WA and other markets - in combination with their own life 
cycles and family needs impacted their decision to stay or leave WA.

Findings presented in Chapter 7 indicate that what did impact participants' decision to leave was the perception that their employment experience in Perth had been just one more assignment in a global labour market. The testimonials of all three HSIs who left WA between Phases 2 and 3 suggest that they left as a response to the reassessment of their PCs as their organisations faced constraints caused by the political-economic context - in this case, in the context of the oil and gas industry.

P6 and P24 renegotiated their psychological contracts with their employers as a response to organisational opportunities in other countries: P6 accepted a new role in the US, and P24 accepted one in Indonesia. They both had their expectations regarding career progression previously fulfilled by their organisations, and their successful outcomes in Australia increased their tendency to consider a relocation package with their employers. As their employers promised better positions and more interesting projects in other countries while reducing their operations in WA, these individuals expanded their commitment and embraced change as the next step in their trajectories:

The labour market in Houston is booming (...) so I have been promoted, given a pay increase and twice offered shares to show that they want to keep me (...) I expect to be supported and to maintain the role for three to five years, at which stage I believe it will be time to move on (P06).

P22, on the other hand, justified her decision to leave WA (and her employer) as a negative reaction to PC breach. She had moved to Perth to follow the prospect of career growth and interesting projects, expectations that quickly faded as her organisation had to adjust to financial constraints:

So I think that even if we had stayed in Australia I would probably end up looking for another job, because it was getting very boring towards the end (P22).

Despite the fact that these three individuals (P6, P22 and P24) initially came to Australia by being sponsored by their employers and with temporary visa arrangements, they changed their status over time. By the end of this research, P06 was an Australian citizen and P24 had permanent residency. However, they had no intentions to settle in WA, nor did they feel like they belonged to Australia. Their pursuit of membership was grounded in instrumental motives (Aguillar Jr. 1999), such as facilitated admission to Australia in the future and access to a greater pool of labour opportunities. These 
participants described themselves as 'global citizens' (Suutari \& Taka 2004), able to adjust quickly to wherever they could find interesting and available positions:

I don't feel I belong anywhere. I don't feel like I belong here even though I have an Australian passport, because I am not Australian, I think you are just a global person (P06).

My basket has always been pretty much mobile. I can take my basket to any country and I will be okay (...) I wonder if with the fact that we are comfortable with (cultural) change it means that we almost have become a global employee. That becomes our culture. Despite being South African, or being British, this is such a small part of your make-up, but the big part of your make-up now is that you are a global citizen and that is the culture. And that is why we fit in; we can transfer quite easily because we can fit in different environments, because we are really not connected to a country anymore ( $\mathrm{P} 22)$.

It doesn't mean that with the PR I need to stay, but it is kind of a milestone, you need to make a decision there (P24).

On the other hand, by the end of this research, 11 HSIs had taken a long-term view and settled permanently in WA. By then, nine of them had acquired Australian citizenship; the other two (a married couple) were still British citizens. As described in Chapter 7, this couple (P07 and P08) came to Australia with the intention of returning to the UK or moving elsewhere after a few years, but the longer they stayed the more they became embedded in WA's social fabric (OECD 2001). By Phase 3, their oldest child was starting school, and they were facing the option of buying their first property in Perth.

At this point in their trajectories, throughout the ups and downs of their industries in WA's economy, some participants (P03, P10, P17, P19) during Phase 3 were counting on their perceptions of increased employability, grounded in a better understanding about WA's labour market and stronger professional networks, to justify a sense of security that had started to re-emerge. Others (P01, P11, P25, P26) started to pursue alternative paths - what some of them called back-up plans - to ensure that some income would be generated even if they lost their jobs, and that the permanency of their families in Australia was guaranteed.

\section{Findings from Chapter 7 thus indicate that individuals' decision to stay in WA was} very much grounded in their life cycle and general family circumstances. During the final phase of data collection, it was not unusual to hear testimonies about how much participants' personal lives had changed in the past four years in Australia. HSIs also frequently reported that after having children, they began to re-evaluate the importance of work and career in their lives. 
Participants, therefore, started to seek more flexible employment arrangements and an increased work-life balance with their employers $(n=5)$; they also adjusted their expectations regarding career growth and professional development $(n=7)$. Despite their perceptions regarding the embeddedness of WA's labour market in the context of economic uncertainty, these individuals settled in WA, embracing Perth as their home.

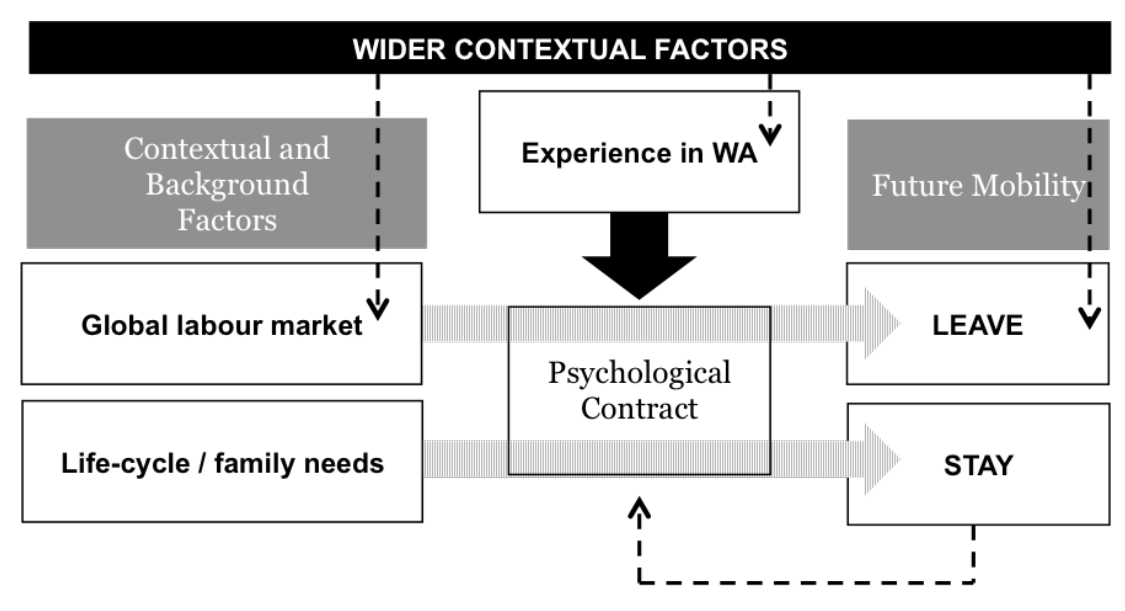

Figure 8.3. HSIs' intentions to stay or leave WA.

In answering Research Question 2 (How do highly skilled immigrants' (HSIs) psychological contracts (PC) impact their intentions to stay in WA?), this study contends that the PCs of HSIs does influence individuals' decision-making process with regard to staying or leaving WA. Findings from this research, as discussed in Chapter 7, show that a reassessment of their PCs influenced the decision by all participants to stay or leave WA. While the specificity of the contextual and background factors differed among HSIs, it was because contextual and background factors shifted (impacting what participants expected) that HSIs either left or remained in WA. This idea is illustrated in Figure 8.3 above.

A changed labour market context (when compared to the context that pulled these HSIs toward WA) along with changes in individual-level circumstances caused participants to reassess their PCs in terms of the outcomes they were seeking from their employment relationship. For some (P6, P22 and P24), changes in the economic context and pulling conditions in other labour markets triggered a shift in their PCs towards the outcome 'to leave', as their PCs were dominated by the desire to progress their careers by gaining other employment. For these participants, this reassessment of their PCs guided their behaviour to move elsewhere to take up career opportunities they had been offered. 
While the changes in the economic context also triggered shifts in the PCs of others (P01, P03, P07, P08, P10, P11, P17, P19, P25, P26), these were affected by other changes, such as personal circumstances and the attainment of a satisfactory lifestyle. For these participants, this combination of factors fostered a reassessment of their PCs towards the outcome 'to stay' and guided their subsequent behaviour of finding new avenues of employment, including developing their own self-employment enterprises.

In summary, the results from among those in the sample suggest that shifts in HSIs' background factors (such as participants' personal circumstances) and in the wider context in which their employment relations were embedded (e.g. the development of professional opportunities in other labour markets) affect what individuals need, and thus what they expect and aspire for, from their employment arrangements. This, in turn, ultimately drives HSIs' decision to stay or leave, resulting in settlement or mobility behaviour, as previously discussed in this chapter.

\subsection{Implications for the psychological contract theory}

The psychological contract literature has been around for more than 50 years and has gained substantial standing within organisational research (Conway \& Brinner 2009). The PC framework has played a valuable role in the management and employment literature, particularly since the 1980s, by enabling the development of a greater understanding of changes in individuals' employment experiences (Beaumont \& Harris 2002; Freese et al. 2011), perceptions of violation and betrayal in the workplace (Kickul 2001; Morrison \& Robinson 1997; Robinson \& Rousseau 1994), and employees' behavioural and attitudinal outcomes towards their employers (Coyle-Shapiro \& Kessler 2000; Pate et al. 2003).

However, it has been argued that the construct is unable to account for and properly explain contemporary employment relations (Guest 2004a, 2004b; Cullinane \& Dundon 2006). The PC is believed to be 'out of touch' with the idiosyncratic nature of employment and the sources of influence that play a role in the employment relationship, such as the forces of globalisation, deregulation and systemic organisation rationalisation (Cullinane \& Guest 2006; Thompson 2003). The context, the process, and the issues existing in present-day employment relations have changed (Cullinane \& Dundon 2006; Guest 2004a), and they are now much different from the organisational 
reality of the 1980s, when the PC literature gained the most traction (Conway \& Briner 2009).

In the period between 1945 and the mid-1970s, job security and opportunities for career advancement were available for most workers in Western societies, and employers' power over the terms of employment was restricted by employees' right to collective bargaining (Kalleberg 2009). In addition to a monetary wage, employees were usually eligible for benefits paid by the employer, entitlements to cover contingency risks, and social transfers from the State (Standing 1997). Long-term relationships and systems of internal development (such as promotions) facilitated investments in training that improved employees' performance, provided motivation for those who were able to move up the hierarchical ladder, and shaped loyalty and commitment (Cappelli 1999; Kalleberg 2001).

However, with the rise of globalisation in the past three decades (Webster et al. 2008), as well as technological advances (Castells 2010; Leys 2001), increased global competition (Strazdins et al. 2004), the 'financialisation' of the workplaces (Thompson 2003, 2011), and the decline of unions (Guest 2004a), the orientation in employment systems' has been pushed towards a focus on external markets (Bidwell et al. 2013). Downsizing, outsourcing and casualisation have become common practices as organisations have increasingly used layoffs to restructure their operations (Webster et al. 2008).

The stable long-term exchanges between employers and employees have been replaced by more flexible and individualised arrangements (Bidwell et al. 2013). The 'traditional psychological contract', focused on corporate career ladder and job security was replaced by the an organisational discourse towards transferable skills and employability (Thompson 2003). From a human resources management perspective, research has mostly focused on scrutinising individual-level behavioural responses to the changes imposed by these contextual dynamics over 'traditional' employment arrangements (Cullinane \& Dundon 2006; Godard 2014; Thompson 2011).

It has been argued that many organisational theories are still grounded in the experience of workers who go to their company's site on daily basis to put in a fixed number of hours with the expectation of a lifelong career (Ashford et al. 2007; Shamir 1992). This thesis contends that the psychological contract is one of these outdated organisational 
theories. PC research is mostly framed by the reality of 'standard workers' - workers who put in set hours at a firm's location with the expectation of long careers (Ashford et al. 2007) - even though a substantial number of professionals (including highly skilled migrants) are no longer in 'standard' or 'traditional' employment relationships.

Critical management academics (Cullinane \& Dundon 2006; Guest 2004a; Thompson 2011) have thus called for a new analytical framework capable of taking these matters into consideration by providing a better account of the context in which contemporary employment relations are embedded. This goal is what this research has aimed for, by using Polanyi's (1957 [1944]) approach to embeddedness as a methodological principle (Gemici 2008; Krippner et al. 2004) to properly emphasise the 'interconnectedness and wholeness' of the different spheres surrounding the HSIs' employment experience (Castles et al. 2011, p. 7), and with a methodological approach incorporating a qualitative longitudinal research design informed by the ECM (Burawoy 1998).

The conceptual framework that resulted from this case study (Figure 8.2) especially considers the effects of WCFs on the employment relationship and their role in shaping the content and outcomes of individuals' PCs. This approach to PC investigation, built from HSIs' perceptions during the three phases of data collection and analysis, suggests that contemporary employment relationships are not confined to the dyadic association between employee and employer. Rather, it recognises that there is a range of WCFs that impact this relationship and thus shape employees' judgements and the formation of their expectations (Cullinane \& Dundon 2006).

Accordingly, findings from this research and the conceptual framework offered in this chapter corroborate the argument developed in Chapter 1 that contemporary employment relationships must be perceived as a 'system of labour' that is embedded in a wider social system (Polanyi 2002 [1934], p. 239, cited in Dale 2011, pp. 320-321). In this system of labour, highly skilled employees offer their knowledge and labour not in exchange for benefits, social entitlements (Standing 1997) or a long-term relationship with their employers (Cappelli 1999), but rather for opportunities for development and professional challenges in a global labour market. So long as these requirements are met, highly skilled employees will stay with their employers. The political-economic conditions in WA and the policy features of the skilled migration framework in Australia are significant characteristics that frame the employment experience of the HSIs in this system. WCFs, therefore, cannot be left out of the understanding of HSIs' 
PCs, because they ultimately shape what HSIs desire, expect from, and seek in their employment arrangements, as well as what organisations are capable of delivering.

The observation of psychological contracts in light of the contextual forces that shape employment relations also allows for a greater understanding of situations of PC breach and the violation of expectations. Traditional explanations for psychological contract breach and violation have, so far, mostly focused on managerial failure (Kickul 2001) or market pressure (Guest \& Conway 2002). Research usually does not consider that these are 'surface level issues' (Cullinane \& Dundon 2006, p. 120) which result from the liberal market environment in which employment relations are embedded.

Findings from this study illustrate how a range of economic and institutional factors were perceived by HSIs as putting pressure on their employers and competitors, and shaping general economic conditions in a very volatile market, including the need for cost reduction, bargaining, and increasing workforce flexibility. Structural factors that emerged from the globalised and neoliberal setting in which employment relations are embedded provided substantial challenges for employers in meeting the expectations of the individuals in the sample. As Chapter 6 described, in this case study, these structural factors were, more precisely, the federal elections in 2013, the downfall of the resources industry and consequent economic downturn in WA, and the reduced funds for education in the State after the release of the Gonski Report. According to the HSIs' discourses, their organisations mostly reflected what was happening outside, in the wider political economy of global capitalism.

This thesis therefore allows for a better consideration of the embedded nature of the exchange relationship between employers and employees, rather than the promissory focus that has mostly characterised analyses of the PC (Rousseau 1989). It not only recognises the changing world of work as previous studies have done (Cullinane \& Dundon 2006; Guest 2004a), but enunciates what this really means for HSIs' PCs. This study offers a more in-depth understanding of which structural factors impacted the organisational ability to fulfil HSIs' PCs when the economic conditions in WA started to change by the second half of 2012, as well as the outcomes that HSIs expected from the PCs. Finally, it provides some grounding for reconsiderations about individuals' consciousness in the process of psychological formation, fulfilment and breach. 
As Chapter 5 discussed, HSIs' psychological contracts were mostly grounded in normative expectations; thus, expectations arose from what these individuals perceived as common practices occurring around them (Roehling 2008). HSIs barely recognised any agreement other than contractual ones, or any explicit promises in their employment relationships. This particular group seemed to have an understanding that institutional, economic, political and regulatory issues are significant matters that impact their organisations and their ability to deliver the deal. However, they also acknowledged that these structural factors are typically outside of management control:

The company has to find that balance over what they provide outside of the basics of your salary and the hours, against how they balance the rest of the economy of the company while they wait for these [structural] things to happen. So for instance, they might ask people to only work four days a week and that type of thing and, of course, employees don't want that because it is a reduction in salary, but by the same token, there is not much work (P06).

\subsection{New outcomes to the PC: Issues of insecurity, membership and belonging}

The discussion about migrant insecurity in the global system is usually focused on diasporic communities, minority groups and low-skilled labour movements (Robertson 2015b). While it has been recognised that insecurity manifests itself within different nations, ethnic groups, and communities (McDuie-Ra 2007), the discussion usually does not include the highly skilled. Findings from this research, however, reveal that there is a level of insecurity that also affects this group.

A general feeling of insecurity was evident among participants in Phase 2 of this study, as these individuals witnessed massive dismissals in their organisations, among their competitors, and even within other sectors of WA's economy. Findings reported in this study show that HSIs do experience job insecurity and distress just by observing the context of their employment relationships, even if they do not feel like their jobs are directly under threat (Strazdins et al. 2004).

As discussed in Chapter 6, individuals who held a temporary 457 business visa during Phase 2 felt particularly more insecure during this period, as they perceived a stronger threat of losing their jobs (Greenhalgh \& Rosenblatt 1984) than those who already had permanent residency status. Temporary labour migration has been largely used in Australia since the 1990s, but the expansion of employer-sponsored visas was motivated by a broader agenda of promoting greater labour market flexibility (Walsh 
2014; Wright 2012). Historically, temporary working visas have been used to respond to oscillations in the Australian economy, supporting specific economic sectors facing workforce shortages (Caspersz 2012; Collins 2013).

When WA's economy declined from the second half of 2012 (Tillet 2012), these temporary migrants found themselves in a highly vulnerable situation. HSIs' uncertainty emerged not from their 'imperfect knowledge' conditions in Australia or elsewhere, but because of the unpredictability of the future (Williams \& Balaz 2011, p. 168). When this study was conducted, in the case of dismissal, 457 visa holders had just 28 days to find another organisation willing not only to employ them, but also to become their sponsors (DIAC 2012d). Temporary skilled immigrants were aware of the precariousness of their positions with their employers, and acknowledged that the prospect of staying was dependent on their employers' goodwill (Boese et al. 2013). Participants also recognised the challenge of acquiring a new sponsoring employer in such an unpredictable economic environment:

On the other hand, from an employee perspective, you have your four weeks' notice and that's it, so you can be gone quite quickly (...) what concerned me was indeed if you lose your job, you have four weeks to leave the country unless you find a new job (P14).

You know you have just one month to find another job and a sponsor (...) I would be sad and afraid if I lost my job. Australia is the place I want to live now (P19).

For this group, the consequences of a potential job loss seemed to go beyond the monetary compensation that a job is expected to ensure (Thompson 1967). It affected their perceptions of employability and opportunities for future career development (Ghoshal \& Bartlett 1997). More importantly, though, the uncertainty encompassed their and their families' personal lives, as the threat of losing their jobs created a greater threat of having to leave the country altogether (DIAC 2012d).

Despite the fact that these individuals did not experience any income inequalities while in Australia - as discrimination in terms of the distribution of resources, status and power is considered decisive for pursuing further opportunities (Faist \& Bilecen 2015) they were not citizens and thus acknowledged a limited range of rights. Those with temporary visa arrangements were particularly affected, as they were unable to vote in elections or get involved in political roles; they were also unable to apply for job positions in the public sector, had no access to welfare and social protection structures, and had to pay for public education. They were not the 'precariat' in the full sense of 
Standing's $(2012$, 2014) definition, but they were 'denizens': aliens with partial membership rights (Faist 2010) in the civil, cultural, political and social spheres (Standing 2014). In order to increase their feeling of membership - and thus social security - nine out of the 11 individuals in the sample who came to Australia with a 457 visa pursued permanent residency as soon as they were eligible for it. By the end of Phase 3, 15 of the 26 individuals in the sample were Australian citizens.

Acquiring Australian citizenship ensured that the individuals who stayed in WA developed a stronger affiliation to their communities, increased political participation and access to social rights (Faist 2010). Formal features of their membership in Australian society - in the civil and political spheres, for example - suggested that these HSIs had achieved social inclusion, at least at a formal level. It also suggested that they were no longer denizens with partial rights, living in a 'grey area' between inclusion and exclusion (Robertson 2015b, p. 939), but citizens with full membership in Australian society (Standing 2012, 2014). Citizenship has been seen as a fundamental process of 'boundary drawing' and a definer of inclusion and exclusion across much of the world over the last two centuries (Faist 2010, p. 1679). Particularly in the context of skilled labour migration, the offer of citizenship for talented individuals with specific knowledge and skills has strengthened its character as a "strategically produced form of capital", as defined by Bauder (2008, p.315).

However, these individuals occasionally recounted feelings of still being foreigners. They reported a continuous process of assimilation (Portes 1997) - grasping the culture, working on their social ties, and adjusting to the absence of family, for example - even after living and working in Australia for a few years. Practiced and cultural aspects of their lives in Australia (Bauder 2008) still left these individuals with some vulnerabilities, impacted their constructions of identity, and inflicted feelings of exclusion:

It may sound silly but when you sit with others, Aussies, and you have a conversation, it is exactly when you feel that you don't belong. Because the sense of humour is different, the cultural background is completely different... I would call this the 'vegemite-effect'. It is not good, nobody would say that it tastes good, but you eat Vegemite since you were one-year-old, so you learn it, it is a cultural thing. We will never like Vegemite and that applies to everything - food, songs, humour, anything, you name it (P03).

A 'bad Australian day' was a day where something happened that would have been very foreign and would have made me long to go back. So it could have been anything from having walked into a shop and, if I was looking for a particular cook 
book because I wanted a recipe and it was something that I wanted to make and I would go into the shop and walk up and down the aisles and just wouldn't be able to find the equivalent here (...) And it would hit me on a bad day and I would think that South Africa was still home (...) Or it would be when I had spoken to my mum on the phone and was really missing my family (P11).

Even if these individuals were no longer excluded from politics and the Australian welfare system, by Phase 3 of the research, participants who had settled in WA were still working on their integration in a number of spheres, including social and cultural ones. Differently from the group who left WA, though, none of these individuals classified themselves as 'global citizens' (Suutari \& Taka 2004). They felt accomplished in Australia and determined to overcome any signs of cultural alienation - if not for them, then at least for their children.

It is important to note that the outcomes that emerged in the case of HSIs in WA's labour market, which were related to participants' perception of insecurity and issues they faced regarding perceptions of membership and belonging, are only perceptible when individuals' experiences are observed via a holistic approach (Block 2003; Gemici 2008). Only when individuals' PCs are considered in the wider context in which their employment relationships are embedded (Polanyi 1957 [1944]) can significant outcomes that go beyond the dyadic relation between employee and employer be acknowledged.

Issues of belonging and membership are becoming particularly problematic among those in non-standard employment arrangements (Ashford et al. 2007), such as migrants. Their 'precarity' surrounds their labour and the most intimate spheres of their lives (Robertson 2015b). Therefore, as this thesis suggests, a more comprehensive approach to the PC construct contributes to the development of an understanding of the outcomes that matter for skilled and mobile workforces - outcomes that delineate these individuals' intentions to stay or leave a destination. These outcomes are particularly important in the context of Australia's need to enhance competitiveness in the global economy (Hugo 2004), the significance of labour migration for fostering the labour market flexibility that will encourage such competitiveness (Shah et al. 2005; Wright 2014), and the demographic challenges facing Australian society (Caspersz 2012), as discussed in Chapter 1. 


\subsection{Implications for management and policy}

The theoretical implications that this work offers include a conceptualisation of and empirical contribution about the significance of contextual factors for the understanding of HSIs' psychological contracts, as this chapter has described. This research has offered a fine-tuned model for examining contemporary PCs and valuable insights about the employment experiences of skilled labour migrants. Implications for management and policy are discussed next.

Over the past 20 years, interest in global forms of employment has increased. A great deal of literature has been published on global careers and talent flows (Al Ariss 2014; Dickmann \& Harris 2005; Suutari \& Taka 2004; Thomas et al. 2005) as the processes whereby economically valuable individuals migrate between countries, as was depicted in this thesis. Scholars agree that this is a phenomenon with implications for individuals, their employers, and both sending and receiving countries. At the individual level, global forms of employment impose not only career transition concerns and perceptual barriers, but also stress, coping strategies, and the transformation of identity and belonging (Shaffer et al. 2012). In the organisational sphere, these forms drive human resources (HR) strategies, including the identification, attraction, development and retention of the high skilled (Suutari et al. 2013). On a policy level, migratory movements are increasingly challenging national frameworks, particularly regarding welfare regimes and provisions (Faist et al. 2015).

Findings from this research have provided a clearer understanding of HSIs' psychological contracts. This understanding offers significant implications for those managing such global talents in WA's organisations, in the context of the switching on and switching off of demand for immigrants (Castles 2000). The findings reflected the role that labour movements have in determining other aspects of HSIs' lives - for example, their families' choice about whether to settle in a destination country. Organisations must thus embrace the fact that they have responsibility and accountability for the skilled migrants they bring to Australia, and that their relationship goes far beyond the contractual aspects of an employment agreement.

The findings also suggest that a major challenge for HR practitioners involves understanding individuals' objectives for migration when formulating development or career plans for HSIs. It also involves dealing with eventual breaches in their PCs - 
even if the breaches are imposed by outside forces - and the problems these breaches present in terms of trust and perceptions of fairness. Beyond just offering a more flexible package of responsibilities and rewards to highly skilled employees, HR practitioners must endeavour to set and honour individual deals, after thoroughly discussing the aims and needs of each one of the HSIs they intend to retain. This is a complex task even for organisations with well-established performance management processes, requiring not only open and regular dialogue, but also conscious and capable leadership.

Furthermore, findings from this research offer noteworthy implications for migration policy. Australian international migration policy has been influenced by a paradigmatic shift in focus since the 1990s, from migration as a definitive permanent relocation process to a transnationalism perspective (Hugo 2011). For many years, Australia's migration framework comprised a range of visa categories designed to attract temporary residents to work in the country, a strategy that was in accordance with similar shifts occurring all around the globe. A report from the Global Commission on International Migration (2005, p. 31) concluded that "the old paradigm of permanent migrant settlement is progressively giving away to temporary and circular migration" and that there is a need "to grasp the developmental opportunities that this important shift in migration patterns provides".

Yet, this study has shown that this claim is only partly true. Indeed, WA receives HSIs who are not interested in settling in Australia, but rather in learning new skills, developing new capabilities, and moving a step further in their global career paths. However, permanent settlement in Australia was not seen as an 'old paradigm' for most individuals in the sample, who actually used their qualifications to secure for their families what they believed to be a better life: more professional opportunities for those coming from Europe and a greater perception of safety for those coming from Africa, for example. As previous research has found (Boese et al. 2013), skilled migrants see themselves as being on a path towards settlement and citizenship in the destination country.

As Castles (2013) argued, migration is an important aspect of human development, and throughout human history, people have migrated in order to improve their livelihoods. The primacy of Australia as a settler immigration society must be regained, and the country should reject the trend towards a predominantly guest-work immigration model 
(Collins 2013, p. 170). The amendments that came into force from July 2013, extending to 90 days the period in which 457 visa holders can stay in Australia following the termination of their employment (rather than 28 days) may represent a first step in this direction.

Notwithstanding, this research's findings also suggest that greater attention needs to be paid to how the PCs of HSIs change as a response to contextual factors in the wider economic and political context in which they live. While linked to wider life cycles and family needs, decision making by HSIs about remaining in or leaving WA is strongly impacted by their lived employment experiences while in the Australian labour market. These experiences can lead to commitment, gratitude, loyalty and the intention to stay. However, more recently, these experiences have increasingly led to insecurity, uncertainty and precarity. At a policy-making level, then, greater attention needs to be paid to how to mitigate the effects of these changes on the lived experiences of skilled immigrants. Fostering relations and social networks that create a sense of belonging may ensure their retention even when the context encourages them to leave.

\subsection{Limitations}

The findings presented in this thesis must be considered against a number of limitations resulting from the research design adopted, as well as some other restrictions. These refer to budget and time constraints, continuous access to participants throughout the three waves of data collection, and the impossibility of access to organisations (therefore, employers). Although these limitations must be stated, they do not reduce the value of this research's findings.

While the use of a qualitative case study design was justified by the objectives of this study, as previously discussed in Chapter 4, some methodological limitations were intrinsic to this methodological approach. This refers particularly to the issue of generalisation in case studies (Stark \& Torrance 2004). Findings from one specific group - HSIs working in the context of WA's labour market during the 2010-2014 period - must be understood in light of the specific conditions in which the case is embedded.

Even so, the findings do paint a picture that reflects contemporary trends of skilled labour migration as a growing phenomenon in terms of scope and complexity (Caspersz 
2013, p. 169), as well as its inevitable use as a labour force-planning and skill strategy (Castles 2013; Collings et al. 2009; DTWD 2011). This picture can be particularly applied to other receiving countries, such as Canada and the US, which have also been promoting temporary migration as a mechanism of labour market flexibility in response to their industries' needs (Walsh 2014).

It is also important to note that the main goal of this research as an ECM was not the generalisation of findings, but a contextualisation to allow for greater elaboration of the PC as a pre-existing theory (Burawoy 1998). The methodology adopted in this research supported a theoretical confrontation of the PC construct, and provided a framework that can be applied to psychological contract research in other conditions, times and spaces, as discussed in this chapter.

In addition to these methodological boundaries, the research findings must be considered within the time and budget constraints characteristic of $\mathrm{PhD}$ studies. In the case of this thesis, time and budget limitations actually represented the main difficulty faced by the researcher: access to participants, both individuals and organisations, throughout the four-year period of data collection.

The researcher initially aimed to have an organisation as part of the sample so that access to employees would be better facilitated, as well as access to those who could represent the employer in the employment relationship. As time passed though, it proved impossible to have organisations engaged with this study. The researcher had to adjust the research design and recruit participants in accordance to the sampling frame, a process that took two years (2010-2012) because the researcher also had a maternity leave in this period.

Although a group of 26 individuals with the required characteristics was achieved by the third year of the $\mathrm{PhD}$ candidature, a longitudinal perspective on their experiences and PCs was necessary to answer the research questions. Thus, time restrictions determined the closing date for each one of the subsequent waves of data collection, sometimes limiting the number of participants in each phase. Some of the participants left WA after the first round of interviews, and although social media helped the researcher to map these individuals, they were no longer experiencing the WA labour market; a such, they could no longer be considered a part of the sample for the longitudinal investigation. 
Finally, the absence of the employer's voice when exploring the impacts of organisational constraints, managerial failure and PC renegotiation was the main limitation in this study. Employers' perspectives on PC formation and violation have been largely unexplored in the literature (Cullinane \& Dundon 2006; Guest \& Conway 2002). If the employer perspective had been considered in the PC research, it would undoubtedly have allowed a greater understanding of the mutual perceptions of promises and obligations in the employment relationship and provided better insight into the social exchange interaction between the parties. Furthermore, it would have allowed the researcher to better explore the constraints imposed on Australian organisations when the political-economic scenario became more volatile, as well as the reasoning behind employers' decisions to promote or dismiss skilled labour migrants.

This work recognises that the psychological contract, like the employment contract, involves two parties (Guest 2004a, p. 6), but it also acknowledges the difficulties in exploring the employer side of the deal, as discussed in Chapter 3. Focusing on the interpretations of the messages that employees received during the research period, not only from their employers but also from the wider socioeconomic scenario in which their employment was embedded, was an alternative path towards overcoming this limitation.

\subsection{Future research}

A number of opportunities for future academic research were identified as a result of this case study. These are summarised in this section.

First, the investigation of the impacts of contextual factors over HSIs' PCs suggests that players (other than the employer) in the wider environment do impact individuals' perceptions and expectations regarding their employment relationships. In the case of HSIs, some of these players include migration agents and international recruiters. Some individuals' testimonials suggested that these intermediaries generated significant anticipation during their migration process, creating work-related normative expectations even before these they actually had an employment arrangement at the destination. Although not explored in this thesis, intermediaries seem to offer 'societal beliefs' during HSIs' pre-employment phase, an occurrence widely recognised by the literature as influential in PC formation and evolution (Guest \& Clinton 2010; Rousseau 2001). Future research must confirm the impact of third party input on immigrants' 
perceptions and expectations and further investigate the message that these intermediaries are conveying with regard to WA.

Second, it would be interesting and relevant to investigate employers' perspectives in WA's labour market. As justified in the previous section, findings from this thesis do not reveal the perspectives of the employers as the other parties in the employment relationship. However, HSIs' testimonials suggest that different organisations have different perceptions and policies towards the skilled individuals they recruit or bring to Australia. The findings also suggest that some approaches to talent management and retention were very successful, while others were not. Is this a matter of leadership competency, HR policies, or just different approaches towards the retention of those who are more (or less) valuable employees?

Third, gender issues are another area for further investigation, especially those focusing on spousal arrangements. It would be interesting and relevant to investigate women's perspectives, given that the findings suggest that many female HSIs have more limited expectations and career ambitions due to their dual roles, even when they are highly skilled and the primary holders of their PR visas.

Fourth, Faist and colleagues (2015) have recently argued that migration studies should inquire about migrants' cross-border social protection strategies - as the multiple forms individuals use to cope with the risks resulting from their involvement in production and reproduction processes. Social protection was not a topic explored in this research, nor was formal, State-based social protection or informal protection by migrants' networks. However, the findings did suggest that even skilled migrants face insecurity and risk, despite having a more secure working status (Faist \& Bilecen 2015). HSIs' perspectives regarding their social protection while in Australia and how this impacted their employment relationships and/or intentions to stay, must be further investigated and discussed in the context of this group's global mobility and transnational interconnectedness.

Finally, although there is much about WA's context that can be further investigated, this thesis represents a particular case study focused on a very peculiar labour market embracing a period of economic uncertainty. However, this longitudinal investigation can be extended to other cities and other countries. Furthermore, the conceptual framework designed for this research (Figure 8.2) can be applied to any other PC 
investigation that takes into consideration the role of the context in which the employment relationship is embedded.

\section{Concluding remarks}

The aim of this thesis was to explore the psychological contracts (PCs) of highly skilled immigrants (HSIs) in Western Australia (WA) and how HSIs' PCs influence their decision to engage and remain in WA's labour market. To provide this analysis, the PC conceptual framework was adjusted to consider contextual eventualities that influence the employment relationship and employees' perceptions regarding their deals in the contemporary context of capitalism and free market ideology (Cullinane \& Dundon 2006; Guest 2004a, 2004b). This research was thus guided by Polanyi's (1957[1944]) concept of embeddedness to give proper consideration to the wider social, political and economic context that affected the PCs of HSIs in the period of this study, from 2010 to 2014.

Burawoy's (1998) extended case method (ECM) was chosen to inform this case study because, as a methodology, it was expected to allow for rich descriptions of these individuals' realities in their particular contexts; moreover, the ECM approach was also expected to support this research in its aim to contribute towards a more contemporary development of the PC construct. The ECM supported extracting the general from the unique, moving from micro to macro, and allowing for reflection upon and improvement of pre-existing theory (Burawoy 1998). From the findings of this research - reported in Chapters 5, 6 and 7-two key arguments previously discussed in Chapter 8 can be used to answer the questions that guided this research.

Firstly, wider contextual factors influence HSIs' psychological contracts by influencing individuals' motives to migrate, their choice of destination, their normative expectations, and their general perceptions in their workplaces, particularly with respect to what they believe their employers are able to deliver. This happens because contextual factors are internalised by HSIs, shaping their consciousness and their overall perceptions regarding their employment arrangements. HSIs' perceptions and expectations change as a response to labour market conditions, political circumstances, and macro-economic context, among other factors.

This research supports the argument that the employment experiences of highly skilled 
immigrants are complex and context-dependent, and thus their psychological contracts must be understood in light of the multi-layered circumstances in which they are embedded (Guest 2004a, 2004b; Cullinane \& Dundon 2006). This involves individuals' background factors, such as their life cycles, and the socioeconomic and political environment, not only in the places where their employment is taking place but in other prospective migration destinations as well. This thesis offered a framework for the investigation of psychological contracts that took these contextual aspects into consideration.

Secondly, results from this research indicate that HSIs' relocation pathways are supported by strategically motivated professional goals as well as emotional attachments resulting from their increased membership in local communities. HSIs' psychological contracts are shaped by individual background factors and contextual factors; HSIs' PCs influence individuals' decision-making processes with respect to staying or leaving a destination.

Participants' intentions to leave WA were justified by their perceptions regarding economic conditions in Australia and other labour markets. Those who left reported making an assessment, based on fulfilment and breach, of their expectations while in WA. These participants (P06, P22, P24) had career expectations above any other, and left WA when economic constraints started to impact their organisations and projects. Those who had organisational support for their next move continued in their employment relationships. They had their expectations, trust, and behavioural outcomes towards their employment relationships reinforced in a feedback loop.

Participants' intentions to stay in WA, however, were grounded in their own life cycle, particular family needs, and the personal ties they had developed over time. During the four-year period of this investigation, participants started families and had children, developing stronger participation in their communities through school, sports or church involvement. Those who stayed based their decision on individual factors, but also reassessed their PCs in terms of what they could truly expect from their employment and their careers. HSIs (P01, P03, P08, P10, P11, P17, P19, P25) reduced professional expectations and focused on flexibility, work-life balance or increasing their employment security. All of these individuals had their PCs fulfilled in the past, and once holding the 'assets' believed to ensure them some level of employability prestigious work experience in WA, professional networks and the PR (or Australian 
citizenship) - did not intend to leave.

Two other sets of findings provided significant insights into the lived experience of HSIs in WA. Firstly, despite HSIs' possession of valued skills and mobility potential, they experienced insecurity when the context in WA changed and imposed constraints on their employing organisations. The threat of job loss was particularly severe (Greenhalgh \& Rosenblatt 1984) for those with temporary business visa arrangements, who faced the risk of having to leave Australia altogether. HSIs' statements reinforced the necessity for more comprehensive discussions about migrants' insecurity, beyond the focus on diasporas, refugees, and low-skilled or forced labour migrants.

Secondly, longitudinal analysis indicated that individuals with different visa arrangements on arrival presented different characteristics and intentions towards their employment arrangements, in accordance with other studies previously conducted elsewhere (Andresen et al. 2012; Biemann \& Andresen 2010; Inkson et al. 1997; Jokinen et al. 2008; Suutari \& Brewster 2000). In this sample, individuals who held a temporary business visa sponsored by their employers tended to describe a relational PC (Rousseau 1989), demonstrating affective commitment (Meyer \& Allen 1991) and gratitude (Adler \& Fagley 2005) towards their employers more often. For those for whom migration was a self-initiated venture, staying with their employers was dependent on the employment arrangement being perceived as beneficial to their professional trajectories in the new country - this group was more focused on their prosperity within Australia. As HSIs' status changed from temporary to permanent over time, so did the characteristics and content of their PCs with their employers.

It has been argued that the migration literature has so far failed to conceptualise with precision how changes in macro conditions impact the causes and continuance of migration (De Haas 2010). It has also been argued that the existing psychological contract framework needs to be reviewed and modified to enable the analysis of social exchange interactions that occur between employee and employer in the wider context of neoliberal capitalism (Cullinane \& Dundon 2006). In attempting to build a conceptual framework more suitable for investigating the psychological contract of highly skilled migrants in the context of the free market ideology that pulls and pushes these individuals worldwide, this study tried to reconcile these two arguments, as well as the migration and employment relations theories. As a result, this study also 
reconciled associations between macro and micro levels; between time and space; between dynamics and outcomes; between settlement and movement.

Although findings from this study reflect perceptions collected in a particular labour market during a specific period in time, they also illustrate how socio- and politicaleconomic contextual factors are in fact internalised by HSIs, moulding their consciousness and lived experiences. Contextual factors shape an understanding that is developed through time about how HSIs' industries and organisations operate in a global scenario and what their employers are really able to deliver in this neoliberal setting. As a result, these contextual factors do influence individuals' PCs, their normative expectations, and the outcomes of their employment relationships. Ultimately, contextual factors influence HSIs' decisions towards leaving or staying in a destination.

In conclusion, the significance of contextual factors was reinforced many times throughout the participants' stories. WCF influenced not only what HSIs expected from WA (their reasons for migrating), but also what they expected from their employers and what they perceived as a PC breach. The existence of a sponsor relationship between employer and employee, which emerges strictly from a contextual need (skill shortages, given economic development), drives the type of attachment employees will have with their employer-sponsor, and any eventual outcomes from there. Finally, the wider context in which employment relationships occur affects an organisation's ability to fulfil the 'deal'. The understanding of HSIs' PCs, therefore, must not neglect the environment in which their employment relationships are embedded.

This thesis has a number of limitations, as previously discussed in this chapter. Particularly, it lacks the 'employer side' when trying to unpack the impact of contextual constraints on organisations and managerial perceptions regarding PC renegotiation. Even so, it has provided a number of contributions. It has contributed to the employment relations literature by empirically illustrating the importance of contextual factors to the PC construct; moreover, it has supported arguments for the adjustment of the framework to better account for the employment relations of mobile individuals in this new milieu of free market and globalisation. It has also contributed to the migration literature and policymaking by enhancing our understanding of HSIs' professional experiences in WA and their willingness to stay, as they represent significant participation in Australia's labour market flexibility. It has explored the experiences of 
this particular group and considered issues of citizenship, membership, and inclusion and exclusion, which are usually reserved for refugees and unskilled migrants. Finally, it has contributed to the debate around labour market insecurity, which is no longer confined to low- and non-skilled individuals. 


\section{Reference List}

ABC News 2013, 'What's in the Gonski report? ', ABC News, 2 August 2013. Available from: http://www.abc.net.au/news/2012-08-27/what's-in-the-gonski-report/4219508 [3 August 2013]

Abella, M 2006, 'Policies and Best Practices for Management of Temporary Migration', International Symposium on International Migration and Development. Turin, 28-30 June.

Adler, MG \& Fagley, NS 2005, 'Appreciation: Individual differences in finding value and meaning as a unique predictor of subjective well-being', Journal of Personality, vol. 73, pp. $79-114$.

AEGIS/AMWU 2006, Temporary Skilled Migration: A new form of indentured servitude. A report based on research undertaken by the Australian Expert group in Industry Studies, University of Western Sydney and the Australian Manufacturing Workers' Union. Available from: www.australianreview.net/digest/2008/04/cooper.html [10 October 2015].

Aguillar Jr., FV 1999, 'The triumph of instrumental citizenship? Migrations, identities, and the nation-state in Southeast Asia', Asian Studies Review, vol. 23, no. 3, pp. 307-336.

Al Ariss, A 2014, Global Talent Management, Springer, Switzerland.

Al-Rodhan, NRF \& Stoudmann, G 2006, Definitions of Globalization: A Comprehensive Overview and a Proposed Definition, Geneva Centre for Security Policy, Geneva.

Amaral, EF \& Fusco, W 2005, Shaping Brazil: The Role of International Migration, Migration Policy Institute.

Anderson, N \& Schalk, R 1998, 'The psychological contract in retrospect and prospect', Journal of Organizational Behavior, vol. 19, pp. 637-647.

Andersson, LM 1996, 'Employee cynism: an examination using a contract violation framework', Human Relations, vol. 49, no. 11, pp. 1359-1418.

Andresen, M, Biemann, T \& Pattie, M 2012, 'What makes them move abroad? Reviewing and exploring differences between self-initiated and assigned expatriation', The International Journal of Human Resource Management, pp. 1-16.

Argyris, C 1960, Understanding Organisational Behaviour, Dorsey, Homewood, IL.

Armstrong, RW \& Krasnostein, JP 1995, 'The cultural convergence of MBA education across Australia, Singapore and Malaysia', Journal of Teaching in International Business, vol. 7, no. 1, pp. 45-60.

Arthur, M \& Rousseau, DM 1996, The Boundaryless Career: A New Employment Principle for a New Organisational Era, Oxford University Press, New York.

Ashford, SJ, George, E \& Blatt, R 2007, 'Old Assumptions, New Work: The Opportunities and Challenges of Research on Nonstandard Employment', Academy of Management Annals, vol. 1, no. 1, pp. 65-117.

Atkinson, J 1984, 'Manpower Strategies for Flexible Organisations', Personnel Management, vol. August, pp. 28-31.

Atkinson, C 2007, 'Trust and the psychological contract', Employee Relations, vol. 29, no. 3, pp. 227-246.

Australian Associated Press (AAP) 2013, End of 'jobs for life' in WA public sector in Australian Associated Press (AAP), 30 May 2013.

Australian Bureau of Agricultural and Resource Economics and Sciences (ABARES) 2011, Australian Commodities - Statistical Tables, Government of Australia, Canberra.

Australian Bureau of Statistics (ABS) 2010, The Global Financial Crisis and Its Impacts on Australia, Government of Australia, Canberra.

Australian Bureau of Statistics (ABS) 2011, Australian National Accounts: State Accounts 2009-10, Table 6, Government of Australia, Canberra.

Australian Bureau of Statistics (ABS) 2011a, Labour force, Australia, Detailed, Quarterly, Government of Australia, Canberra.

Australian Bureau of Statistics (ABS) 2012, Reflecting a Nation: Stories from the 2011 Census, 2012-2013, Government of Australia, Canberra. 
Australian Bureau of Statistics (ABS) 2012a, Western Australia at a Glance 2012, Government of Australia, Canberra.

Australian Bureau of Statistics (ABS) 2012b, Average Weekly Earnings, May 2012, Cat.6302.0, Government of Australia, Canberra.

Australian Bureau of Statistics (ABS) 2012c, Year Book Australia 2012, Government of Australia, Canberra.

Australian Bureau of Statistics (ABS) 2014, Mining Operations, Australia, 2012-13 Cat.8415.0, Government of Australia, Canberra.

Australian Bureau of Statistics (ABS) 2015, Migration, Australia, 2013-14, Cat. 3412-0, Government of Australia, Canberra.

Australian Petroleum Production \& Exploration Association (APPEA) 2013, Cutting Green Tape - Streamlining Major Oil and Gas Project Environmental Approvals Processes in Australia, Australia.

Australian Petroleum Production \& Exploration Association (APPEA) 2015, Australia LNG Projects. Available from: $<\mathrm{http}: / / \mathrm{www}$.appea.com.au/oil-gasexplained/operation/australian-lng-projects/>. [14 January 2016].

Australian Trade Commission (ATC) 2013, Oil and Gas, Australian Trade Commission (ATC), Commonwealth of Australia, Canberra.

Bakewell, O 2010, 'Some Reflections on Structure and Agency in Migration Theory', Journal of Ethnic and Migration Studies, vol. 36, no. 10, pp. 1689-1708.

Balaz, V, Williams, AM \& Kollar, D 2004, 'Temporary versus Permanent Youth Brain Drain: Economic Implications', International Migration, vol. 42, no. 4, pp. 3-32.

Banerjee, P \& Ridzi, F 2008, 'Indian IT workers and black TANF clients in the new economy: a comparative analysis of the racialization of immigration and welfare policies in the US', Race, Gender \& Class, vol. 15, no. 1-2, pp. 98-114.

Bankins, S 2014, 'Delving into promises: Conceptually exploring the beliefs constituting the contemporary psychological contract', Journal of Management \& Organization, vol. 20, no. 4 , pp. 544-566.

Barnetson, B \& Foster, J 2013, 'The Political Justification of Migrant Workers in Alberta, Canada', International Migration \& Integration, vol. 15, pp. 349-370.

Barry, CA 1998, 'Choosing Qualitative Data Analysis Software: Atlas/Ti and Nudist Compared', Sociological Research Online, vol. 3, no. 3, pp. 1-17.

Baruch, Y 2001, 'Employability: a substitute for loyalty?' Human Resource Development International, vol. 4, no. 4, pp. 543-566.

Bauder, H 2008, 'Citizenship as Capital: The Distinction of Migrant Labour', Alternatives, vol. 33 , no. 3, pp. 315-333.

Baxter, P \& Jack, S 2008, 'Qualitative Case Study Methodology: Study Design and Implementation for Novice Researchers', The Qualitative Report, vol. 13, no. 4, pp. 544-559.

Bazeley, P \& Jackson, K 2007, Qualitative Data Analysis with NVivo, Sage Publications Thousand Oaks, CA.

Beaumont, PB \& Harris, RID 2002, 'Examining white-collar downsizing as a cause of change in the psychological contract', Employee Relations, vol. 24, no. 4, pp. 378-388.

Beaverstock, JV 2002, 'Transnational elites in global cities: British expatriates in Singapore's financial district', Geoforum, vol. 33, pp. 525-538.

Beaverstock, JV 2005, 'Transnational Elites in the City: British Highly-Skilled Inter-Company Transferees in New York City's Financial District', Journal of Ethnic and Migration Studies, vol. 31, no. 2, pp. 245-268.

Beckert, J 2007, 'The Great Transformation of Embeddedness: Karl Polanyi and the New Economic Sociology', Max Planck Institute for the Study of Societies, vol. Discussion Paper 07/1.

Bellou, V 2007, 'Psychological Contract assessment after a major organizational change: the case of mergers and acquisitions', Employee Relations, vol. 29, no. 1, pp. 68-88.

Berg, L 2016, Migrant Rights at Work: law's Precariousness at the Intersection of Immigration and Labour, Routledge, Oxon.

Berger, FR 1975, 'Gratitude', Ethics, vol. 85, pp. 298-309.

Berntson, E, Naswall, K \& Sverke, M 2010, 'The moderating role of employability in the 
association between job insecurity and exit, voice, loyalty and neglect', Economic and Industrial Democracy, vol. 3, no. 2, pp. 215-230.

Bidwell, M, Briscoe, F, Fernandez-Mateo, I \& Sterling, A 2013, 'The Employment Relationship and Inequality: How and Why Changes in Employment Practices are Reshaping Rewards in Organizations', The Academy of Management Annals, vol. 7, no. 1, pp. 61121.

Biemann, T \& Andresen, M 2010, 'Self-initiated foreign expatriates versus assigned expatriates: Two distinct types of international careers?' Journal of Managerial Psychology, vol. 25, no. 4, pp. 430-488.

Birrell, B \& Healy, E 2008, 'How are skilled migrants doing?' People and Place, vol. 16, no. 1, pp. 1-19.

Birrell, B \& Healy, E 2012, Immigration Overshoot, Melbourne.

Bowen, C 2012, 'Immigration paves our way into the Asian century', The Australian, 9 March 2012, p. 14.

Blackmon, D 2013, 'Texas Oil and Gas Numbers Fly Off the Charts', Forbes Magazine, 08 August 2013.

Blau, PM 1964, Exchange and power in social life, Wiley, New York.

Blitz, B 2010, 'Highly Skilled Migration', in The International Studies Encyclopaedia, WileyBlackwell, Oxford, pp. 3292-3320.

Block, F 2003, 'Karl Polanyi and the Writing of The Great Transformation', Theory and Society, vol. 32 , no. 3 , pp. 275-306.

Boltanski, L \& Chiapello, E 2005, The new spirit of capitalism, Verso, London.

Boese, M 2015, 'The roles of employers in the regional settlement of recently arrived migrants and refugees', Journal of Sociology, vol. 51, no. 2, pp. 401-416.

Boese, M \& Campbell, I 2013, 'Temporary labour migration and experiences of risk and uncertainty', in Proceedings of the Australian Sociological Association (TASA) Conference; Reflections, Intersections and Aspirations 50 years of Australian Sociology, eds N Osbaldiston, C Strong \& H Forbes-Mewett, Melbourne, Australia, pp. $1-17$.

Boese, M, Campbell, I, Roberts, W \& Tham, J 2013, 'Temporary migrant nurses in Australia: Sites and sources of precariousness', The Economic and Labour Relations Review, vol. 24, no. 3, pp. 316-339.

Borjas, G \& Bratsberg, B 1996, 'Who leaves? The outmigration of foreign-born', The Review of Economics and Statistics, vol. 78, pp. 165-176.

Borrie, WD 1975, Populations and Australia, a demographic analysis and projection: first report of the National Population Inquiry, Australian Government Publishing Service, Canberra.

Brannen, MY \& Thomas, DC 2010, 'Bicultural individuals in organizations: Implications and opportunity', International Journal of Cross Cultural Management, vol. 10, no. 5-16.

Braun, V \& Clarke, V 2006, 'Using thematic analysis in psychology', Qualitative Research in Psychology, vol. 3, pp. 77-101.

Brenner, N, Peck, J \& Theodore, N 2010, 'After Neoliberalization?' Globalizations, vol. 7, no. 3, pp. 327-345.

Brinkmann, S 2013, Qualitative Interviewing, Oxford University Press, Oxford.

Buchanan, B 1974, 'Building organizational commitment: the socialization of managers in work organizations', Administrative Science Quarterly, vol. 19, pp. 533-546.

Burawoy, M, Fall 1994, Sociology 272E, Participant Observation, University of California. Available from: <http://burawoy.berkeley.edu/syllabus/272E.pdf $>$. [15 October 2015].

Burawoy, M 1998, 'The Extended Case Method', Sociological Theory, vol. 16, no. 1, pp. 1-33.

Burawoy, M 2009, The Extended Case Method: Four Countries, Four Decades, Four Great Transformations, and One Theoretical Tradition, University of California Press, CA.

Burke, V 2011, 'Panacea or band aid to Perth's skills crisis?', ABC News, 19 July 2011. Available from: Factiva. [25 July 2011].

Cameron, R \& Harrison, J 2010, 'Australian human resource practitioner views \& use of temporary skilled migration', Justice and Sustainability in the Global Economy: 10th International Federation of Scholarly Associations of Management (IFSAM 2010). 
Campbell, CM 1997, 'The determinants of dismissal, quits and layoffs: A multinomial logic approach', Southern Economic Journal, vol. 63, no. 4, pp. 1066-1073.

Cappelli, P 1999, The new deal at work, Harvard Business School Press, Boston.

Carr, SC, Inkson, K \& Thorn, K 2005, 'From global careers to talent flow: Reinterpreting 'brain drain", Journal of World Business, vol. 40, pp. 386-398.

Carter, SM 2006, 'Longitudinal Qualitative Research Design: Experience Over Time', ACSPRI Social Science Methodology Conference.

Cassar, V \& Briner, RB 2011, 'The relationship between psychological contract breach and organizational commitment: exchange imbalance as a moderator of the mediating role of violation', Journal of Vocational Behavior, vol. 78, no. 2, pp. 283-289.

Caspersz, DM 2007, 'Temporary Migration into Australia: Reviewing Labour Issues', 12th International Metropolis Conference, Melbourne, 8-12 October.

Caspersz, DM 2012, 'The effect of politics, ideas and discourse in policy swings regulating the employment of temporary labour migration in Australia', 26th AIRAANZ Conference: Re-Organising Work', Gold Coast, 8-10 February.

Caspersz, DM 2013, 'Organising international migrant labour: international comparisons', Journal of Industrial Relations, vol. 55, no. 2, pp. 169-173.

Castells, M 2010, The Rise of the Network Society, Wiley-Blackwell, Oxford.

Castles, S 2000, Ethnicity and globalization: from migrant worker to transnational citizen, Sage Publications, London.

Castles, S 2002, 'Migration and Community Formation under Conditions of Globalization', International Migration Review, vol. 36, no. 4, pp. 1143-1168.

Castles, S 2004, 'The Factors that Make and Unmake Migration Policies', International Migration Review, vol. 38, no. 3, pp. 852-884.

Castles, S 2013, 'The Forces Driving Global Migration', Journal of Intercultural Studies, vol. 34, no. 2, pp. 122-140.

Castles, S, Cubas, MA, Kim, C, Koleth, E, Ozkul, D \& Williamson, R 2011, Karl Polanyi's Great Transformation as a Framework for understanding Neo-Liberal Globalisation in Social Transformation and International Migration in the 21st Century - Working Paper 1, The University of Sydney, Australia.

Castles, S \& Davidson, A 2000, Citizenship and Migration: Globalization and the Politics of Belonging, Routledge, New York.

Castles, S \& Miller, J 1998, The Age of Migration: International Population Movements in Modern World, MacMillan, London.

Castles, S, Vasta, E \& Ozkul, D 2012, 'The internal dynamics of migration processes and their consequences for Australian government migration policies', Working Paper for the Department of Immigration and Citizenship, vol. February 2012.

Castree, N, Kitchen, R \& Rogers, A 2013, A Dictionary of Human Geography, Oxford University Press.

Cerna, L 2010, Policies and practices of highly skilled migration in times of economic crisis, International Labour Office (ILO), Geneva.

Chaloff, J \& Lemaitre, G 2009, Managing Highly Skilled Labour Migration: A Comparative Analysis of Migration Policies and Challenges in OECD Countries, OECD Publishing, Paris.

Chamber of Commerce and Industry of Western Australia (CCIWA) 2010, Discussion Paper: Building Western Australia's Workforce for Tomorrow, Perth.

Chao, GT \& Moon, H 2005, 'The Cultural Mosaic: A Metatheory for Understanding the Complexity of Culture', Journal of Applied Psychology, vol. 90, no. 6, pp. 1128-1140.

Chaudhry, A, Coyle-Shapiro, J \& Wayne, SJ 2011, 'A Longitudinal Study of the Impact of Organisational Change on Transactional, Relational and Balanced Psychological Contracts', Journal of Leadership and Organizational Studies, vol. 18, no. 2, pp. 247267.

Chew, J 2004, 'Managing MNC Expatriates through Crises: A Challenge for International Human Resource Management', Research and Practice in Human Resource Management, vol. 12, no. 2, pp. 1-30.

Chiswick, BR \& Taengnoi, S 2007, 'Occupational Choice of High Skilled Immigrants in the United States', International Migration, vol. 45, no. 5, pp. 3-34. 
Coelli, M \& Wilkins, R 2008, 'Are Skills Shortages a Constraint on Increasing Employment in Australia?' The Australian Economic Review, vol. 41, no. 3, pp. 310-322.

Collings, D, Scullion, H \& Dowling, P 2009, 'Global staffing: a review and thematic research agenda', The International Journal of Human Resource Management, vol. 20, no. 6, pp. 1253-1272.

Collins, J 1991, Migrant Hands in a Distant Land: Australia's Post-War Immigration, Pluto Press Australia, Leichardt.

Collins, J 2008, 'Globalisation, Immigration and the Second Long Post-War Boom in Australia', Journal of Australian Political Economy, vol. 61, pp. 244-268.

Collins, J 2013, 'Rethinking Australian Immigration and Immigrant Settlement Policy', Journal of Intercultural Studies, vol. 34, no. 2, pp. 160-177.

Committee for Economic Development of Australia (CEDA), Economic and Political Overview 2011 Series Summary. Available from: $<$ http://ceda.com.au/newsarticles/2011/03/21/epo_summary>. [March 13th 2012].

Commonwealth Bank 2014, Future Business Index, Canberra. Available from: https://www.commbank.com.au/corporate/your-industry/future-business-index.html

Construction, F, Mining, and Energy Union of Western Australia (CFMEUWA), Campaigns Are you affected by 457 temporary visa workers? Available from:

$<$ http://www.cfmeuwa.com/go/campaigns/457-guest-workers>. [27 November 2012].

Conway, N \& Briner, RB 2005, Understanding Psychological Contracts at Work - A Critical Evaluation of Theory and Research, Oxford University Press, Oxford.

Conway, N \& Briner, RB 2009, 'Fifty years of psychological contract research: what do we know and what are the main challenges?' International Review of Industrial and Organizational Psychology, vol. 24, pp. 71-131.

Conway, N, Kiefer, T, Hartley, J \& Briner, RB 2014, 'Doing More with Less? Employee Reactions to Psychological Contract Breach via Target Similarity or Spillover during Public Sector Organizational Change', British Journal of Management, vol. 25, no. 737754.

Coopers, A 2013, 'Woodside shelves huge gas project in Australia', Agence France Press, 12 April 2013. Available from: Factiva. [13 April 2014].

Corben, A 2012, 'China slowdown cost Australia \$US2.4bn', Australian Associated Press, 17 December 2012. Available from: Factiva. [13 April 2014].

Corbetta, P 2003, Social research: Theory, methods and techniques, Sage Publications, London.

Coyle-Shapiro, J \& Kessler, I 2002, 'Contingent and non-contingent working in local government: contrasting psychological contracts', Public Administration, vol. 80, no. 1, pp. 77-101.

Coyle-Shapiro, JAM, \& Shore, L.M. 2007, 'The employee-organization relationship: Where do we go from here?' Human Resource Management Review, vol. 17, pp. 166-179.

Craw, V \& Ma, W 2014, 'What you missed from the Federal Budget 2014', News.com.au, 15 May 2014. Available from: Factiva. [6 July 2015].

Creswell, JW 2007, Qualitative inquiry and research design: choosing among five approaches, Sage Publications, Thousand Oaks, CA.

Crock, M, Howe, S \& McCallum, R 2012, 'Conflicted Priorities? Enforcing Fairness for Temporary Migrant Worker', in Migrants at Work - Exploring the Interlinkages, Oxford.

Crouch, S \& Housden, M 2003, Marketing Research for Managers, Elsevier, Burlington.

Crowe, D 2013, 'Parties divided on the future vision of post-boom Australia', The Australian, 25 June 2013. Available from: Factiva [13 April 2014].

Cullinane, N \& Dundon, T 2006, 'The psychological contract: a critical review', International Journal of Management Reviews, vol. 8, no. 2, pp. 113-129.

Cully, M 2012, 'Skilled migration selection policies: recent Australian reforms', Migration Policy Practice, vol. 1, no. 1.

Dale, G 2011, 'Lineages of Embeddedness: On the Antecedents and Successors of a Polanyian Concept', American Journal of Economics and Sociology, vol. 70, no. 2, pp. 306-339.

Daley, G 2013, 'Resources boom falls to earth', Financial Review, 22 May 2013. Available from: Factiva. [13 April 2014].

De Haas, H 2005, 'International Migration, Remittances and Development: Myths and Facts', 
Third World Quarterly, vol. 26, no. 8, pp. 1269-1284.

De Haas, H 2010, 'The Internal Dynamics of Migration Processes: A Theoretical Inquiry', Journal of Ethnic and Migration Studies, vol. 36, no. 10, pp. 1587-1617.

De Witte, H \& Naswall, K 2003, '“Objective" vs "subjective" job insecurity: Consequences of temporary worknfor job satisfaction and organizational commitment in four European countries', Economic and Industrial Democracy, vol. 24, no. 149-188.

Deloitte 2014, Oil \& Gas Reality Check 2014, Deloitte, London. Available from: $\mathrm{http} / / / \mathrm{www} 2$. deloitte.com/content/dam/Deloitte/ru/Documents/aboutdeloitte/Oil_and_gas_reality_check_2014.pdf

Denzin, N 1978, Sociological Methods. New York, McGraw-Hill.

Denzin, N \& Lincoln, YS 2005, Handbook of Qualitative Research, Sage Publications, London.

Department of Foreign Affairs and Trade (DFAT), About Australia - People, culture and lifestyle, Australian Government, Department of Foreign Affairs and Trade. Available from: <http://www.dfat.gov.au/facts/people_culture.html $>$. [13th July 2012].

Department of Immigration and Citizenship (DIAC), Immigration Timeline. Available from: $<$ http://www.immi.gov.au/about/anniversary/immigration-timeline.htm>. Government of Australia, Canberra [12 October 2012].

Department of Immigration and Citizenship (DIAC) 1999, DIMA Annual Report 1989-1999, Canberra [18 October 2012].

Department of Immigration and Citizenship (DIAC) 2007, Fact Sheet 8 - Abolition of the 'White Australia' Policy, Government of Australia, Canberra [May 1st 2012].

Department of Immigration and Citizenship (DIAC) 2008, Fact Sheet 4 - More than 60 Years of Post-war Migration, Government of Australia, Canberra [May 1st 2009].

Department of Immigration and Citizenship (DIAC) 2009, Population flows: Immigration aspects 2007-08, Government of Australia, Canberra [August 18th 2011].

Department of Immigration and Citizenship (DIAC) 2010, Press Release - UK skilled workers in hot demand down under, Government of Australia, Canberra, August 4th 2010 [February 10th 2012].

Department of Immigration and Citizenship (DIAC) 2011, 2010-11 Migration Program Report, Government of Australia, Canberra [March 12th 2012].

Department of Immigration and Citizenship (DIAC) 2011a, Migrant Economic Outcomes and Contributions, Government of Australia, Canberra [February 10th 2012].

Department of Immigration and Citizenship (DIAC) 2011b, Skilled migration to support growth in Western Australia and the resource sector, Government of Australia, Canberra [10 October 2012].

Department of Immigration and Citizenship (DIAC) 2011c, Fact Sheet $48 b$ - Temporary Business (Subclass 457) Visa, Government of Australia, Canberra [23 October 2012].

Department of Immigration and Citizenship (DIAC) 2012, 2011-12 Migration Program Report, Government of Australia, Canberra.

Department of Immigration and Citizenship (DIAC) 2012a, Population flows: immigration aspects 2010-2011, Government of Australia, Canberra.

Department of Immigration and Citizenship (DIAC) 2012b, Fact Sheet 1: Immigration - The Background, Government of Australia, Canberra [19 October 2012].

Department of Immigration and Citizenship (DIAC) 2012c, Fact Sheet 48: Assisting Skilled and Business People, includes information on assisting business people to migrate, Government of Australia, Canberra [19 October 2012].

Department of Immigration and Citizenship (DIAC). 2012d. Filling the gaps: Findings from the 2012 survey of subclass 457 employers \& employees.

Department of Immigration and Citizenship (DIAC) 2013, 2012-13 Migration Program Report, Government of Australia, Canberra [25 April 2014].

Department of Immigration and Citizenship (DIAC) 2013a, Annual Report 2012-13, Canberra.

Department of Immigration and Border Protection (DIBP) 2014, The Place of Migrants in Contemporary Australia, Government of Australia, Canberra.

Department of Immigration and Border Protection (DIBP) 2014a, Australia's Migration Trends 2013-14, Government of Australia, Canberra [29 June 2015].

Department of Immigration and Border Protection (DIBP) 2014b, Australia's Migration Trends 2012-13, Government of Australia, Canberra [29 June 2015]. 
Department of Immigration and Border Protection (DIBP) 2014c, 2013-14 Migration Program Report, Government of Australia, Canberra [29 June 2015].

Department of Immigration and Border Protection (DIBP) 2014e, Subclass 457 quarterly report, Government of Australia, Canberra [1 July 2016].

Department of Immigration and Border Protection (DIBP) 2015, Historical Migration Statistics, Government of Australia, Canberra.

Department of State Development (DSD) 2013, Annual Report 2012/13, Government of Western Australia, Perth [28 April 2014].

Department of State Development (DSD) 2014, Western Australia Economic Profile, Government of Western Australia, Perth, pp. 1-10 [28 April 2014].

Department of Training and Workforce Development (DTWD) 2010, Skilling WA - A workforce development plan for Western Australia, Government of Western Australia, Perth.

Department of Training and Workforce Development (DTWD) 2011, Western Australian skilled migration strategy, Government of Western Australia, Perth.

Department of Treasury and Finance (DTF) 2013, Annual Report 2012 - 2013, Government of Western Australia, Perth.

Department of Treasury of Western Australia (DTWA) 2014, The Structure of the Western Australian Economy, Department of Treasury, Government of Western Australia, Perth.

Dexter, LA 1970, Elite and specialized interviewing, Northwestern University Press, Evanston, IL.

Dickmann, M \& Harris, H 2005, 'Developing career capital for global careers: The role of international assignments', Journal of World Business, vol. 40, no. 4, pp. 399-408.

Dilthey, W 1987, Introduction to the human sciences, Scholarly Book Services, Toronto, ON.

Dobbins, T, Plows, A \& Lloyd-Williams, H 2014, 'Make do and mend' after redundancy at Anglesey Aluminum: critiquing human capital approaches to unemployment', Work, Employment and Society, vol. 28, no. 4, pp. 515-532.

Doherty, N 2012, 'Understanding the Self-initiated Expatriate: A Review and Directions for Future Research', International Journal of Management Reviews, vol. early view before published.

Dundon, T \& Dobbins, T 2015, 'Militant partnership: a radical pluralist analysis of workforce dialectics', Work, Employment and Society, vol. 29, no. 6, pp. 912-913.

Dye, TR 1963, 'The local-cosmopolitan dimension and the study of urban politics', Social Forces, vol. 41, no. 2, pp. 239-246.

Eisenhardt, KM \& Graebner, ME 2007, 'Theory Building from Cases: Opportunities and Challenges', Academy of Management Journal, vol. 50, no. 1, pp. 25-32.

Emmons, RA \& Crumpler, CA 2000, 'Gratitude as a human strength: appraising the evidence', Journal of Social and Clinical Psychology, vol. 19, pp. 56-69.

Evans, N, Macdonald, K \& Emerson, D 2012, 'Workers shocked as FMG swings the axe', The West Australian, 5 September 2012, p. 1.

Faist, T 2010, 'Towards Transnational Studies: World Theories, Transnationalisation and Changing Institutions', Journal of Ethnic and Migration Studies, vol. 36, no. 10, pp. 1665-1687.

Faist, T \& Bilecen, B 2015, 'Social Inequalities Through the Lens of Social Protection: Notes on the Transnational Social Question', Population, Space and Place, vol. 21, pp. 282-293.

Faist, T, Bilecen, B, Barglowski, K \& Sienkiewicz, J 2015, 'Transnational Social Protection: Migrants' Strategies and Patterns of Inequalities', Population, Space and Place, vol. 21, pp. 193-202.

Fauconnier, G 2001, 'Conceptual Blending and Analogy', in The Analogical Mind: Perspectives from Cognitive Science, eds D Gentner, KJ Holyoak \& BN Nokinov, MIT Press, Cambridge, MA.

Farrall, S 2006, What is Qualitative Longitudinal Research? London School of Economics and Political Science, London, UK.

Fitzgerald, B 2013, 'China still holds key to Pilbara', The Australian, 27 May 2013, p. 3. Available from: Factiva. [13 April 2014].

Flick, U 2006, An introduction to qualitative research, Sage Publications, London.

Fox, A 1974, Beyond contract: Work, power and trust relations, Faber and Faber, London.

Freeman, GP 2005, 'Political science and comparative immigration politics', International 
migration research: constructions, omissions and the promises of interdisciplinary, pp. 111-128.

Freese, C \& Schalk, R 2008, 'How to measure the psychological contract? A critical criteriabased review of measures', South African Journal of Psychology, vol. 38, no. 2, pp. 269-286.

Freese, C, Schalk, R \& Croon, M 2011, 'The impact of organisational changes on psychological contracts', Personnel Review, vol. 40, no. 4, pp. 404-422.

Garfinkel, H 1967, Studies in Ethnomethodology, Prentice Hall, New York.

Garnett, AM 2012, 'The Effect of the Resource Boom on the Population and Labour Market of Western Australia', Economic Papers, vol. 31, no. 1, pp. 63-75.

Garfinkel, H 1967, Studies in Ethnomethodology, Prentice Hall, New York.

Gbrich, C 2007, Qualitative Data Analysis: An Introduction, Sage Publications, London.

Gemici, K 2008, 'Karl Polanyi and the antinomies of embeddedness', Socio-Economic Review, vol. 6, pp. 5-33.

Global Commission on International Migration (GCIM) 2005, Migration in an Interconnected World: New Directions from Action, Geneva. Greenhalgh, L \& Rosenblatt, Z 1984, 'Job insecurity: Towards new conceptual clarity', Academy of Management Review, vol. 9, no. 3, pp. 438-448.

Godard, J 2014, 'Provocation Series Paper: The psychologisation of employment relations?', Human Resource Management Journal, vol. 24, no. 1, pp. 1-18.

Goh, JWP 2009, 'Globalization's culture consequences of MBA education across Australia and Singapore: sophistry or truth?' High Education, vol. 58, pp. 131-155.

Golbert, R 2001, 'Transnational Orientations from Home: Constructions of Israel and Transnational Space among Ukrainian Jewish Youth', Journal of Ethnic and Migration Studies, vol. 27, no. 4, pp. 713-731.

Goshal, S \& Bartlett, A 1997, The Individualized Corporation, HarperCollins, New York.

Granovetter, M 1985, 'Economic Action and Social Structure: The Problem of Embeddedness', The American Journal of Sociology, vol. 91, no. 3, pp. 481-510

Green, F 2008, 'Temporary Work and Insecurity in Britain: A Problem Solved?', Social Indicators Research, vol. 88, pp. 147-160.

Greenhalgh, L \& Rosenblatt, Z 1984, 'Job insecurity: Towards new conceptual clarity', Academy of Management Review, vol. 9, no. 3, pp. 438-448.

Groutsis, D, Van den Broek, D \& Harvey, WS 2015, 'Transformations in Network Governance: The Case of Migration Intermediaries', Journal of Ethnic and Migration Studies, vol. 41, no. 10, pp. 1558-1576.

Guest, DE 1998, 'Is the psychological contract worth taking seriously?' Journal of Organizational Behavior, vol. 19, pp. 649-664.

Guest, DE 2004a, 'Flexible employment contracts, the psychological contract and employee outcomes: an analysis and review of the evidence', International Journal of Management Reviews, vol. 5/6, no. 1, pp. 1-19.

Guest, DE 2004b, 'The Psychology of the Employment Relationship: An Analysis Based on the Psychological Contract', Applied Psychology: an International Review, vol. 53, no. 4, pp. 541-555.

Guest, DE \& Clinton, M 2010, 'Causes and Consequences of the Psychological Contract', in Employment Contracts, Psychological Contracts, and Employee Well-Being: An International Study, ed. D Guest, K Isaksson \& H De Witte, Oxford University Press, Oxford.

Guest, DE, \& Conway, N. 2002, 'Communicating the psychological contract: an employer perspective', Human Resource Management Journal, vol. 12, no. 2, pp. 22-38.

Guest, DE, Oakley, P, Clinton, M \& Budjanovcanin, A 2006, 'Free or precarious? A comparison of the attitudes of workers in flexible and traditional employment contracts', Human Resource Management Review, vol. 16, pp. 107-124.

Guillén, MF 2001, 'Is Globalization Civilizing, Destructive or Feeble? A Critique of Five Key Debates in the Social Science Literature', Annual Review of Sociology, vol. 27, pp. 235260.

Gundel, S \& Peters, H 2008, 'What determines the duration of stay of immigrants in Germany? Evidence from a longitudinal duration analysis', International Journal of Social 
Economics, vol. 35, no. 11, pp. 769-782.

Guzzo, RA 1996, 'The Expatriate Employee', Journal of Organizational Behavior, vol. 3, pp. 123-137.

Hall, P \& Soskice, D 2001, Varieties of capitalism: The Institutional Foundations of Comparative Advantage, Oxford University Press, New York.

Harney, B 2009, 'Exploring the roads less travelled in HRM-performance research: a critical realistic alternative to "big science"', in Proceedings of the 61st Annual Meetings of the Labor and Employment Relations Association. Labor and Employment Relations Association, Urbana-Champaign, IL.

Harney, N 2006, 'Precarious migrant knowledge workers: new entrepreneurial identities in Naples, Italy', International Journal of Manpower, vol. 27, no. 6, pp. 572-587.

Harvey, D 1989, The Condition of Postmodernity: An Inquiry into the Conditions of Cultural Change, Blackwell, Oxford.

Harvey, D 2005, A Brief History of Neoliberalism, Oxford University Press, Oxford.

Harvey, D 2007, 'Neoliberalism as Creative Destruction', Annals of the American Academy of Political and Social Science, vol. 610, March 2007, pp. 22-44.

Haslberger, A, \& Brewster, C. 2009, 'Capital Gains: Expatriate Adjustment and the Psychological Contract in International Careers', Human Resource Management Review, vol. 48, no. 3, pp. 379- 397.

Hawley, S 2013, 'Government cuts university funds to pay for Gonski', ABC News, 13 April 2013.

Hawthorne, L 1997, 'The Question of Discrimination: Skilled Migrants' Access to Australian Employment', International Migration, vol. 35, no. 3, pp. 395-419.

Hawthorne, L 2005, 'Picking Winners: The Recent Transformation of Australia's Skilled Migration Policy', International Migration Review, vol. 39, no. 3, pp. 663-696.

Hawthorne, L 2014, 'WHO four-country study: Health workforce migration in Australia', in Migration of Health Workers: The WHO code of practice and the global economic crisis, World Health Organization, Geneva.

Healy, J, Mavromaras, K \& Sloane, PJ 2012, Skill shortages: prevalence, causes, remedies and consequences for Australian business, vol. 09/2012, FU National Institute of Labour Studies (NCVER), Department of Education, Employment and Workplace Relations (DEEWR), Adelaide.

Herriot, P 1992, The Career Management Challenge: Balancing Individual and Organisational Needs, Sage Publications, London.

Herriot, P \& Pemberton, C 1997, 'Facilitating new deals', Human Resource Management Journal, vol. 7, no. 1, pp. 45 - 56.

Hirschman, A 1970, Exit, Voice, and Loyalty: Response to Decline in Firms, Organisations and States, Harvard University Press, Cambridge.

Ho, E 2011, 'Migration Trajectories of Highly Skilled Middling Transnationals: Singaporean Transmigrants in London', Population, Space and Place, vol. 17, no. 1, pp. 116-129.

Hobbs, M 2012, 'No happy new year for construction ', The Australian Financial Review. Available from: Factiva [26 October 2012].

Hofstede, G 1980, Culture Consequences, Sage Publications, Beverly Hills.

Hogan, W 2013, 'Economic overview', in Economic and political overview 2013, ed. Committee for Economic Development of Australia (CEDA), Melbourne.

Holland, J, Thomson, R \& Henderson, S 2006, Qualitative Longitudinal Research: A Discussion Paper, Families \& Social Capital ESRC Research Group, London, UK.

Holton, R 2000, 'Globalization's Cultural Consequences', American Academy of Political and Social Science, vol. 570, pp. 140-152.

Hong, Y 2009, 'A dynamic constructivist approach to culture: Moving from describing culture to explaining culture', in Understanding culture: theory, research and application, eds RSJ Wyer, C Chiu \& Y Hong, Psychology Press, New York, NY, pp. 3-23.

Hong, Y \& Mallorie, LM 2004, 'A dynamic constructivist approach to culture: Lessons learned from personality psychology', Journal of Research in Personality, vol. 38, pp. 59-67.

Hoodashtian, A 2001, 'Globalization: A short study', in Eurasian Market Institute, Almaty.

Howe-Walsh, L \& Schyns, B 2010, 'Self-initiated expatriation: implications for HRM', The International Journal of Human Resource Management, vol. 21, no. 2, pp. 260-273. 
Hugo, G 2004, 'International Mobility of the Highly Skilled: An Australian Perspective', in Beyond Brain Drain - Mobility, Competitiveness \& Scientific Excellence, Brisbane.

Hugo, G 2006, 'An Australian Diaspora?' International Migration, vol. 44, no. 1, pp. 105-133. Hugo, G 2006b, 'Globalization and changes in Australian international migration', Journal of Population Research, vol. 23, no. 2, pp. 107-134.

Hugo, G 2008, 'Australia's State-Specific and Regional Migration Scheme: An Assessment of its Impacts in South Australia', International Migration \& Integration, vol. 9, no. 2, pp. 125-145.

Hugo, G 2011, The Changing Dynamics of the Australia / Asia-Pacific Migration System and Its Implications for Australian International Migration Policy, Department of Immigration and Citizenship, Canberra.

Hui, C, Lee, C \& Rousseau, DM 2004, 'Psychological Contract and Organizational Citizenship Behavior in China: Investigating Generalizability and Instrumentality', Journal of Applied Psychology, vol. 89, no. 2, pp. 311-321.

Hutchinson, F 2004, 'Globalisation and the 'Newer' International Division of Labour', Labour and Management in Development Journal, vol. 4, no. 6, pp. 1-24.

Hyman, L \& Baptist, EE 2014, American Capitalism, A Reader, Simon \& Schuster, New York, NY.

Ingram, T 2014, 'Ore downturn sparks wide job losses', The Age, 6 December 2014, p. 29. Available from: Factiva [2 September 2015].

Inkson, K, Heising, A \& Rousseau, DM 2001, 'The interim manager: prototype of the 21 stcentury worker?', Human Relations, vol. 54, pp. 259-84.

Inkson, K \& Khapova, S 2008, 'International Careers', in The Handbook of Cross-Cultural Management Research, ed. P Smith \& M Peterson, Thomas, D., Sage Publications, Thousand Oaks, pp. 151-164.

Inkson, K, Pringle, J., Arthur, M. B., \& Barry, S. 1997, 'Expatriate Assignment Versus Overseas Experience: Contrasting Models of International HR Development', Journal of World Business, vol. 32, no. 4, pp. 351-368.

International Organisation for Migration (IOM) 2011, Glossary on Migration in International Migration Law Series vol. 25, Geneva.

Iredale, R 2000, 'Migration Policies for the Highly Skilled in the Asia-Pacific Region', International Migration Review, vol. 34, no. 3, pp. 882-906.

Iredale, R 2001, 'The Migration of Professionals: Theories and Typologies', International Migration, vol. 39, no. 5, pp. 7-27.

Janda, M 2012, 'Unemployment jumps on rising participation', ABC News, 11 October 2012. Available from: Factiva. [26 October 2012].

Janda, M 2013, 'WA unemployment rate jumps to highest level in a decade', ABC News, 13 March 2014. Available from: Factiva. [13 April 2014].

Joffe, H \& Yardley, L 2004, 'Content and Thematic Analysis', in Research Methods for Clinical and Health Psychology, ed. DF Marks \& L Yardley, Sage Publications, Thousand Oaks.

Johnson, S 2013, 'Aussie costs a big challenge: Shell', Australian Associated Press.

Jokinen, T, Brewster, C \& Suutari, V 2008, 'Career capital during international work experiences: contrasting self-initiated expatriate experiences and assigned expatriation', The International Journal of Human Resource Management, vol. 19, no. 6, pp. 979998.

Kalleberg, AL 2009, 'Precarious Work, Insecure Workers: Employment Relations in Transition', American Sociological Review, vol. 74, pp. 1-22.

Kalleberg, AL \& Rognes, J 2000, 'Employment relations in Norway: some dimensions and correlates', Journal of Organizational Behavior, vol. 21, pp. 315-335.

Kanter, RM 1990, When giants learn to dance: mastering the challenges of strategy, management and careers in the 1990's, Unwin Paperbacks, London.

Kanter, RM 1993, 'Employability security', BSR Symposium: Is the Good Corporation Bad?

Katou, AA 2013, 'The link between HR practices, psychological contract fulfilment, and organisational performance in Greece: An economic crisis perspective', Journal of Industrial Engineering and Management, vol. 6, no. 2, pp. 568-594.

Katz, J 1983, 'A Theory of Qualitative Methodology: The Social System of Analytical 
Fieldwork', in Contemporary Field Research, ed. R Emerson, Waveland Press, Prospect Heights, Illinois, pp. 127-148.

Kearney, L 2012, 'Mining and minerals in South Africa', SouthAfrica.info, 8 August 2012.

Available from: Factiva [25 October 2012].

Keep, E \& Mayhew, K 2010, 'Moving beyond skills as a social and economic panacea', Work, Employment and Society, vol. 24, no. 3, pp. 565-577.

Kelly, J \& McGrath, RG 1988, On Time and Method, Sage Publications, Thousand Oaks.

Ker, P 2013, 'Rio swings axe in iron ore business', The Sydney Morning Herald, 20 June 2013.

Khoo, SE, McDonald, P, Voigt-Graf, C \& Hugo, G 2007, 'A Global Labor Market: Factors Motivating the Sponsorship and Temporary Migration of Skilled Workers to Australia', International Migration Review, vol. 41, no. 2, pp. 480-510.

Khoo, SE, Hugo, G \& McDonald, P 2008, 'Which Skilled Temporary Migrants Become Permanent Residents and Why?' International Migration Review, vol. 42, no. 1, pp. 193-226.

Kickul, J 2001, 'When Organizations Break Their Promises: Employee Reactions to Unfair Processes and Treatment', Journal of Business Ethics, vol. 29, pp. 289-307.

Kickul, J, Lester, S.W., \& Belgio, E. 2004, 'Attitudinal and Behavioral Outcomes of Psychological Contract Breach: A Cross Cultural Comparison of the United States and Hong Kong Chinese', International Journal of Cross Cultural Management, vol. 4, no. 2, pp. 229-252.

King, JE 2000, 'White-Collar Reactions to Job-Insecurity and the Role of the Psychological Contract: Implications for Human Resource Management', Human Resource Management Journal, vol. 39, no. 1, pp. 79-92.

Kingsley, P 2012, 'Financial crisis: timeline', The Guardian, 7 August 2012. Available from: Factiva. [13 April 2014].

Kitney, D \& Garvey, P 2013, 'Business calls for policy stability', The Australian, 29 June 2013. Available from: Factiva. [13 April 2014].

Kleinig, J 2007, Loyalty in Stanford Encyclopaedia of Philosophy, Stanford University, California, [April 30th 2012].

Knell, J 2000, Most Wanted: The Quiet Birth of the Free Worker, The Industrial Society, London.

Koleth, E 2010, Multiculturalism: a review of Australian policy statements and recent debates in Australia and overseas, Canberra.

Kosny, A, Santos, I \& Reid, A 2016, 'Employment in a Land of Opportunity? Immigrants' Experiences of Racism and Discrimination in the Australian Workplace', International Migration \& Integration, vol. 17, pp. 1-15.

Kotter, JP 1973, 'The Psychological Contract: Managing the Joining up Process', California Management Review, vol. 15, pp. 91-99.

KPMG 2011, Australia's resources boom: the infrastructure ripple effect, KPMG, Australia. KPMG 2013, 2013 Energy Industry Outlook Survey, KPMG Global Energy Institute, USA.

Krippendorff, K 2004, Content analysis: an introduction to its methodology, Sage Publications, London.

Krippner, GR 2001, 'The elusive market: Embeddedness and the paradigm of economic sociology', Theory and Society, vol. 30, pp. 775-810.

Krippner, GR, Granovetter, M, Block, F, Biggart N., Beamish, T, Hsing, Y, Hart, G, Arrighi, G, Mendell, M, Hall, J, Burawoy, M, Vogel, S \& O'Riain, S 2004, 'Polanyi Symposium: a conversation on embeddedness', Socio-Economic Review, vol. 2, pp. 109-135.

Krippner, GR \& Alvarez, A 2007, 'Embeddedness and the Intellectual Projects of Economic Sociology', Annual Review of Sociology, vol. 33, no. 219-240.

Lambert, R, Gillan, M \& Fitzgerald, S 2005, 'Electrolux in Australia: Deregulation, Industry Restructuring and the Dynamics of Bargaining', The Journal of Industrial Relations, vol. 47, no. 3, pp. 261-275.

Langley, A \& Stensaker, I 2012, 'Longitudinal research and analysis', in Qualitative Organizational Research: Core Methods and Current Challenges, eds G Symon \& C Cassel, Sage Publications, London.

Lapointe, E, Vandenberghe, C \& Boudrias, JS 2013, 'Psychological contract breach, affective commitment to organization and supervisor, and newcomer adjustment: A three-wave 
moderated mediation model', Journal of Vocational Behavior, vol. 83, no. 3, pp. 528538.

Levinson, H, Price, CR, Munden, KJ \& Solley, CM 1962, Men, Management, and Mental Health, Harvard University Press, Cambridge, MA.

Lester, SW \& Kickul, JR 2001, 'Psychological contracts in the 21st century: What employees value most and how well organizations are responding to these expectations', $H R$. Human Resource Planning, vol. 24, no. 1, pp. 10-21.

Lester, SW, Kickul, JR \& Bergmann, TJ 2007, 'Managing employee perceptions of the psychological contract over time: the role of employer social accounts and contract fulfillment', Journal of Organizational Behavior, vol. 28, pp. 191-208.

Levitt, T 1993, 'The globalization of markets', Harvard Business Review, vol. 70, no. 3, pp. $92-$ 102.

Lewis, H, Dwyer, P, Hodkinson, S \& Waite, L 2015, 'Hyper-precarious lives: Migrants, work and forced labour in the Global North', Progress in Human Geography, vol. 39, no. 5, pp. 580-600.

Leys, C 2001, Market-Driven Politics: Neoliberal Democracy and the Public Interest, Verso, London.

Li, PS 2008, 'World Migration in the Age of Globalization: Policy Implications and Challenges', New Zealand Population Review, vol. 33/34, pp. 1-22.

Lincoln, YS 1995, 'Emerging Criteria for Quality in Qualitative and Interpretive Research', Qualitative Inquiry, vol. 1, no. 3, pp. 275-289.

Lincoln, YS \& Guba, EG 1985, Naturalistic Inquiry, Sage Publications, London.

Lofland, J \& Lofland, LH 1984, Analyzing social settings: a guide to qualitative observation and analysis, Wadsworth Pub. Co., Belmond, CA.

Lorenzo, FM, Galvez-Tan, J \& Javier, L 2007, 'Nurse Migration from a Source Country Perspective: Philippines Country Case Study', Health Services Research, vol. 42, no. 3p2, pp. 1406-1418.

Mayer, RC, Davis, JE \& Schoorman, D 1995, 'An integrative model of organisational trust', Academy of Management Review, vol. 20, no. 3, pp. 709-734.

Marshall, C \& Rossman, GB 2011, Designing qualitative research, Sage Publications, Thousand Oaks.

Maykut, P \& Morehouse, R 1994, Beginning qualitative research: a philosophic and practical guide Falmer Press, London.

McDevitt, R, Giapponi, C \& Houston, DM 2013, 'Organizational Downsizing During an Economic Crisis: Survivors' and Victims' Perspectives', Organization Management Journal, vol. 10, pp. 227-239.

McDowell, L, Batnitzky, A \& Dyer, S 2009, 'Precarious work and economic migration: Emerging immigrant divisions of labour in Greater London's service sector', International Journal of Urban and Regional Research, vol. 33, no. 1, pp. 3-25.

McDuie-Ra, D 2007, 'The Constraints on Civil Society beyond the State: Gender-based Insecurity in Meghalaya, India', Voluntas, vol. 18, pp. 359-384.

McGrew, A 1998, 'Global Legal Interaction and Present-Day Patterns of Globalization', in Emerging Legal Certainty: Empirical Studies on the Globalization of Law, eds V Gessner \& AC Budak, Dartmouth Publishing Company, Ashgate.

McKibbin, W \& Stoeckel, A 2009, 'The Global Financial Crisis: Causes and Consequences', Working Papers in International Economics, vol. 2, no. 09, pp. 1-39.

McLeod, P 2012, 'Shortage drives up engineering salaries', The Australian, 21 April 2012.

MacNeil, IR 1974, 'The Many Features of Contract', Southern California Law Review, vol. 47, pp. 691-816.

Meckler, M, Drake, BH \& Levinson, H 2003, 'Putting Psychology Back Into Psychological Contracts', Journal of Management Inquiry, vol. 12, no. 3, pp. 217-229.

Meyer, JP \& Allen, NJ 1991, 'A three-component conceptualization of organisational commitment: Some methodological considerations', Human Resource Management Review, vol. 1, pp. 61-98.

Miles, M \& Huberman, A 1994, Qualitative data analysis, 2nd edition, Sage Publications, Thousand Oaks, CA.

Morrison, EW \& Robinson, SL 1997, 'When employees feel betrayed: a model of how 
psychological contract violation develops', Academy of Management Review, vol. 22, no. 1, pp. 226-256.

Mowday, RT, Porter, LW \& Steers, RM 1982, Employee-organization linkages: the psychology of commitment, absenteeism, and turnover (vol.153), Academic Press, New York.

Munck, R 2002, Globalisation and labour: the new 'Great Transformation', Palgrave, London.

Murphy, J, Stewart, C \& Gerritsen, N 2013, 'WA bottom of the class in Gonski funds', The Australian Financial Review, 16 April 2013. Available from: Factiva. [14 April 2014].

National Australia Bank (NAB) 2015, State Update: Western Australia - September 2015, National Australia Bank (NAB), Canberra.

Nelson, L, Tonks, G \& Weymouth, J 2006, 'The Psychological Contract and Job Satisfaction: Experiences of a Group of Casual Workers', Research and Practice in Human Resource Management, vol. 14, no. 2, pp. 18-33.

Noy, C 2008, 'Sampling Knowledge: The Hermeneutics of Snowball Sampling in Qualitative Research', International Journal of Social Research Methodology, vol. 11, no. 4, pp. 327-344.

O'Donnell, A \& Mitchell, R 2000a, Immigrant Labour in Australia: The Regulatory Framework.

O'Donnell, A \& Mitchell, R 2000b, 'Immigration Law and Policy, and its Contribution to Labour Market Regulation: a Historical Survey to 1979', Centre for Employment and Labour Relations Law, Melbourne Law School, vol. Working Paper No.16.

Oliver, C 1991, 'Strategic Responses to Institutional Processes', Academy of Management, vol. 16, no. 1, pp. 145-179.

Ong, R \& Shah, S 2012, 'Job Security Satisfaction in Australia: Do Migrant Characteristics and Gender Matter?' Australian Journal of Labour Economics, vol. 15, no. 2, pp. 123-139.

Oke, N 2012a, 'Introduction - Transnational Work: Inclusion and Participation', Journal of Intercultural Studies, vol. 33, no. 1, pp. 1-7.

Oke, N 2012b, 'Temporary Migration, Transnational Politics? The Politics of Temporary Migration in Australia', Journal of Intercultural Studies, vol. 33, no. 1, pp. 85-101.

Panchal, S \& Cartwright, S 2001, 'Group differences in post-merger stress', Journal of Managerial Psychology, vol. 16, no. 6, pp. 424-433.

Papademetriou, D, Somerville, W \& Tanaka, H 2008, 'Talent in the 21 st Century Economy', in Economic Competitiveness and International Migration, ed. MP Institute.

Pate, J 2010, 'The changing nature of the traditional expatriate psychological contract', Employee Relations, vol. 32, no. 1, pp. 56-73.

Pate, J, Martin, G \& McGoldrick, J 2003, 'The impact of psychological contract violation on employee attitudes and behaviour', Employee Relations, vol. 25, no. 6, pp. 557-573.

Patton, MQ 1990, Qualitative Evaluation and Research Methods, Sage Publications, Newbury Park, CA.

Patton, MQ 2005, 'Qualitative Research', in Encyclopedia of Statistics in Behavioral Science, eds BS Everitt \& DC Howell, John Wiley \& Sons, Chichester.

Peck, J 2010, Constructions of Neoliberal Reason, Oxford University Press, New York.

Perakyla, A 2005, 'Analyzing Talk and Text', in Handbook of Qualitative Research, Sage Publications, London.

Pettigrew, AM 1990, 'Longitudinal Field Research on Change: Theory and Practice', Organizational Science, vol. 1, no. 3, pp. 267-292.

Phillips, J \& Spinks, H 2012, Skilled Migration: Temporary and Permanent Flows to Australia, Parliament of Australia, Canberra [15 August 2012].

Pink, D 2001, Free Agent Nation, Warner Business, New York.

Piper, H \& Simons, H 2004, 'Ethical Responsibility in Social Research', in Research Methods in the Social Science, ed. B Somekh \& C Lewin, Sage Publications, London.

Polanyi, K 1957 [1944], The great transformation, Beacon Press, Boston.

Polanyi, K 1968, Primitive, Archaic, and Modern Economies: Essays of Karl Polanyi, Anchor Books, New York, NY.

Polanyi, K 2002 [1934], 'Lancashire als Menschheitsfrage', in Cronik der groben Transformation, ed. M Cangiani \& C Thomasberger, Metropolis, Marburg.

Portes, A 1997, 'Immigration Theory for a New Century: Some Problems and Opportunities', International Migration Review, vol. 31, no. 4, pp. 799-825. 
Portes, A 2010, 'Migration and Social Change: Some Conceptual Reflections', Journal of Ethnic and Migration Studies, vol. 36, no. 10, pp. 1537-1563.

Reid, A 2012, 'Under-use of migrants' employment skills linked to poorer mental health', Australian and New Zealand Journal of Public Health, vol. 36, no. 2, pp. 120-125.

Richmond, AJ 1991, 'International Migration and Global Change', International Conference on Migration, Centre for Advanced Studies, Faculty of Arts and Social Sciences, National University of Singapore, February.

Rigotti, T, Otto, K \& Mohr, G 2007, 'Justice and Trust: Possible Reasons and Consequences East-West Differences in Employment Relations, Organizational', Economic and Industrial Democracy, vol. 28, no. 2, pp. 212-238.

Ritchie, J, Lewis, J, Nicholls, CM \& Ormston, R 2014, Qualitative Research Practice: A Guide for Social Science Students and Researchers, Sage Publications, Thousand Oaks, CA.

Roberts, RC 1991, 'Virtues and rules', Philosophy and Phenomenological Research, vol. 51, pp. 325-343.

Roberts, R 2011, 'Unfolding Stories of Skilled Migrants', Social Alternatives, vol. 30, no. 2, pp. 35-39.

Robertson, S 2015a, 'The temporalities of International Migration: Implications for Ethnographic Research', in Social Transformation and Migration, eds S Castles, D Ozkul \& MA Cubas, Palgrave Macmilan, Basingstoke, pp. 45-60.

Robertson, S 2015b, 'Contractualization, depoliticization and the limits of solidarity: noncitizens in contemporary Australia', Citizenship Studies, vol. 19, no. 8, pp. 936-950.

Robinson, SL 1996, 'Trust and Breach of the Psychological Contract', Administrative Science Quarterly, vol. 41, pp. 574-599.

Robinson, SL, \& Morrison, EW 1995, 'Psychological contracts and OCB: The effect of unfulfilled obligations on civic behavior', Journal of Organizational Behavior, vol. 16, no. 3, pp. 289 - 298.

Robinson, SL \& Morrison, EW 2000, 'The development of psychological contract breach and violation: a longitudinal study', Journal of Organizational Behavior, vol. 21, no. 5, pp. 525-546.

Robinson, SL \& Rousseau, DM 1994, 'Violating the psychological contract: not the exception but the norm', Journal of Organizational Behavior, vol. 15, no. 3, pp. 245-259.

Roehling, MV 1997, 'The origins and early development of the psychological contract', Journal of Management History, vol. 3, no. 2, pp. 204-214.

Roehling, MV 2008, 'An Empirical Assessment of Alternative Conceptualizations of the Psychological Contract Construct: Meaningful Differences or "Much to do about Nothing"?' Employee Responsibilities and Rights Journal, vol. 20, pp. 262-290.

Rosewarne, S 2001, 'Globalization, Migration, and Labor Market Formation - Labor's Challenge?', Capitalism, Nature, Socialism, vol. 12, no. 3, pp. 71-165.

Rousseau, DM 1989, 'Psychological and Implied Contracts in Organizations', Employee Responsibilities and Rights Journal, vol. 2, no. 2, pp. 121-139.

Rousseau, DM 1990, 'New hire perceptions of their own and their employer's obligations: A study of psychological contracts', Journal of Organizational Behavior, vol. 11, no. 5, pp. 389-400.

Rousseau, DM 1995, Psychological contracts in organizations: understanding written and unwritten agreements Sage Publications, Thousand Oaks.

Rousseau, DM 2000, Psychological Contract Inventory: technical report, Carnegie Mellon University, Pittsburgh, PA.

Rousseau, DM 2001, 'The Idiosyncratic Deal: Flexibility versus Fairness?', Organizational Dynamics, vol. 29, no. 4, pp. 260-273.

Rousseau, DM, \& Schalk, R. 2000, Psychological Contracts in Employment: Cross-National Perspectives, Sage Publications, Thousand Oaks.

Rousseau, DM \& Tijoriwala, SA 1998, 'Assessing psychological contracts: Issues, alternatives and measures', Journal of Organizational Behavior, vol. 19, pp. 679-695.

Rout, M 2011, 'WA in new fight with PM on skills', The Australian, 12 May 2011.

Royce, J 1908, The Philosophy of Loyalty, The MacMillan Company, New York.

Sadowski-Smith, C \& Li, W 2014, 'Return Migration and the Profiling of Non-Citizens: Highly Skilled BRIC Migrants in the Mexico-US Borderlands and Arizona's SB 1070', 
Population, Space and Place, pp. 1868-1882.

Saldaña, J 2003, Longitudinal Qualitative Research, Altamira Press, Oxford.

Samuels, GM 2009, 'Using the extended case method to explore identity in a multicultural context', Ethnic and Racial Studies, vol. 32, no. 9, pp. 1599-1618.

Sandelowski, M 1995, 'Sample Size in Qualitative Research', Research in Nursing \& Health, vol. 18 , no. 2 , pp. 179-183.

Sapeha, H 2014, Explaining Variations in Success of Subnational Immigration Programme in Canada and Australia, thesis, McMaster University.

Sappey, JR 2006, Flexible Delivery in Australian Higher Education and its Implications for the Organisation of Academic Work, thesis, Griffith University.

Schmidt, C 2004, 'The Analysis of Semi-Structured Interviews', in A Companion to Qualitative Research, eds U Flick, E von Kardoff \& I Steinke, Sage Publications, London, pp. 253258.

Schalk, R, de Jong, J, Rigotti, T, Mohr, G, Peiró, JM \& Caballer, A 2010, 'The Psychological Contacts of Temporary and Permanent Workers', in Employment Contracts, Psychological Contracts, and Employee Well-Being: An International Study, ed. D Guest, K Isaksson \& H De Witte, Oxford University Press.

Schalk, R \& Roe, RE 2007, 'Towards a Dynamic Model of the Psychological Contract', Journal for the Theory of Social Behaviour, vol. 37, no. 2, pp. 167-181.

Schalk, R \& Rousseau, DM 2001, 'Psychological Contracts in Employment', in Handbook of Industrial, Work \& Organizational Psychology, vol. 2, ed. N Anderson, DS Ones \& HK Sinangil, Sage, London, pp. 133-142.

Schein, EH 1965, Organizational Psychology, Prentice-Hall, Englewood Cliffs, NJ.

Schmidt, VA 2016, 'The roots of neo-liberal resilience: Explaining continuity and change in background ideas in Europe's political economy', The British Journal of Politics and International Relations, vol. 18, no. 2, pp. 318-334.

Segal-Horn, S, Asch, D \& Suneja, V 1998, 'The globalization of the European white goods industry', European Management Journal, vol. 16, no. 1, pp. 101-109.

Shachar, A 2006, 'The race for talent: highly skilled migrants and competitive immigration regimes', New York University Law Review, vol. 81, pp. 148-206.

Shaffer, M, Kraimer, ML, Chen, YP \& Bolino, M 2012, 'Choices, Challenges, and Career Consequences of Global Work Experiences: A Review and Future Agenda', Journal of Management, vol. 38, no. 4, pp. 1282-1327.

Shah, C \& Burke, G 2005, 'Skills shortages: Concepts, measurements and policy responses', Australian Bulletin of Labour, vol. 31, pp. 44-71.

Shah, C, Cooney, R, Long, M \& Burke, G 2005, Availability of skilled labour in selected occupations in Western Australia, Melbourne, Australia.

Shamir, B 1992, 'Home: the perfect workplace?' in Work, families, and organisations, ed. S

Zedeck, Jossey-Bass, San Francisco, pp. 272-311.

Siggelkow, N. 2007. "Persuasion with Case Studies." Academy of Managemenl Journal 50

(1):20-24.

Skrbis, Z 2008, 'Transnational Families: Theorising Migration, Emotions and Belonging', Journal of Intercultural Studies, vol. 29, no. 3, pp. 231-46.

Smith, A 1790/1976, The Theory of Moral Sentiments, Liberty Classics, Indianapolis.

Smith, D 2010, 'World Cup kicks violent South African crime into touch', The Guardian, 10 July 2010.

Smith, N 2003, 'Cross-sectional profiling and longitudinal analysis: research notes on analysis in the longitudinal qualitative study, 'Negotiating Transitions to Citizenship",

International Journal of Social Research Methodology, vol. 6, no. 3, pp. 273-277.

Simons, H 2009, Case Study Research in Practice, Sage Publications, London.

Sinkovics, R \& Alfoldi, EA 2012, 'Progressive Focusing and Trustworthiness in Qualitative Research: The Enabling Role of Computer-Assisted Qualitative Data Analysis Software (CAQDAS)', Management International Review, vol. 52, pp. 817-845.

Sila, I, Gracia, FJ \& Peiró, JM 2005, 'Job Insecurity and Health-Related Outcomes among Different Types of temporary Workers', Economic and Industrial Democracy, vol. 26, no. 1 , pp. 89-117.

Silverman, D 2010, Doing Qualitative Research: A Practical Handbook, 3rd edition, Sage 
Publications, Thousand Oaks.

Somerville, K \& Walsworth, S 2009, 'Vulnerabilities of Highly Skilled Immigrants in Canada and the United States', American Review of Canadian Studies, vol. 39, no. 2, pp. 147161.

Sparker, A 2005, 'Narrative analysis: exploring the whats and hows of personal stories', in Qualitative Research in Health Care, ed. I Holloway, Open University Press, Berkshire, pp. 191-208.

Sparrow, PR 1996, 'Careers and the Psychological Contract: Understanding the European Context', European Journal of Work and Organizational Psychology, vol. 5, no. 4, pp. 479-500.

Sparrow, PR 1998, 'Reappraising Psychological Contracting', International Studies of Management \& Organizations, vol. 28, no. 1, pp. 30-63.

Spooner, R 2012, 'Irish and British head for Australian jobs, but where are the Greeks?', The Age, 25 February 2012, p. 4.

St George Bank 2015, WA Economic Outlook, St George Bank, Perth. Available from: https://www.stgeorge.com.au/corporate-business/report-centre/economic-outlook.

St John, W \& Johnson, P 2000, 'The pros and cons of data analysis software for qualitative research', Journal of Nursing Scholarship vol. 32, no. 4, pp. 393-397.

Stake, R 2005, 'Qualitative Case Studies', in The Sage Handbook of Qualitative Research, ed. N Denzin \& YS Lincoln, Sage Publications, London.

Standing, G 1997, 'Globalization, Labour Flexibility and Insecurity: The Era of Market Regulation', European Journal of Industrial Relations, vol. 3, no. 1, pp. 7-37.

Standing, G 2008, 'Economic Insecurity and Global Casualisation: Threat or Promise?', Social Indicators Research, vol. 88, pp. 15-30.

Standing, G 2012, 'The Precariat: From Denizens to Citizens?', Polity, vol. 44, no. 4, pp. 588608.

Standing, G 2014, 'The precariat', Contexts, vol. 13, no. 4, pp. 10-12.

Stark, S \& Torrance, H 2004, 'Case Study', in Research Methods in the Social Science, ed. B Somekh \& C Lewin, Sage Publications, London.

Steger, BB 2010, 'Globalization', in The Encyclopedia of Political Thought, John Wiley \& Sons, pp. 1488-1499.

Stewart, DW \& Kamins, MA 1993, Secondary research information sources and methods, Sage Publications, Newbury Park, Calif.; London.

Stone, J 1995, 'Empty or full? The debate over the population of Australia', in Population 2040: Australia's Choice - Annual General Meeting of the Australian Academy of Science, Canberra.

Strazdins, L, D'Souza, RM, Lim, L, Broom, DH \& Rodgers, B 2004, 'Job Strain, Job Insecurity, and Health: Rethinking the Relationship', Journal of Occupational Health Psychology, vol. 9, no. 4, pp. 296-305.

Sturges, J, Conway, N, Guest, D \& Liefooghe, A 2005, 'Managing the career deal: the psychological contract as a framework for understanding career management, organizational commitment and work behaviour', Journal of Organizational Behavior, vol. 26 , no. 7 , pp. 821-838.

Sutton, G \& Griffin, MA 2004, 'Integrating expectations, experiences, and psychological contract violations: A longitudinal study of new professionals', Journal of Occupational and Organizational Psychology, vol. 77, pp. 493-514.

Suutari, V \& Brewster, C 2000, 'Making Their Own Way: International Experience Through Self-Initiated Foreign Assignments', Journal of World Business, vol. 35, no. 4, pp. 417436.

Suutari, V, Brewster, C, Riusala, K \& Syrjakari, S 2013, 'Career decision making of global careerists', Journal of Global Mobility, vol. 1, no. 2, pp. 118-138.

Suutari, V \& Taka, M 2004, 'Career Anchors of Managers with Global Careers', Journal of Management Development, vol. 23, no. 9, pp. 833-847.

Sverke, M, Hellgren, J \& Naswall, K, Job insecurity, a literature review. Available from: $<$ http://citeseerx.ist.psu.edu/viewdoc/download?doi=10.1.1.517.3749\&rep=rep1\&type= pdf $>$. [16 November 2015].

Swidler, A 1986, 'Culture in action: symbols and strategies', American Sociological Review, vol. 
51, pp. 273-286.

Tasker, S 2012, 'Mount Gibson to slash 270 jobs', The Australian, 19 October 2012. Available from: Factiva. [26 October 2012].

Taylor, A 2009, 'Belonging', in International Encyclopedia of Human Geography, eds R Kitchin \& N Thrift, Elsevier, Amsterdam, pp. 294-299.

Teicher, J, Shah, C \& Griffin, G 2000, 'Australian immigration: the triumph of economics over prejudice?', ACER, Monash University, vol. Working Paper 33, no. December 2000.

Tesch, R 1990, Qualitative research: analysis types and software tools, Falmer Press, New York.

Tham, J \& Campbell, I 2011, 'Temporary Migrant Labour in Australia: The 457 Visa Scheme and Challenges for Labour Regulation', Centre for Employment and Labour Relations Law, Melbourne Law School, no. 50, pp. 1-48.

The Organisation for Economic Co-operation and Development (OECD) 2001, International Mobility of the Highly Skilled, OECD Publications Service, Paris.

The Organisation for Economic Co-Operation and Development (OECD) 2008, The Global Competition for Talent: The Mobility of the Highly Skilled, OECD Publishing, Paris.

The Organisation for Economic Co-operation and Development (OECD) 2010, OECD Economic Surveys: Australia 2010, OECD.

Thomas, DC, Fitzsimmons, S, Ravlin EC, Au, K, Ekelund, B \& Barzantny, C 2010, 'Psychological contracts across cultures', Organization Studies, vol. 31, pp. 1437-1458.

Thomas, DC, Lazarova, M.B., \& Inkson, K. 2005, 'Global careers: New phenomenon or new perspectives?', Journal of World Business, vol. 40, pp. 340-347.

Thompson, EP 1967, 'Time, Work-Discipline, and Industrial Capitalism', Past and Present, vol. 38 , no. 1 , pp. $56-97$.

Thompson, JA \& Bunderson, JS 2003, 'Violations of Principle: Ideological Currency in the Psychological Contract', Academy of Management Review, vol. 28, no. 4, pp. 571-586.

Thompson, P 2003, 'Financialization and the workplace: extending and applying the disconnected capitalism theory', Work, Employment and Society, vol. 27, no. 3, pp. 472488.

Thompson, P 2011, 'Provocation Series Paper: The trouble with HRM', Human Resource Management Journal, vol. 21, no. 4, pp. 355-367.

Thomson, R, Plumridge, L \& Holland, J 2003, 'Longitudinal qualitative research: a developing methodology', International Journal of Social Research Methodology, vol. 6, no. 3, pp. $185-187$.

Tillett, A 2012, 'End in sight to WA's mining boom: report', The West Australian, 23 July 2012.

Tillett, A 2014, 'Jobless rate gives rise to visa debate: Jobless rate at 12-year high', The West Australian, 8 August 2014, p. 2.

Tilly, C 2011, 'The impact of the economic crisis on international migration: a review', Work, Employment and Society, vol. 25, no. 4, pp. 675-694.

Tipples, R 2009, 'Editor's Foreword: Fifty Years of Psychological Contract Research - from the Touchy/Feely to the Concrete Personal Deal', New Zealand Journal of Employment Relations, vol. 34, no. 2, pp. 1-3.

Toner, P \& Wooley, R 2008, 'Temporary Migration and Skills Formation in the Trades: A provisional Assessment', People and Place, vol. 16, no. 3, pp. 47-57.

Trenwith, C 2011, 'WA's crippling skills crisis is 'not over", WA Today, 20 July 2011.

Turnley, WH \& Feldman, DC 1999, 'The Impact of Psychological Contract Violations on Exit, Voice, Loyalty and Neglect', Human Relations, vol. 52, no. 7, pp. 895-921. [May 25th 2010].

United Nations (UN) 2009, World Investment Report: Transnational Corporations, Agricultural Production and Development, United Nations, Geneva [20 March 2014].

United Nations (UN) 2013, General Assembly - International migration and development: Report of the Secretary-General, United Nations, Geneva.

United Nations Development Programme (UNDP) 2009, Human development report 2009: overcoming barriers - human mobility and development, United Nations, New York [15 November 2015].

Uren, D 2013, 'Iron ore price shocks a big deal for the economy', The Australian, 28 January 2013. 
Vaismoradi, M, Turunen, H \& Bondas, T 2013, 'Content analysis and thematic analysis: Implications for conducting a qualitative descriptive study', Nursing \& Health Sciences, vol. 15, pp. 389-405.

Vallance, RJ 2005, 'Working with Longitudinal Qualitative Date: Using NVivo as an Analytic Tool', 6th International Strategies in Qualitative Research Conference. Durham, 21-23 September.

Van Hear, N 2010, 'Theories of Migration and Social Change', Journal of Ethnic and Migration Studies, vol. 36, no. 10, pp. 1531-1536.

Van Manen, M 1990, Researching lived experience, Althouse Press, London.

Van Manen, M 2004, 'Lived experience', in Encyclopedia of social science research methods, ed. M Lewis-Beck, A Bryman \& T Liao, Sage Publications, Thousand Oaks, pp. 580581.

Vertovec, S 2004, 'Migrant Transnationalism and Modes of Transformation', International Migration Review, vol. 38, no. 3, pp. 970-1001.

Vogt, WP 1999, Dictionary of Statistics and Methodology: A Nontechnical Guide for the Social Sciences, Sage Publications, London.

Wadhwa, V, Saxenian, AL, Freeman, R, Gereffi, G \& Slakever, A 2009, America's loss is the world's gain: America's new immigrant entrepreneurs, UC Berkeley School of Information and Ewing Marion Kauffman Foundation, CA.

Walsh, J 2014, 'From nations of immigrants to states of transience: Temporary migration in Canada and Australia', International Sociology, vol. 29, no. 6, pp. 584-606.

Weber, RP 1990, Basic content analysis, Sage Publications, London.

Weber, RA 1969, 'Convergence or divergence?' The Columbia Journal of World Business, vol. 4, pp. 75-83.

Weber, M [1922] 1947, 'Social stratification and class structure', in The Theory of Social and Economic Organization, ed. T Parsons, The Free Press, New York, pp. 424-429.

Webster, E, Lambert, R \& Bezuidenhout, A 2008, Grounding Globalization, Blackwell Publishing, Carlton.

Weiss, DD \& Gross, AC 1995, 'Industry corner: Major household appliances in Western Europe', Business Economics, vol. 30, no. 3, pp. 67-71.

Weitzman, EA 2000, 'Software and Qualitative Research', in Handbook of Qualitative Research, eds N Denzin \& YS Lincoln, Sage Publications, Thousand Oaks.

Wiener, Y 1982, 'Commitment in Organizations: A Normative View', Academy of Management Review, vol. 7, no. 3, pp. 418-428.

Williams, AM \& Balaz, V 2012, 'Migration, Risk, and Uncertainty: Theoretical Perspectives', Population, Space and Place, vol. 18, pp. 167-180.

Wilson-Chapman, A 2012, 'Why all roads are leading to Perth - Hold on to good people', Sunday Times, 9 September 2012, pp. 6-7.

World Trade Organization (WTO) 2001, Annual Report 2001, Geneva.

Wright, CF 2012, 'Immigration policy and market institutions in liberal market economies', Industrial Relations Journal, vol. 43, no. 2, pp. 110-136.

Wright, CF 2014, 'How do States Implement Liberal Immigration Policies? Control Signals and Skilled Immigration Reform in Australia', Governance, vol. 27, no. 3, pp. 397-421.

Wright, CF 2015, 'Why Do States Adopt Liberal Immigration Policies? The Policymaking Dynamics of Skilled Visa Reform in Australia', Journal of Ethnic and Migration Studies, vol. 41, no. 2, pp. 306-328.

Yang, R 2003, 'Globalization and higher education development: A critical analysis', International Review of Education, vol. 49, no. 3/4, pp. 269-291.

Yeates, C 2011, 'Rises for miners fail to spark income spiral', The Sydney Morning, 20 May 2011. Available from: Factiva. [13 April 2014].

Yin, RK 1989, Case study research: design and methods, Sage Publications, Thousand Oaks.

Yin, RK 2014, Case Study Research: Design and Methods, Sage Publications, Thousand Oaks.

Young, C, Savola, K \& Phelps, E 1991, Inventory of longitudinal studies in the social sciences, Sage Publications, Thousand Oaks.

Zellmer-Bruhn, ME \& Gibson, CB 2014, How Does Culture Matter? A Contextual View of Intercultural Interaction in Groups, Oxford University Press.

Zukin, S \& DiMaggio, P 1990, 'Introduction', in Structures of Capital: The Social Organization 
of Economy, eds S Zukin \& P DiMaggio, Cambridge University Press, Cambridge, pp. $1-36$. 


\section{Appendix}

\section{A1. Appendix 1 - The Australian Migration Framework}

The Migration Act of 1958 and the Migration Regulations of 1994 govern the Australian Migration Program. The program's overall objective is 'to contribute to Australia's economic, demographic, and social wellbeing by facilitating the permanent and temporary entry or stay of people' (DIAC 2009, p. 25). The Australian immigration program is highly planned in the direction of meeting labour market needs, with the government setting a target for each year and forecasting levels for each of the program's components.

Australia's Migration Program is composed of two main streams (DIAC 2012b): 1) a family stream, designed to bring to Australia partners, children, parents, and other family members of citizens or permanent residents; 2) and a skill stream, which targets skills overseas that could contribute to Australia's economic needs. In addition to these streams, there is a special eligibility category for former residents, another for New Zealand citizens, and a humanitarian program that offers settlement to refugees and displaced people who have suffered violations of their human rights (DIAC 2012b). There are also a number of categories in which individuals may enter Australia on a temporary basis. These include visitors, international students, individuals who come from selected countries under the Working Holiday Maker Program, and temporary skilled workers (DIBP 2014d).

This Appendix describes only Australian visas designed to attract skilled applicants, whether they intended to become permanent skilled immigrants or whether they entered Australia with a temporary business visa. As per the focus of this research, these skilled visas focus on allowing trained and qualified individuals from other countries to engage in Australia's labour market, enabling Australian businesses and government to meet either short-, medium-, or long-term skill shortages in the country.

\section{Permanent Skilled Immigration}

Permanent skilled migration has long been renowned as critical in generating a highly skilled and productive labour force in Australia, whilst meeting the challenges of an 
ageing population and contributing to the nation's population's growth (DIBP 2014d). The skill stream of the Australia Migration Program is aimed at workers who have the skills, qualifications, and entrepreneurialism most needed for the future growth of the Australian economy (DIBP 2014b).

Since July 2012, all skilled applicants are assessed through SkillSelect, a points-based online program grounded on the economic needs of Australia. This new process has two steps: in the first step, applicants submit an expression of interest (EOI) in skilled immigration, providing information that will be used in their points-test score; in the second, these individuals are invited to lodge a visa application, or they may be sponsored for skilled visas by Australian employers, states, or territories (Cully 2012; DIBP 2015).

Through SkillSelect, the points-test is used to assess applicants in relation to a range of skill-related factors, such as age, English language ability, educational qualifications, and work experience. An individual's occupation should be listed in the Consolidated Sponsored Occupations List (CSOL), a new list of professional occupations experiencing shortages in Australia's labour market. The number of points prescribed for each factor reflects their relative importance in the context of an applicant's potential contribution to Australia (DIBP 2015) ${ }^{6}$.

There are four major components in the skilled stream of the Australian Migration Framework (DIBP 2014b):

- Points-Tested Skilled Migration: the largest component of the skill stream has three categories - independent, state/territory sponsored, and skilled regional. This is a permanent visa arrangement designed for skilled individuals without employer sponsorship.

- Permanent Employer-Sponsored: an Australian employer seeking to fill a genuine vacancy in their business must sponsor applicants for this visa. This arrangement commonly caters to migrants in Australia on other visas - such as the Temporary Work (Skilled) (subclass 457) visa - aiming to becoming permanent residents.

6 All the information about SkillSelect is available through the program website: http://www.immi.gov.au/skills/skillselect/ [25 April 2014] 
- Distinguished Talent: is exclusively for applicants with special or unique talents of benefit to Australia. It is typically granted to individuals internationally recognised for their outstanding achievements in arts, sports, research, and academia.

- Business Innovation and Investment: is granted to applicants who have a history of success in innovation and business and who want to own and manage a business in Australia or maintain a business and investment in the country.

\section{Temporary Skilled Immigration}

There is a range of visas in Australia for temporary labour migrants; however, the Temporary Business (Long Stay) subclass 457 is the most commonly used to sponsor overseas skilled workers on a temporary basis to Australia (DIAC 2011c; DIBP 2014d). It is designed to assist Australian employers in filling skilled vacancies that they have been unable to fill through local employment due to shortages experienced in the Australian labour market. This visa currently allows skilled overseas workers to enter Australia to work for a sponsoring Australian employer for up to four years and can also be used by overseas businesses seeking to establish a branch in Australia, participate in joint ventures, transfer employees between branches, or fulfil a specific contract (DIAC 2012; DIBP 2015). As this scheme is totally driven by employer demand (Cully 2012), it is also subject to times of high economic growth and low unemployment (DIAC 2011; DIAC 2012).

There are a number of conditions imposed on businesses that want to sponsor and bring workers from overseas: the employer must show that the nomination of the position to be filled by an overseas skilled worker requires special knowledge or qualifications that cannot be filled with local labour; the employer must receive approval that the business complies with immigration laws and has a satisfactory record on training staff or introducing new skills into Australia with the sponsorship; and the nominated employee/visa holder must have the skills to perform the activities indicated in the respective position (Crock et al. 2012; DIAC 2012).

Subclass 457 visa holders can work in Australia for up to four years and can bring eligible dependants who are also allowed to work and study. However, there are several requirements that prospective visa applicants must meet to be granted a visa: They must demonstrate satisfactory English language ability, validate the skills and experience 
necessary to perform the nominated occupation, possess adequate health insurance for the period of stay in Australia, and meet standard visa requirements such as character and health checks. Applicants for the 457 visa can use the SkillSelect program, although this is not mandatory. Nomination can occur directly between an employer and employee located overseas.

The 457 visa is also commonly used for individuals in short-term intra-company transfers. Intra-company transfers are movements of employees who are temporarily allocated to a different country to provide services, for a limited period, for the same company by which he/she is employed (DIBP 2014b). Frequently, an application for a 457 visa indicates that the applicant is travelling on an internal company transfer arrangement; however, some transferred individuals who plan to stay less than a year in Australia - for a conference or business negotiation, for example - may enter the country on other visas, including the short-term business visitors visa (DIBP 2014b). 


\section{Phase 1 (2010-2012)}

\section{Part 1: Understanding Employee's Background}

1. Why did you decide to come to Australia?

2. What were your motivations?

3. What were your sources for getting information about life in Australia?

4. What are your intentions toward settlement in Australia?

5. Has the company hired you overseas / or transferred you from another city / country?

a. If not, what is your history with this company?

b. If so, what have they done to help you and your family relocate / settle?

\section{Part 2: Exploring Psychological Contract}

1. What were your expectations regarding work/career when you came to Australia?

2. Who do you think created these expectations?

3. Were they fulfilled?

4. Because you are an immigrant who came here to fulfil a skill shortage, what obligations do you think Australia has towards you?

5. Why have you decided to work for this company?

6. What did the company offer / promise you?

7. What expectations do you have towards this employer?

8. How were these expectations created?

9. Is this a shared belief in your organisation?

10. Do you think your employer fulfils your expectations?

11 . What do you think you owe your employer in return?

12. What would you say are the obligations this employer has towards you?

13. What do you believe are your obligations towards this organisation and why?

14. What impacts have this move had in your career? Did you feel you gave a step back / forward?

15. How do you think it would be easy or difficult to get another job if you lost this one? Why? Do you feel secure?

16. (Employability) How does this job help you to become more employable? How do you improve your employability?

17. How long are you planning to keep working for this company and why? Have you committed to staying for a specific amount of time?

18. Do you have tasks you may complete beyond the typical job description? How do you relate to them? What do you expect and what do you get by doing these tasks?

19. Do you acknowledge that another person (or any institution) has contributed to the success of your immigration process?

20. Do you feel gratitude for your employer? Do you feel gratitude for the opportunity of coming here? What do you mean by gratitude?

21. Are you a member of any union or association? How do they help / represent you?

\section{Part 3: Exploring Cultural Issues}

1. How diverse is your working group? Do you face any conflict related to the diversity of the group or related to the differences in how things are done in the workplace?

2. How do you think you were prepared to work in such a diverse environment? Or how were you prepared to work in a culture different from yours?

3. How would you describe teamwork in your workplace?

4. How does Australia compare to your previous experiences? 
5. How would you describe hierarchy in your organisation? How is it different from your previous experiences? Do you think it reflects Australian society?

Phase 2 (2013)

\section{Part 1: Reviewing Previous Interview}

1. In our first interview you mentioned (x). What has happened? How are you feeling now?

2. Back then, you also mentioned that what attracted you was (x).

a. Are you in the same project?

b. Did you change positions? (If moved from professional to manager, check if this has changed the employment relationship).

c. Are you still happy with $(\mathrm{x})$ ?

d. Fulfilment of expectations?

e. Explore breach if there was breach.

3. What are your expectations towards this job today?

4. How were these expectations created?

5. Did they make any promise to you?

Part 2: Employment Relationship

1. What do you value most in your employment relationship today?

2. What makes you engage and put effort into guaranteeing a good delivery every day?

3. Do you believe your employer is fair with you? Why?

4. Can you give me examples of fairness in your workplace?

5. Do you trust your employer? Do you think s/he trusts you? Why?

6. Where do you think the 'power' in your relationship lies?

7. Understand who 'the employer' is.

8. What does your employment contract say?

9. Is there any clause related to your dismissal?

\section{Part 3: Job Security, Employability and Other New Issues}

1. How do you think it would be easy or difficult to get another job if you lost this one now? Why?

2. Do you feel secure?

3. What makes you secure?

4. How does this job help you to become more employable? How do you improve your employability?

5. Did the recent vulnerability of the labour market, with dismissals in many big companies and big projects cancelled in both mining and construction, affect your company?

6. How did this scenario impact your perceptions of job security and employability?

7. Did this scenario impact the delivery of some promises in your workplace?

8. How do you consider yourself loyal to your employer? Why?

9. What would make you change jobs? 


\section{Phase 3 (2014)}

\section{Part 1: Reviewing Previous Interview and Their PCs}

1. In our first interview, you mentioned (x). What has happened? How are you feeling now?

2. Back then you also mentioned that what attracted you was (x).

a. Are you in the same project / role?

b. Did you change positions? (If moved from professional to manager, explore the impact over the ER).

c. Fulfilment of previous expectations?

d. Explore breach if there was breach.

3. How would you describe your obligations towards this company nowadays?

4. What are your expectations with this job today?

5. How were these expectations created?

6. Did the company make any new promise to you in the past (x) months? (Who was that - HR, manager, owner)

\section{Part 2: Employment Relationship}

1. What has changed in your workplace since you started working for this company?

2. How would you say these shifts in context have affected your relationship with your organisation? Do you think 1) it enhanced your commitment to secure / restore productivity; or 2) improved your desire to look for another job; or 3) it took away your motivation to come to work?

3. Do you feel secure nowadays? What makes you feel secure (or not)? (Understand how the labour market has been affecting the company and feelings of security / employability.)

4. What does insecurity mean to you? Do you feel anxious?

5. What do you value most in your employment relationship today?

6. What are your outcomes in this employment relationship? What do you give back to your employer?

7. (If mentioned gratitude before) Do you still feel gratitude?

8. (If mentioned commitment, explore) What is commitment to you? Do you identify with organisational goals and values?

9. Is your employer fair to you? Can you give me examples of fairness in your workplace?

10. Is there trust in your employment relationship?

11. How do you think it would be easy or difficult to get another job if you lost this this one now? Why? How would losing a job affect you?

12. What are your plans towards this organisation? How do you consider yourself loyal to your employer? Why?

\section{Part 3: Exit Questions}

1. When you decided to migrate to Australia, you had a set of work-related expectations. How do you see your achievements and/or opportunities in relation to those premigration expectations? Try to explore again how those pre-migration expectations were created.

1. Can you recall and reconstruct your professional experience in the past four years?

2. In one sentence, what has changed through time?

3. What are your predictions about the future?

4. Do you feel like you belong in Australia? 


\section{A3. Appendix 3 - Guidelines for Interviews with Intermediaries}

\section{Interview with the Department of Education and Workforce Development (DTWD)}

1. Recently, the department launched Skilling WA to build, attract, and retain skilled workforce, specifically targeting skilled immigration. Two of your strategic goals are especially important to my research:

Strategic goal 2 - supplement the WA workforce with skilled immigrants to fill employment vacancies unable to be filled by the local workforce

Strategic goal 3 - attract workers with the right skills to the WA workforce and retain them

Can I ask you some questions about these strategies?

1.1. 'Marketing WA to the world' - marketing WA as a destination of choice. Can you tell me about the department's enterprises? What is the message? What are the criteria for selecting a destination for your communication? By that I mean, how do you choose a specific country to deliver your presentation to or to target migration agencies?

1.2. 'Awareness of employment opportunities for migrants' - DTWD will promote awareness of employment opportunities, the availability of high-quality skilled migrants, and visa pathways among prospective migrants and employers. Is the Migration Portal the only tool you are using or do you have other initiatives to promote the awareness?

1.3. 'Migrant Career Development' - DTWD will expand the roles of the Career Centre and Workforce Development Centre to provide support to migrants and employers and to improve their skills and workforce participation. What kind of support can the department provide? What did these centres used to do for migrants, and what are they doing now?

1.4. 'Enterprise attraction and retention' - about industries sharing best practices. Are there any materials available about that or any other planned events?

1.5. Most of the department's retention initiatives are partnerships with the industries. Can you name your main partners?

2. Regarding the attraction of skilled immigrants to WA, what is in your discourse? What are your messages? (Confirm and understand the statements below.)

CCIWA Skilled Immigration in WA Report - recommends that WA's 1) quality of life, 2) environment, 3) growing job opportunities, and 4) high-quality working conditions must be marketed to ensure WA continues to be a destination of choice for skilled immigrants. "If you are seeking a fantastic career or an incredible lifestyle, the opportunities are endless in Western Australia" (Portal)

3. Do you believe there is any promise implied in these messages?

4. Most of the deliveries of these promises - lifestyle, environment, and even the career opportunities - are usually other's responsibility, not DTWD's. Does the department have initiatives to access individual's satisfaction after they arrive here - that is, to check if the government promises are being delivered?

5. What does the department expect from the immigrants that are coming here?

6. How do you communicate to them what Australia expects from them?

7. Does the department offer any kind of support once they are here?

8. What do you think people expect when they are coming here?

9. WA is very particular when compared to other big cities in Australia regarding the cultural background of the skilled immigrants. Here we have large groups from UK and South Africa for example, and Asian countries like China are underrepresented. Do you have any research / material about that? Do you believe it is a matter of industry representation? Do you experience differences in expectations and perceptions from people from different countries?

10. Do you have any research or statistics related to skilled immigrants' satisfaction, loyalty, or intentions to stay? 
1. Can you please start by giving me an overview of your background and experience? Confirm expertise in mining and engineering industries, expertise in WA market.)

2. Would it be ok for you to describe your process - when you have, for example, a position for project manager in an EPCM, where do you start your research for the appropriate candidate? When do you go overseas?

3. When recruiting overseas, what are your criteria?

- Check if starts with biggest competitors and validate Brazil as a source of qualified professionals.

- Database - tell me about the presence of professionals especially from SA and BR?

4. Is there a set of important characteristics in a highly skilled migrant?

5. What reasoning does your team, as recruiters, use to promote Australia as a good place to live / migrate to? Is that necessary or are people willing to come?

6. Can you comment about what companies are offering / promising for skilled migrant candidates in terms of packages? Has this offer changed in the last few years?

7. Can you please comment on your perspectives regarding changes in labour migration since 2010 ?

8. Have you noticed any changes in terms of 'where the power is' in the employment relationship in the last few years?

9. Do you believe the recent vulnerability of the labour market, with a lot of projects cancelled and dismissals in a number of big companies, has affected people's perceptions of job security? Is it pushing people to become more employable? Is this pulling the highly skilled away?

10. Can you share with me your expectations for the short-term future, in terms of high-skilled labour migration to Australia?

\section{Interview with Migration Agent}

1. Can you please start by giving me an overview of your background and experience? (Confirm expertise in WA market.)

2. Can you please describe your role in the migration process for skilled immigrants? Do you work with companies or for individuals?

- Do you play an active role matching potential employers and employees?

- Do you focus on any particular sector / industry?

3. Have you participated, as a migration agent, in any of the migration expos that are done overseas?

- Who organises these expos?

- Who participates, and what are their roles?

- What information is used to promote Australia as a good place to live or migrate to labour market, lifestyle?

4. Do you think labour migration has changed in WA over the past four or five years?

5. A number of spaces available in $2014 / 2015$ migration program didn't change in relation to the year before. In WA, I noticed a reduced number of 457 visa applications during the 2013/2014 period, compared to previous periods. How do you relate this to the market conditions? In your perspective, how is WA different from the rest of Australia?

6. The recent vulnerability of the labour market, with a lot of projects cancelled and dismissals in a number of big companies, has led to a cancellation of a number of visas, as companies sent people back home. Can you see this context also pushing the highly skilled away for more interesting projects somewhere else in the globe?

7. Can you share with me your expectations for the short-term future, in terms of high-skilled labour migration to Australia?

8. When I started my research back in 2010, highly skilled individuals who checked all the boxes were allowed to apply for a PR themselves and come to Australia even without a job. Now this is no longer possible, right? Individuals need to submit an expression of interest and wait for a sponsor. 

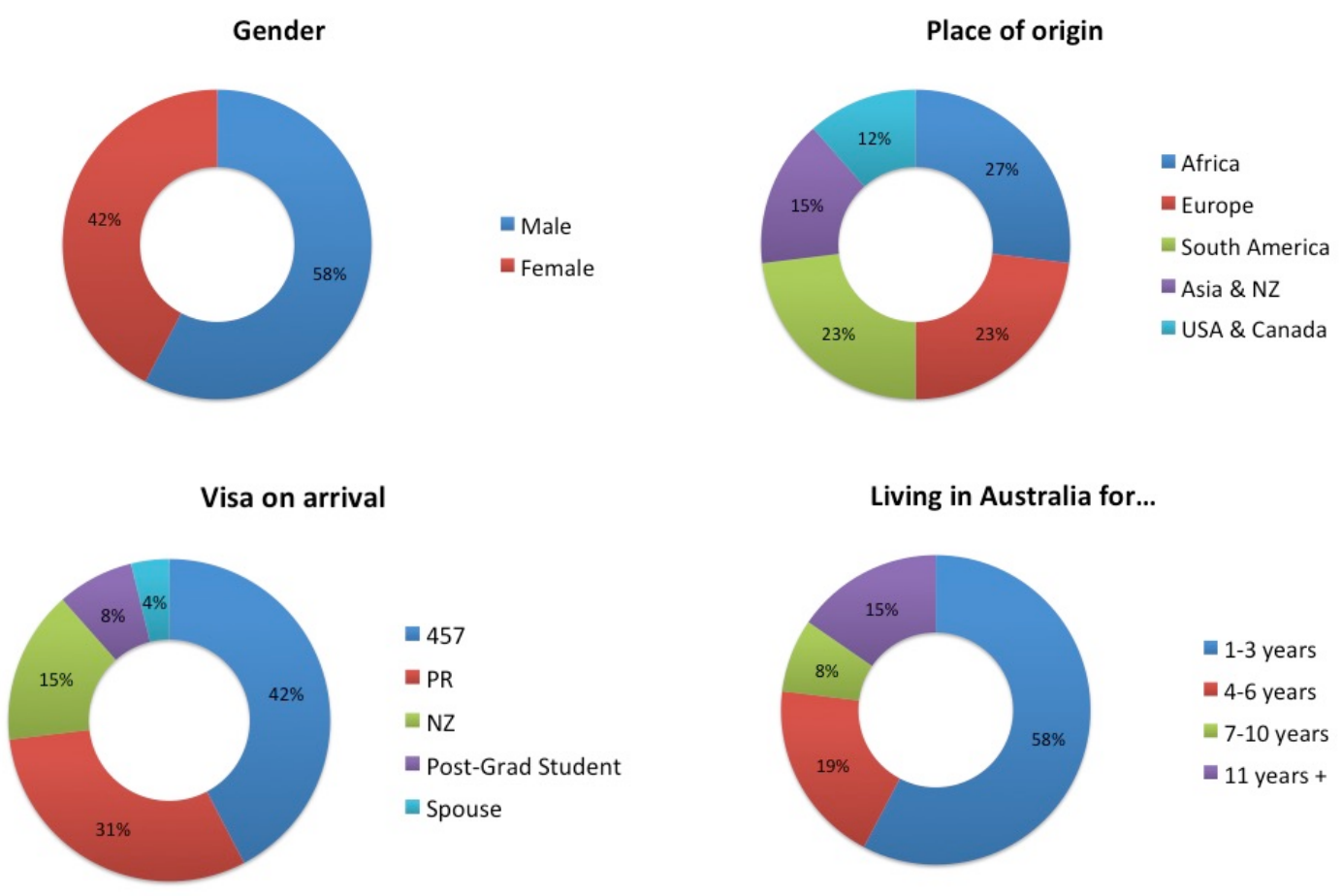

Living in Australia for...
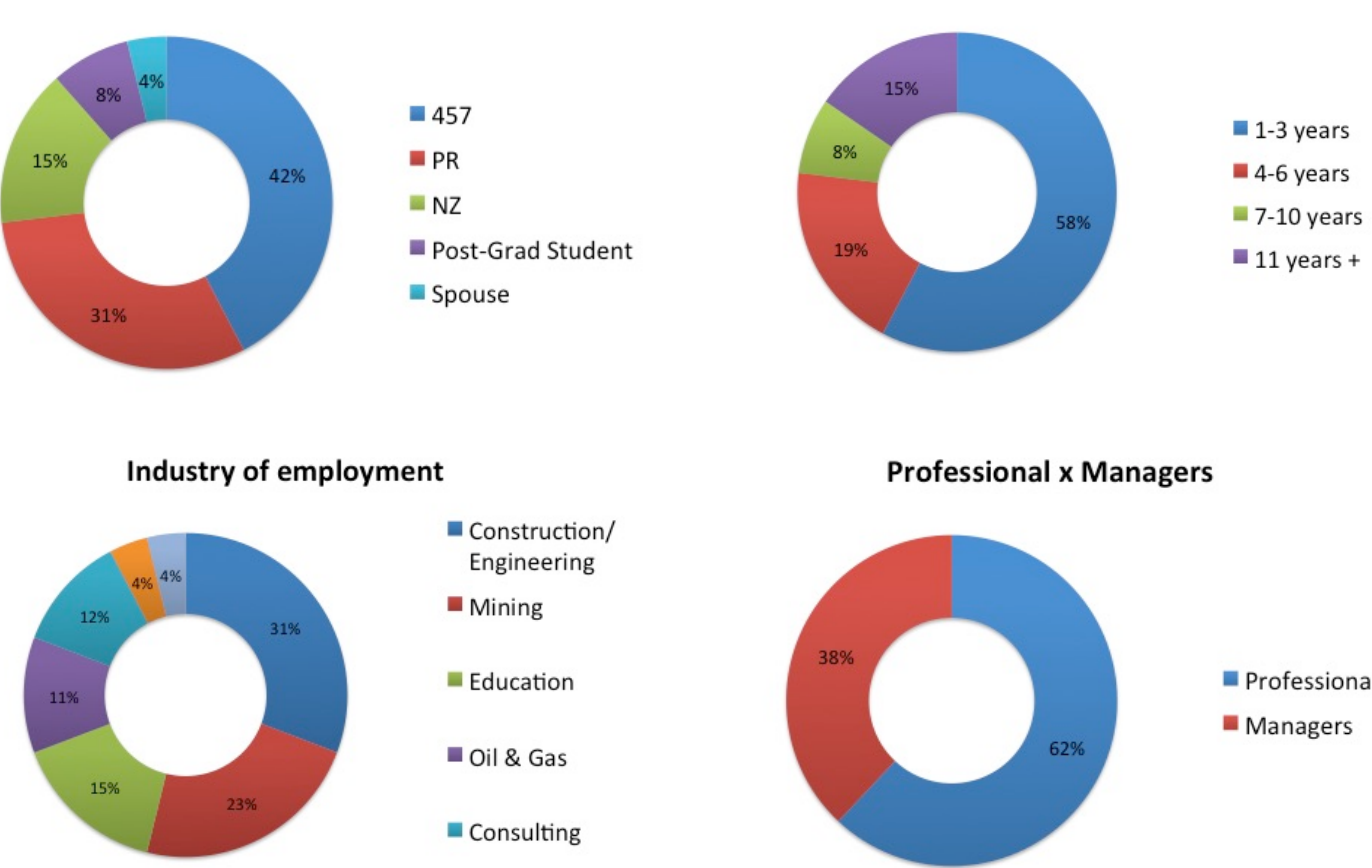

Professional x Managers

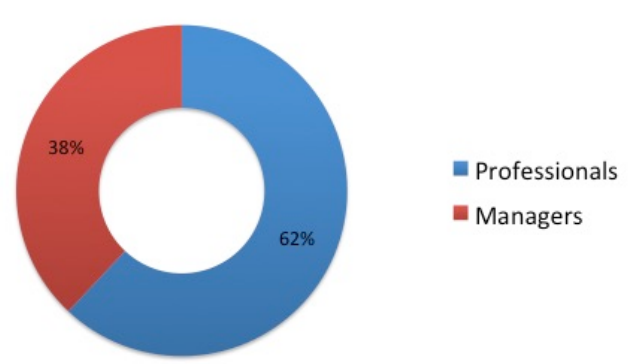

Figure A.1. Sample characteristics in Phase 1: gender, place of origin, visa on arrival, length of time in Australia, industry of employment and position in organisation 
NVIVO :: $1^{\text {st }}$ Coding of transcriptions

Definition of categories of analysis and classification of pieces of transcription

Normative expectation: Beliefs regarding what ought to occur, based upon a prevailing normative standard (Roehling 2008)

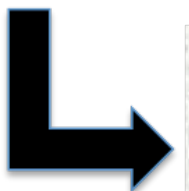

My previous expectations were fulfilled. Now my expectations are to move to another department, and to have more opportunities both vertically and horizontally. (...). Yes, (people moving among areas) is quite frequent in this company. People usually move within the departments, so this is no... it is common, it is part of the culture (Participant 26)

NVIVO :: Indication of frequency for each of the analythical categories

\begin{tabular}{|c|}
\hline Employer Obligations \\
\hline $\begin{array}{c}\text { Provide resources and } \\
\text { safety (7) }\end{array}$ \\
\hline Respect the contract (6) \\
\hline \hline Fair treatment (6) \\
\hline $\begin{array}{c}\text { Offer ongoing } \\
\text { development (4) }\end{array}$ \\
\hline $\begin{array}{c}\text { Offer professional } \\
\text { opportunities (3) }\end{array}$ \\
\hline
\end{tabular}
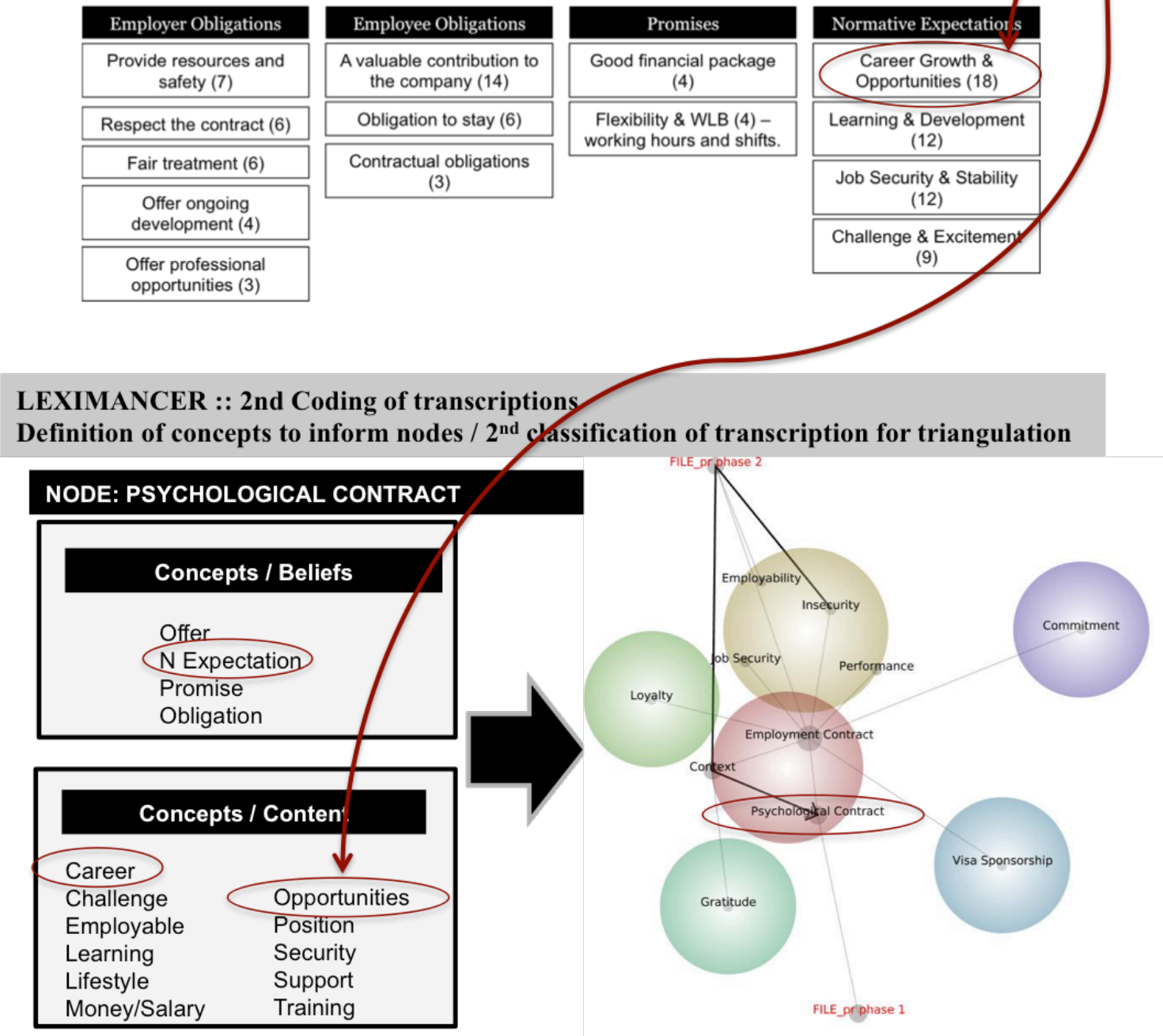

Figure A.2. Illustration of data analysis process for 'psychological contract'/ 'normative expectation' 


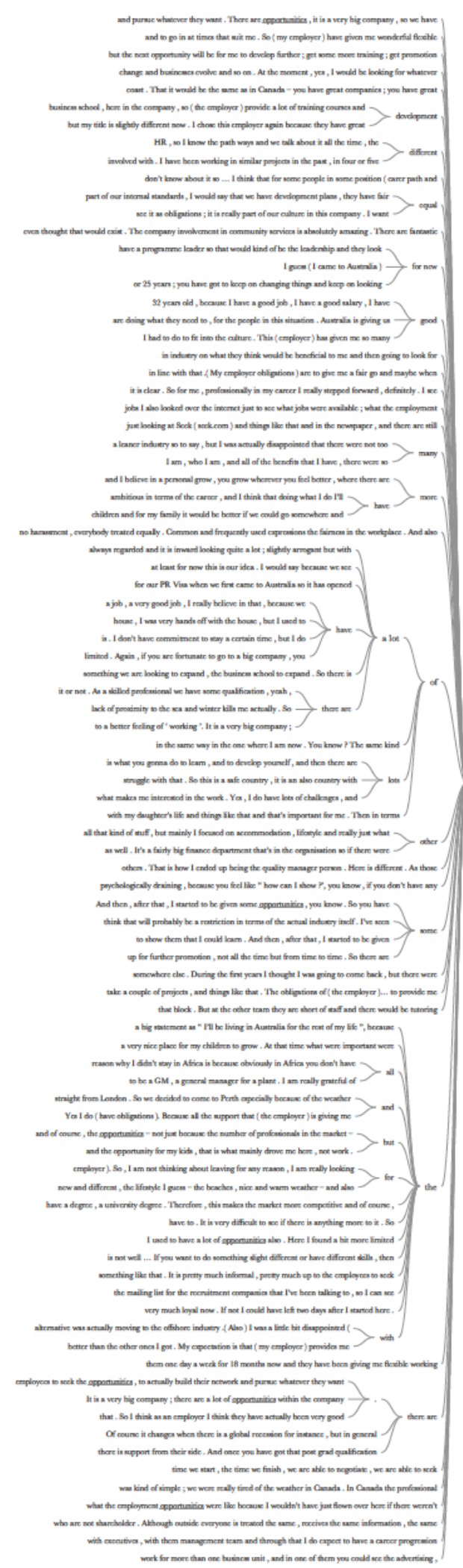

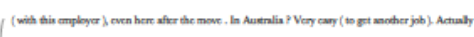

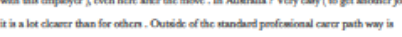

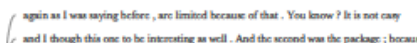

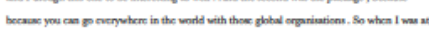

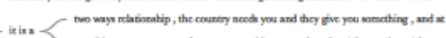

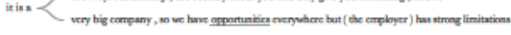

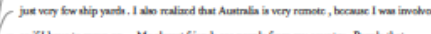

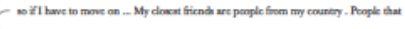

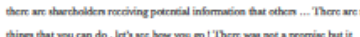

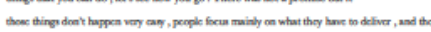

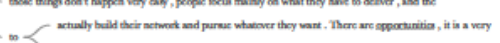

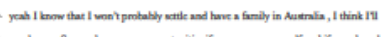

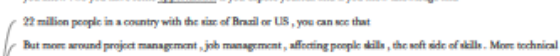

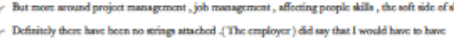

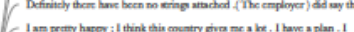

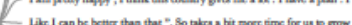

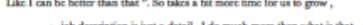

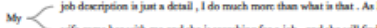

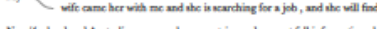

Figure A.3. Word-tree for "opportunities" (NVivo 10, in Phase 1) 


\section{A7. Appendix 7 - Table - Longitudinal Comparison of Changes According to}

\section{participants' Perceptions}

\begin{tabular}{|c|c|c|}
\hline Phase 1 & Phase 2 & Phase 3 \\
\hline \multicolumn{3}{|l|}{ P01 } \\
\hline $\begin{array}{l}\text { I think the most attractive thing } \\
\text { about this company is that it is a } \\
\text { small company, growing; for } \\
\text { example, now we are going to } \\
\text { New Zealand, and I'll have the } \\
\text { opportunity to grow with the } \\
\text { company. }\end{array}$ & $\begin{array}{l}\text { So far the crisis did not hit us. } \\
\text { We are in a grow mode, we } \\
\text { almost doubled the turnover last } \\
\text { year (...) So my expectations } \\
\text { with the company: I want the } \\
\text { company to grow, because if the } \\
\text { company grows, consequently I } \\
\text { will grow together. }\end{array}$ & $\begin{array}{l}\text { A major group bough } 50 \text { per } \\
\text { cent of the company. So what } \\
\text { before was, you know, a good } \\
\text { expectation, now turns out as } \\
\text { bad expectations. All the } \\
\text { financial department of the } \\
\text { company will be transferred to } \\
\text { Victoria, to Melbourne, so it } \\
\text { jeopardized my job. }\end{array}$ \\
\hline \multicolumn{3}{|r|}{ 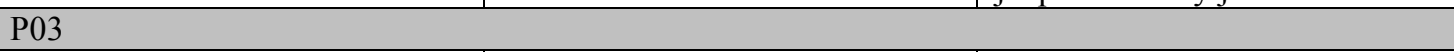 } \\
\hline $\begin{array}{l}\text { When the financial year started I } \\
\text { was promoted again (...) } \\
\text { I don't have any plans about } \\
\text { moving (jobs). I like it. There is } \\
\text { an interesting future ahead. It } \\
\text { has been pointed out and I enjoy } \\
\text { working in there. It is stable. }\end{array}$ & $\begin{array}{l}\text { I'd love to have security, but the } \\
\text { last data that I have heard, since } \\
\text { the iron ore dropped, it seems } \\
\text { like a hundred thousand people } \\
\text { in Australia lose their jobs; } \\
\text { twenty thousand of those within } \\
\text { consultancy. So yes, I'd love to } \\
\text { have security, but I think this is } \\
\text { a utopia (...) What I want I } \\
\text { can't get, so I guess it is time for } \\
\text { me and to my wife to have a } \\
\text { backup plan. I believe that the } \\
2008 \text { GFC didn't exist, and the } \\
\text { GFC is right now. }\end{array}$ & $\begin{array}{l}\text { It was not about the company, } \\
\text { but about the market. There are } \\
\text { market constrains in the } \\
\text { consultancy businesses. The } \\
\text { company is reacting to that (...) } \\
\text { I think everybody including } \\
\text { myself, the ones who started and } \\
\text { are still there, are just one fourth } \\
\text { of my team. }\end{array}$ \\
\hline \multicolumn{3}{|l|}{ P06 } \\
\hline $\begin{array}{l}\text { I chose them. I wanted to work } \\
\text { for this company. The things } \\
\text { they have done are actually the } \\
\text { first in the world so I was quite } \\
\text { interested in that and I wanted to } \\
\text { be part of it. (...) Now, people } \\
\text { will contact you from all over } \\
\text { the world; it doesn't matter } \\
\text { where you live (...) in an } \\
\text { industry like the mining } \\
\text { industry there aren't enough } \\
\text { skilled people so people have to } \\
\text { come in - geologists and others } \\
\text { from Brazil; lots of people come } \\
\text { for that and the mining. And oil } \\
\text { and gas is predominantly people } \\
\text { from England and the UK } \\
\text { because of experience. }\end{array}$ & $\begin{array}{l}\text { They are doing a global } \\
\text { restructure so what they do } \\
\text { during that process is if there are } \\
\text { going to be no suitable role for } \\
\text { you here they may offer you } \\
\text { work elsewhere. If you don't } \\
\text { take that option then obviously } \\
\text { you would be the same as a } \\
\text { contractor; you would need to } \\
\text { be finished (...) The things that } \\
\text { are affecting (the company) are } \\
\text { the government that's in and the } \\
\text { voting in September (...) I think } \\
\text { the remainder of this year into } \\
\text { early next year will be quite a } \\
\text { slog in WA for oil and gas. }\end{array}$ & $\begin{array}{l}\text { I was asked if I would consider } \\
\text { relocation and I agreed if it was } \\
\text { a suitable package to move my } \\
\text { family, during the discussions it } \\
\text { became apparent it was an } \\
\text { opportunity not to be missed } \\
\text { (...) The labour market in } \\
\text { Houston is booming, they are } \\
\text { now advertising overseas to } \\
\text { bring people in. }\end{array}$ \\
\hline \multicolumn{3}{|l|}{ P07 } \\
\hline $\begin{array}{l}\text { To do what I do in UK now... } \\
\text { there are a lot of people in there } \\
\text { trying to find a job. I know } \\
\text { people in the same position of } \\
\text { me, and they haven't actually } \\
\text { seen any sort of pay rise in three } \\
\text { years or something like this in } \\
\text { UK. So for my career point of } \\
\text { view it was a really lucky } \\
\text { decision. I am a geologist, so the } \\
\text { payment and the benefits are so } \\
\text { much better, maybe twice as }\end{array}$ & & $\begin{array}{l}\text { With (this employer) it was } \\
\text { more like getting rid of lots of } \\
\text { people because that's what } \\
\text { everyone was doing and I think } \\
\text { they did it probably about three } \\
\text { months before I arrived and they } \\
\text { did it again three or four months } \\
\text { ago. And they will do it again, } \\
\text { so I think it is just what } \\
\text { happens. But the thing is with } \\
\text { these companies they seem to } \\
\text { do that and then they hire again. }\end{array}$ \\
\hline
\end{tabular}




\begin{tabular}{|c|c|c|}
\hline good here. & & $\begin{array}{l}\text { It does make me feel a bit } \\
\text { insecure... }\end{array}$ \\
\hline \multicolumn{3}{|l|}{ P08 } \\
\hline $\begin{array}{l}\text { (Career as a nurse in Australia) } \\
\text { took a part in the decision of } \\
\text { coming here definitely. Back in } \\
\text { UK I couldn't get a permanent } \\
\text { position; I was just working in } \\
\text { several shifts. I thought here } \\
\text { would be quite easy to get } \\
\text { something and it was. It was } \\
\text { very easy. (...) After a couple of } \\
\text { months I found the (employer) } \\
\text { where I am working now and } \\
\text { they offered me the hours that I } \\
\text { wanted, the days that I wanted, } \\
\text { they were fantastic. Really } \\
\text { flexible. }\end{array}$ & & $\begin{array}{l}\text { Before Christmas they } \\
\text { announced a big recruitment } \\
\text { freeze across all public health } \\
\text { for all nurses, so there was no } \\
\text { one being employed; anyone } \\
\text { who was on a temporary } \\
\text { contract wasn't having it } \\
\text { renewed. Contracts weren't } \\
\text { extended, so hours weren't } \\
\text { increased; they could decrease } \\
\text { but they weren't increased. And } \\
\text { also they cut a lot of extra } \\
\text { casual shifts so if someone } \\
\text { called in sick, no, no } \\
\text { replacement (...) On the ground } \\
\text { it basically means if someone } \\
\text { calls in sick they are not } \\
\text { replaced. But the same number } \\
\text { of patients is still coming } \\
\text { through. }\end{array}$ \\
\hline \multicolumn{3}{|r|}{ 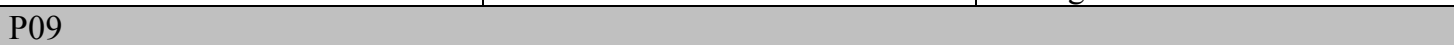 } \\
\hline $\begin{array}{l}\text { During the first years I thought I } \\
\text { was going to come back, but } \\
\text { there were opportunities here } \\
\text { and I was staying... (...) For me } \\
\text { saying that I am going to } \\
\text { another company I do have that } \\
\text { feeling that after all the effort } \\
\text { that they put in my } \\
\text { development... I feel a bit like } \\
\text { "no". }\end{array}$ & $\begin{array}{l}\text { Last year we had here a scenario } \\
\text { in which you could lose your } \\
\text { job, because there were no job, } \\
\text { so your skills were no longer in } \\
\text { need (...) I saw people very } \\
\text { highly experienced, who have } \\
\text { been in the company for a very } \\
\text { long time, and this loyalty didn't } \\
\text { even matter for the company in } \\
\text { the end of the day (...) They } \\
\text { sacked some people last year, } \\
\text { and we felt wow, this person has } \\
\text { been with this company for like } \\
\text { ten years, you know? In the end } \\
\text { of the day this is an institution } \\
\text { based on money, and it is not } \\
\text { personal. I think that this } \\
\text { changed me a little bit. }\end{array}$ & \\
\hline \multicolumn{3}{|c|}{ ( } \\
\hline $\begin{array}{l}\text { I phoned two hospitals, and one } \\
\text { of them came back to me and } \\
\text { offered me contract employment } \\
\text { within a few days. Then we both } \\
\text { had full-time jobs within two } \\
\text { months of arriving. }\end{array}$ & & $\begin{array}{l}\text { We have more limited time for } \\
\text { certain projects, and they } \\
\text { scrutinize your hours in much } \\
\text { more details, they became } \\
\text { tighter with the new budget. } \\
\text { (...) A few weeks ago there } \\
\text { were a lot of rumours of } \\
\text { redundancy. At this stage I think } \\
\text { I still feel secure because I am } \\
\text { permanent. If I was just casual, } \\
\text { or in a contract, I probably } \\
\text { wouldn't feel as secure. }\end{array}$ \\
\hline \multicolumn{3}{|l|}{ P11 } \\
\hline $\begin{array}{l}\text { In the beginning of this year I } \\
\text { just sent my CV to (this } \\
\text { company), just asking if they } \\
\text { had tutoring work. And they've } \\
\text { asked if I would take the unit } \\
\text { coordination of that course for }\end{array}$ & $\begin{array}{l}\text { In } 2011 \text { it got very, very busy. } \\
\text { But (the employer) kept } \\
\text { everything on a six monthly } \\
\text { contracts which suited them } \\
\text { because they were facing a } \\
\text { potential restructure. }\end{array}$ & $\begin{array}{l}\text { Because of the changes within } \\
\text { the university environment, the } \\
\text { (faculty) had a huge restructure } \\
\text { and retrenchment and they lost a } \\
\text { lot of permanent staff members. } \\
\text { So there is a lot of work }\end{array}$ \\
\hline
\end{tabular}




\begin{tabular}{|c|c|c|}
\hline $\begin{array}{l}\text { this semester. So I just stepped } \\
\text { in. }\end{array}$ & & $\begin{array}{l}\text { available for sessional at the } \\
\text { moment. I don't know how long } \\
\text { that will last, but for now it is } \\
\text { there because they have lost so } \\
\text { many permanent staff members. }\end{array}$ \\
\hline \multicolumn{3}{|r|}{ 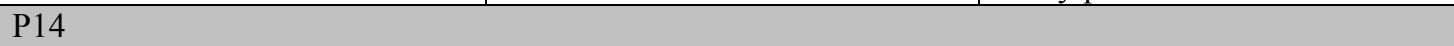 } \\
\hline $\begin{array}{l}\text { I came here as a normal senior } \\
\text { consultant but then I took over } \\
\text { the Business Unit so I was } \\
\text { responsible for the Perth office } \\
\text { and in May I was promoted to } \\
\text { General Manager (...) we did } \\
\text { come through the global } \\
\text { financial crisis without anyone } \\
\text { leaving the company or having } \\
\text { to be dismissed so that was } \\
\text { good (...) this relationship is } \\
\text { very special; it is very trustful } \\
\text { and my obligation is loyalty I } \\
\text { think. I wouldn't just hand in } \\
\text { my resignation and leave. }\end{array}$ & $\begin{array}{l}\text { If certain things are not } \\
\text { appreciated or if certain things } \\
\text { that frustrate you are not } \\
\text { overcome then at some stage } \\
\text { you need to make the hard } \\
\text { decision and say, OK, it was } \\
\text { good, but I need to move on } \\
\text { (...) We are in a niche market so } \\
\text { we came through the GFC quite } \\
\text { OK; we had to let go a few } \\
\text { people but I think only one or } \\
\text { two. There was a degree of } \\
\text { uncertainty for a while so } \\
\text { people thought OK, who's next? } \\
\text { (..) In terms of Perth market and } \\
\text { the situation here in WA } \\
\text { obviously there is a risk because } \\
\text { we rely on (client) at the } \\
\text { moment to a certain extent. }\end{array}$ & \\
\hline \multicolumn{3}{|c|}{ 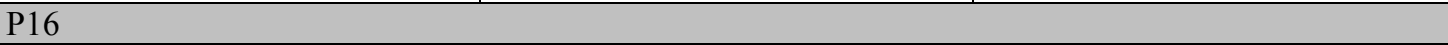 } \\
\hline $\begin{array}{l}\text { I think we were very fortunate } \\
\text { because in an economic point of } \\
\text { view WA is the best place in the } \\
\text { world to be right now, in the } \\
\text { world! Because if you can't find } \\
\text { a job here in WA there is } \\
\text { something wrong with you. I } \\
\text { mean, some sort of job, because } \\
\text { there are jobs out there. In US, } \\
\text { in Europe, and in many other } \\
\text { places, it is still... the economy } \\
\text { is terrible. And this affects your } \\
\text { entire life. }\end{array}$ & & $\begin{array}{l}\text { These organisations (which } \\
\text { went through projects } \\
\text { cancelations and dismissals) } \\
\text { they are clients, or prospective } \\
\text { clients. So we have seen a } \\
\text { downturn in expending at the } \\
\text { moment, because people are } \\
\text { retracting, there are less } \\
\text { projects, it is more about } \\
\text { maintaining than a building } \\
\text { phase. That being said, because } \\
\text { in terms of the workforce, most } \\
\text { functions are still there, they } \\
\text { need somebody to help them, so } \\
\text { there are still opportunities out } \\
\text { there. They are different types } \\
\text { of opportunities, it is more about } \\
\text { saving money than expanding } \\
\text { services, so we had also a shift } \\
\text { in focus. }\end{array}$ \\
\hline \multicolumn{3}{|l|}{ P17 } \\
\hline $\begin{array}{l}\text { They hired me overseas and } \\
\text { they brought me in (...) My } \\
\text { expectation is that they provide } \\
\text { me with the opportunities for a } \\
\text { good career; I am planning on } \\
\text { staying with them for many } \\
\text { years. I know that the market is } \\
\text { really hot up there and there are } \\
\text { many jobs for the people with } \\
\text { my skills (...) so I don't see } \\
\text { myself losing my job unless } \\
\text { something really unexpected } \\
\text { happened to all the company's } \\
\text { projects in Perth which is } \\
\text { unlikely. }\end{array}$ & $\begin{array}{l}\text { My previous project was } \\
\text { cancelled, in my previous job, } \\
\text { and they didn't have any more } \\
\text { projects to do, so they let me } \\
\text { know that I could look for } \\
\text { alternatives (...) This is the } \\
\text { nature of engineering work that } \\
\text { I do, it is always project driven, } \\
\text { and projects are driven by } \\
\text { market conditions. When market } \\
\text { conditions change, things get } \\
\text { shattered (...) The reason to } \\
\text { shelving this project was some } \\
\text { governmental condition (...) in } \\
\text { the end the general feeling is } \\
\text { that it was a market change, the }\end{array}$ & $\begin{array}{l}\text { (The market) has impacted the } \\
\text { company greatly from a } \\
\text { resourcing perspective; there is } \\
\text { a lot less people out there } \\
\text { working harder in order to keep } \\
\text { things moving (...) (the } \\
\text { employer) left the teams pretty } \\
\text { much in the dark for a long } \\
\text { time. I think the company itself } \\
\text { was also trying to sort out what } \\
\text { they needed to do or not but the } \\
\text { feeling that I have at least is that } \\
\text { once they figured out the plan } \\
\text { that they were going to go for, } \\
\text { they came to us and } \\
\text { communicated effectively with }\end{array}$ \\
\hline
\end{tabular}




\begin{tabular}{|c|c|c|}
\hline & $\begin{array}{l}\text { price of the mineral came down, } \\
\text { the commodity went down, and } \\
\text { things are no longer viable (...) } \\
\text { The bottom line, about this new } \\
\text { opportunity, is that I was just } \\
\text { glad to have a job, like anybody } \\
\text { would. }\end{array}$ & $\begin{array}{l}\text { addressing the 'elephant in the } \\
\text { room' and really saying black } \\
\text { on white: this is what's going to } \\
\text { happen; these teams are not } \\
\text { going to get impacted. }\end{array}$ \\
\hline \multicolumn{3}{|c|}{ ( } \\
\hline $\begin{array}{l}\text { I knew that the idea was to hire } \\
\text { people just to perform these } \\
\text { trainings, but when I arrived I } \\
\text { saw that there was a lot of space } \\
\text { for me to develop (...) I have a } \\
\text { career path in my mind and till } \\
\text { now, with } 8 \text { months in this } \\
\text { company this career path is } \\
\text { becoming real quicker than I } \\
\text { thought. }\end{array}$ & $\begin{array}{l}\text { I am a project manager but } \\
\text { unfortunately we lost that client } \\
\text { (...) Our main focus is in the } \\
\text { mining and construction } \\
\text { industries. So yes, we were } \\
\text { impacted by the market, and the } \\
\text { situation and yes, people had to } \\
\text { leave unfortunately (...) I have } \\
\text { having all these meetings with } \\
\text { the CEO and the chairman and I } \\
\text { was constantly receiving } \\
\text { messages and clues and being } \\
\text { communicated with that 'your } \\
\text { position is secure' so I had this } \\
\text { sense that OK, the company is } \\
\text { going through this very difficult } \\
\text { process but I will survive. }\end{array}$ & $\begin{array}{l}\text { In this last year my company } \\
\text { has been going through a } \\
\text { restructuring process: most job } \\
\text { positions are being redeveloped } \\
\text { or changed with different job } \\
\text { positions (...) So what I am } \\
\text { focusing on now is to pursue } \\
\text { other opportunities to be a } \\
\text { project manager with other } \\
\text { clients. There is a lot of new } \\
\text { work on the pipeline and I am } \\
\text { expecting to move a little bit } \\
\text { more to that space. }\end{array}$ \\
\hline \multicolumn{3}{|c|}{ ( } \\
\hline $\begin{array}{l}\text { Part of the incentive to come } \\
\text { over here was that they actually } \\
\text { made me an employee with a } \\
\text { career path, because at that point } \\
\text { I was kind of stalled where I } \\
\text { was and the GFC hit and I } \\
\text { wasn't sure what the next step } \\
\text { was (...) It is quite easy to find } \\
\text { another job in my current level } \\
\text { of experience (...) I think } \\
\text { people have this perception that } \\
\text { you can come here and just get a } \\
\text { job; I don't think that's true } \\
\text { across all the skills; I think they } \\
\text { still want a very specific } \\
\text { package of skills and knowledge } \\
\text { so I'm lucky that I've got quite } \\
\text { a lot of that. }\end{array}$ & $\begin{array}{l}\text { Australia is contracting so the } \\
\text { job has become a lot less than } \\
\text { what it was when I first got here } \\
\text { so I am stuck with a job that I } \\
\text { can do with my eyes closed and } \\
\text { hands tied behind my back } \\
\text { that's got no career prospects } \\
\text { and has already become a lot } \\
\text { less than what it was (...) I have } \\
\text { a really good set of skills; I am } \\
\text { very employable so it is a good } \\
\text { time for me to go. }\end{array}$ & $\begin{array}{l}\text { My partner was transferred to } \\
\text { Toronto, and there was no } \\
\text { (company's) office in there, so I } \\
\text { resigned. So I haven't been } \\
\text { working for a year. }\end{array}$ \\
\hline \multicolumn{3}{|l|}{ P24 } \\
\hline $\begin{array}{l}\text { So I came to Perth to a different } \\
\text { company within the group (...) } \\
\text { After a year, which is unusual, I } \\
\text { got a promotion, and the } \\
\text { company was ready to fulfill } \\
\text { many of my demands (...) like } \\
\text { travel, projects in other } \\
\text { countries, training courses, they } \\
\text { were always trying to fulfill it } \\
\text { (...) I use to receive job offers } \\
\text { twice a week, at least once a } \\
\text { week for Australia. }\end{array}$ & $\begin{array}{l}\text { The company has lost big, big } \\
\text { projects very recently (...) you } \\
\text { know this is not the only } \\
\text { company that is having this } \\
\text { trouble in terms of work, in } \\
\text { terms of project and everything, } \\
\text { many companies are facing the } \\
\text { same worldwide in this industry. } \\
\text { So in terms of expectations in } \\
\text { this job, I still feel pretty safe } \\
\text { with this job, with the work that } \\
\text { I have in the company right } \\
\text { now. And we do have many } \\
\text { proposals in the market right } \\
\text { now and I am pretty confident } \\
\text { that I will still have work to do } \\
\text { (...) In the rest of the world I } \\
\text { think the industry is still going }\end{array}$ & $\begin{array}{l}\text { (The employer) offered me this } \\
\text { position (in Indonesia) in mid } \\
\text { last year and so that's when } \\
\text { pretty much the market in } \\
\text { Australia started going down a } \\
\text { little bit. I can't say that I didn't } \\
\text { see any threats to my position in } \\
\text { Australia but it was kind of a } \\
\text { little bit complicated because we } \\
\text { had pretty much no job back in } \\
\text { Australia and not much to do } \\
\text { there and no good future coming } \\
\text { up. }\end{array}$ \\
\hline
\end{tabular}




\begin{tabular}{|c|c|c|}
\hline & $\begin{array}{l}\text { all good, it is really good in the } \\
\text { US, and the head-hunters are } \\
\text { searching for anywhere you can } \\
\text { imagine, like Emirates, } \\
\text { Singapore, very few for } \\
\text { Australia. }\end{array}$ & \\
\hline \multicolumn{3}{|l|}{ P25 } \\
\hline $\begin{array}{l}\text { I wouldn't have just flown over } \\
\text { here if there weren't } \\
\text { opportunities for us to find work } \\
\text { (...) The other thing was that the } \\
\text { Visa that we came in on was a } \\
\text { Skilled Migration Visa so } \\
\text { basically my profession is on } \\
\text { the list of skills that they are } \\
\text { requiring so that also made a } \\
\text { difference for me because I } \\
\text { wouldn't have come over here if } \\
\text { there wasn't an opportunity and } \\
\text { I would just be struggling all the } \\
\text { time for work. }\end{array}$ & $\begin{array}{l}\text { I think at the moment (this } \\
\text { university) is going to go } \\
\text { through a couple of tough years; } \\
\text { I think the whole industry is } \\
\text { going to go through a couple of } \\
\text { tough years. So with the } \\
\text { changes that have just been } \\
\text { announced in the Gonski } \\
\text { Review and things like that and } \\
\text { there is this } 2015 \text { Half Cohort } \\
\text { coming which is also going to } \\
\text { knock off a couple of students } \\
\text { going into the sector (...) (this } \\
\text { company) is going to have some } \\
\text { structural changes (...) so I must } \\
\text { say at the moment I don't have } \\
\text { massive expectations about } \\
\text { what they are able to do. }\end{array}$ & $\begin{array}{l}\text { There are a lot of changes in the } \\
\text { industry but they are all } \\
\text { contraction changes rather than } \\
\text { expansion changes (...) at the } \\
\text { same time, I think we made a } \\
\text { decision as a family unit when } \\
\text { (baby) came along that we } \\
\text { found that for me to go into a } \\
\text { promoted role it would mean a } \\
\text { lot of travelling and, as a family } \\
\text { unit, we decided that... well, } \\
\text { (daughter) is now } 16 \text { months, } \\
\text { but at least for the first } 2 \text { to } 3 \\
\text { years it is not viable. So I think } \\
\text { that's why we have put those } \\
\text { plans on hold a bit. }\end{array}$ \\
\hline \multicolumn{3}{|c|}{ ( } \\
\hline $\begin{array}{l}\text { there are a lot of opportunities } \\
\text { within the company. There are } \\
\text { opportunities even if I want to } \\
\text { go overseas, because they have } \\
\text { many offices (...) In this } \\
\text { industry it would be absolutely } \\
\text { easy (to get another job). I am } \\
\text { getting offers every week, } \\
\text { obviously because it is a boom } \\
\text { time. }\end{array}$ & $\begin{array}{l}\text { The labour market has changed } \\
\text { and it is not that they have } \\
\text { power, they probably have no } \\
\text { choice when they have to let } \\
\text { someone go (..) Getting } \\
\text { another job now it would be } \\
\text { more difficult than two years } \\
\text { ago, by at least } 30 \text { or } 40 \text { per } \\
\text { cent. You know that I have } \\
\text { completely swop industries } \\
\text { from ship building to pipeline } \\
\text { design, so if I was trying to do it } \\
\text { today I would not be able to do } \\
\text { that. Two years ago they were } \\
\text { actually looking for anyone with } \\
\text { any kind of engineering } \\
\text { experience, to make an easy } \\
\text { transition. Today they have } \\
\text { available all these skilled } \\
\text { people! }\end{array}$ & $\begin{array}{l}\text { I opened the (recruitment) } \\
\text { website for curiosity more than } \\
\text { anything, and disappointment } \\
\text { with my previous position (...) } \\
\text { They called me immediately the } \\
\text { day after, and from that point it } \\
\text { went very quickly, and I just left } \\
\text { a bit of space to be sure that it } \\
\text { was that what I wanted, because } \\
\text { my previous employer was a } \\
\text { very safe company. Even if I } \\
\text { wasn't very happy, I was well } \\
\text { paid, and I was secure (...) The } \\
\text { market is getting quiet, you } \\
\text { probably heard of that. It is } \\
\text { quite across the board, so it is } \\
\text { affecting our company as well. } \\
\text { At this point, in that case, all } \\
\text { you can expect is to survive. I } \\
\text { was promoted the other day, but } \\
\text { at the same time, there were } \\
\text { some cuttings in our wages. }\end{array}$ \\
\hline
\end{tabular}

Table A.1. Longitudinal comparison of Changes According to participants' perceptions. 
- This Appendix contains the 'interview maps' for each of the 26 highly skilled immigrants that participated in at least one phase of this study. The code on top of the page of his/her map (P01, for example) is the same used to identify one's quote along the report.

- These maps aim to illustrate the main events and feelings reported by these individuals, but they do not contain all aspects mentioned by them.

- Each individual who participated in Phase 3 received a copy of his/her map (with the two previous phases) for review.

- The profile information presented on top of the page refers to Phase 1 of data collection. If they changed visa status, employer, sector, or role along the period of research, this will be mentioned in the map. 
A8. P01 (P01) Male, accountant, Brazil, post-grad, 457 (came with student visa for post-grad), professional, small business (wholesales)

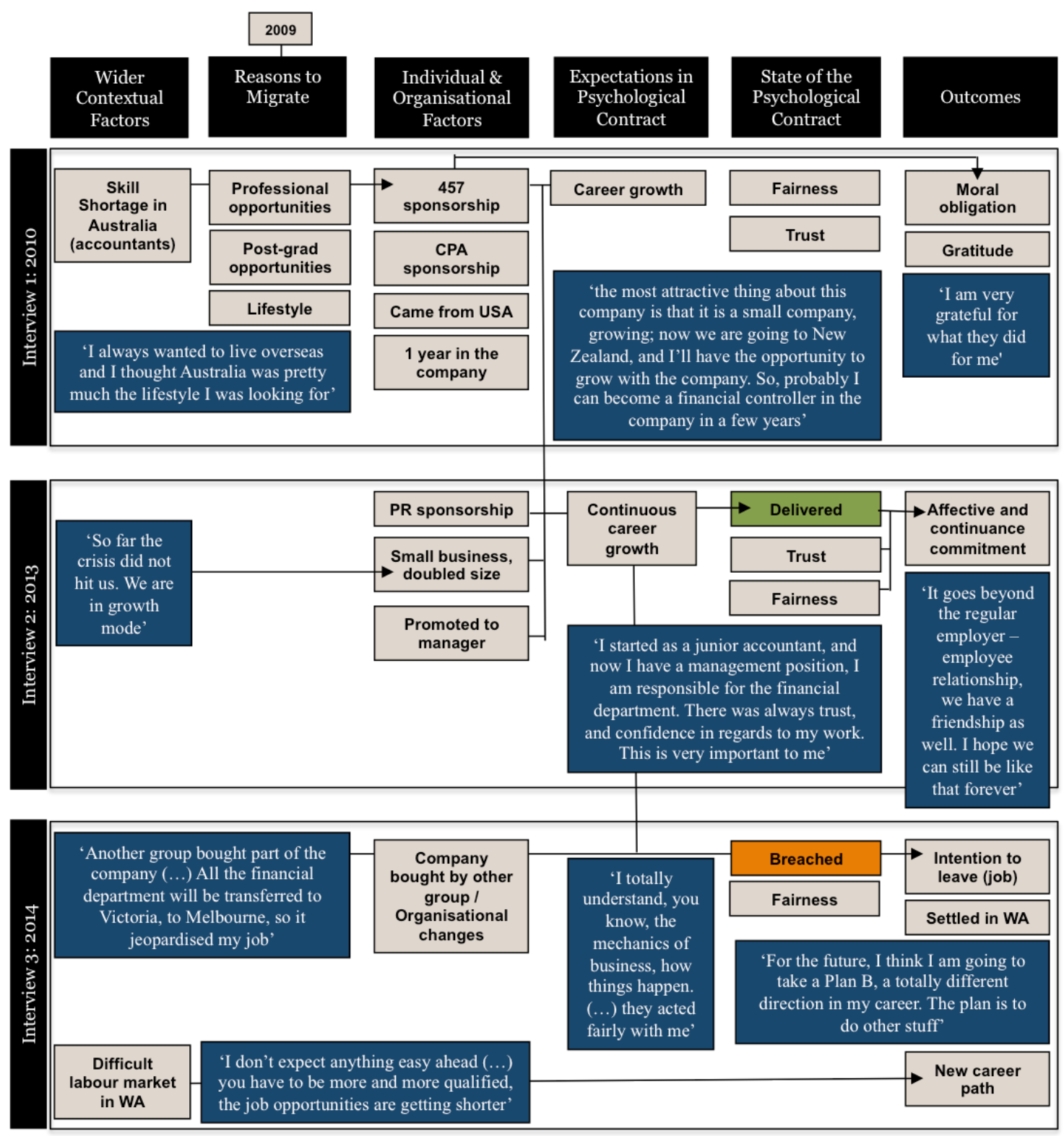

'I think my expectations (with immigration) were fulfilled. I got into the market quickly, you know, according to what I was expecting' (2014)

'I call Australia my home now; I am now an Australian citizen. I think I will always be a foreigner. I always feel like that, but it is up to you how you are going to deal with that. I am settled here' (2014) 


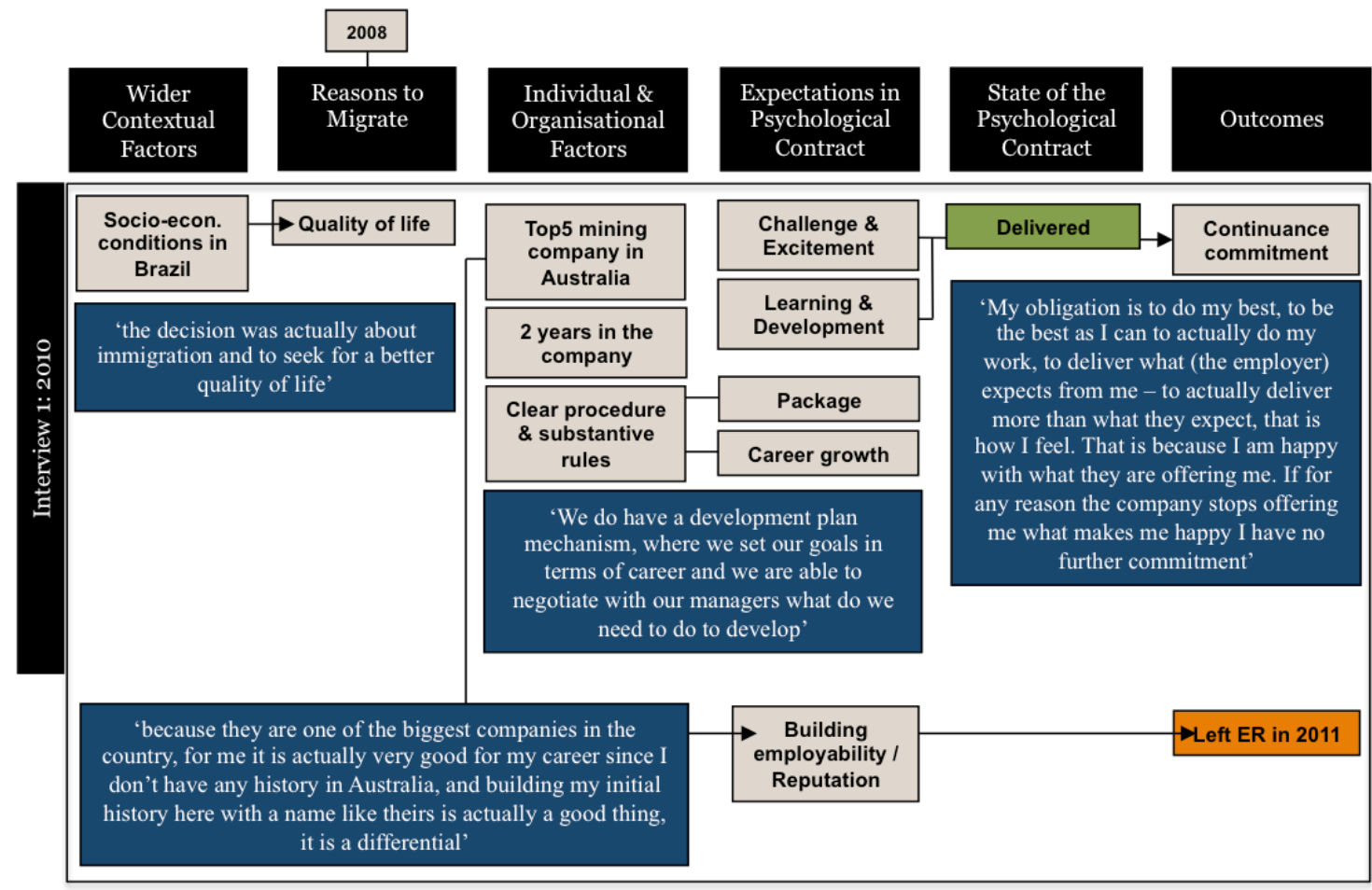

P02 left this job in 2011 and opened his own management consultancy business following market opportunities. As a contractor, without a typical ER, his second interview was discharged. 

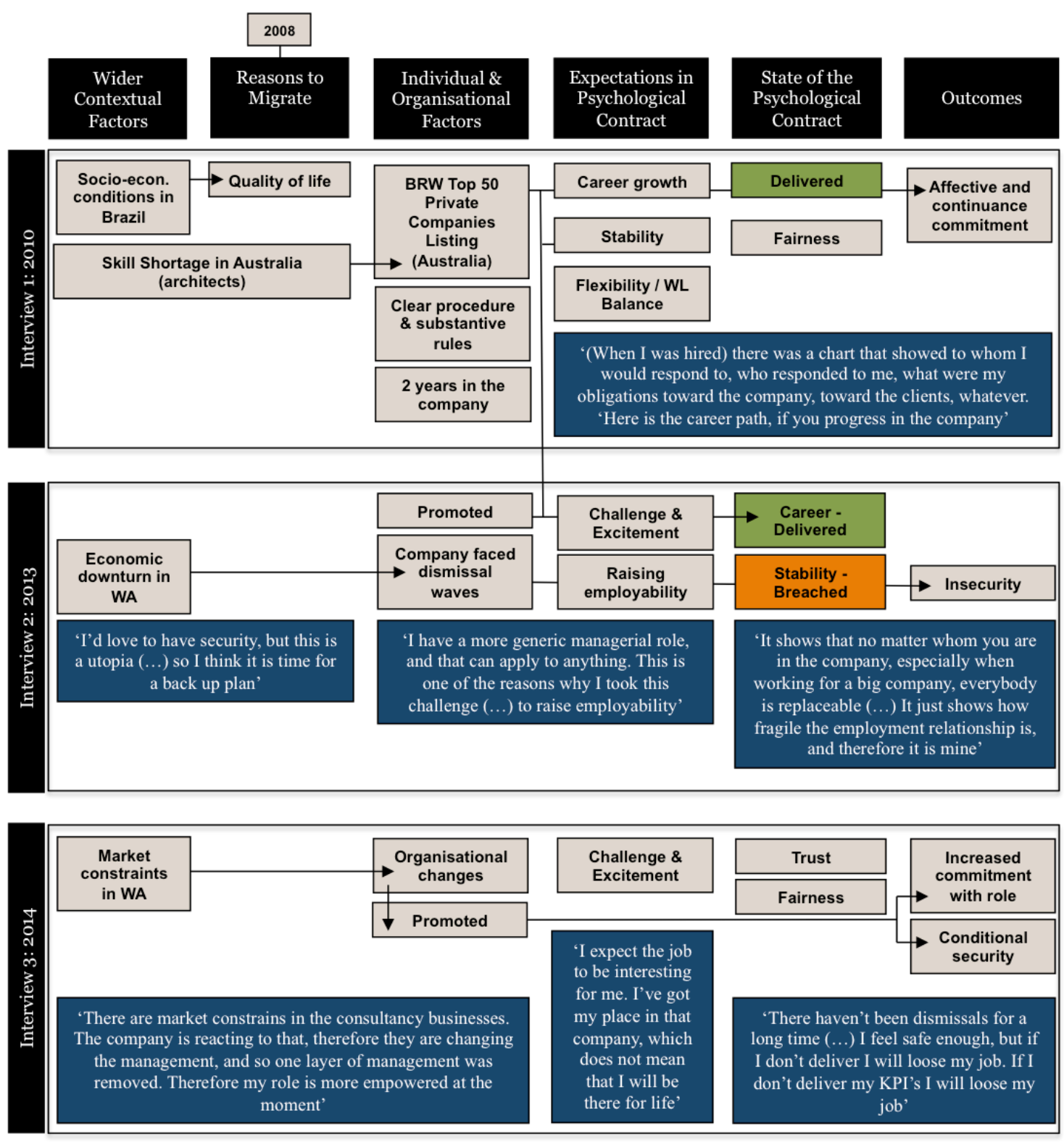

'Financially (expectations) have been fulfilled, because of the job, because of the people I deal with, because of the work I put out, they have been fulfilled. The importance of work in my life, that is what changed, more than ever. It was priority number one when we made the move. So now my priority changed, and the job is just a job' (2014)

'I have changed. I am a converted ozzie, I am an Australian with a Brazilian background, I am no longer a Brazilian trying to understand what Australia is' (2014) 


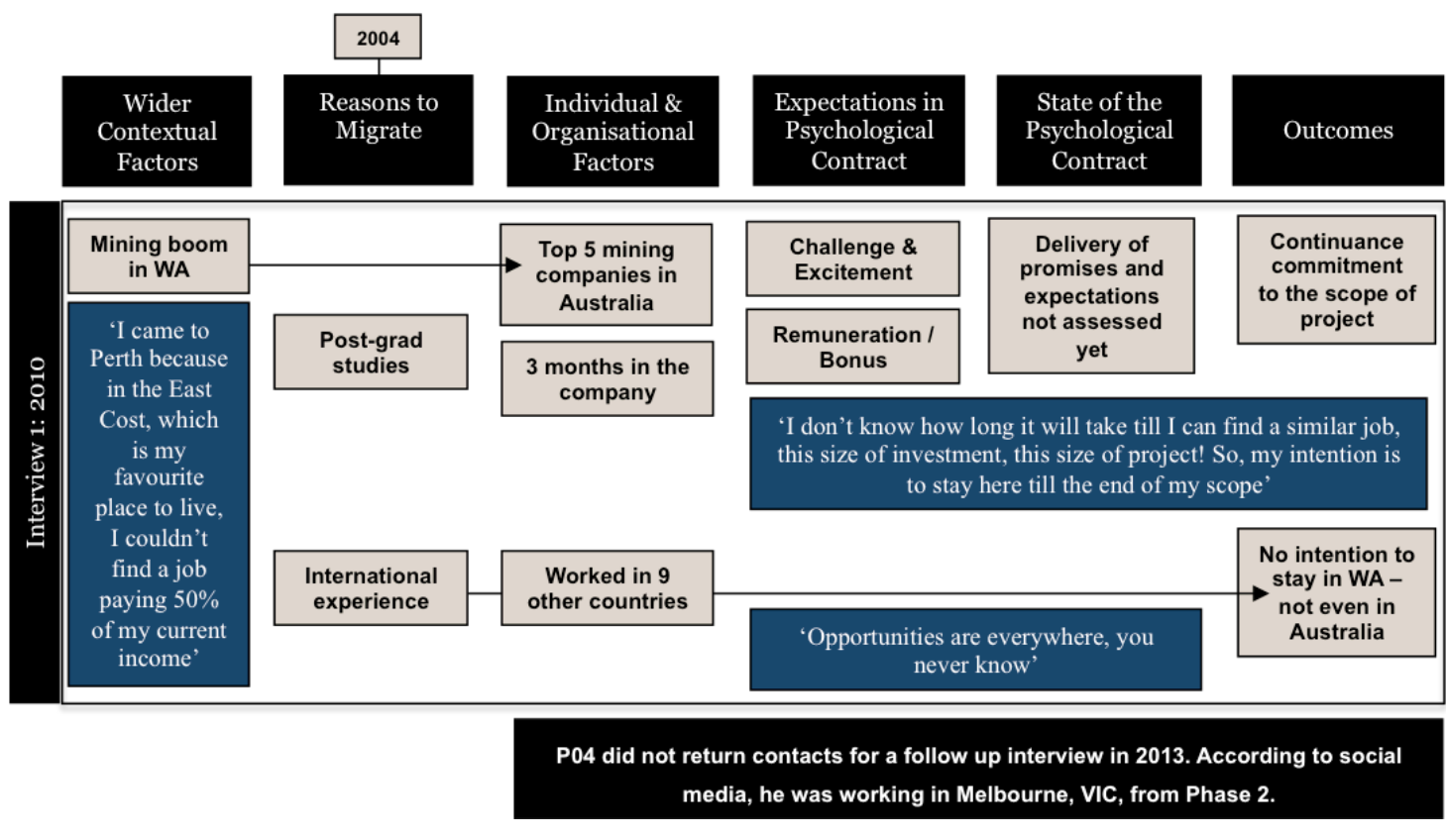




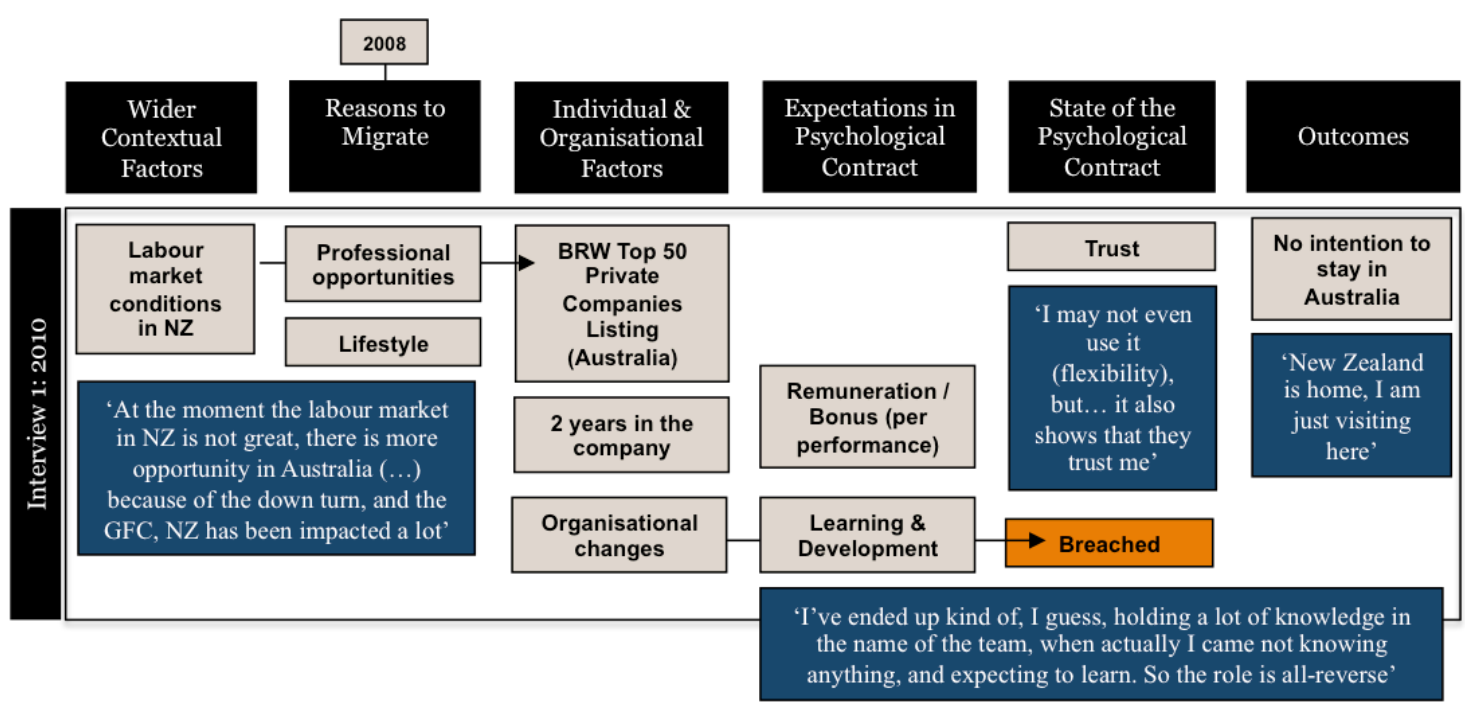

P05 did not return contacts for a follow up interview in 2013. According to social media, she was back in Auckland from Phase 2, working for the same organisation. 


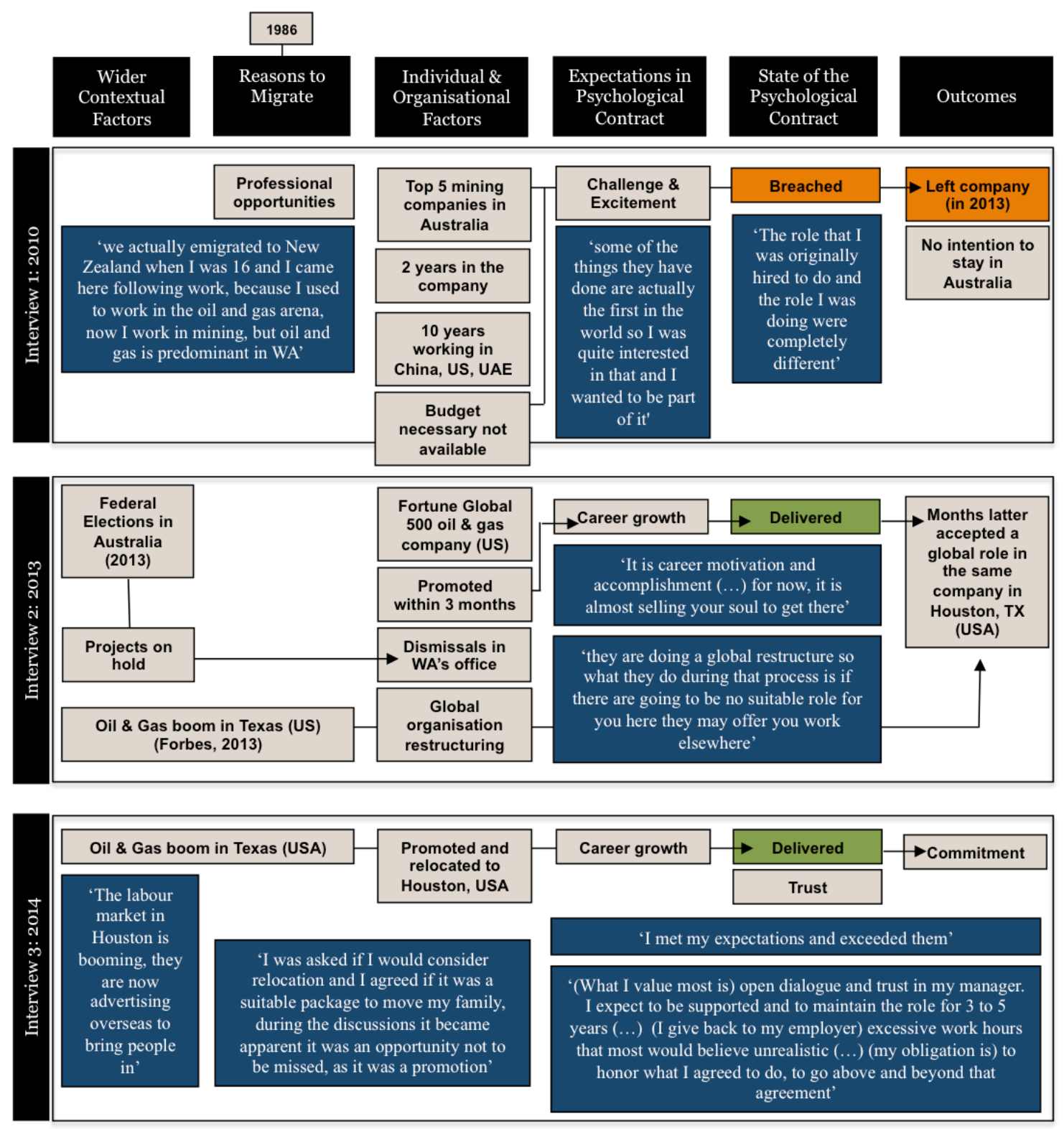

'I don't think security is long term in any organisation in $21^{\text {st }}$ Century, we all have a life span within (companies) where either party decides its hit the limit of success in the relationship, I think 5 years is a realistic number. I have limited expectations on this, I understand the market, so you simply plan for the future and ensure your ahead of the game in your area' (2014)

'As far as the work environment in general I see Houston booming where Australia is in a slump, which I don't see changing in the next couple of years, I think the US will gain momentum and this will be an oil and gas hub again of expats, this is the place to be for the next few years' (2014) 

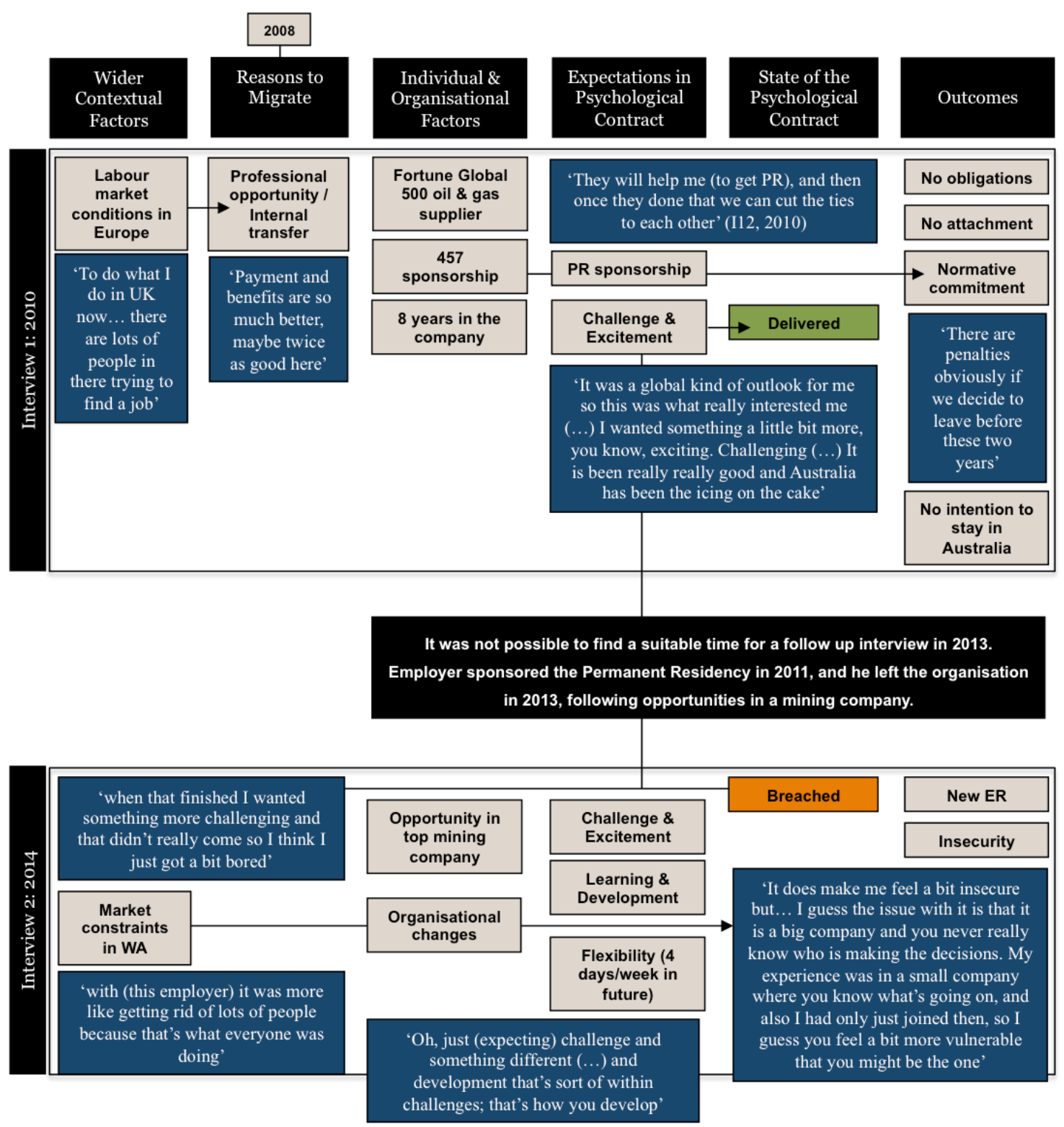

'This wasn't a long term goal coming to Australia; it was like an accident basically (...) In terms of expectations I don't think we could have done much better really. It has all worked out; I didn't lose my job in 2010 or 2011 or whatever it was; I didn't lose my job two months ago; I am enjoying my work(...) I have come a long way in my career and I think we have come a long way as a family and our kids are getting older and older. It has sort of evolved into something bigger but we still don't have a long term plan here, not really' (2014) 


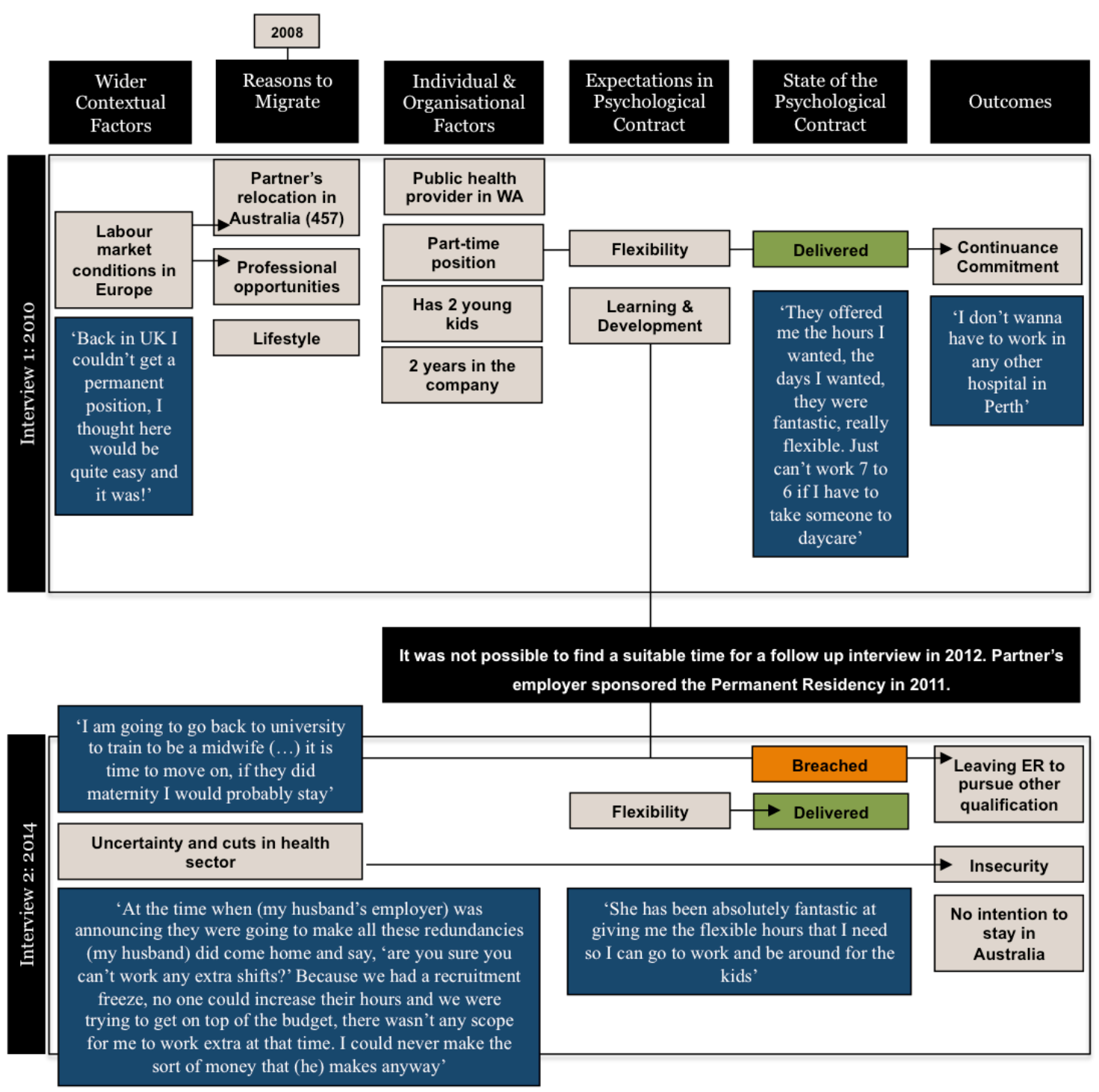

'When I think of my work related expectations before moving here, I think at that time maybe I was just really naive; we had just had a baby and having recently graduated as a nurse and thinking that I would progress my career as well as have babies; well it didn't quite work out like that. So I think that would have happened regardless of whether we had moved to Australia or not. But part of the past years for me is that there is definitely some disappointment about not having progressed in my career as I would have liked to have, but the opportunities were there if I had wanted them' (2014)

'I would like to (leave); it is that it is a big decision - isn't it with the kids? It is almost easier to stay put. I know in my heart I would like to work in lots of different places; I'd like to work in the outback or go to Africa in the future' (2014) 


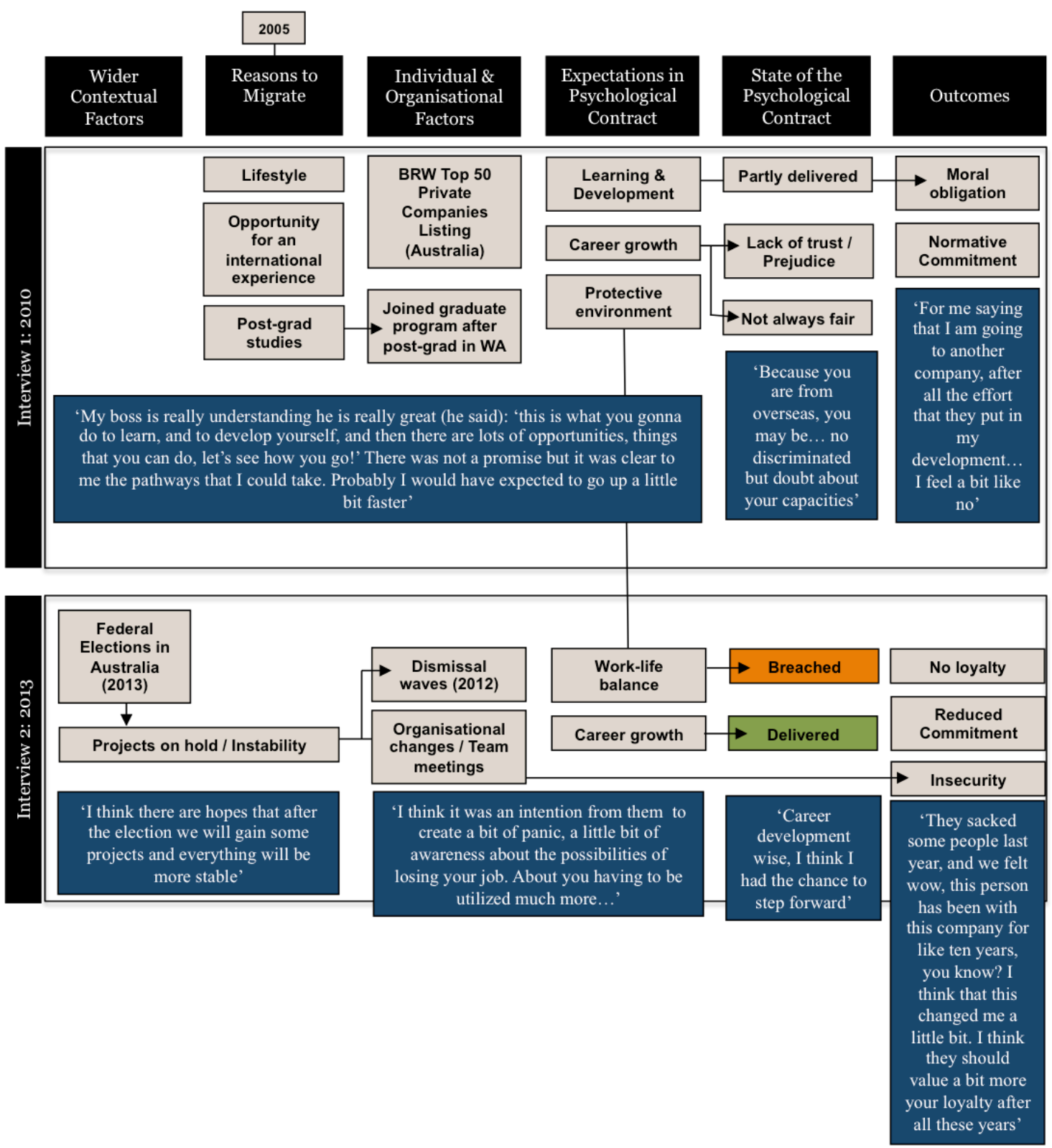

P09 did not return contacts for a follow up interview in 2014. According to social media she was still in the same position, with same employer. 


Wider
Contextual
Factors
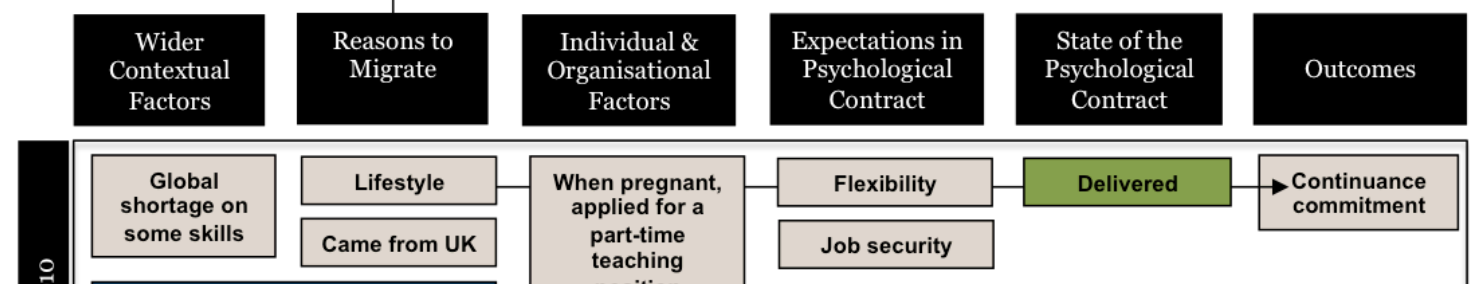

'Physiotherapy has given us the opportunity to move $(. .$.$) because$

we went to England because of a

job that I got there (...) and we

went on my skills for our PR when we came to Australia'

\begin{tabular}{|l|}
\hline $\begin{array}{c}\text { When pregnant, } \\
\text { applied for a } \\
\text { part-time } \\
\text { teaching } \\
\text { position }\end{array}$ \\
\hline Training college \\
\hline $\begin{array}{c}2 \text { years in the } \\
\text { company }\end{array}$ \\
\hline
\end{tabular}

'I phoned two hospitals, and one of them (...) offered me contract employment within a few days. Then we both had full time jobs within two months of arriving'

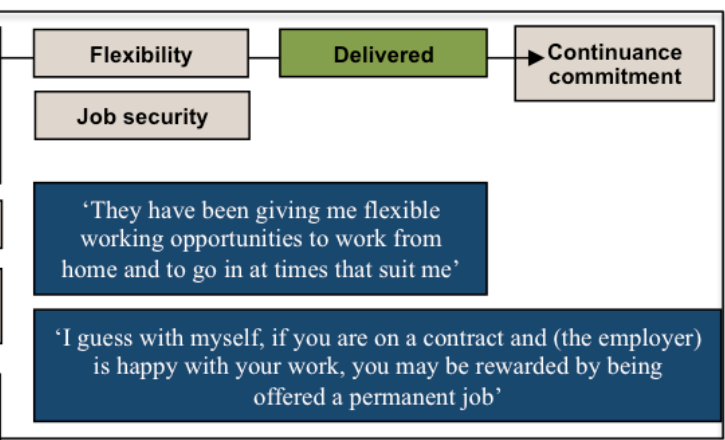

'They have been giving me flexible

working opportunities to work from

guess with myself, if you are on a contract and (the employer) offered a permanent job'

It was not possible to find a suitable time for a follow up interview in 2012.

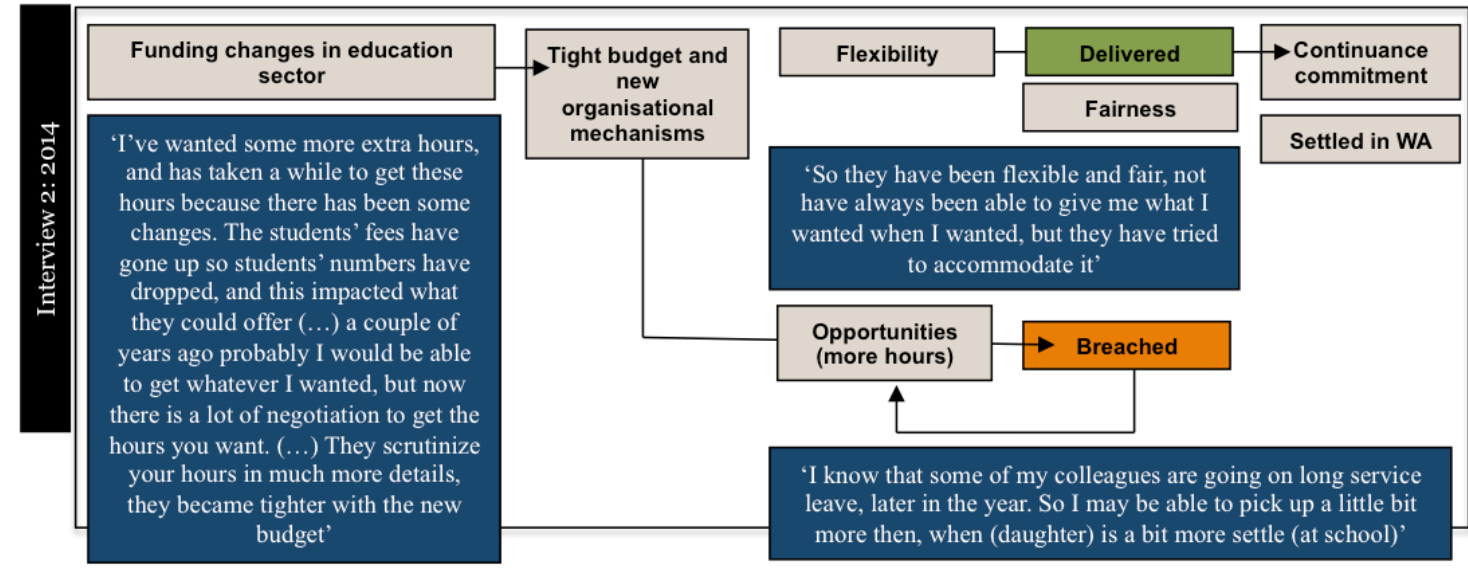

'When I first arrived, I didn't really like it here, but now that I have children I feel much more part of the community, I feel like I belong here more. This is what has changed in the past few years. And because I feel I am more part of the community, I also like to contribute by doing a good job. I feel we are quite settled here now; it has been eight and a half year. I don't see us moving elsewhere unless my husband's job takes us somewhere. Because my child starts school now, I don't want to move her around too much' (2014) 

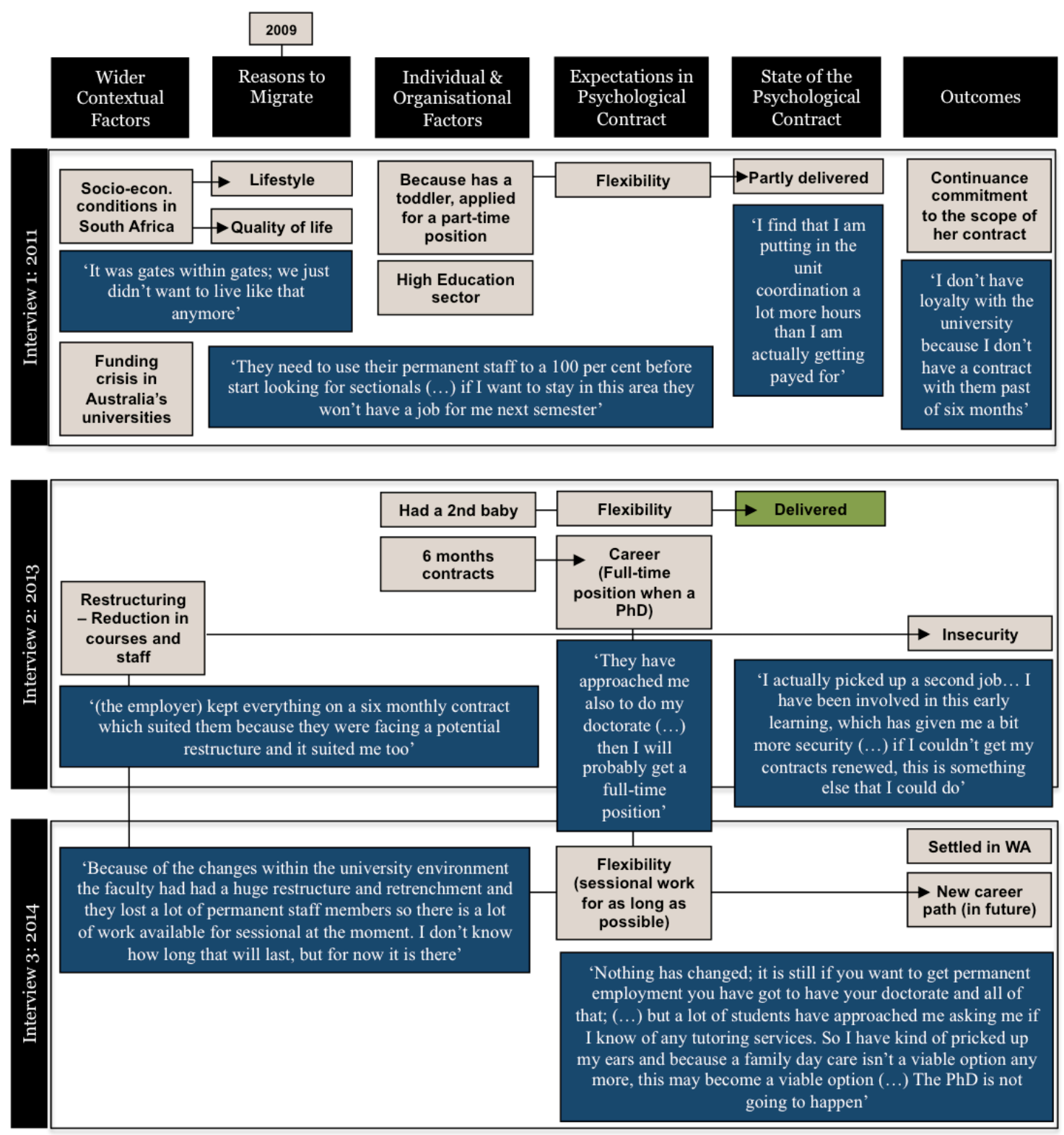

'I can't tell you the last time I was homesick because I can't remember. This is home so that to me has been the biggest thing. We are giving up our South African citizenship. (...) I like Perth and I would love to stay in Perth but I also realise if it doesn't happen we will go and live somewhere else. I think that's the one thing that's switched on for me is that I'm not anchored to a particular place necessarily any more. If we had a situation where we were struggling to find work I'd go and live in Brisbane or Melbourne or wherever" (2014) 


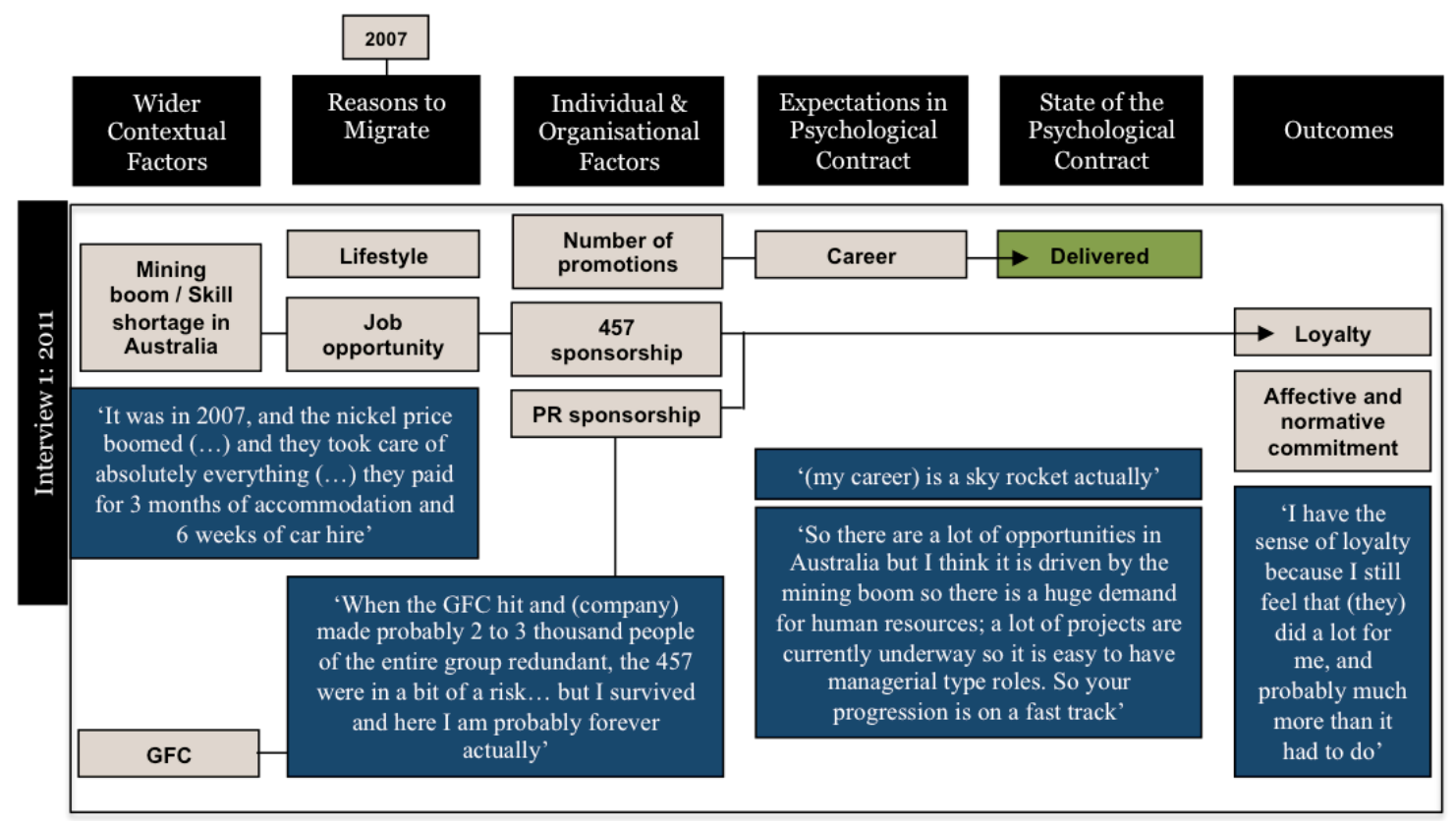

It was not possible to find a suitable time for a follow up interview in 2013 or 2014. However, P12 continued with the same employer along the period of this research. 


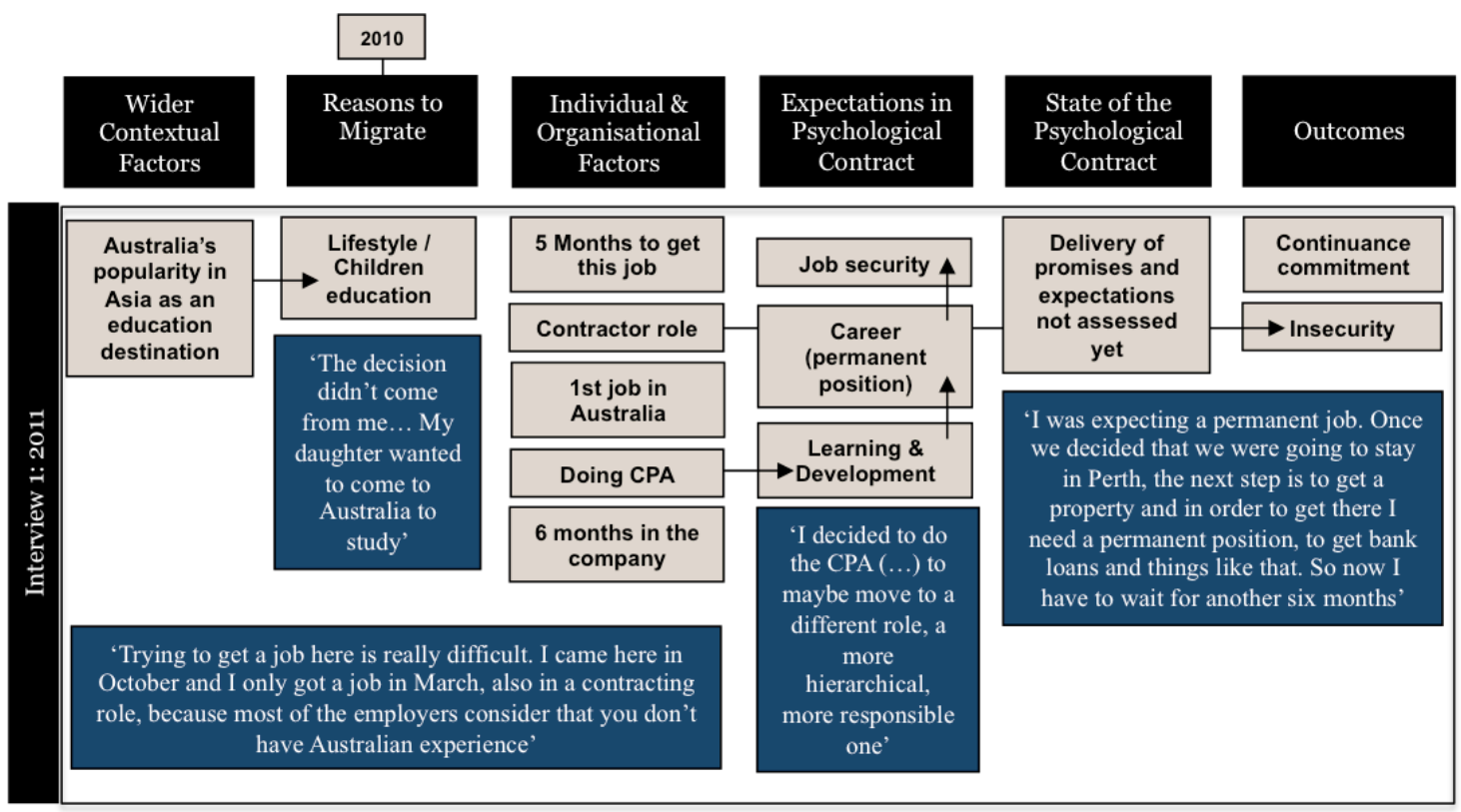

P13 did not return contacts for a follow up interview in 2013 or 2014. 

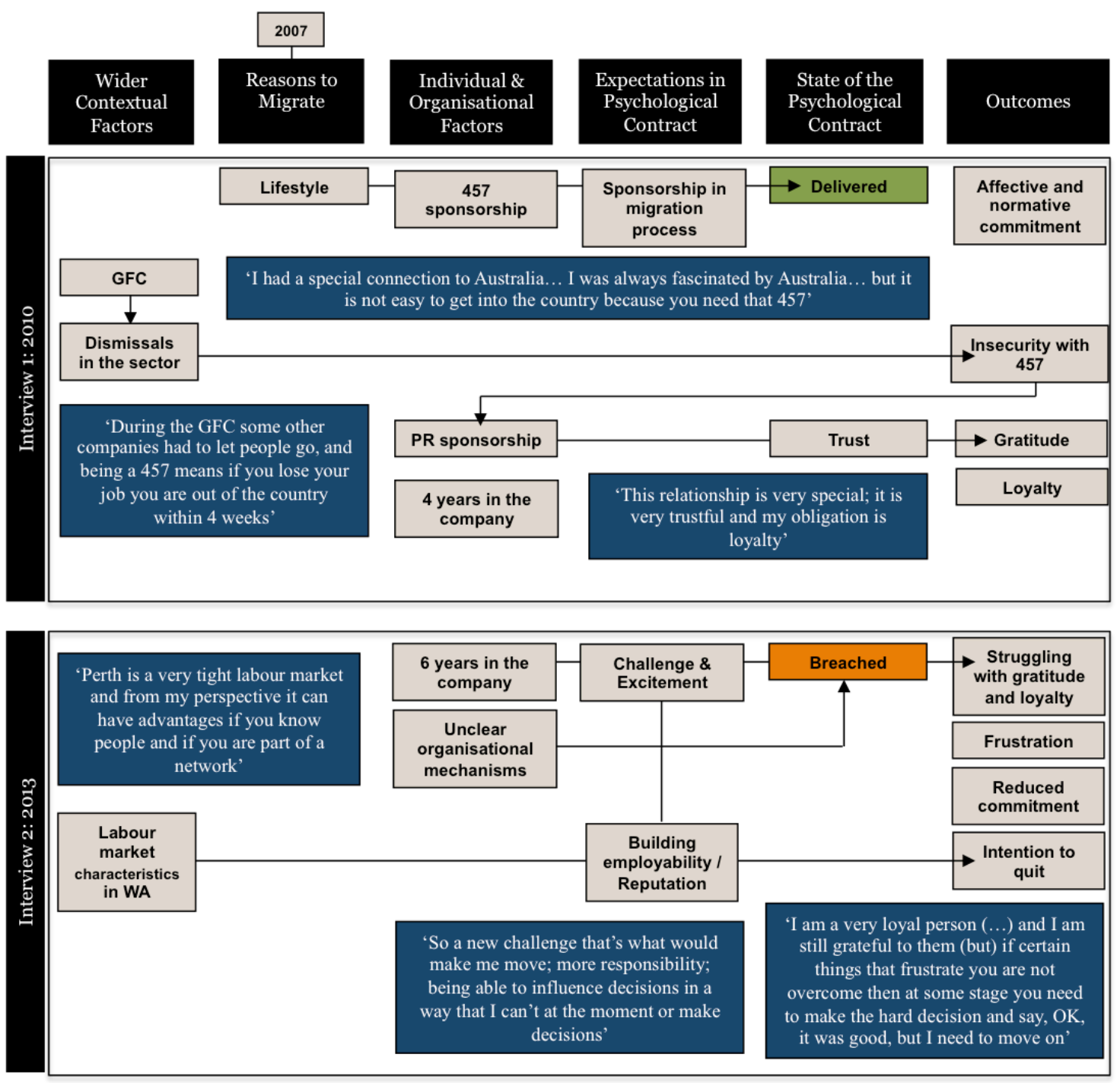

It was not possible to find a suitable time for a follow up interview in 2014. P14 left his employer shortly after Phase 2 though, joining another consulting organisation. 


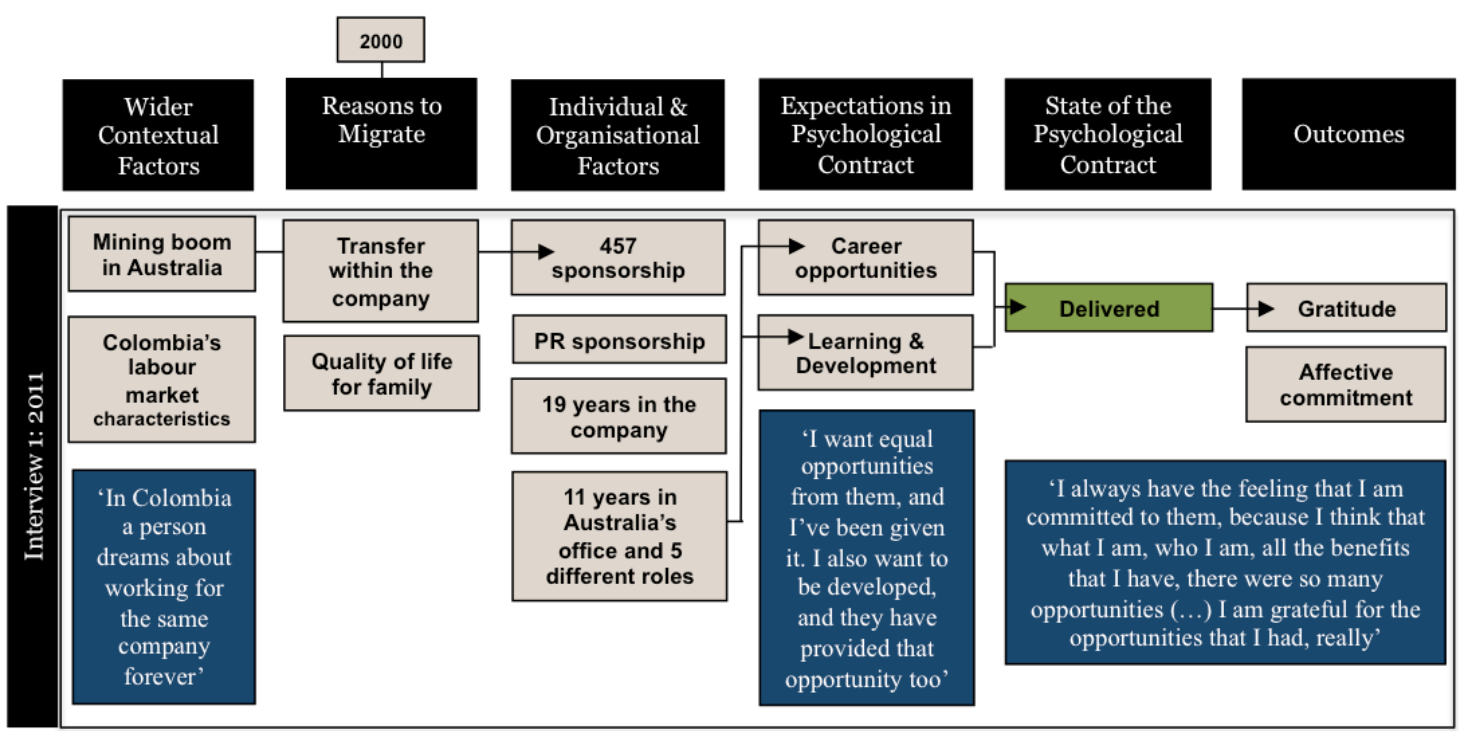

P15 did not return contacts for a follow up interview in 2013. According to social media, she was transferred to Melbourne, and was still working for the same organisation in Phase 2. 


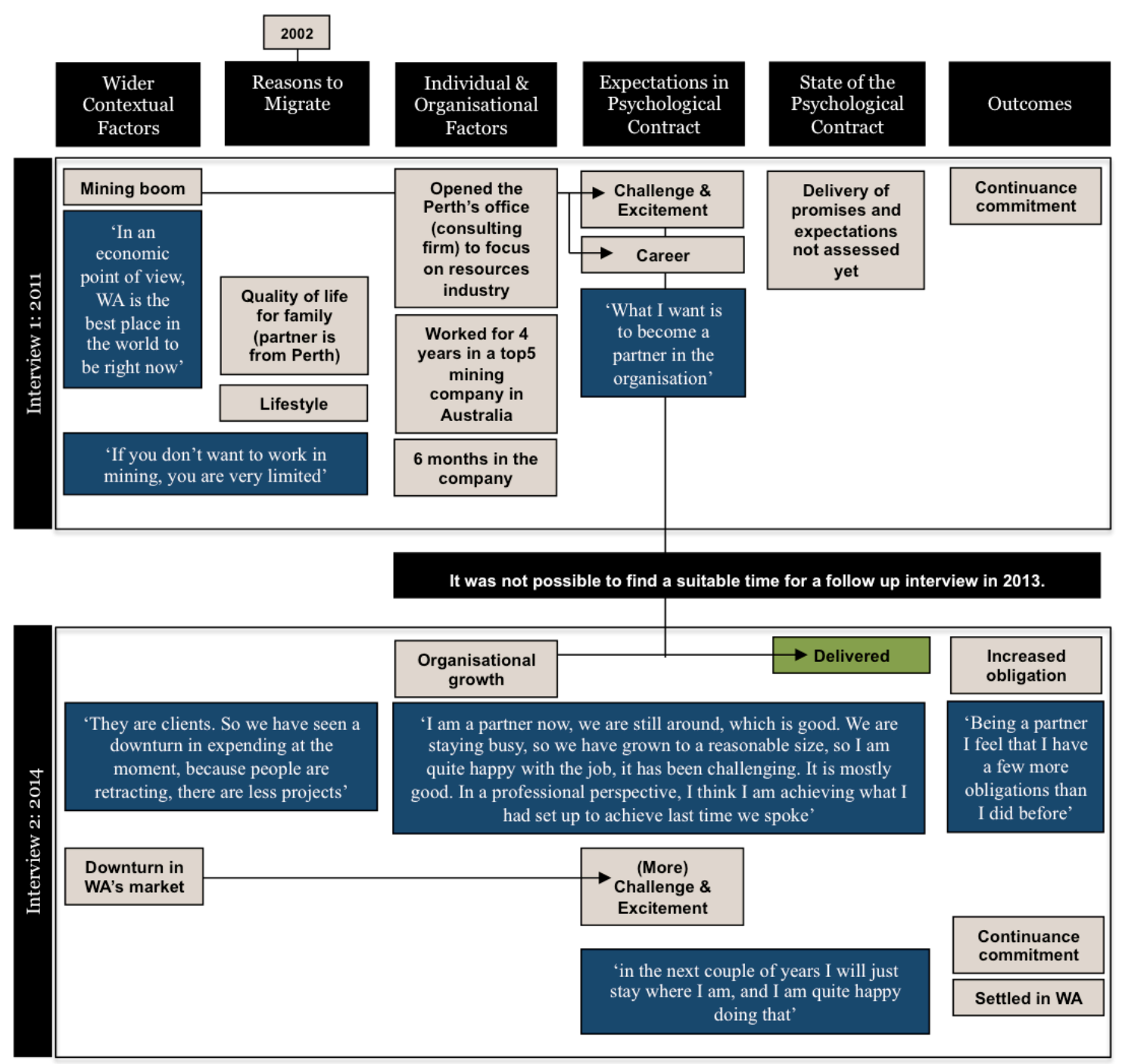

'Just for being older, and having kids, this is probably (what has changed) more than anything else. And maybe my expectations regarding what is important in life... I came here and life is very different from what it would be back in the States, generally. Maybe what was more important there is not so important here, and that is not a bad thing. We have more lifestyle, kids focused, and that is what is really important' (2014) 

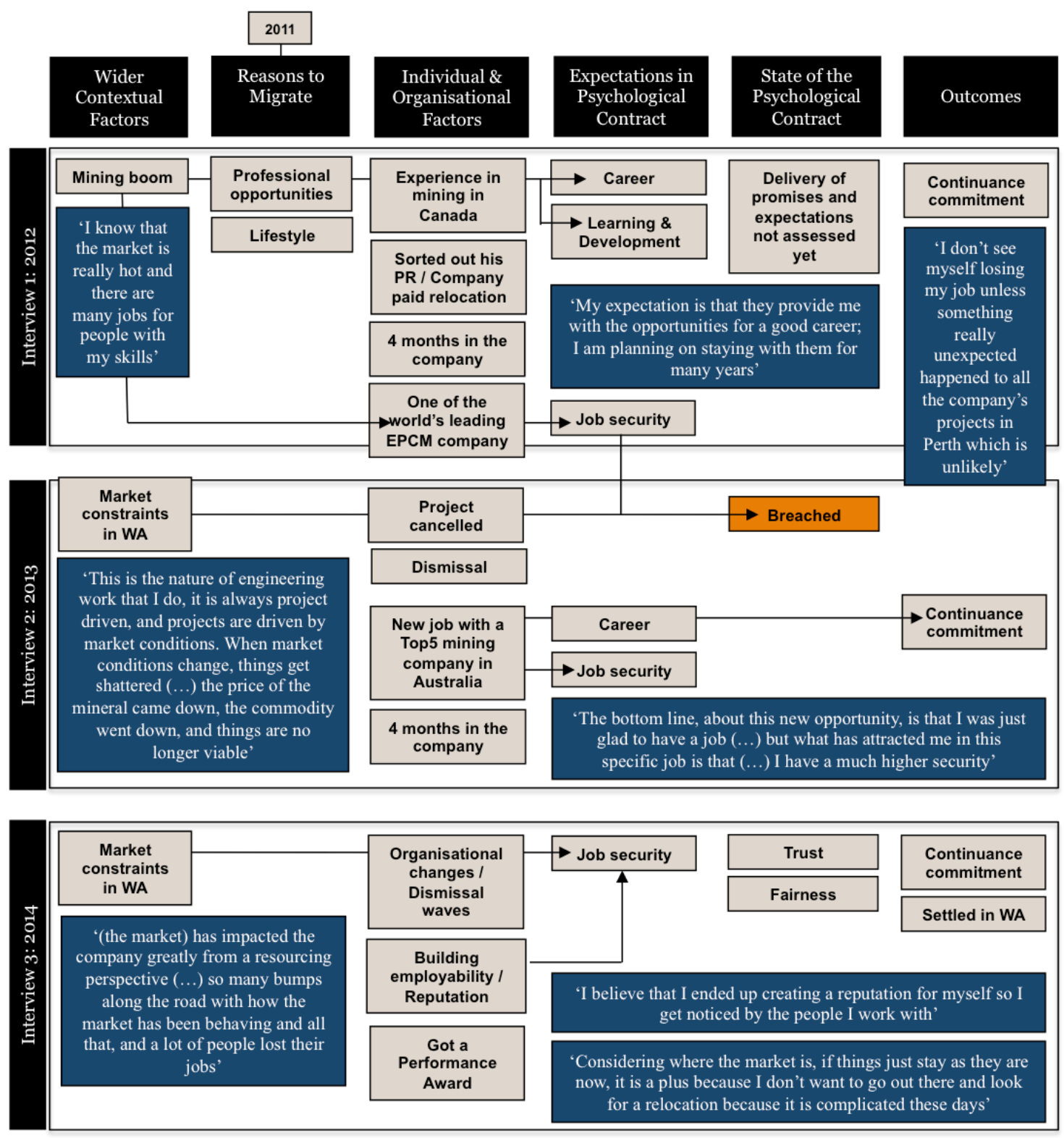

'Australia has paid off very well in that regard: when one door closed the door that opened was a way better opportunity than I would have thought, particularly at that time. When we immigrated here the job was great, but this is better (...) We are not going anywhere' (2014)

'A lot has changed but if I could put it into one sentence, I think the experiences over the last four years have put me at ease in understanding that things will be alright in this place. I think it is the serenity of knowing that things will be alright' (2014) 


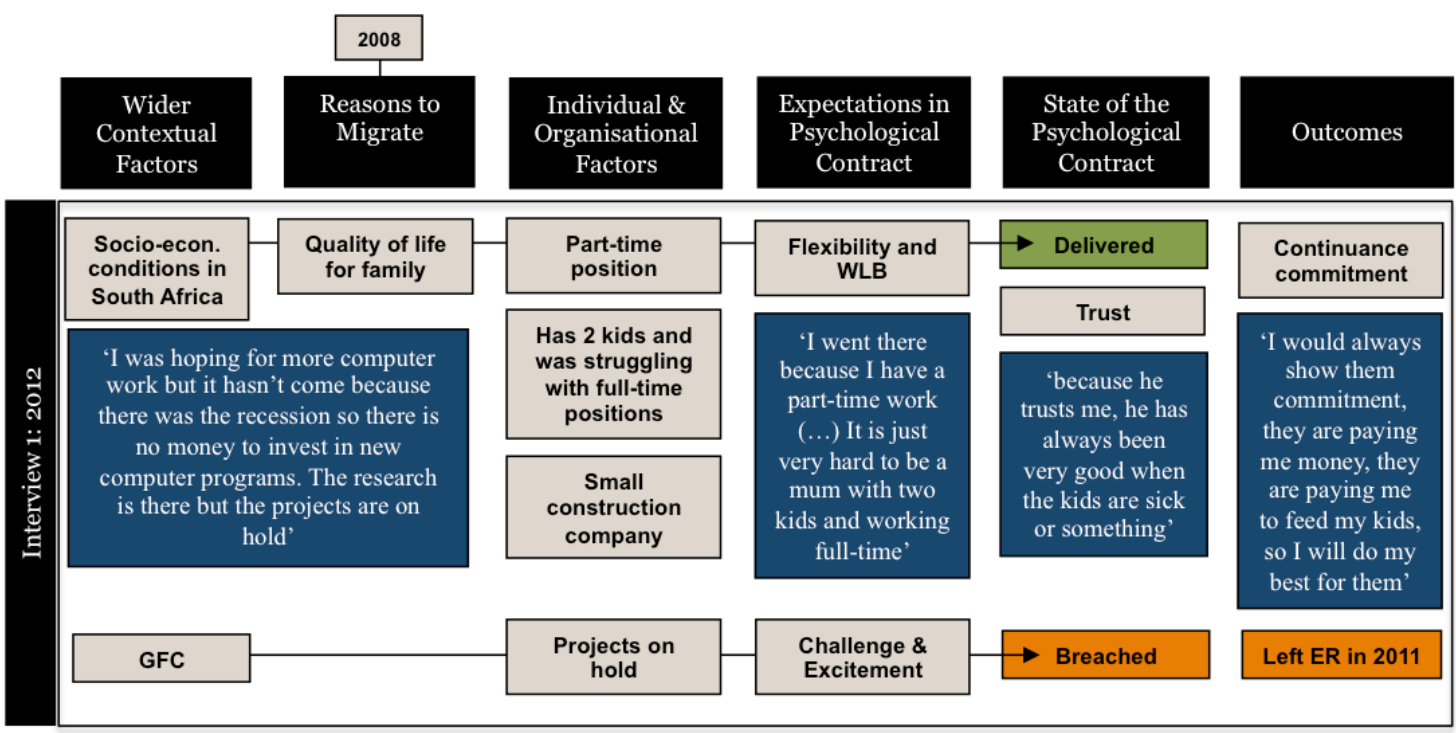

P18 left this job in 2013 and opened her own consultancy business, following market opportunities. As a contractor, without a typical ER, her second interview 


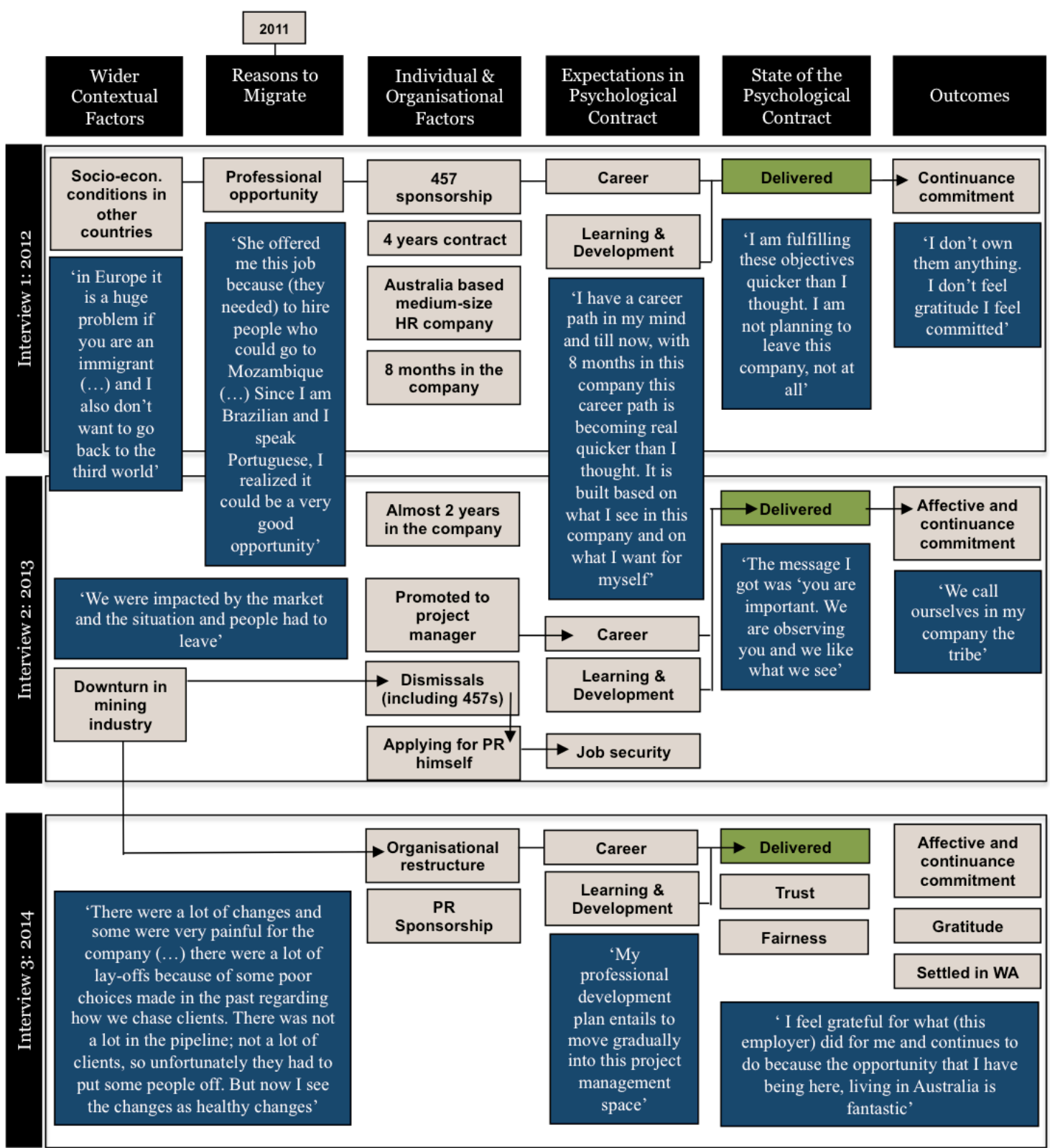

'Yes, our plan is to stay. If I could do whatever I wanted in my life and if I was a millionaire I would live in Italy. That's where I would like to live with its great culture, but the plan for me and my family is to do whatever we can to stay in Australia and possibly forever. They have job opportunities here; the country is safe and organised so yes, we will do whatever we can to stay. I feel in control of my safety; I feel in control of my quality of life and so I have this sense of belonging' (2014) 


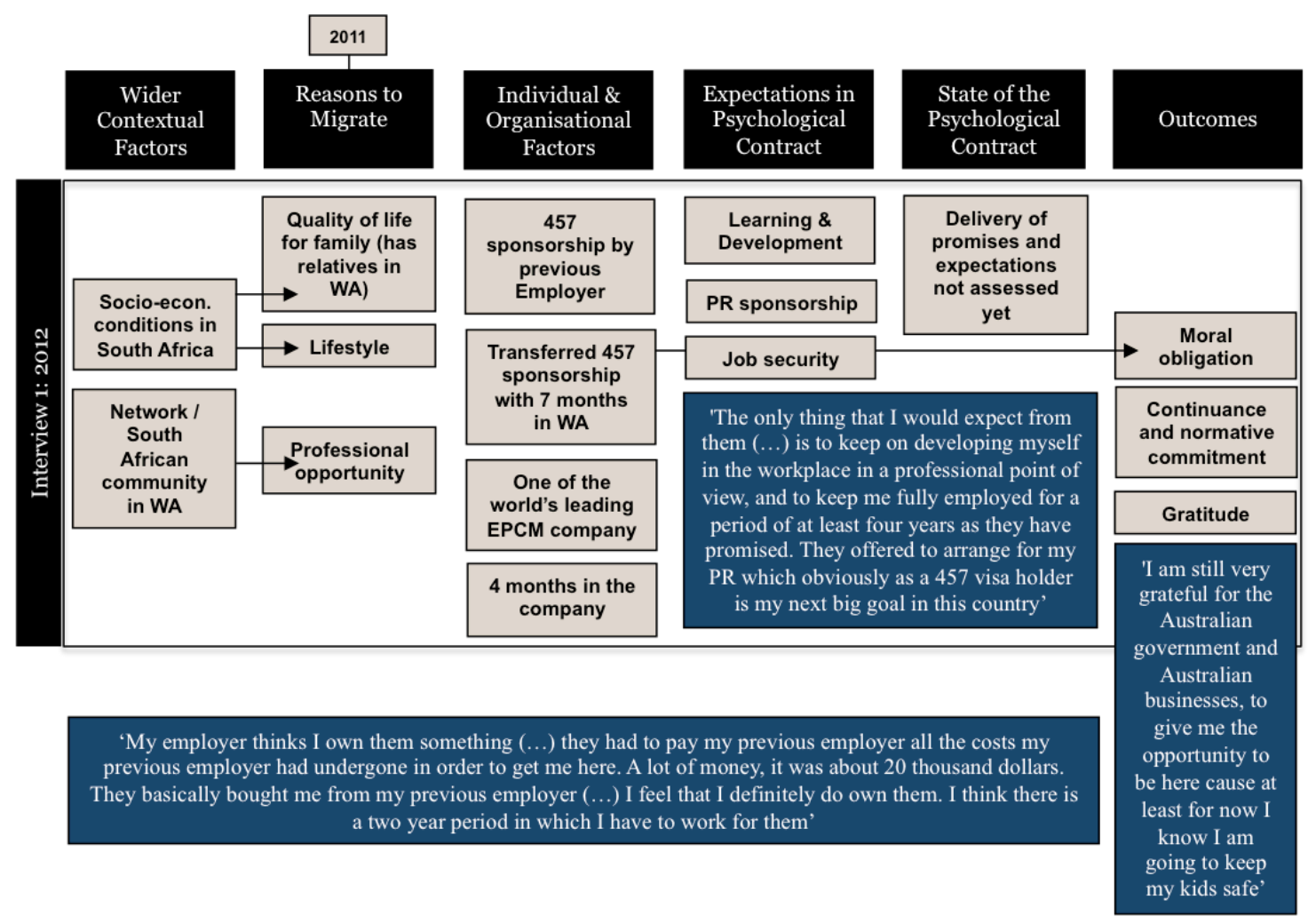

P20 did not return contacts for a follow up interview in 2013. According to social media he is still in Perth, working for the same organisation. 


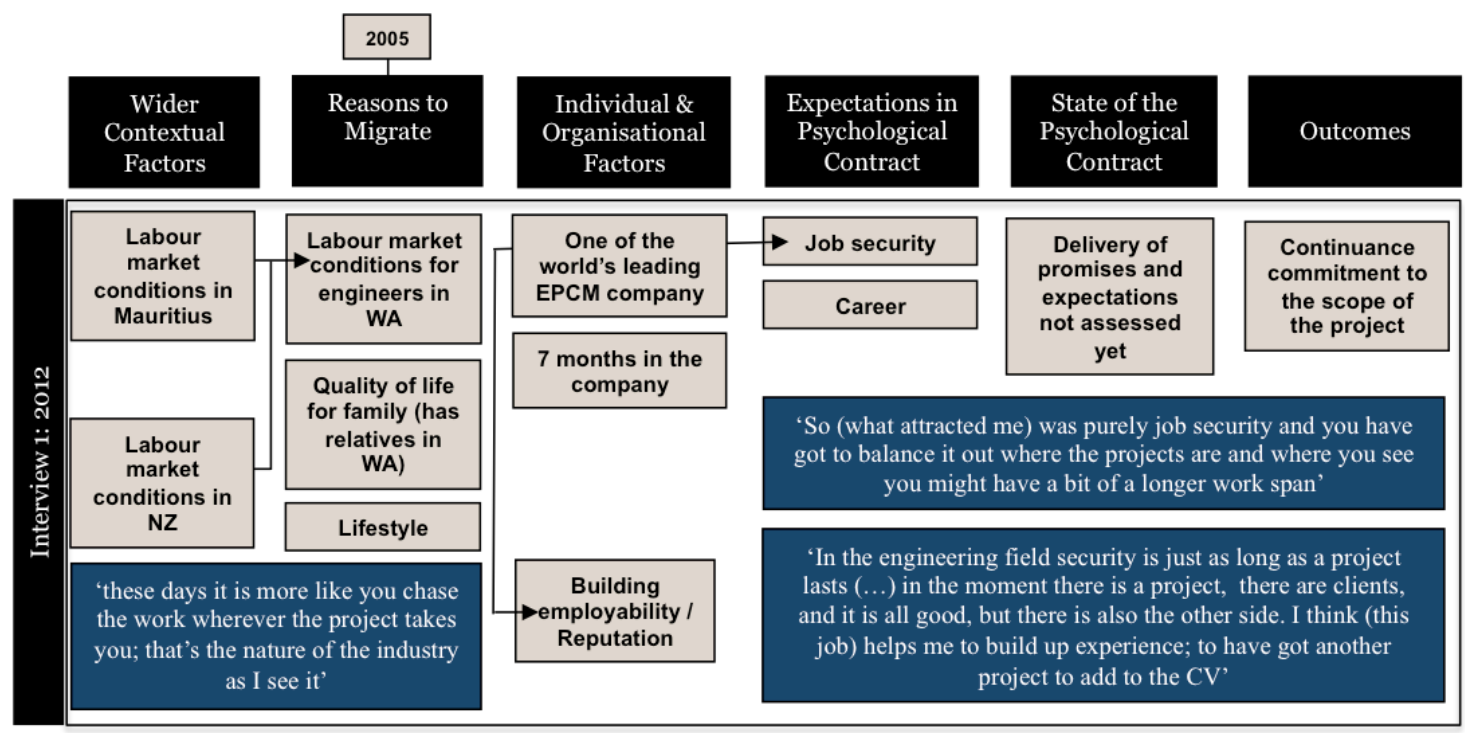

P21 did not return contacts for a follow up interview in 2013. According to social media he is still in Perth, working for the same organisation. 


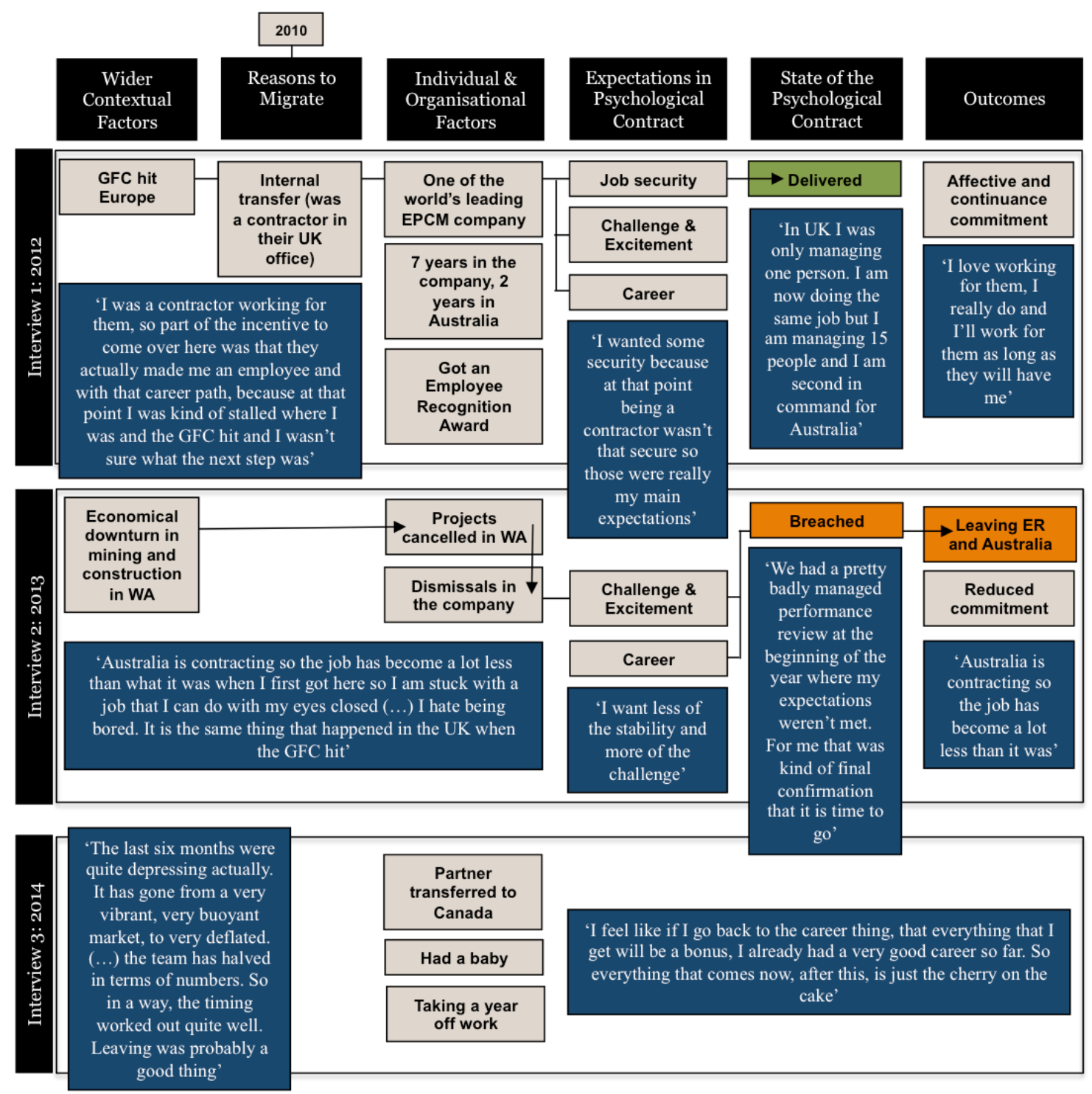

'What I would say has changed is my perception that a career is not the most life defining thing in your life. I find that having had a child, I think that this is the most perfect moment in my life' (2014)

'(The future) is a bit uncertain (...) by the end of the year we may know if we are going to stay here. There are a couple of possibilities in the pipeline, and we might end up going somewhere else, we might go back to the UK, you know, some different things. (...) The good thing about have moved around a lot and have faced different types of jobs, is that you can go to most places and you can fit in and find a job. You will be a pretty attractive prospect for an employer (...) my basket has always been pretty much mobile. I can take my basket to any country and I will be okay' (2014) 


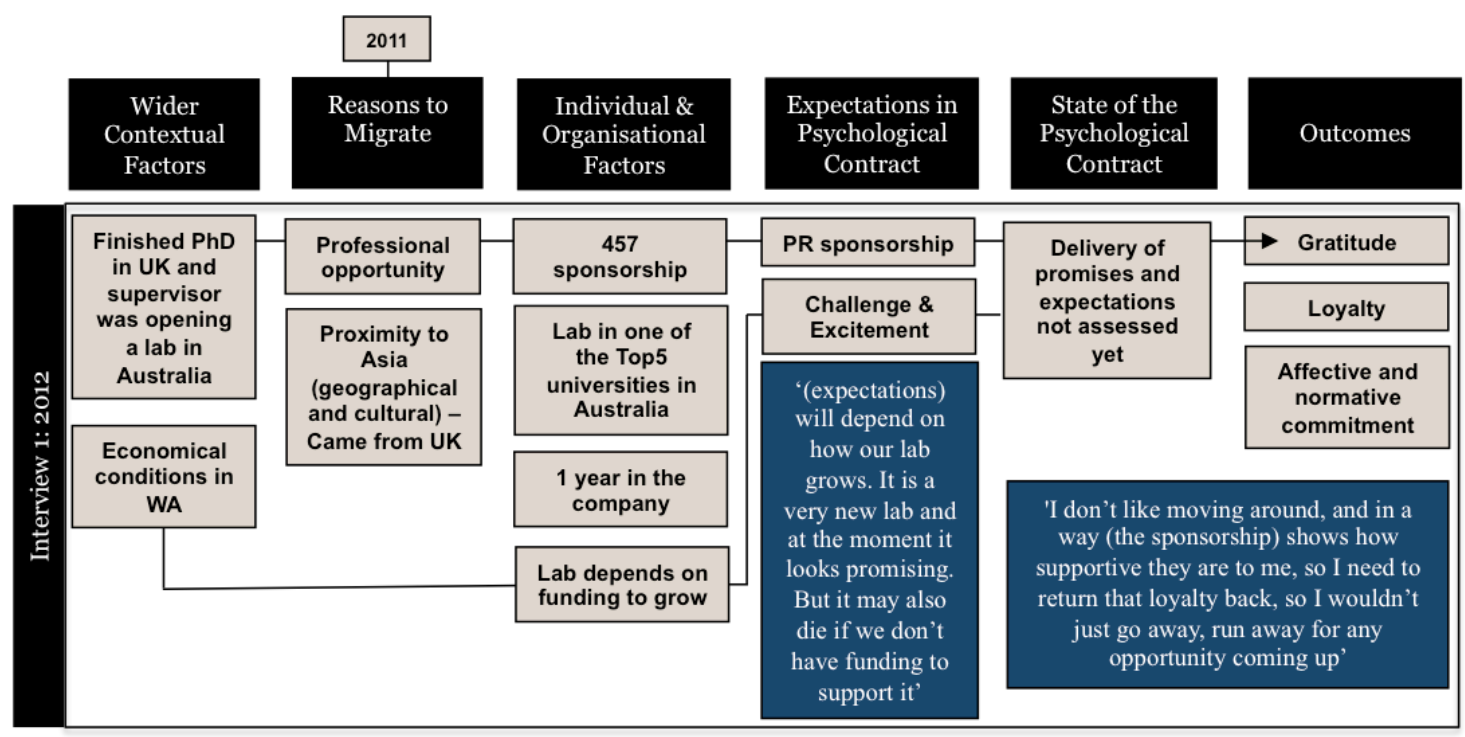




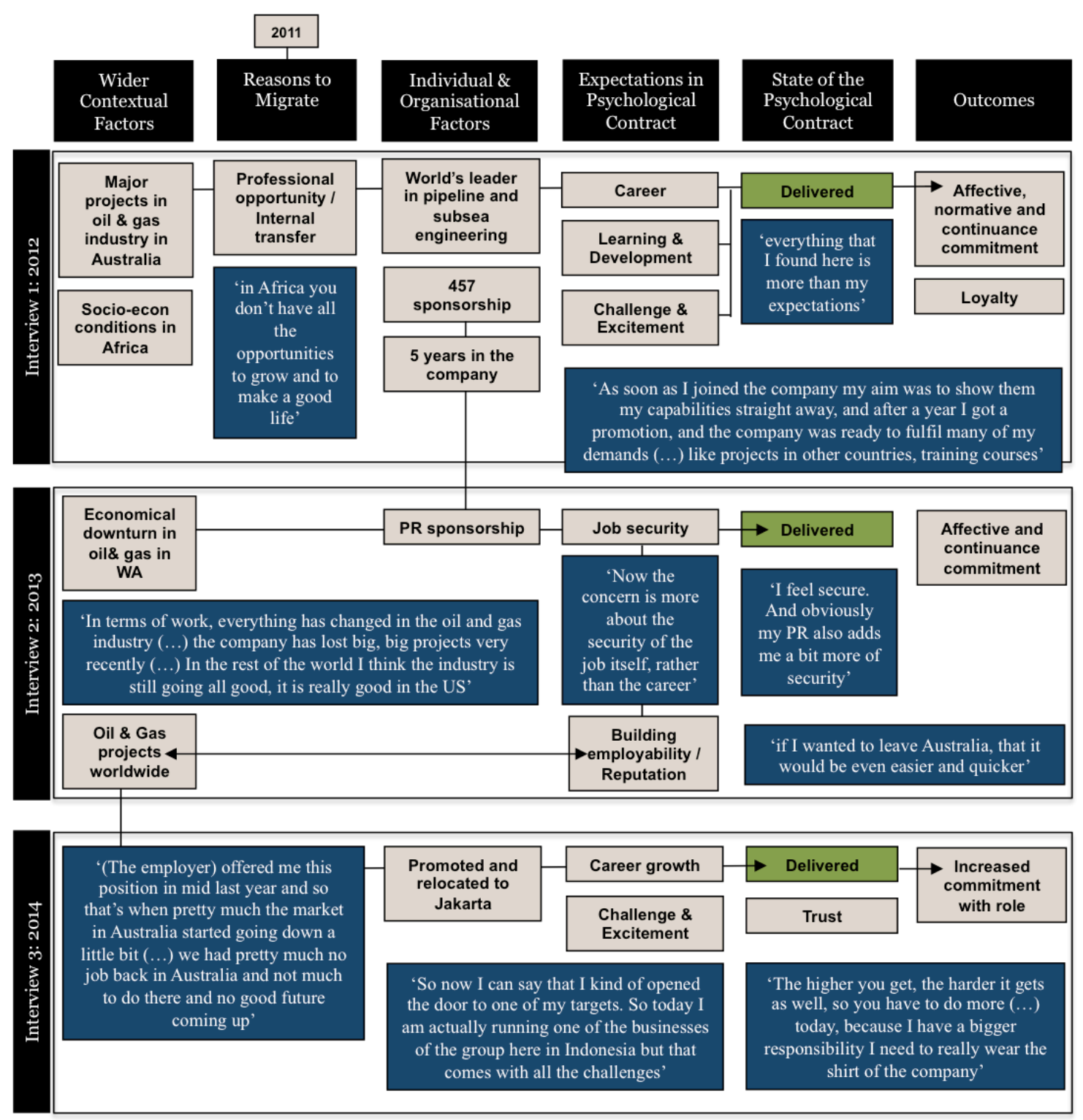

'There was more that I would have expected, but only if I had stayed in Australia for a longer time. For the period of time that I stayed in Australia I think everything went pretty good and I could achieve most of my objectives down in Australia' (2014)

'Any time I predict something it changes anyway; I mean I let it change, but you always have to plan something and predict something, that's the way it is, even if it doesn't go that way it is fine. So I will probably be here in Indonesia for quite a long time I would say probably three to four years at least' (2014) 


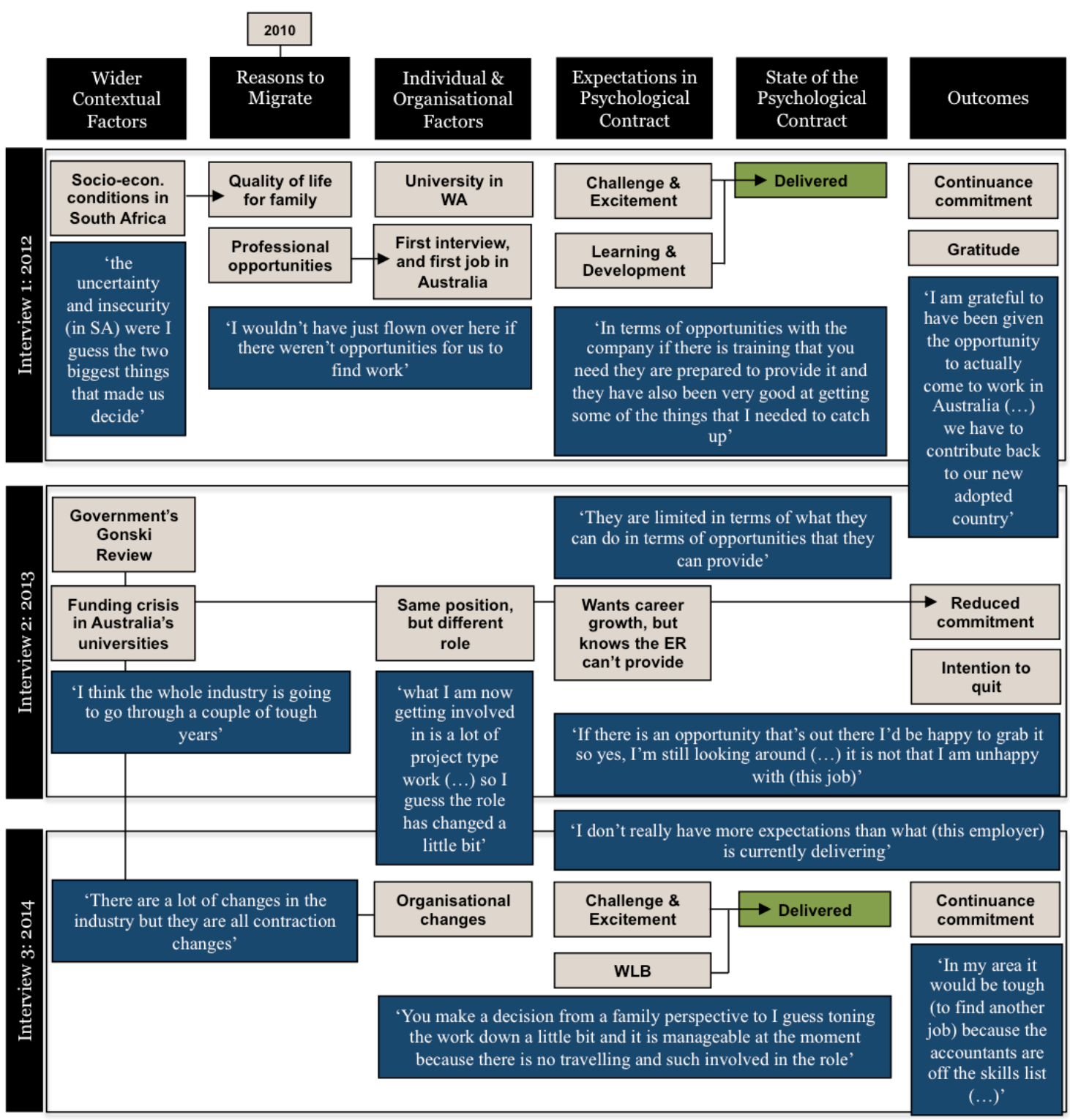

'There were a couple of things that I didn't expect and one was the amount of skilled labour that's in the market. So when you get 70 job applications and they are all in the Masters category you start thinking 'crikey!' (2014)

'Australia is home now. I think there has been a shift to where the citizenship thing is a natural thing to us now. We are not going to maintain dual citizenship either. (Our daughters) are going to be as Australian as other Australians growing up here. We are settled in Australia but there will always be something that's foreign, do you know what I mean, because we weren't born here. There is still some of the language that I need to go look up' (2014) 

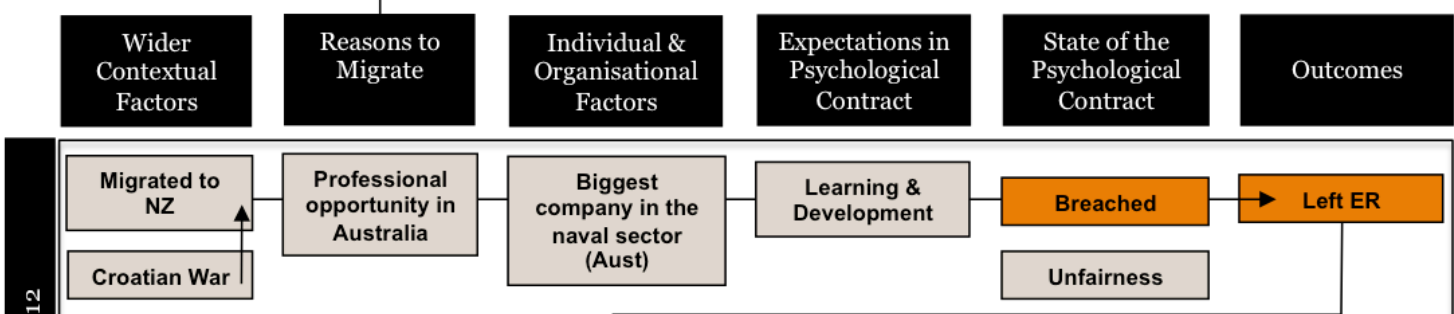

Left ER

'because I've been working for

ten years in a company, changing

(industry) means that I was

losing a bit of status, stability, and security. I felt that if I failed

I would be stepping back
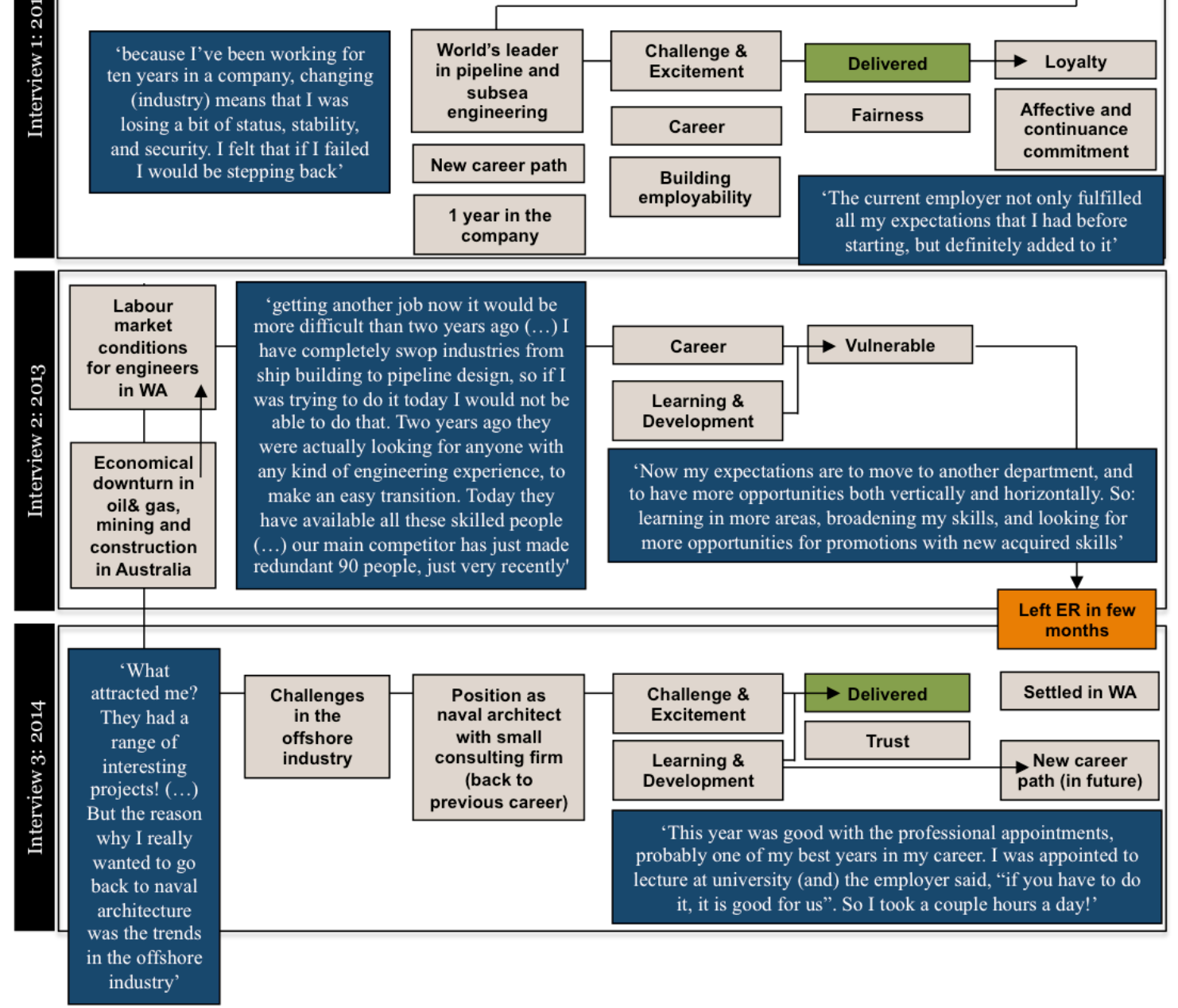

'I was very lucky to come into that time of a really huge growth of Western Australia, especially Perth. So I cannot even describe this experience, how it was beneficial... it fulfilled all my expectations, I don't know whether anything describes the professional achievements that I had, I couldn't feel happier (...) But growing older it does make me a bit sad about being away from my own country. This is something that actually stroke me last, last couple of years (...) I don't have plans, I have hopes. Everything is pretty nice and stable. I wish everything stays as stable as it is' (2014) 